\title{
DINÂMICA DA MATÉRIA ORGÂNICA E DESTINO DE METAIS PESADOS EM DOIS SOLOS SUBMETIDOS À ADIÇÃO DE LODO DE ESGOTO
}

Larissa Macedo dos Santos

Dissertação apresentada ao Instituto de Química de São Carlos, da Universidade de São Paulo para obtenção do título de Mestre em Ciências (Química Analítica).

Orientador: Dr. Ladislau Martin Neto

São Carlos

2006 
À Deus

pela sabedoria, visão e força.

\section{OFEREÇO}

Aos meus queridos pais

José Alfredo e Nilcéa

pelo exemplo de vida e de caráter

traduzidos em um consistente alicerce familiar.

À minha alegre irmã

Poliana

pelo carinho. 


\section{AGRADECIMENTOS}

Ao Dr. Ladislau Martin Neto pela orientação, incentivo, confiança, amizade e preocupação com o meu bem estar durante a realização deste trabalho. Meus sinceros agradecimentos.

Ao Dr. Wilson Tadeu Lopes da Silva, Dra. Débora Marcondes Bastos Pereira Milori, , Dr. Marcelo Luiz Simões, pela valiosa colaboração na realização deste trabalho.

Ao Prof. Dr. Wanderley José de Melo, da Unesp-Jaboticabal, por ter concedido as amostras de solo e pelo seu atencioso acompanhamento durante todo o trabalho.

À Dra. Ana Rita de Araújo Nogueira, juntamente com seus orientados Fernanda Santiago e Edivan Carvalho Vieira, pela valiosa colaboração, simpatia, atenção e boa vontade.

À Profa. Dra. Maria Olímpia de Oliveira Rezende e a sua orientada Jussara Cotta, pela valiosa colaboração.

Ao Renê por sua valiosa e prestativa ajuda no laboratório de química e principalmente pela criatividade tecnológica.

Ao Dr. Mario Miyazawa e Vicente Parabocz do IAPAR, pela valiosa colaboração.

Aos secretários, bibliotecárias, telefonistas, estagiários, técnicos, pesquisadores, etc., à todos os colegas da Embrapa, sempre atenciosos e prestativos.

Aos colegas e amigos de trabalho, Lucimar, Aline, Marcilene, Kelly, Ursula (Ursulita), Juliana, Jean, Garbin, Martha, Alessandra (Ale), Humberto (Humberti), Helder, Kleber, Vanessa, Ana Flávia, Adriana, Tatiana (Tati), Tiago (Ti), Fábio Leite, Eduarda, Nelson, Thais (Tatá), Francieli (Fran), Priscila (Pri), Milena, Rafael (Ceará), Luciana, Olívia (Baiana), Jeferson, Elisângela, Fernando Garbuio meus agradecimentos pela agradável convivência e amizade.

Aos meus amigos de Ponta Grossa pelo incentivo e amizade.

As minhas companheiras de casa pela agradável convivência que juntas tivemos, em especial a Dona Marlene minha mãe Sãocarlense.

Ao Prof. Dr. Jorge Iulek, pelo exemplo de profissional, seriedade, respeito e dedicação.

A Embrapa Instrumentação Agropecuária pela infra-estrutura e pelo excelente ambiente de trabalho.

Ao Instituto de Química de São Carlos da Universidade de São Paulo.

A todos que direta ou indiretamente contribuíram para a realização desse trabalho. 
LISTA DE TABELAS

LISTA DE ABREVIATURAS E SIGLAS

RESUMO

ABSTRACT

\section{SUMÁRIO}

1 INTRODUÇÃO

OBJETIVOS

2 REVISÃO DE LITERATURA

$2.1 \quad$ LODO DE ESGOTO

2.1.1 Composição do lodo de esgoto

2.1.2 O uso agrícola do lodo de esgoto

2.2 MATÉRIA ORGÂNICA DO SOLO

2.2.1 Importância da matéria orgânica para o solo

2.2.2 Dinâmica da matéria orgânica do solo

2.2.3 Substâncias húmicas

2.2.4 Interações das substâncias húmicas com metais 14

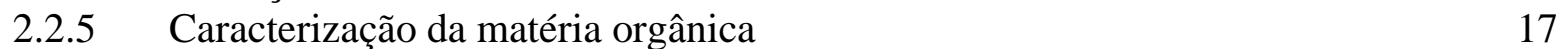

2.2.5.1 Métodos químicos 17

2.2.5.1.1 Determinação da composição elementar (CHNS) 17

2.2.5.1.1.1 Determinação da razão C/N 18

2.2.5.1.2 Determinação de carbono por via seca-Total Organic Carbon 18

(TOC)

2.2.5.1.3 Determinação do teor de matéria orgânica por via úmida (Walkley- 19

Black)

(TOC)

2.2.5.1.2 Determinação de carbono por via seca-Total Organic Carbon 19

2.2.5.2 Métodos Espectroscópicos 20

2.2.5.2.1 Absorção de radiação no UV-Vis 20

$\begin{array}{lll}2.2 .5 .2 .2 & \text { FTIR } & 24\end{array}$

$\begin{array}{lll}2.2 .5 .2 .3 & \text { RMN } & 27\end{array}$

2.2.5.2.4 RPE 31

2.2.5.2.5 Fluorescência 34

$\begin{array}{lll}2.2 .5 .2 .6 & \text { FIL } & 37\end{array}$

2.3 Contaminação do solo por metais pesados 39

2.3.1 Caracterização espectrométrica 41

2.3.1.1 ICP OES 41

3 MATERIAIS E MÉTODOS 43

3.1 AMOSTRA DE LODO DE ESGOTO 43

3.2.1 Área experimental 43

$\begin{array}{lll}3.2 .2 & \text { Classificação dos solos } & 43\end{array}$

3.2.3 Tratamentos 44

3.2.4 Amostragem 44

3.3 PREPARO DAS AMOSTRAS DE SOLO E LODO DE ESGOTO PARA A 45 EXTRAÇÃO

3.4 EXTRAÇÃO E PURIFICAÇÃO DAS SUBSTÂNCIAS HÚMICAS

3.5 DETERMINAÇÃO DE METAIS NO PROCESSO DE EXTRAÇÃO DAS 47 SUBSTÂNCIAS HÚMICAS

3.6 FRACIONAMENTO FÍSICO POR GRANULOMETRIA 48

3.7 CARACTERIZAÇÃO DA MATÉRIA ORGÂNICA 50 
3.7.1 Métodos químicos $\quad 50$

3.7.1.1 Determinação da composição elementar (CHNS) 50

3.7.1.1.1 Determinação da razão C/N 50

3.7.1.2 Determinação de carbono por via seca (TOC) 50

Black)

3.7.1.3 Determinação do teor de matéria orgânica por via úmida (Walkley- $\quad 50$

3.7.2 Métodos espectroscópicos 51

3.7.2.1 Absorção de radiação no UV-Vis 51

3.7.2.2 FTIR 52

$\begin{array}{lll}3.7 .2 .3 & \text { RMN } & 52\end{array}$

$\begin{array}{lll}3.7 .2 .4 & \text { RPE } & 53\end{array}$

3.7.2.5 Fluorescência 53

3.7.2.4 FIL

3.8 DETERMINAÇÃO DE METAIS PESADOS 56

$\begin{array}{lll}3.8 .1 & \text { ICP OES } & 56\end{array}$

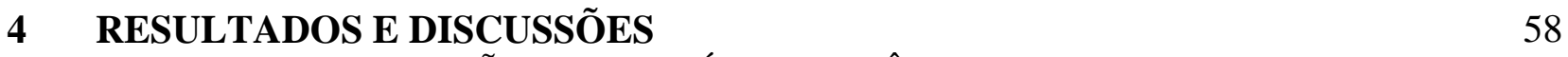

4.1 CARACTERIZAÇÃO DA MATÉRIA ORGÂNICA 58

4.1.1 Métodos químicos $\quad 58$

4.1.1.1 Determinação da composição elementar (CHNS) 60

$\begin{array}{lll}\text { 4.1.1.1.1 Determinação da razão C/N } & 61\end{array}$

4.1.1.2 Determinação de carbono por via seca (TOC) 63

Black)

4.1.1.3 Determinação do teor de matéria orgânica por via úmida (Walkley- 65

4.1.2 Métodos espectroscópicos 66

4.1.2.1 Absorção de radiação no UV-Vis 66

4.1.2.2 FTIR 71

$\begin{array}{lll}4.1 .2 .3 & \mathrm{RMN} & 75\end{array}$

$\begin{array}{lll}4.1 .2 .4 & \text { RPE } & 82\end{array}$

4.1.2.5 Fluorescência $\quad 85$

4.1.2.5.1 Espectros de emissão $\quad 86$

$\begin{array}{lll}\text { 4.1.2.5.2 Espectros de varredura sincronizada } & 93\end{array}$

$\begin{array}{lll}\text { 4.1.2.6 FIL } & 96\end{array}$

4.2 DETERMINAÇÃO DE METAIS 99

4.2.1 Lodo de esgoto $\quad 99$

$\begin{array}{lll}4.2 .2 & \text { Solo intacto } & 100\end{array}$

$\begin{array}{lll}4.2 .3 & \text { Frações físicas } & 102\end{array}$

4.2.3.1 Fração areia $(>53 \mu \mathrm{m}) \quad 102$

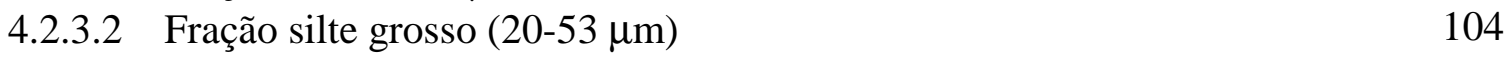

4.2.3.3 Fração silte fino $(2-20 \mu \mathrm{m}) \quad 106$

$\begin{array}{lll}\text { 4.2.3.4 Fração argila }(<2 \mu \mathrm{m}) & 108\end{array}$

4.2.4 Frações químicas 109

4.2.4.1 Fração humina $\quad 110$

4.2.4.2 Água de lavagem da humina 110

4.2.4.3 Fração ácido fúlvico $1 \quad 111$

4.2.3.4 Fração ácido fúlvico $2 \quad 112$

4.2.3.5 Fração ácido húmico 112

5 CONCLUSÕES 115

6 RESULTADOS BIBLIOGRÁFICAS 117 


\section{LISTA DE FIGURAS}

Figura 2.1 - Composição do lodo de esgoto doméstico (Melo; Marques, 2000)

Figura 2.2 - Modelo de ácido húmico proposto por Schulten e Schnitzer (1993)

Figura 2.3 - Modelos conceituais propostos pela teoria macromolecular: (a) moléculas das substâncias húmicas aleatoriamente enoveladas (Swift, 1989) e (b) ácido húmico proposto por Schulten e Schnitzer (1997), carbono=azul; oxigênio=vermelho; nitrogênio=preto e hidrogênio=branco. As letras A, B e C indicam os espaços "vazios" presentes na molécula das substâncias húmicas capazes de interagir com outros compostos

Figura 2.4 - Esquema de estrutura das substâncias húmicas proposto por (Simpson et al., 2002b). As unidades vermelhas representam os cátions metálicos, as unidades pretas os polissacarídeos, as unidades azuis os polipeptídios, as unidades verdes as cadeias alifáticas e as unidades marrons os fragmentos aromáticos provenientes da lignina

Figura 2.5 - Exemplos de complexos organometálicos

Figura 2.6 - Níveis de energia eletrônica molecular (Skoog; Holler; Nieman, 2002)

Figura 2.7 - Cromóforos presentes nas substâncias húmicas

Figura 2.8 - Algumas vibrações típicas de átomos. Os sinais + e - significam vibrações perpendiculares ao plano do papel (Stuart, 1996)

Figura 2.9 - Espectro de ${ }^{13} \mathrm{C}$ RMN típico de ácido húmico mostrando os grupos funcionais associados às bandas correspondentes (Skjemstad; Janik; Taylor, 1998)

Figura 2.10 - Efeito Zeeman: (a) desdobramento dos níveis de energia do spin eletrônico na presença de um campo magnético; (b) forma da linha de absorção de energia do campo de microondas; (c) primeira derivada da linha de absorção

Figura 2.11 - Esquema da estabilização do radical livre do tipo semiquinona (Senesi; Schnitzer, 1977)

Figura 2.12 - Espectro de RPE típico de ácido húmico mostrando o sinal do radical livre do tipo semiquinona

Figura 2.13 - Transição eletrônica fluorescência molecular

Figura 2.14 - Pastilhas de solo utilizadas para a obtenção do espectro de FIL

Figura 2.15 - Sistema para medida de FIL

Figura 3.1 - Biossólido originado do lodo de esgoto coletado na ETE da SABESP, Barueri-SP

Figura 3.2 - Solos Analisados: Perfil dos solos (a) LVef) e (b) LVd

Figura 3.3 - Aplicação do lodo de esgoto ao solo

Figura 3.4 - Coleta das amostras de solo

Figura 3.5 - Esquema simplificado de extração e purificação das substâncias húmicas do solo

Figura 3.6 - Esquema simplificado de extração e purificação das substâncias húmicas do solo, mostrando as etapas para determinação de metais nas diversas fases do processo

Figura 3.7 - Esquema simplificado do fracionamento físico por granulometria 
Figura 4.1 - Valores da razão $\mathrm{C} / \mathrm{N}$ obtidos para os ácidos húmicos extraídos do (a) LVef sem e com adição de lodo de esgoto e (b) LVd sem e com adição de lodo de esgoto. As profundidades variam de 0-60 cm onde: $\mathrm{P} 1 \rightarrow 0-10 ; \mathrm{P} 2 \rightarrow 10-20 ; \mathrm{P} 3 \rightarrow 20-40$ e $\mathrm{P} 4 \rightarrow$ 40-60 cm.

Figura 4.2 - Dados dos teores de carbono para as amostras de solo intacto determinados pelo método de TOC para os solos (a) LVef sem e com adição de lodo de esgoto e (b) LVd sem e com adição de lodo de esgoto em diferentes profundidades.

Figura 4.3 - Correlações entre os teores de carbono obtidos pelos métodos: (a) análise elementar e TOC, (b) análise elementar e WalKley-Black e (c) TOC e Walkley-Black.

Figura 4.4 - Espectros de absorção de absorção de radiação no UV-Vis de ácido húmico extraídos do (a) LVef $\rightarrow$ sem adição de lodo de esgoto, (b) LVef $+\mathrm{B} \rightarrow$ com adição de lodo de esgoto, (c) LVd $\rightarrow$ sem adição de lodo de esgoto e (d) LVd $+\mathrm{B} \rightarrow$ com adição de lodo de esgoto. As profundidades variam de $0-60 \mathrm{~cm}$ onde: $\mathrm{P} 1 \rightarrow 0-10 ; \mathrm{P} 2 \rightarrow 10-20 ; \mathrm{P} 3 \rightarrow 20-40$ e $\mathrm{P} 4 \rightarrow 40-60 \mathrm{~cm}$.

Figura 4.5 - Espectro de absorção de radiação no UV-Vis de ácido húmico extraído do lodo de esgoto.

Figura 4.6 - Valores da razão $\mathrm{E}_{4} / \mathrm{E}_{6}$ obtidos para os ácidos húmicos extraídos do (a) LVef sem e com adição de lodo de esgoto e (b) LVd sem e com adição de lodo de esgoto. As profundidades variam de 0-60 cm onde: $\mathrm{P} 1 \rightarrow 0-10 ; \mathrm{P} 2 \rightarrow$ 10-20; $\mathrm{P} 3 \rightarrow$ 20-40 e P4 $\rightarrow$ 40-60 cm.

Figura 4.7 - Espectros de FTIR de ácidos húmicos extraídos do (a) LVef $\rightarrow$ sem adição de lodo de esgoto e (b) $\mathrm{LVef}+\mathrm{B} \rightarrow$ com adição de lodo de esgoto. As profundidades variam de 0-60 cm onde: $\mathrm{P} 1 \rightarrow$ 0-10; $\mathrm{P} 2$ $\rightarrow 10-20 ; \mathrm{P} 3 \rightarrow 20-40$ e P4 $\rightarrow$ 40-60 cm.

Figura 4.8 - Espectros de FTIR de ácidos húmicos extraídos do (a) LVd $\rightarrow$ sem adição de lodo de esgoto e (b) $\mathrm{LVd}+\mathrm{B} \rightarrow$ com adição de lodo de esgoto. As profundidades variam de 0-60 cm onde: $\mathrm{P} 1 \rightarrow$ 0-10; $\mathrm{P} 2$ $\rightarrow 10-20 ; \mathrm{P} 3 \rightarrow 20-40$ e P4 $\rightarrow$ 40-60 cm.

Figura 4.9 - Espectro de FTIR do ácido húmico extraído do lodo.

Figura 4.10 - Espectros de ${ }^{13} \mathrm{C}$ RMN de ácidos húmicos extraídos do (a) LVef $\rightarrow$ sem adição de lodo de esgoto e (b) LVef $+\mathrm{B} \rightarrow$ com adição de lodo de esgoto. As profundidades variam de $0-60 \mathrm{~cm}$ onde: $\mathrm{P} 1 \rightarrow 0$ $10 ; \mathrm{P} 2 \rightarrow 10-20 ; \mathrm{P} 3 \rightarrow 20-40$ e P4 $\rightarrow$ 40-60 cm.

Figura 4.11 - Espectros de ${ }^{13} \mathrm{C}$ RMN de ácidos húmicos extraídos do (a) LVd $\rightarrow$ sem adição de lodo de esgoto e (b) LVd $+\mathrm{B} \rightarrow$ com adição de lodo de esgoto. As profundidades variam de 0-60 cm onde: $\mathrm{P} 1 \rightarrow 0$ $10 ; \mathrm{P} 2 \rightarrow 10-20 ; \mathrm{P} 3 \rightarrow 20-40$ e P4 $\rightarrow$ 40-60 cm.

Figura 4.12 - Espectro de ${ }^{13} \mathrm{C}$ RMN do ácido húmico extraído do lodo

Figura 4.13 - Gráfico da (a) Aromaticidade e Alifaticidade das amostras de ácido húmico extraídas dos solos LVef $\rightarrow$ sem adição de lodo de esgoto, LVd $\rightarrow$ sem adição de lodo de esgoto, e +B refere-se aos mesmos solos tratados com lodo de esgoto e Lodo $\rightarrow$ ácido húmico extraído do lodo de esgoto. Na profundidade de $10-20 \mathrm{~cm}$.

Figura 4.14 - Nível de radical livre do tipo semiquinona em spins $\mathrm{g}^{-1}$ de carbono obtidos para os ácidos húmicos extraídos do (a) LVef sem e com adição de lodo de esgoto e (b) LVd sem e com adição de lodo de esgoto, em diferentes profundidades.

Figura 4.15 - Espectros de emissão de fluorescência $(\lambda \operatorname{exc}=240 \mathrm{~nm}$ ) de ácidos húmicos extraídos do (a) LVef $\rightarrow$ sem adição de lodo de esgoto, (b) LVef $+\mathrm{B} \rightarrow$ com adição de lodo de esgoto, (c) LVd $\rightarrow$ sem adição de lodo de esgoto e (d) $\mathrm{LVd}+\mathrm{B} \rightarrow$ com adição de lodo de esgoto. As profundidades variam de $0-60 \mathrm{~cm}$ onde: $\mathrm{P} 1 \rightarrow 0-10 ; \mathrm{P} 2 \rightarrow 10-20 ; \mathrm{P} 3 \rightarrow 20-40$ e $\mathrm{P} 4 \rightarrow 40-60 \mathrm{~cm}$.

Figura 4.16 - Espectro de emissão de fluorescência $(\lambda \operatorname{exc}=240 \mathrm{~nm})$ do ácido húmico extraído do lodo de esgoto. 
Figura 4.17 - Valores do índice de humificação obtidos para os ácidos húmicos extraídos dos solos, (a) LVef sem e com adição de lodo de esgoto e (b) LVd sem e com adição de lodo de esgoto. As profundidades variam de 0-60 cm onde: $\mathrm{P} 1 \rightarrow 0-10 ; \mathrm{P} 2 \rightarrow 10-20 ; \mathrm{P} 3 \rightarrow 20-40$ e P4 $\rightarrow$ 40-60 cm.

Figura 4.18 - Espectros de emissão de fluorescência $(\lambda \operatorname{exc}=465 \mathrm{~nm})$ de ácidos húmicos extraídos do (a) LVef $\rightarrow$ sem adição de lodo de esgoto, (b) LVef $+\mathrm{B} \rightarrow$ com adição de lodo de esgoto, (c) LVd $\rightarrow$ sem adição de lodo de esgoto e (d) $\mathrm{LVd}+\mathrm{B} \rightarrow$ com adição de lodo de esgoto. As profundidades variam de $0-60 \mathrm{~cm}$ onde: $\mathrm{P} 1 \rightarrow 0-10 ; \mathrm{P} 2 \rightarrow 10-20 ; \mathrm{P} 3 \rightarrow 20-40$ e $\mathrm{P} 4 \rightarrow 40-60 \mathrm{~cm}$.

Figura 4.19 - Espectro de emissão de fluorescência $(\lambda \mathrm{exc}=465 \mathrm{~nm})$ do ácido húmico extraído do lodo.

Figura 4.20 - Valores de $\mathrm{A}_{465}$ obtidos para os ácidos húmicos extraídos dos solos, (a) LVef sem e com adição de lodo de esgoto e (b) LVd sem e com adição de lodo de esgoto. As profundidades variam de 0-60 cm onde: $\mathrm{P} 1 \rightarrow$ 0-10; $\mathrm{P} 2 \rightarrow$ 10-20; $\mathrm{P} 3 \rightarrow$ 20-40 e P4 $\rightarrow$ 40-60 cm.

Figura 4.21 - Espectros sincronizado de fluorescência de ácidos húmicos extraídos do (a) LVef $\rightarrow$ sem adição de lodo de esgoto, (b) LVef $+\mathrm{B} \rightarrow$ com adição de lodo de esgoto, (c) LVd $\rightarrow$ sem adição de lodo de esgoto e (d) $\mathrm{LVd}+\mathrm{B} \rightarrow$ com adição de lodo de esgoto. As profundidades variam de 0-60 $\mathrm{cm}$ onde: $\mathrm{P} 1 \rightarrow 0-10 ; \mathrm{P} 2 \rightarrow 10-20 ; \mathrm{P} 3 \rightarrow 20-40$ e P4 $\rightarrow$ 40-60 cm.

Figura 4.22 - Espectro sincronizado de fluorescência do ácido húmico extraído do lodo.

Figura 4.21 - Espectros sincronizado de fluorescência de ácidos húmicos extraídos do (a) LVef $\rightarrow$ sem adição de lodo de esgoto, (b) LVef $+\mathrm{B} \rightarrow$ com adição de lodo de esgoto, (c) LVd $\rightarrow$ sem adição de lodo de esgoto e (d) $\mathrm{LVd}+\mathrm{B} \rightarrow$ com adição de lodo de esgoto. As profundidades variam de 0-60 $\mathrm{cm}$ onde: $\mathrm{P} 1 \rightarrow 0-10 ; \mathrm{P} 2 \rightarrow 10-20 ; \mathrm{P} 3 \rightarrow 20-40$ e $\mathrm{P} 4 \rightarrow 40-60 \mathrm{~cm}$.

Figura 4.24 - Correlação entre as metodologias utilizadas: (a) Zsolnay e Milori; (b) Zsolnay e Kalbitz e (c) Milori e Kalbitz

Figura 4.25 - Valores de $\mathrm{H}_{\mathrm{FIL}}$ obtidos para as amostras de solo intacto do (a) LVef sem e com adição de lodo de esgoto e (b) LVd sem e com adição de lodo de esgoto. As profundidades variam de 0-60 cm onde: $\mathrm{P} 1 \rightarrow 0-10 \mathrm{~cm} ; \mathrm{P} 2 \rightarrow 10-20 \mathrm{~cm} ; \mathrm{P} 3 \rightarrow 20-40 \mathrm{~cm}$ e P4 $\rightarrow 40-60 \mathrm{~cm}$.

Figura 4.26 - Correlação entre o grau de humificação determinado pela FIL e as metodologias de fluorescência em solução utilizadas: (a) $\mathrm{H}_{\mathrm{FIL}}$ e $\mathrm{A}_{4} / \mathrm{A}_{1}$; (b) $\mathrm{H}_{\mathrm{FIL}}$ e $\mathrm{A}_{465}$ e (c) $\mathrm{H}_{\mathrm{FIL}}$ e $\mathrm{I}_{460} / \mathrm{I}_{399}$.

Figura 4.27 - Efeitos dos teores totais de (a) Fe e (b) Mn para as amostras da fração areia (> $53 \mu$ m) extraídas do LVd submetidos à adição de lodo de esgoto.

Figura 4.28 - Efeitos dos teores totais de (a) Cr, (b) Cu e (c) Co para a fração silte grosso (20-53 $\mu \mathrm{m}$ ) extraídas do LVef submetido à adição de lodo de esgoto e efeitos dos teores totais de (d) Zn para a fração silte grosso $(20-53 \mu \mathrm{m})$ extraídas do LVd submetido à adição de lodo de esgoto.

Figura 4.29 - Efeitos dos teores totais de (a) Cu e (b) Zn para a fração silte fino $(2-20 \mu \mathrm{m})$ extraídas do LVd submetido à adição de lodo de esgoto. 


\section{LISTA DE TABELAS}

Tabela 3.1 - Solos estudados e sua classificação conforme o Sistema Brasileiro de Classificação de Solos da Embrapa (1999), as profundidades coletadas e os tratamentos aos quais foram submetidos os solos.

Tabela 3.2 - Descrição e condições operacionais do espectrômetro de ICP OES.

Tabela 3.3 - Elementos analisados e seus comprimentos de onda.

Tabela 3.4 - Limites de detecção dos metais analisados

Tabela 4.1 - Teor de carbono, hidrogênio e nitrogênio em (\%) das amostras de ácido húmico extraídas do LVef e LVd e do lodo de esgoto, determinados pelo método de análise elementar.

Tabela 4.2 - Teor de carbono em $\left(\mathrm{g} \mathrm{kg}^{-1}\right)$ das amostras de solo intacto, determinados pelos métodos de análise elementar, TOC e Walkley-Black.

Tabela 4.3 - Valor da razão $\mathrm{C} / \mathrm{N}$ das amostras de ácido húmico obtidos através da determinação da composição elementar (CHNS).

Tabela 4.4 - Dados referentes à absorção de absorção de radiação no UV-Vis em 468 nm ( $\left.E_{4}\right)$ e em 665 nm $\left(\mathrm{E}_{6}\right)$ e a razão entre as mesmas $\left(\mathrm{E}_{4} / \mathrm{E}_{6}\right)$ para os ácidos húmicos extraídos do LVef e LVd e do lodo de esgoto.

Tabela 4.5 - Intensidades relativas (porcentagem da área total) das bandas nos espectros de ${ }^{13} \mathrm{C}$ RMN com VACP-MAS de amostras sólidas de ácidos húmicos.

Tabela 4.6 - Grau de Aromaticidade e Alifaticidade de amostras sólidas de ácidos húmicos extraídos dos solos e do lodo de esgoto.

Tabela 4.7 - Concentração de radicais livres do tipo semiquinona e largura de linha das amostras de ácidos húmicos extraídos dos solos, LVef e LVd e do lodo de esgoto, fornecida pela espectroscopia de RPE.

Tabela 4.8 - Dados referentes ao índice de humificação proposto por Zsolnay.

Tabela 4.9 - Dados referentes ao índice de humificação proposto por Milori.

Tabela 4.10 - Dados referentes ao índice de humificação proposto por Kalbitz.

Tabela 4.11 - Dados referentes à análise elementar de carbono pela técnica de TOC e área dos espectros de FIL de amostras de solo intacto.

Tabela 4.12 - Concentração em $\mathrm{mg} \mathrm{kg}^{-1}$ de metais pesados permitida e determinada para o lodo de esgoto.

Tabela 4.13 - Concentração em $\mathrm{mg} \mathrm{kg}^{-1}$ de metais pesados determinados para o solo por ICP OES.

Tabela 4.14 - Concentração em $\mathrm{mg} \mathrm{kg}^{-1}$ de metais de pesados determinados para a fração areia por ICP OES.

Tabela 4.15 - Concentração em $\mathrm{mg} \mathrm{kg}^{-1}$ de metais de pesados determinados para a fração silte grosso por ICP OES.

Tabela 4.16 - Concentração em $\mathrm{mg} \mathrm{kg}^{-1}$ de metais de pesados determinados para a fração silte fino por ICP OES.

Tabela 4.17 - Concentração em mg kg-1 de metais de pesados determinados para a fração argila por ICP OES. 
Tabela 4.18 - Concentração em $\mathrm{mg} \mathrm{kg}^{-1}$ de metais de pesados determinados para a fração humina por ICP OES.

Tabela 4.19 - Concentração em $\mathrm{mg} \mathrm{L}^{-1}$ de metais de pesados determinados para a água de lavagem da humina por ICP OES.

Tabela 4.20 - Concentração em $\mathrm{mg} \mathrm{L}^{-1}$ de metais de pesados determinados para a fração ácido fúlvico 1 por 111 ICP OES.

Tabela 4.20 - Concentração em $\mathrm{mg} \mathrm{L}^{-1}$ de metais de pesados determinados para a fração ácido fúlvico 2 por 112 ICP OES.

Tabela 4.21 - Concentração em $\mathrm{mg} \mathrm{kg}^{-1}$ de metais de pesados determinados para a fração ácido húmico por 112 ICP OES. 


\section{LISTA DE ABREVIATURAS E SIGLAS}

ACF Área do espectro de emissão de FIL

CETESB Companhia de Tecnologia de Saneamento Ambiental

CONAMA Conselho Nacional do Meio Ambiente

COT Valor do Carbono Orgânico Total

CP Polarização Cruzada

ETE Estação de Tratamento de Esgoto

FIL Fluorescência Induzida por Laser

FTIR Infravermelho com Transformada de Fourier

IAP Instituto Ambiental do Paraná

IAPAR Instituto Agronômico do Paraná

IBGE Instituto Brasileiro de Geografia e Estatística

ICP OES Espectrometria de Emissão Atômica com Plasma Indutivamente Acoplado

IHSS Sociedade Internacional de Substâncias Húmicas

LVd Latossolo Vermelho distrófico

LVef Latossolo Vermelho eutroférrico

MAS Rotação segundo o Ângulo Mágico

PROSAB Programa de Pesquisa e Saneamento Básico

RMN Ressonância Magnética Nuclear

RPE Ressonância Paramagnética Eletrônica

SABESP Companhia de Saneamento Básico do Estado de São Paulo

TOC Total Organic Carbon

UV-Vis Ultravioleta-Visível

VA Amplitude Variável 


\section{RESUMO}

Em regiões agrícolas próximas dos grandes centros urbanos e onde há o uso intensivo de recursos naturais, em especial do solo, a reciclagem para fins agrícolas de lodos de esgotos aparece como alternativa promissora. Contudo, a sustentabilidade dessa prática deve ser avaliada, ainda mais se considerado a escassez de informações sobre possíveis impactos ambientais em áreas tropicais. Com esse objetivo esse trabalho avaliou os efeitos da adição de lodo de esgoto em dois solos, Latossolo Vermelho eutroférrico e Latossolo Vermelho distrófico, coletados no $7^{\circ}$ ano de um experimento em campo, instalado em 1997 na Faculdade de Ciências Agrárias e Veterinárias da Unesp, em Jaboticabal-SP. O lodo de esgoto foi proveniente da Estação de Tratamento de Esgoto da Companhia de Saneamento Básico do Estado de São Paulo, em Barueri-SP. Para observar os efeitos da adição do lodo de esgoto foram analisados os ácidos húmicos extraídos dos solos utilizando absorção de radiação no UV-Visível, infravermelho com transformada de Fourier, ressonância magnética nuclear, ressonância paramagnética eletrônica, fluorescência e análise elementar. Para a análise do solo intacto utilizou-se a fluorescência induzida por laser, e para as frações físicas e químicas a emissão atômica com plasma indutivamente acoplado. Experimentos de infravermelho com transformada de Fourier e ressonância magnética nuclear forneceram espectros com bandas características de grupos alifáticos para o ácido húmico extraído do lodo, comprovando seu alto grau de alifaticidade. O nível de radicais livres do tipo semiquinona determinado por ressonância paramagnética eletrônica diminuiu significativamente para os solos submetidos à adição de lodo. Dados de fluorescência utilizando diferentes metodologias (Zolnay et al., 1999; Milori et al., 2002; Kalbitz et al., 1999) e fluorescência induzida por laser, de amostras de solo intacto, apresentaram comportamento similar. De forma geral, os resultados obtidos por análises espectroscópicas mostraram à incorporação de compostos menos humificados, com um alto grau de alifaticidade e baixo grau de aromaticidade. A análise de metais em solos tratados com lodo de esgoto em algumas situações não tem evidenciado o aumento destes elementos, mesmo quando o lodo apresenta níveis superiores aos valores encontrados no solo. Assim fica a pergunta, onde e como estão os metais pesados oriundos do lodo e que deveriam ser detectados em níveis maiores nos solos tratados. Neste trabalho procuramos ampliar as avaliações para além dos procedimentos convencionais com análises das frações físicas e químicas. Os metais pesados estudados foram: $\mathrm{Cd}, \mathrm{Cr}, \mathrm{Cu}, \mathrm{Fe}, \mathrm{Co}, \mathrm{Mn}, \mathrm{Mo}, \mathrm{V}$ e $\mathrm{Zn}$. Os resultados obtidos mostraram maior afinidade dos metais pelas frações físicas de menor tamanho (argila e silte fino). Contudo, maiores teores de metais foram observados nas frações químicas do solo, sugerindo maior poder de complexação das substâncias húmicas do solo. A concentração de $\mathrm{Zn}$ observada na água de lavagem da humina foi superior a encontrada na fração humina, mostrando maior afinidade desse metal pela matéria orgânica dissolvida. Esse resultado é importante, pois evidencia a perda desse metal durante o processo de fracionamento químico, visto que essa água é descartada. As frações de ácido fúlvico 1 e 2 apresentaram concentrações significativas de metais, principalmente $\mathrm{Cd}, \mathrm{Cu}, \mathrm{Mn}$ e $\mathrm{Zn}$, sendo as maiores encontradas para o ácido fúlvico 1. O ácido húmico, devido a grande quantidade de grupos reativos (carboxílicos e fenólicos), mostrou ser um forte agente complexante de metais. Esses resultados indicam diferente afinidade dos metais pelas frações físicas e químicas do solo, ressaltando a importância do estudo do destino dos metais nas diferentes frações do solo. 


\begin{abstract}
In agricultural regions near big urban areas and where the intensive use of natural resources exists, in particular of the soil, recycling sewage sludge with agricultural finality appears as a promising alternative. However, the sustainability of this practice needs to be further assessed, even more so when considering there is lack of information on environmental impacts in tropical areas. The present work evaluated the effects of sewage sludge addition to two soils, Rhodic Eutrodox and Rhodic Hapludox by FAO Taxonomy) colleted from a field experiment, installed in 1997 in the city of Jaboticabal, São Paulo State. Sewage sludge was obtained from the Barueri sewage sludge treatment plant, located in the metropolitan region of São Paulo State, Brazil, operated by the Basic Sanitation Company of the State of São Paulo. In order to observe the effects of the sewage sludge addition, the humic acids extracted from soils were analyzed by absorption of ultraviolet and visible radiation, Fourier transform infrared, nuclear magnetic resonance, eletronic paramagnetic resonance, fluorescence and elementar analyses. To analyse the intact soil laser induced fluorescence was used, and for physics and chemical inductively coupled plasma atomic emission was used. The results obtained by Fourier transformed infrared and nuclear magnetic resonance showed spectra with characteristic bands from aliphaticity groups for humic acid from sewage sludge, confirming their high aliphacitity degree. The level of the semiquinona free radicals determined by electronic paramagnetic resonance decreased for soils under sewage sludge application. Data from fluorescence utilizing different methodologies (Zolnay et al., 1999; Milori et al., 2002; Kalbitz et al., 1999) and laser induced fluorescence, from intact soil, showed similar results. In a general manner, the results obtained for spectroscopy analyses showed incorporation of less humified compounds, with high aliphaticity degree and lower aromaticity degree. Analyses of the metals in soils under sewage sludge application in some cases have not evidenced the increase of these elements, even when the sewage show higher levels to those found in the soils. Thus, the question remains, where and how are the heavy metals from sewage sludge? Which, should have been detected in higher levels in soils under sewage sludge application? The objective of this work was to amplify the valuations beyond the conventional proceedings with analyses of physics and chemical fractions. The heavy metals studied were: $\mathrm{Cd}, \mathrm{Cr}, \mathrm{Cu}, \mathrm{Fe}, \mathrm{Co}, \mathrm{Mn}, \mathrm{Mo}, \mathrm{V}$ and $\mathrm{Zn}$. The results obtained showed higher affinity of metals for physical fractions that have smaller size (clay and fine silt). However, higher heavy metals concentrations were observed in the chemical fractions of the soils, due to higher complexity power of the humic substances of soils. The $\mathrm{Zn}$ concentration observed in the water of the humin wash was higher than what was observed in the humina fraction, showing higher affinity of this metal for dissolved organic matter. This result is important, because it evidences the loss of this metal during the extraction process of the humic substances, since this water is discarded. The fractions of fulvic acids 1 and 2 showed significative concentrations of the metals, mainly $\mathrm{Cd}, \mathrm{Cu}, \mathrm{Mn}$ and $\mathrm{Zn}$, being that the biggest were for humic acids, because the most quantity of the reactive groups (charboxilics and phenolics), showed to be a strong complex agent of the metals. Such results indicate different affinity of metals for physics and chemical fractions from soils, emphasizing the importance of the study of the course of heavy metals in the different fractions of the soil.
\end{abstract}




\section{CAPÍTULO 1 INTRODUÇÃO}

Atualmente, em âmbito global, se discutem as causas, os efeitos e as soluções para o aquecimento do planeta e alterações nos padrões climáticos. Regionalmente, e não menos importante, a poluição de rios e a degradação dos solos são problemas graves que afetam a qualidade de vida de toda uma população local, em especial dos economicamente menos favorecidos, cujas opções de moradia, poder de consumo e acesso a medicamentos são restritos. Nesse sentido, a geração e o descarte de resíduos têm sido atacada por diversas frentes, de modo a minimizar sua geração e selecionar técnicas ecologicamente favoráveis de reutilização ou destino final dos materiais não passíveis de reuso. Dentre as medidas práticas atualmente empreendidas encontra-se o tratamento dos esgotos antes da devolução aos corpos d'água receptores. Tal prática, respeitando a capacidade de suporte e resiliência do meio, melhora consideravelmente os índices de qualidade de águas superficiais (Bettiol; Camargo, 2001). Entretanto, como toda atividade humana gera resíduos, sejam decorrentes de seu próprio metabolismo ou da atividade industrial, isso não é diferente com relação ao tratamento dos esgotos nas estações, podendo-se citar dentre os resíduos mais problemáticos o lodo de esgoto.

Os mais recentes resultados do Instituto Brasileiro de Geografia e Estatística (IBGE2000), mostram que pouco mais de $35 \%$ da população brasileira é atendida por sistema de coleta e tratamento de esgoto. No estado de São Paulo, cerca de $40 \%$ de sua população é atendida por redes coletoras e tratamento de esgoto.

A SABESP maior produtora de lodo de esgoto do país, estima que a Região Metropolitana da cidade de São Paulo estará produzindo cerca de 785 toneladas (base seca) de lodo de esgoto por dia no ano de 2015 (Tsutya, 2000). Na Estação de Tratamento de Esgoto (ETE) de Barueri-SP, uma das principais ETE desta região, estimou-se que a produção para os anos 2005, 2010 e 2015 será respectivamente de 227, 294 e 310 toneladas (base seca) por 
dia (Santos; Tsutiya, 1997). O estado do Paraná, pioneiro no país no tratamento de lodo de esgoto, vem desde o começo da década de 90 desenvolvendo pesquisas nesta área, atualmente, produz cerca de 54 toneladas por mês do lodo de esgoto. Devido aos baixos índices de coleta e tratamento de esgoto, há uma clara tendência a um grande aumento na produção de lodo, dados apresentados por Tsutya, 2000.

Dentre as alternativas para a disposição final do lodo de esgoto, tais como, incineração, reuso industrial, disposição em aterro sanitário, disposição oceânica, o uso agrícola apresentase como uma das mais convenientes, visto que o lodo de esgoto contém matéria orgânica e nutrientes (macro e micronutrientes), fundamentais na produção agrícola e na manutenção da fertilidade do solo (Tsutya, 2000).

Entretanto, este pode apresentar algumas restrições devido à presença de sais solúveis, patógenos, compostos orgânicos persistentes e metais pesados. As concentrações de metais pesados no lodo de esgoto são determinadas pela atividade e pelo tipo de desenvolvimento urbano e industrial da área que abastece a estação de tratamento (Oliveira et al., 2002).

A contaminação de solos por metais pesados pode ter conseqüências maléficas para o ecossistema como, a perda da produtividade agrícola, a redução da qualidade da cadeia alimentar com danos a saúde humana e animal e a contaminação de fontes de água. Portanto, torna-se necessário determinar as concentrações disponíveis desses elementos no solo.

Diversos países dispõem de legislação para o uso do lodo de esgoto na agricultura. Porém, no Brasil apenas dois estados apresentam normatização, o Estado de São Paulo, onde a prática vigente segue Norma P 4.230 - Aplicação de lodos de sistemas de tratamentos biológicos em áreas agrícolas - Critérios para projetos e operação, da Companhia de Tecnologia de Saneamento Ambiental (CETESB), publicada em agosto de 1999, e o Estado do Paraná, onde a prática atual segue a Norma IAP - Utilização agrícola de lodo de esgoto, do Instituto Ambiental do Paraná (IAP), publicada em dezembro de 2003. Contudo, uma regulamentação brasileira vem sendo estudada e elaborada pelos Ministérios do Meio 
Ambiente e da Agricultura, Pecuária e do Abastecimento, através do Conselho Nacional do Meio Ambiente (CONAMA) com a finalidade de se definir critérios e procedimentos, para o uso agrícola de lodos gerados em ETE sanitário e seus produtos derivados.

\section{OBJETIVOS}

Estudar através das técnicas espectroscópicas de: absorção de radiação no UV-Vis, infravermelho com transformada de Fourier (FTIR), ressonância magnética nuclear (RMN), ressonância paramagnética eletrônica (RPE), Fluorescência e fluorescência induzida por laser (FIL), a dinâmica, reatividade e aspectos estruturais da matéria orgânica e seus constituintes húmicos em solos submetidos à adição de lodo de esgoto, em experimentos de campo de longa duração;

Caracterizar quali e quantitativamente através da espectrometria atômica com plasma indutivamente acoplado (ICP OES) os metais pesados presentes nas amostras de solo, submetidas à adição de lodo de esgoto, e suas frações físicas (areia, argila e silte) e químicas (ácido húmico, ácido fúlvico, humina). 


\subsection{LODO DE ESGOTO}

O lodo de esgoto é o resíduo que se obtém após o tratamento das águas servidas (esgotos), com a finalidade de torná-las o menos poluídas possível, de modo a permitir o seu retorno ao meio ambiente sem que sejam agentes de poluição significativa. Quando devidamente higienizado, estabilizado e seco, o lodo de esgoto recebe o nome de biossólido (Melo; Marques, 2000).

\subsubsection{Composição do lodo de esgoto}

A composição do lodo de esgoto varia enormemente em função de sua origem, ou seja, se proveniente de uma área tipicamente residencial ou industrial, da época do ano e do processo utilizado na ETE. Os dados apresentados na (Figura 2.1), dão uma idéia da composição média do lodo de esgoto.

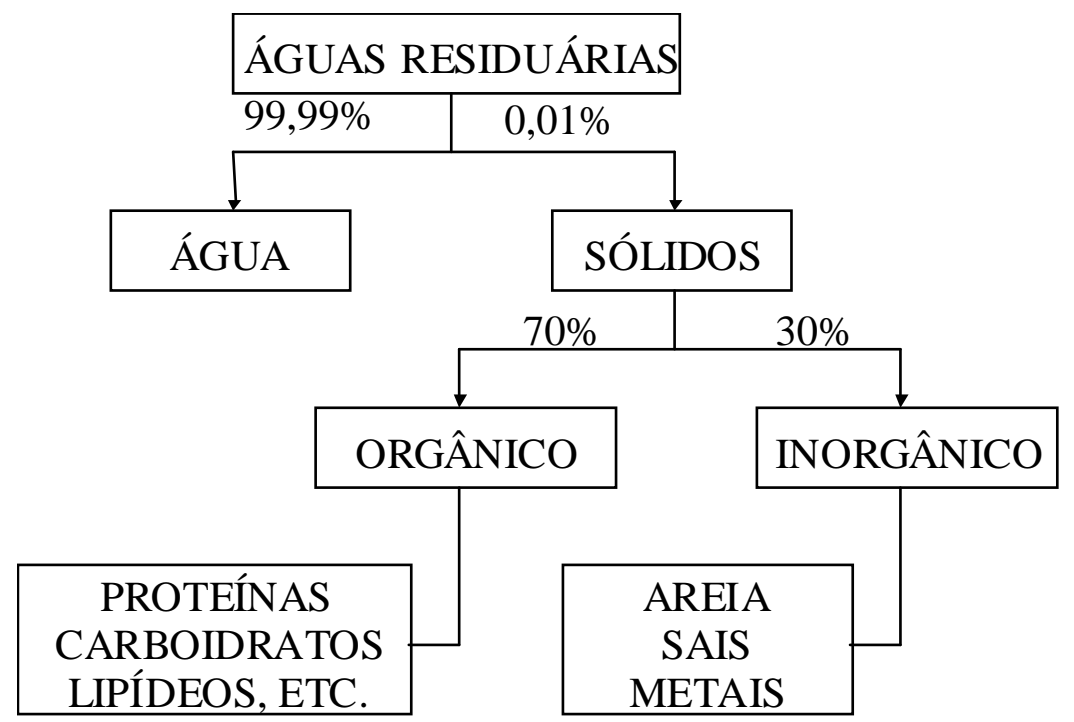

Figura 2.1 - Composição típica do lodo de esgoto doméstico (Melo; Marques, 2000).

Como se pode observar, cerca de 99,99\% do esgoto doméstico é constituído por água. Durante o processo de tratamento, ocorre a separação das frações sólida e líquida. A fração 
sólida, que encerra na sua composição componentes orgânicos e inorgânicos, é submetida a um processo de digestão e desidratação. Parte da fração mineral e da fração orgânica, aquela solúvel em água, permanecem na parte líquida, enquanto a areia, os sais e a fração orgânica, insolúveis em água, permanece na fração sólida. Na fração sólida encontram-se biomoléculas como carboidratos, proteínas, lipídeos, substâncias húmicas, entre outros, que se constituem em fonte de carbono e de energia para organismos heterotróficos, e cujo metabolismo conduz à liberação de gás carbônico, fosfatos, nitratos e outros íons (Melo; Marques, 2000).

\subsubsection{O uso agrícola do lodo de esgoto}

A utilização do lodo de esgoto em solos agrícolas vem sendo avaliada desde 1925 nos Estados Unidos da América, Holanda, Reino Unido e Dinamarca, onde cerca de $45 \%$ do lodo de esgoto produzido são aproveitados na agricultura (Kirkham, 1982; Pedroza et al., 2003). No Brasil, recentes trabalhos desenvolvidos pelo Programa de Pesquisa e Saneamento Básico (PROSAB), no estado do Paraná, confirmaram que a reciclagem agrícola do lodo é uma técnica alternativa para a disposição final do lodo, quando os teores de metais pesados e a presença de organismos patogênicos estão dentro dos limites propostos pela legislação (Fernandes; Andraus; Andreoli, 1996).

Quanto à legislação, a CETESB publicou em agosto de 1999, a Norma P 4.230, com o objetivo de estabelecer os procedimentos para a elaboração de projetos sobre a utilização de biossólido em áreas agrícolas no Estado de São Paulo (CETESB, 1999) e o IAP publicou em dezembro de 2003, a Norma IAP, sobre a utilização agrícola de lodo de esgoto no Estado do Paraná (IAP, 2003).

O lodo de esgoto contêm matéria orgânica, macro (nitrogênio e fósforo) e micronutrientes (zinco, cobre, ferro, manganês e molibdênio) que exercem um papel fundamental na produção agrícola e na manutenção da fertilidade do solo (Tsutya, 2000; Bettiol; Camargo, 2001). 
Quanto à melhoria das condições físicas do solo, o lodo de esgoto, de maneira semelhante a matéria orgânica, aumenta a retenção de umidade em solos arenosos e melhora a permeabilidade em e infiltração nos solos argilosos, melhora o estado de agregação das partículas do solo, diminui sua densidade, aumenta a aeração e a capacidade de troca de cátions (Melo; Marques, 2000; Bettiol; Camargo, 2001).

Porém, a presença de metais pesados no lodo de esgoto é motivo de grande preocupação ambiental, e vem tornado-se um entrave na generalização do uso agrícola deste resíduo (Bertoncini, 2002).

Em solos poluídos, os metais podem estar na forma solúvel, adsorvidos na fração inorgânica, complexados com os componentes orgânicos ou simplesmente precipitados. Os contaminantes solúveis estão sujeitos à migração para a solução do solo, assimilação pelas plantas ou organismos aquáticos ou volatilização para a atmosfera (Fungaro; Flues; Celebroni, 2004).

O comportamento dos metais pode ser influenciado por atributos do solo, tais como: teor de argila, matéria orgânica, conteúdo de óxidos e pH. Portanto, os critérios para aplicação do lodo de esgoto deveriam ser baseados também nos atributos do solo e não apenas nos teores totais de metais no lodo de esgoto.

A fração orgânica do solo é muito complexa e compõe-se de uma grande variedade de compostos solúveis e insolúveis que são capazes de reagir com os micronutrientes e com os metais pesados.

\subsection{MATÉRIA ORGÂNICA DO SOLO}

A matéria orgânica é um importante constituinte do solo, sendo um componente fundamental na qualidade dos sistemas agrícolas em razão de seu conteúdo e sua qualidade serem os mais importantes fatores que mantêm a fertilidade dos solos e a sustentabilidade dos agroecossistemas (Reeves, 1997). 
Segundo (Stevenson, 1994), a matéria orgânica do solo consiste de uma mistura de compostos em vários estágios de decomposição, que resultam da degradação biológica de resíduos de plantas e animais, e da atividade sintética de microrganismos. Pode ser agrupada em substâncias húmicas e não húmicas. As substâncias não húmicas são compostas por substâncias com características químicas definidas, tais como, polissacarídeos, aminoácidos, açúcares, proteínas e ácidos orgânicos de baixa massa molar. As substâncias húmicas não apresentam características químicas e físicas bem definidas, e se dividem em ácido húmico, ácido fúlvico e humina, com base nas suas características de solubilidade (Stevenson, 1994).

\subsubsection{Importância da matéria orgânica para o solo}

Em solos tropicais e subtropicais altamente intemperizados, a matéria orgânica tem grande importância no fornecimento de nutrientes às culturas, na retenção de cátions, na complexação de elementos tóxicos e de micronutrientes, na estabilidade da estrutura, na infiltração e retenção de água, na aeração e na atividade e diversidade microbiana, constituindo assim, um componente fundamental da sua capacidade produtiva (Stevenson, 1994). Nessas regiões, a degradação da matéria orgânica em condições inadequadas de manejo é rápida e vem acompanhada de processo de deterioração das características químicas, físicas e biológicas do solo (Mielniczuk, 1999). Na recuperação dessas áreas, é preciso que sejam adotados sistemas de manejo que priorizem um maior aporte de carbono ao solo, no sentido de elevar a biodisponibilidade da matéria orgânica, a qualidade do solo e mitigar as emissões de $\mathrm{CO}_{2}$ (Bayer et al., 2000).

O uso de lodo de esgoto na agricultura é uma prática de manejo vantajosa por este se tratar de material rico em matéria orgânica.

\subsubsection{Dinâmica da matéria orgânica do solo}

Nos últimos anos, o advento e o aperfeiçoamento do uso dos métodos químicos e espectroscópicas para o estudo da matéria orgânica vêm demonstrando o forte potencial 
desses em auxiliar no entendimento dos processos relacionados com a dinâmica da matéria orgânica após a aplicação de resíduos ao solo (Dias, 2005).

É de grande interesse o estudo da dinâmica da matéria orgânica do solo, devido sua importância tanto do ponto de vista de solos, considerando aspectos relevantes a fertilidade e estrutura, para evitar processos erosivos, quanto aspectos ambientais, com relação as reações e associações com pesticidas, metais pesados e microrganismos, em solos e águas, e ainda considerando aspectos globais da Terra, como o efeito estufa (Silva; Pasqual, 1999; Bayer, 1996; Diekow; Bayer; Mielniczuk, 2004).

A dinâmica da matéria orgânica é de natureza bioquímica e envolve uma série de microrganismos e pode ser caracterizada por dois processos fundamentais: a mineralização e a humificação.

Segundo (Cerri; Moraes, 1992) na mineralização, os constituintes orgânicos são transformados em compostos minerais, normalmente exportados do meio, quer na forma gasosa, quer lixiviados. Com isso, mineralização é a produção de íons inorgânicos pela oxidação de compostos orgânicos (oxidação é o processo pelo qual o carbono orgânico é convertido a dióxido de carbono e perdido para a atmosfera). Os compostos orgânicos mais facilmente decompostos são as proteínas e os carboidratos solúveis, como o amido e a pectina e, os mais difíceis, a celulose e a lignina (Silva; Fay, 2004).

A humificação é o processo no qual as substâncias orgânicas formadas se associam à fração mineral e permanecem no meio. Segundo (Zech et al., 1997) a humificação é a transformação de reservas macromorfologicamente identificáveis em compostos húmicos amorfos. Com isso, as principais transformações que ocorrem durante a humificação, são a perda de polissacarídeos e compostos fenólicos, modificação das estruturas de lignina, e enriquecimento em estruturas aromáticas não lignínicas recalcitrantes. A humificação bem como a decomposição de resíduo, é mediada primeiramente por processo microbiológico, 
controlado principalmente por variáveis locais específicas, tais como, temperatura, regime de água no solo, $\mathrm{pH}$ e disponibilidade de nutrientes.

\subsubsection{Substâncias húmicas}

A habilidade dos solos em reter água e estimular o crescimento das plantas depende da matéria orgânica e especialmente das substâncias húmicas. Nos solos, a matéria orgânica pode apresentar-se em quantidades muito variadas, desde $0,5 \%$ (solos desérticos) até $95 \%$ (solos turfosos) (Luchese; Fávero; Lenzi, 2002). No Brasil, a maior parte dos solos apresentam teores de matéria orgânica entre 1 e $3 \%$ contudo, podemos encontrar solos com teores superiores a esses. As substâncias húmicas podem compor mais de $80 \%$ da matéria orgânica de um solo e por essa razão essas substâncias podem ter um profundo papel nos aspectos físicos e químicos do solo.

Com base nas suas características de solubilidade as substâncias húmicas se dividem em ácido húmico, ácido fúlvico e humina. O ácido fúlvico é solúvel em água e em condições ácidas $(\mathrm{pH}<2,0)$, possui maior presença de grupamentos carboxílicos e de oxigênio, e menor concentração de carbono em relação aos ácidos húmicos, que são insolúveis em meio ácido e solúveis em meio básico. A humina, por sua vez, é insolúvel em meios ácido e básico, sendo mais polimerizada do que o ácido fúlvico e o ácido húmico (Schnitzer; Kodama; Ripmeester, 1991; MacCarthy et al., 1990).

As substâncias húmicas são amorfas, escuras e com grande conteúdo de grupos orgânicos, tais como, carboxílicos, fenólicos, enólicos, alcoólicos, quinonas entre outros. Possuem massa molar aparente que varia de centenas a milhares de unidade de massa atômica e são substâncias bastante resistentes à degradação química e biológica (Schnitzer; Khan, 1978; Stevenson, 1994; Schulten; Schnitzer, 1997). Segundo (Stevenson, 1994), os caminhos pelos quais as substâncias húmicas são formadas são inúmeros, devido à grande quantidade de possíveis estruturas precursoras e ao enorme número de possibilidades de interação entre elas. 
A área da ciência do solo na qual se estuda a composição química e o modelo estrutural das substâncias húmicas, tem tido grandes avanços nas últimas décadas contudo, ainda hoje não existe um modelo estrutural para as substâncias húmicas que explique totalmente a composição química, a estrutura, a forma e o tamanho, sendo que os modelos existentes geram controvérsias e discussões (Clapp; Hayes, 1999; Burdon, 2001; Hayes e Clapp, 2001; MacCarthy, 2001; Piccolo, 2001).

Muitas estruturas foram propostas, cada uma delas foi caracterizada por grupos funcionais similares e a presença de componentes alifáticos e aromáticos.

Baseados em uma variedade de técnicas e análises (Schulten; Schnitzer, 1993) propuseram uma estrutura para o ácido húmico (Figura 2.2).

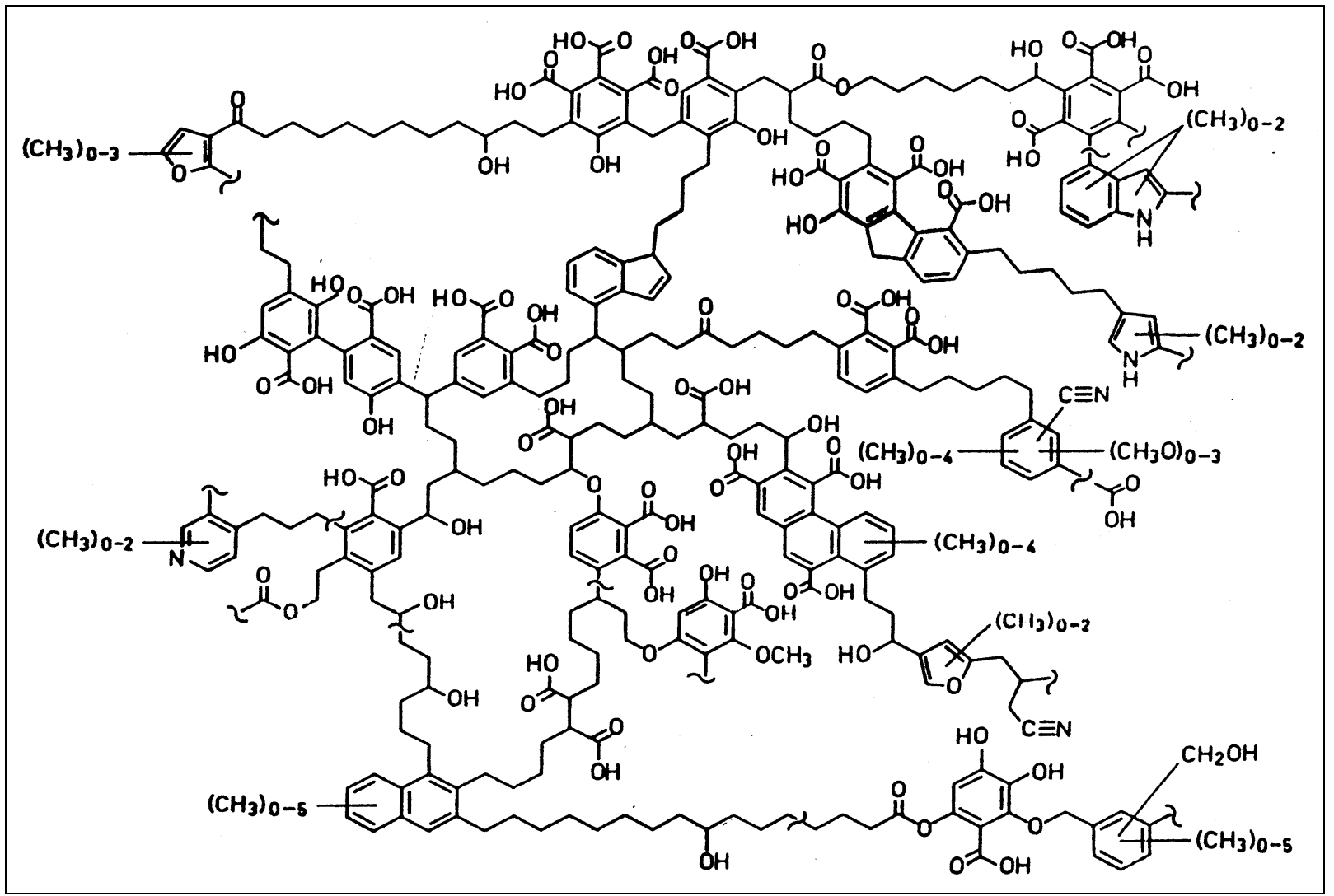

Figura 2.2 - Modelo de ácido húmico proposto por Schulten e Schnitzer (1993).

Neste modelo (Figura 2.2) o oxigênio está presente como grupos carboxílicos, fenólicos, hidroxílicos, ésteres e éteres, nitrogênio está presente como estruturas heterocíclicas e como 
nitrilas. A composição elementar da estrutura do ácido húmico é $\mathrm{C}_{308} \mathrm{H}_{328} \mathrm{O}_{90} \mathrm{~N}_{5}$ e tem tamanho molecular de 5540 Da.

As afirmações e citações feitas anteriormente foram baseadas na proposta que substâncias húmicas seriam macromoléculas orgânicas, com características similares às macromoléculas biológicas como, proteínas, polissacarídeos, ácidos nucléicos e lignina (Swift, 1989).

No entanto, recentemente, uma discussão emergiu na comunidade científica sobre o tipo real de estrutura molecular das substâncias húmicas: se são constituídos de estruturas macromoleculares como sempre se afirmou, ou se de estruturas supramoleculares, resultantes da associação de blocos moleculares relativamente pequenos, através de ligações de hidrogênio, associações de orbitais $\pi-\pi$, ou usando íons metálicos como $\mathrm{Fe}$ (III), $\mathrm{Al}$ (III) ou Cu (II) como mordentes (Piccolo; Nardi; Concheri, 1996).

Atualmente dois modelos tentam explicar as características observadas para as substâncias húmicas, sendo eles:

Macromolecular: neste modelo as variações conformacionais das substâncias húmicas são similares àquelas observadas nas macromoléculas biológicas como, proteínas, polissacarídeos, ácidos nucléicos e ligninas (Figura 2.3a) (Swift, 1989, 1999) e dependem da concentração das moléculas húmicas (Chen; Schnitzer, 1976), do pH (Senesi, Miano, Brunetti, 1996) e da concentração iônica (Ghosh; Schnitzer, 1980; Schnitzer, 1991). Além destas características, (Schulten; Schnitzer, 1997) propõem a existência de "vazios" hidrofóbicos dentro das moléculas (Figura 2.3b), o que foi corroborado pelo trabalho de (Wandruska, 1998), que definiu a estrutura das substâncias húmicas como uma estrutura pseudo-micelar de natureza polimérica. 
(a)

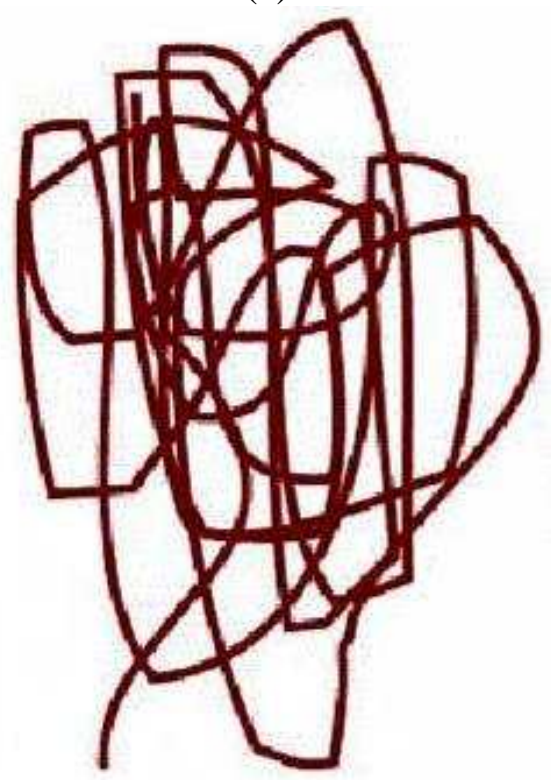

(b)

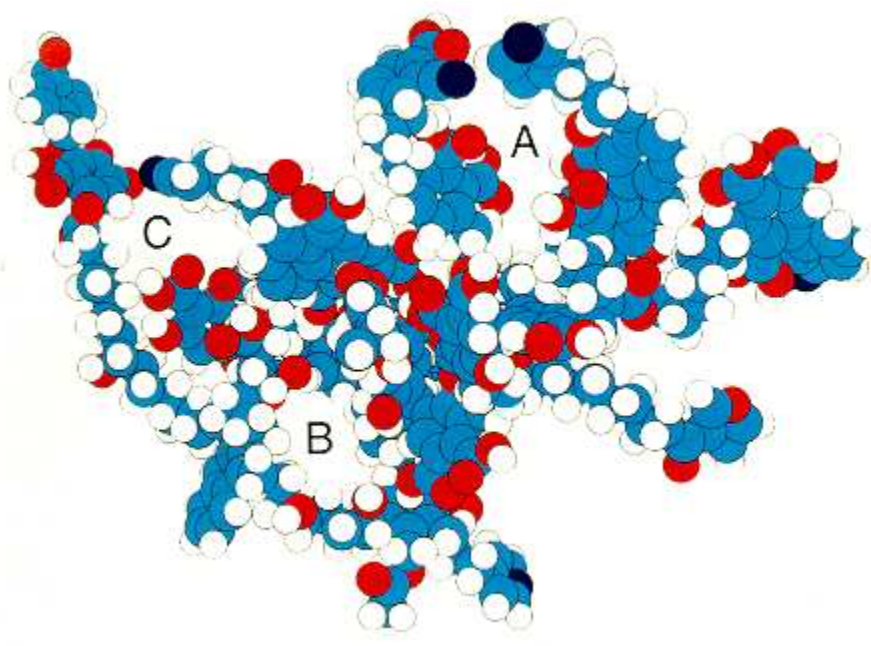

Figura 2.3 - Modelos conceituais propostos pela teoria macromolecular: (a) moléculas das substâncias húmicas aleatoriamente enoveladas (Swift, 1989) e (b) ácido húmico proposto por Schulten e Schnitzer (1997), carbono=azul; oxigênio=vermelho; nitrogênio=preto e hidrogênio=branco. As letras A, B e C indicam os espaços "vazios” presentes na molécula das substâncias húmicas capazes de interagir com outros compostos.

Supramolecular: neste modelo é proposto que as substâncias húmicas em solução formem grandes agregados húmicos que são estabilizados por ligações fracas, tais como, ligações de hidrogênio e/ou interações hidrofóbicas. Além disso, é proposto que as substâncias húmicas são provenientes de produtos de degradação enzimática de plantas e complexos de ligninas (Wershaw, 1986, 1993). Esse modelo foi embasado por (Conte; Piccolo, 1999) que deu origem à teoria supramolecular (Piccolo, 2001, 2002), na qual as substâncias húmicas são formadas por moléculas pequenas e heterogêneas de várias origens, auto-organizadas em conformações supramoleculares, o que explicaria o grande tamanho molecular aparente das substâncias húmicas. No conceito supramolecular, os ácidos fúlvicos são associações de pequenas moléculas hidrofílicas dispersas em solução devido à repulsão eletrostática das cargas negativas provenientes da dissociação dos grupos ácidos, como por exemplo, os carboxílicos, a qualquer valor de pH. Os ácidos húmicos são constituídos por associações de estruturas predominantemente hidrofóbicas (cadeias polimetilênicas, ácidos graxos e esteróides), que são estabilizadas em pH neutro por forças dispersivas hidrofóbicas 
(van der Waals, $\pi-\pi$, e ligações $\mathrm{CH}-\pi$ ). Os ácidos húmicos crescem gradualmente em tamanho com o decréscimo do pH até a sua precipitação. Segundo (Piccolo, 2001), a influência do pH ocorre por meio da protonação da molécula e conseqüente aumento das ligações de hidrogênio intermoleculares. O modelo supramolecular foi reforçado pelos resultados obtidos por (Simpson, 2002ab). Estes autores demonstraram que as substâncias húmicas extraídas de solos são formadas por uma mistura de substâncias agregadas de baixo peso molecular (em torno de $2000 \mathrm{Da}$ ) e propuseram um esquema de estrutura (Figura 2.4) para ilustrar como as principais estruturas identificadas nas substâncias húmicas poderiam formar um agregado na presença de cátions metálicos de ocorrência natural nos ecossistemas terrestres.

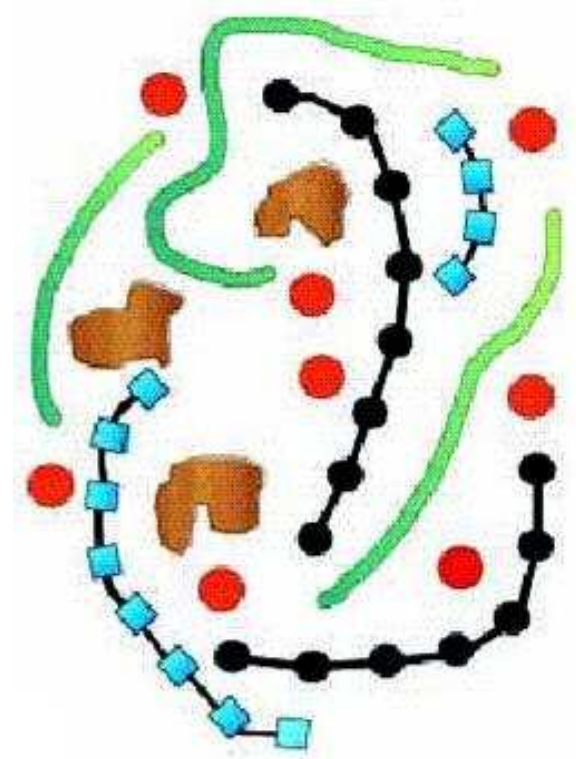

Figura 2.4 - Esquema de estrutura das substâncias húmicas proposto por Simpson et al. (2002b). As unidades vermelhas representam os cátions metálicos, as unidades pretas os polissacarídeos, as unidades azuis os polipeptídios, as unidades verdes as cadeias alifáticas e as unidades marrons os fragmentos aromáticos provenientes da lignina.

Diallo et al. (2003), utilizando dados experimentais e métodos computacionais, excluíram os modelos que sugerem que as substâncias húmicas sejam macromoléculas com alta massa molar ou a mistura de compostos orgânicos complexos e heterogêneos e observaram que as estruturas existentes possuem as características necessárias para formar 
supramoléculas. Contudo, não conseguiram um modelo de isômero em três dimensões (3D) definitivo para o ácido húmico, sendo que apenas alguns isômeros prováveis foram propostos.

Ainda que, inquestionáveis avanços foram promovidos pelo surgimento do modelo que propôs as substâncias húmicas como uma mistura de moléculas reativas e heterogêneas, ele ainda apresenta inúmeras limitações (Clapp; Hayes, 1999; Burdon, 2001; Hayes; Clapp, 2001; MacCarthy, 2001; Piccolo, 2001).

A maior dificuldade encontrada na definição de um modelo para as substâncias húmicas, que englobe composição, estrutura, tamanho e reatividade, é a heterogeneidade química, sendo que há uma variabilidade desta heterogeneidade de acordo com a origem (aquática ou terrestre) ou da localização geográfica (Simões, 2005). Uma recente revisão (Sutton; Sposito, 2005) entende que o modelo que melhor descreve essas propriedades é aquele que propõe que as substâncias húmicas são agrupamentos de diversos componentes de relativamente baixa massa molecular formando associações dinâmicas estabilizadas por interações hidrofóbicas e pontes de hidrogênio.

\subsubsection{Interações das substâncias húmicas com metais}

Uma das mais importantes propriedades das substâncias húmicas é a sua capacidade de interagir com íons metálicos do solo, tanto nutrientes quanto tóxicos, para formar complexos organometálicos e quelatos de diferentes estabilidades e características estruturais (Senesi; Sposito; Martin, 1986), podendo até mesmo controlar sua disponibilidade para as plantas. De modo geral, em solos minerais, pode-se esperar que mais de $50 \%$ do total dos elementos traços esteja associado a matéria orgânica (Kabata-Pendias; Pendias, 1985). A complexação de íons metálicos pelas substâncias húmicas é extremamente importante para a retenção e mobilidade dos contaminantes em solos e águas (Sparks, 1999). Interações entre substâncias húmicas e metais têm sido descritas como troca de íons, sorção superficial, quelação, coagulação e peptização (Kabata-Pendias; Pendias, 1985). Os grupos funcionais das 
substâncias húmicas possuem diferentes afinidades por íons metálicos na ordem decrescente como se mostra abaixo (Sparks, 1999):

$\begin{array}{llccccc}-\mathrm{O}^{5} & -\mathrm{NH}_{2}> & -\mathrm{N}=\mathrm{N}> & \mathrm{N} /> & \mathrm{COO}> & -\mathrm{O}^{5} & -\mathrm{C}=\mathrm{O} \\ \text { (enolato) } & \text { (amina) } & \text { (azo composto) } & \text { (anel } \mathrm{N}) & \text { (carboxilato) } & \text { (éter) } & \text { (carbonil) }\end{array}$

Apesar do conhecimento da existência da interação das substâncias húmicas com íons metálicos (Stevenson, 1982), a natureza e extensão dessas interações não são completamente entendidas. O cátion pode estar ligado a dois ou mais ligantes de diferentes moléculas (Kabata-Pendias; Pendias, 1985).

Praticamente todos os aspectos da química e da reatividade de elementos traços no solo estão relacionados à formação de complexos estáveis com substâncias orgânicas (Stevenson, 1994). Enquanto cátions monovalentes $\left(\mathrm{Na}^{+}, \mathrm{K}^{+}\right.$, etc.) são mantidos principalmente pela simples formação de sais por reações de troca de cátions envolvendo grupos, tais como, carboxílicos e fenólicos. Cátions polivalentes $\left(\mathrm{Cu}^{2+}, \mathrm{Fe}^{3+}\right.$ e outros), podem formar ligações coordenadas com moléculas orgânicas.

A (Figura 2.5) mostra duas propostas de ligação com o $\mathrm{Cu}^{2+}$, (a) a primeira com ligantes nitrogenados, mais estável e portanto menos disponível para as plantas e (b) a segunda, com ligantes oxigenados, menos estável (Martin-Neto et al., 1991).

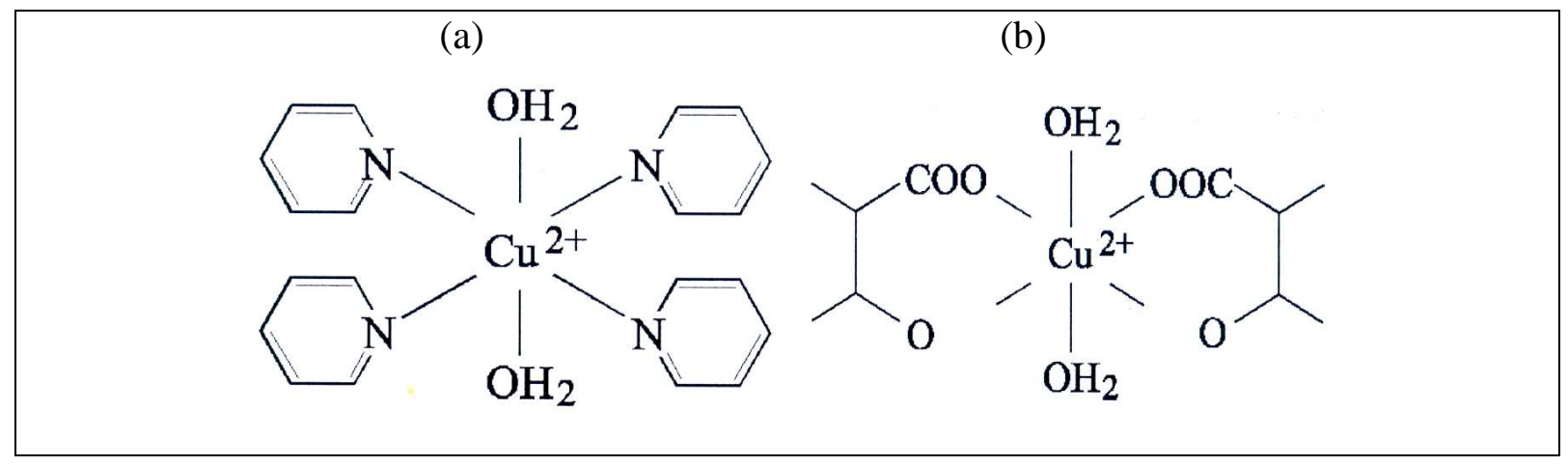

Figura 2.5 - Exemplos de complexos organometálicos. 
Espectroscopia e outros métodos físico-químicos aplicados às substâncias húmicas mostram que existem quatro principais características estruturais dos ácidos húmicos e fúlvicos influenciando suas reatividades químicas (Sposito, 1989):

Polifuncionalidade: que representa a existência de vários grupos funcionais, com reatividade diferentes, que são representativos de uma mistura heterogênea de polímeros que interagem entre si;

Carga macromolecular: possui caráter aniônico, produzindo efeitos na reatividade dos grupos funcionais e na conformação molecular;

Hidrofilicidade: a tendência que as substâncias húmicas possuem de formarem fortes ligações de hidrogênio com moléculas de água do meio, desta forma, solvatando grupos funcionais como $\mathrm{COOH}$ e $\mathrm{OH}$;

Labilidade estrutural: devido à capacidade de associações intermoleculares e de mudanças conformacionais em resposta a mudanças de $\mathrm{pH}$, condições redox, concentração iônica e ligações químicas.

A habilidade de um solo para reter cátions é uma propriedade de suas partículas minerais (argilas) e de seu comportamento húmico, assim ambos contribuem na capacidade de troca de cátions (Stevenson, 1994). A presença de cargas elétricas nas frações argilosas é resultado das substituições isomórficas, da ionização dos grupos $\mathrm{OH}$ e de cargas dependentes do $\mathrm{pH}$ associadas a óxidos de alumínio. Na estrutura macromolecular das substâncias húmicas as cargas provêm da ionização dos grupos carboxílicos e fenólicos, o que confere características polieletrolíticas que permitem formar ligações de hidrogênio com as águas de hidratação de cátions metálicos bem como, interações eletrostáticas mais fracas como, forças de van der Waals. A presença de grupos carboxílicos e fenólicos, permite também a formação de ligações químicas simples e ligações polidentadas produzindo quelatos. 
Contudo, é necessário aprofundar os estudos sobre a complexação dos metais pesados com as frações da matéria orgânica do solo, visando esclarecer o destino destes metais no solo e a participação das substâncias húmicas e das frações físicas na retenção dos metais.

\subsubsection{Caracterização da matéria orgânica}

Efeitos benéficos da utilização de lodo de esgoto na agricultura têm sido evidenciados por alguns pesquisadores (Berton; Camargo; Valadares, 1989; Oliveira, 2000; Melo; Marques, 2000; Simonete, 2001; Rocha; Gonçalves; Moura, 2004), no entanto, permanecem algumas dúvidas sobre a qualidade da fração orgânica do lodo de esgoto, sua dinâmica após aplicação no solo e os efeitos no estoque de carbono e na qualidade da matéria orgânica em áreas tratadas com esse resíduo.

Com isso, os métodos químicos e espectroscópicos tem ampla aplicação no estudo da matéria orgânica do solo, especialmente das substâncias húmicas, bem como na identificação e caracterização dos diferentes compostos húmicos, na avaliação das alterações desses compostos e, no entendimento dos processos relacionados com a dinâmica da matéria orgânica após a aplicação do lodo de esgoto ao solo.

\subsubsection{Métodos químicos}

O conhecimento dos teores de matéria orgânica é fundamental em diversas áreas da ciência do solo, visto que a matéria orgânica do solo desempenha um papel de suma importância do ponto de vista químico, físico e biológico.

Diversos métodos têm sido utilizados para a determinação do teor de matéria orgânica do solo. Porém, há uma carência de informações consistentes quanto à definição e recomendação do método mais adequado para a obtenção de resultados confiáveis e satisfatórios (Conceição et al., 1999).

\subsection{Determinação da composição elementar (CHNS)}


A análise elementar é o método mais usado para a determinação da composição elementar das substâncias húmicas, se baseia na detecção de quatro componentes (nitrogênio, carbono, hidrogênio e enxofre) de uma mistura, eluída e separada por uma coluna cromatográfica e detectada por um detector, na seqüência $\mathrm{N}_{2}, \mathrm{CO}_{2}, \mathrm{H}_{2} \mathrm{O}$ e $\mathrm{SO}_{2}$. Com os dados da análise elementar não é possível se chegar a fórmula molecular dos ácidos húmicos ou ácidos fúlvicos, mas é possível ter uma noção da composição geral da molécula.

A composição das substâncias húmicas é afetada por diversos fatores, como pH, material de origem, vegetação e uso do solo. Assim, solos neutros apresentam uma faixa estreita de valores para carbono, hidrogênio e nitrogênio, enquanto que solos ácidos apresentam uma faixa mais larga. Os ácidos fúlvicos são mais ricos em oxigênio e enxofre, enquanto que os ácidos húmicos são mais concentrados em carbono, hidrogênio e nitrogênio (Senesi; Loffredo, 1999).

De um modo geral, os ácidos húmicos extraídos do lodo de esgoto apresentam altos teores de nitrogênio e enxofre, devido a decomposição de proteínas e surfactantes contendo enxofre.

\subsection{Determinação da razão $\mathrm{C} / \mathrm{N}$}

A partir dos dados da análise elementar é possível calcular a razão $\mathrm{C} / \mathrm{N}$, que é uma das formas mais utilizadas para inferir o grau de humificação. Quanto menor a razão $\mathrm{C} / \mathrm{N}$ maior o grau de humificação (Nicolardot; Recous; Mary, 2001).

A razão $\mathrm{C} / \mathrm{N}$ pode ser utilizada ainda para inferir o grau de estabilização da matéria orgânica, do ponto de vista ao ataque microbiano (Fernandes, 2000).

\subsection{Determinação de carbono por via seca - Total Organic Carbon (TOC)}

$\mathrm{O}$ carbono total é determinado pela oxidação do carbono orgânico e inorgânico à $\mathrm{CO}_{2}$, devido ao aumento da temperatura a $900^{\circ} \mathrm{C}$. 
A determinação do carbono inorgânico é realizada através da acidificação (ácido fosfórico) e, posterior aquecimento a $200^{\circ} \mathrm{C}$. Por diferença do carbono total e inorgânico é calculado o valor do carbono orgânico das amostras.

\subsection{Determinação do teor de matéria orgânica por via úmida (Walkley-Black)}

A determinação da quantidade de matéria orgânica do solo baseia-se na sua oxidação à $\mathrm{CO}_{2}$ por íons dicromato, em meio fortemente ácido. Em amostras que requeiram maior precisão, a determinação da quantidade de íons $\operatorname{Cr}(\mathrm{III})$ reduzidos é realizada indiretamente, por titulação dos íons dicromato em excesso, com íons $\mathrm{Fe}^{2+}$. Alternativamente, pode-se determinar diretamente a quantidade de íons $\mathrm{Cr}$ (III) por colorimetria, medindo-se a intensidade da cor verde produzida por estes íons em solução. A determinação por colorimetria, normalmente utilizada em rotina, requer a montagem de uma curva-padrão de calibração. Essa curva é feita com uma série de amostras de solo, nas quais o teor de matéria orgânica é determinado por titulação, que apresenta maior precisão (Cantarella; Quaggio, Van Raij, 2001). Nos dois casos, a oxidação da matéria orgânica dá-se pela reação (Equação 2.1):

$$
2\left(\mathrm{Cr}_{2} \mathrm{O}_{7}\right)^{2-}+3 \mathrm{C}^{0}+16 \mathrm{H}^{+} \rightarrow 4 \mathrm{Cr}^{3+}+3 \mathrm{CO}_{2}+8 \mathrm{H}_{2} \mathrm{O}
$$

Na reação, considera-se o dicromato reduzido equivalente ao carbono orgânico existente na amostra de solo, e o excesso de dicromato é titulado com íons de $\mathrm{Fe}^{2+}$ obtidos a partir de uma solução padronizada de sulfato ferroso amoniacal.

$$
\left(\mathrm{Cr}_{2} \mathrm{O}_{7}\right)^{2-}+6 \mathrm{Fe}^{2+}+14 \mathrm{H}^{+} \rightarrow 2 \mathrm{Cr}^{3+}+6 \mathrm{Fe}^{3+}+7 \mathrm{H}_{2} \mathrm{O}
$$

Na determinação por titulação, a quantidade de carbono orgânico é obtida pela diferença entre a quantidade de $\mathrm{Fe}^{2+}$ gasta na titulação da prova em branco $(\mathrm{Cr}(\mathrm{VI})$ total adicionado) e aquela gasta na titulação do dicromato que restou após a oxidação do carbono da amostra. Convém frisar, que este método assume que todo o carbono da matéria orgânica está no estado de oxidação zero (Nelson; Sommers, 1996). Basicamente, trata-se de uma modificação do método conhecido por Walkley-Black, proposto para medir a matéria orgânica facilmente 
oxidável ou decomponível do solo, que inclui húmus e resíduos, mas exclui carvão e carbonatos (Walkley, 1947; Walkley; Black, 1934).

A reação, no método Walkley-Black, ocorre sem aquecimento externo, contando somente com o calor desprendido pela diluição do $\mathrm{H}_{2} \mathrm{SO}_{4}$. Desse modo, a oxidação do carbono da matéria orgânica não é completa, para compensar a oxidação parcial aplica-se um fator de correção $(1,33)$. Como o método determina o teor de carbono orgânico, a conversão para o teor de matéria orgânica é realizada através do fator de van Bemmelen $(1,724)$, com base no pressuposto de que a matéria orgânica do solo contém $58 \%$ de carbono orgânico. A fórmula empregada é:

$$
\text { Carbono Orgânico }\left(\mathrm{g} \mathrm{kg}^{-1}\right) / 1,724 \text { = Matéria Orgânica }
$$

\subsubsection{Métodos espectroscópicos}

A extração de substâncias húmicas e sua caracterização por meio de técnicas espectroscópicas têm gerado importantes resultados na avaliação da qualidade do solo, sob condições temperadas e tropicais, uma vez que fornecem informações sobre os grupos funcionais que constituem a matéria orgânica, muito embora, em sistemas tropicais, esses estudos sejam ainda reduzidos (Martin-Neto et al., 1991, 1994ab, 1998; Bayer et al.,1997; Milori et al., 2002; González-Perez et al. 2004). Mangrich (2001) ressalta que o conhecimento das estruturas químicas das substâncias húmicas é essencial para entender a sustentabilidade dos diferentes sistemas agrícolas, o ciclo global do carbono e a lixiviação de espécies químicas, que causam poluição das águas e o empobrecimento do solo.

\subsection{Absorção de radiação no UV-Vis}

A espectroscopia na região do Ultravioleta (200-400 nm) e Visível (400-800 nm) permite a identificação de transições de elétrons dos orbitais moleculares $\sigma$-, $\pi$ - e n- de seu estado energético fundamental para orbitais de maior energia em um estado excitado (Skoog; Holler; Nieman, 2002). 
A absorção de radiação ultravioleta ou visível geralmente resulta da excitação de elétrons de ligação, como consequiência, os comprimentos de onda dos picos de absorção podem ser correlacionados com os tipos de ligações nas espécies em estudo. A espectroscopia de absorção molecular é, portanto, valiosa para identificar grupos funcionais em uma molécula. Mais importantes, no entanto, são as aplicações da absorção de radiação no UV-Vis na determinação quantitativa de compostos contendo grupos absorventes (Skoog; Holler; Neuman, 2002).

Conforme mostrado na (Figura 2.6), as energias dos vários tipos de orbitais moleculares diferem significativamente. Quase sempre o nível de energia de um elétron não-ligante situase entre os níveis de energia dos orbitais $\sigma$ e $\pi$ ligantes e antiligantes. As transições eletrônicas entre certos níveis de energia podem ocorrer por absorção de radiação. As transições possíveis de serem observadas nos espectros eletrônicos são: $\sigma \rightarrow \sigma^{*}, \mathrm{n} \rightarrow \sigma^{*}, \mathrm{n}$ $\rightarrow \pi^{*}$ e $\pi \rightarrow \pi^{*}$. Destas transições, a $\sigma \rightarrow \sigma^{*}$ é o único tipo que pode ocorrer com elétrons envolvidos em ligações simples, por exemplo, o metano, que contém apenas ligações simples $\mathrm{C}-\mathrm{H}$ e pode, portanto, sofrer apenas transições $\sigma \rightarrow \sigma^{*}$, apresenta um máximo de absorção em $125 \mathrm{~nm}$. Em relação a outras transições possíveis, a energia necessária para induzir uma transição $\sigma \rightarrow \sigma^{*}$ é alta, correspondendo a freqüências na região ultravioleta de vácuo. As transições $n \rightarrow \sigma^{*}$ ocorrem em geral em compostos saturados contendo átomos com pares de elétrons não compartilhados, tais como, oxigênio, nitrogênio e enxofre. Em geral essas transições requerem menos energia que o tipo $\sigma \rightarrow \sigma^{*}$ e podem ser produzidas por radiação na região entre 150 e $250 \mathrm{~nm}$, com a maior parte dos picos aparecendo abaixo de $200 \mathrm{~nm}$. As transições $\mathrm{n} \rightarrow \pi^{*}$ e $\pi \rightarrow \pi^{*}$ são consideradas intensas, a maioria das aplicações da espectroscopia de absorção a compostos orgânicos esta baseada em transições de elétrons n e $\pi$ para o estado excitado $\pi^{*}$, porque as energias necessárias para esses processos situam-se em uma região espectral experimentalmente conveniente (200 a $700 \mathrm{~nm}$ ). Ambas as transições 
requerem a presença de um grupo funcional insaturado para fornecer os orbitais $\pi$ (Skoog, Holler; Nieman, 2002).

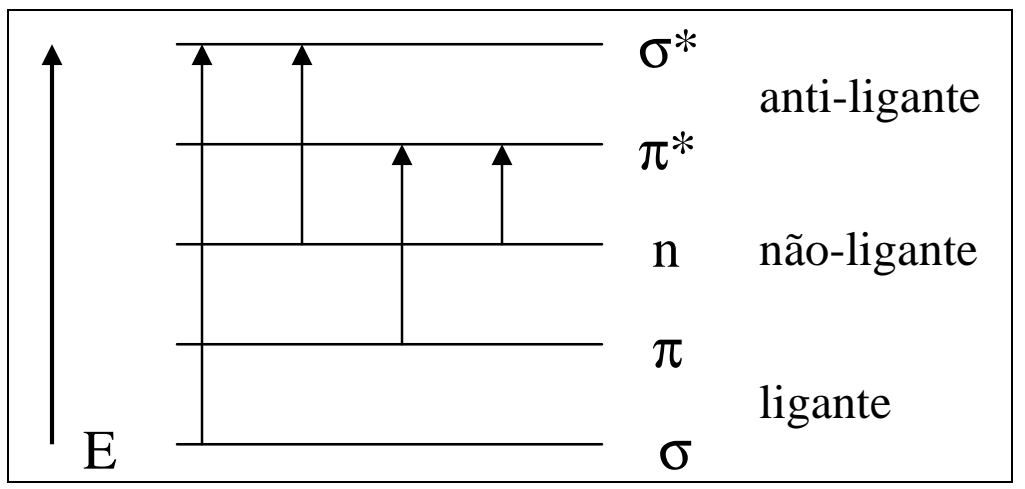

Figura 2.6 - Níveis de energia eletrônica molecular (Skoog; Holler, Nieman, 2002).

A absorção de radiação UV-Vis de maior comprimento de onda está restrita a um número limitado de grupos funcionais (chamados cromóforos) que contêm elétrons de valência com energias de excitação relativamente baixas. Os elétrons que contribuem para a absorção de uma molécula orgânica são aqueles que participam diretamente na formação de ligação entre átomos e, portanto, estão associados a mais de um átomo e elétrons não-ligantes ou isolados externos que estão comumente localizados em átomos como, oxigênio, halogênios, enxofre e nitrogênio (Skoog; Holler; Neiman, 2002).

Em função da grande quantidade e variabilidade de grupos cromóforos existentes nas macromoléculas húmicas, os espectros obtidos são geralmente formados pela sobreposição de várias bandas, sem picos definidos, apresentando absorção decrescente com o aumento do comprimento de onda.

Os grupos responsáveis pela cor escura das substâncias húmicas ainda não estão completamente estabelecidos, mas se suspeita de uma combinação de vários tipos de estruturas (Figura 2.7). Alguns dos grupos mais comuns são (Stevenson, 1994): 


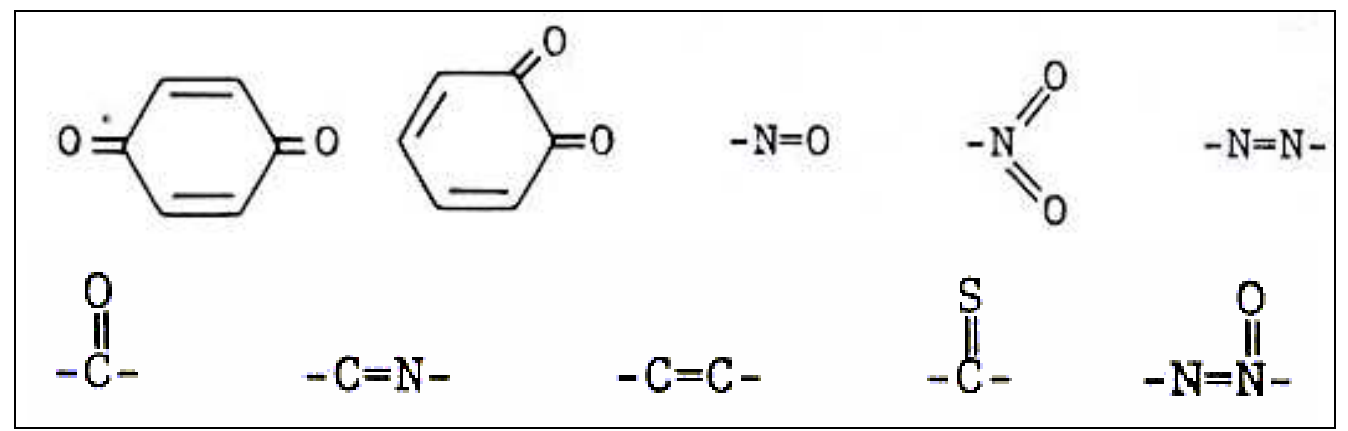

Figura 2.7 - Cromóforos presentes nas substâncias húmicas.

Na região do visível a razão entre as absorbâncias em 465 e 665 nm, chamada de razão $\mathrm{E}_{4} / \mathrm{E}_{6}$, tem sido amplamente usada para caracterização das substâncias húmicas. Segundo (Stevenson, 1994), esta razão decresce com o aumento da massa molecular e da condensação dos anéis, sendo utilizada como um indicador do grau de condensação dos anéis aromáticos das substâncias húmicas e, portanto grau de humificação.

Outros autores, entretanto, não relacionam a razão $\mathrm{E}_{4} / \mathrm{E}_{6}$ a cadeias aromáticas condensadas, mas apenas à presença de cadeias aromáticas. Espectros de fluorescência absorvendo em menores comprimentos de onda e estudos com ${ }^{13} \mathrm{C}$ RMN poderiam indicar melhor a presença de estruturas condensadas e o grau de humificação entre substâncias húmicas isoladas de materiais diversos.

Assim, (Chen; Senesi; Schnitzer, 1977) relaciona a razão $\mathrm{E}_{4} / \mathrm{E}_{6}$ ao tamanho e ao peso molecular das substâncias húmicas, e não à concentração de anéis aromáticos condensados. Baes e Bloom (1990) relacionam a razão $\mathrm{E}_{4} / \mathrm{E}_{6}$ apenas a absorção de fótons por grupos cromóforos, e conseqüentemente à quantidade destes. Colnago et al. (1997) estudando a correlação entre a razão $\mathrm{E}_{4} / \mathrm{E}_{6}$ e aromaticidade dada por ${ }^{13} \mathrm{C} \mathrm{RMN}$ em amostras de ácidos húmicos de Latossolo Vermelho, observaram uma correlação positiva $(r=0,67)$, bem como, aumento da aromaticidade e/ou diminuição da alifaticidade, porém concluem que esta razão relaciona-se a presença de anéis pouco ou muito condensados na molécula e não à aromaticidade total da molécula. 
Os dados obtidos a partir da razão $\mathrm{E}_{4} / \mathrm{E}_{6}$ são controversos na literatura e devem ser utilizados e correlacionados com o devido cuidado com outros parâmetros espectroscópicos mais precisos, como, nível de radicais livres do tipo semiquinona por RPE e grau de aromaticidade por ${ }^{13} \mathrm{C} \mathrm{RMN}$.

\subsection{FTIR}

A radiação de infravermelho é a parte do espectro eletromagnético entre a região visível e as microondas. A região de maior interesse para a espectroscopia é de 4000 a $400 \mathrm{~cm}^{-1}$ (Stevenson, 1994).

Absorção na região do infravermelho é causada por movimentos rotacionais e vibracionais dos grupos moleculares e ligações químicas de uma molécula. Essencialmente, existem duas vibrações fundamentais: estiramento, onde os átomos permanecem no mesmo eixo da ligação, porém a distância entre os átomos aumenta e diminui, e, deformação, onde as posições dos átomos mudam em relação ao eixo de ligação original. Quando luz infravermelha de mesma frequiência de vibração de estiramento ou de deformação incide na amostra a energia é absorvida e a amplitude de vibração é aumentada. Devido à energia de absorção na freqüência de ressonância, o detector do espectrômetro de infravermelho grava um pico de absorção naquele comprimento de onda (Stevenson, 1994). Vibrações típicas de um grupo de átomos são ilustradas na (Figura 2.8). 


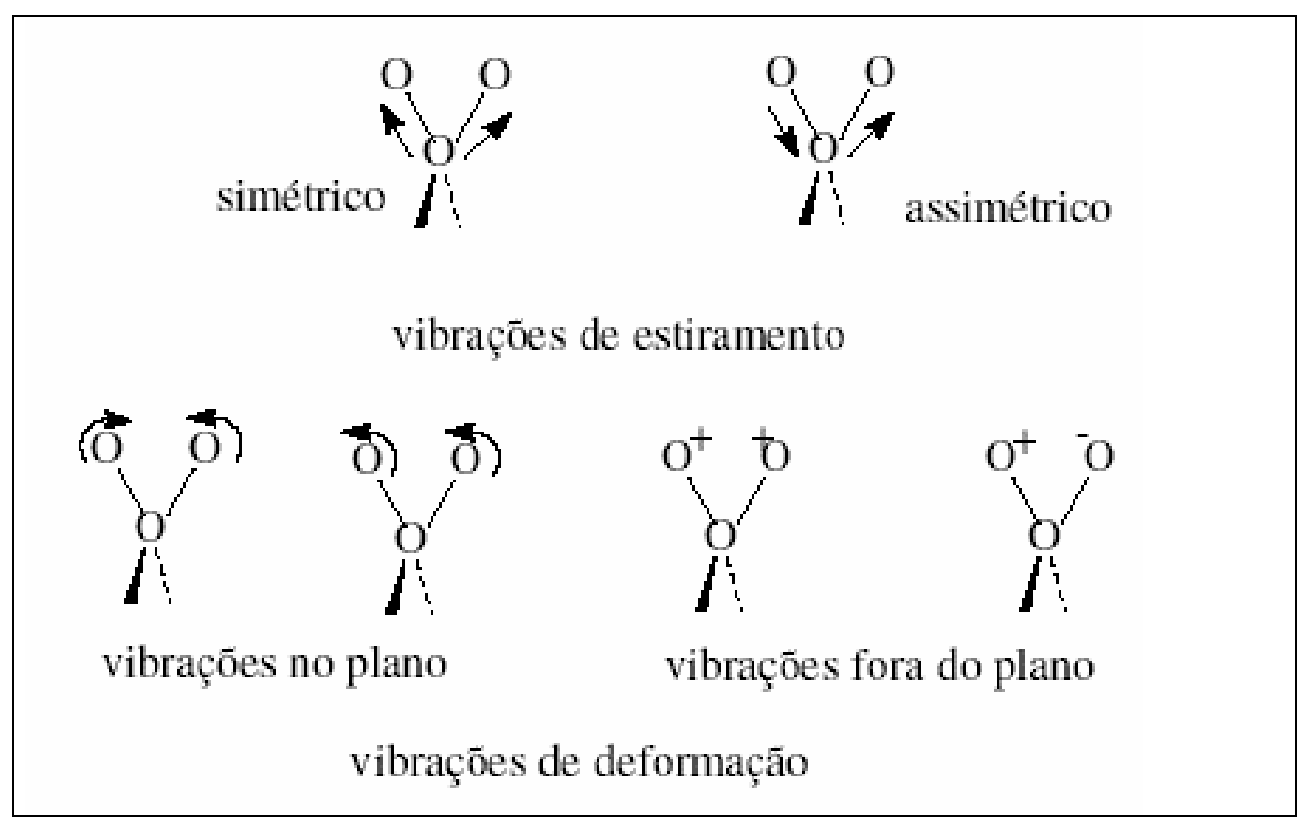

Figura 2.8 - Vibrações típicas de átomos. Os sinais + e - significam vibrações perpendiculares ao plano do papel (Stuart, 1996).

A FTIR é uma ferramenta que permite informar sobre a natureza, reatividade e arranjo estrutural de grupos funcionais contendo oxigênio, a presença de proteínas e carboidratos, e a eficiência do processo de purificação da amostra quanto a contaminantes como argila, metais e sais (Stevenson, 1982). Os espectros de infravermelho podem revelar as interações entre grupos orgânicos, como os carboxílicos e metais pesados, visto que a coordenação dos grupos funcionais orgânicos com metais provoca deslocamento na freqüência de absorção das ligações do íon carboxilato, o que permite a identificação da natureza (iônica ou covalente) da ligação organometálica (Vinkler; Lakatos; Meisel, 1976; Hernandez; Moreno; Costa, 1993).

A espectroscopia de infravermelho tem sido extensivamente usada para a pesquisa de substâncias húmicas e tem fornecido considerável entendimento sobre a natureza, reatividade e arranjo estrutural do grupos funcionais contendo oxigênio nas substâncias húmicas. Espectros no infravermelho de substâncias húmicas resultam da absorção da radiação infravermelha por uma mistura complexa de moléculas que são por si próprias multifuncionais. O resultado do espectro infravermelho contém uma variedade de bandas que 
podem indicar diferentes grupos funcionais presentes nesta mistura complexa (Stevenson, 1994).

Em complementação aos dados obtidos por RMN, as análises de FTIR têm sido tradicionalmente usadas para identificar grupos funcionais como: grupos carboxila, amina, hidroxila, carbonila e outros (Schnitzer; Khan, 1972; Stevenson, 1994). Estas informações são úteis, pois permitem identificar possíveis processos de oxidação e alteração de grupos funcionais, associados aos efeitos de manejos, devido, por exemplo, ao aumento ou redução de aeração do solo, mudança no $\mathrm{pH}$, complexação com micronutrientes provenientes de fertilizantes ou naturalmente ocorrendo no solo, e ainda com metais pesados.

Vibrações de deformação geralmente requerem menos energia e são encontradas em freqüências menores do que as vibrações de estiramento. Estiramento devido à tripla ligação $\left(2300-2000 \mathrm{~cm}^{-1}\right)$ é mais forte do que duplas ligações $\left(1900-1500 \mathrm{~cm}^{-1}\right)$ e estas são mais fortes do que ligações simples, como C-C, C-O e C-N $\left(1300-800 \mathrm{~cm}^{-1}\right)$. Vibrações de estiramento envolvendo prótons (ex. C-H, O-H e N-H) ocorrem em freqüências entre 3700 e $2650 \mathrm{~cm}^{-1}$. O estiramento da ligação O-H ocorre em freqüência mais alta $\left(3700-3200 \mathrm{~cm}^{-1}\right)$ do que para estiramento C-H $\left(3050-2850 \mathrm{~cm}^{-1}\right)$ (Stevenson, 1994). Os principais grupos de absorção no infravermelho (região $400-4000 \mathrm{~cm}^{-1}$ ) nas substâncias húmicas são:

$3395-3400 \mathrm{~cm}^{-1}$ (estiramento $\mathrm{OH}$ ligado e estiramento $\mathrm{N}-\mathrm{H}$ );

$2930 \mathrm{~cm}^{-1}$ (estiramento CH alifáticos);

$1705-1716 \mathrm{~cm}^{-1}$ (estiramento $\mathrm{C}=\mathrm{O}$ das cetonas e dos ácidos $\mathrm{COOH}$ );

$1630-1650 \mathrm{~cm}^{-1}$ (estiramento assimétrico $\mathrm{C}-\mathrm{O}$ dos íons carboxilato COO-estiramento $\mathrm{C}=\mathrm{C}$ dos anéis aromáticos, estiramento $\mathrm{C}=\mathrm{O}$ e deformação $\mathrm{N}-\mathrm{H}$ das amidas primárias);

$1510 \mathrm{~cm}^{-1}$ (deformação N-H de amida II e estiramento C=C dos aminoácidos);

$1450 \mathrm{~cm}^{-1}$ (deformação C-H dos $-\mathrm{CH}_{2} \mathrm{e}-\mathrm{CH}_{3}$ );

$1420 \mathrm{~cm}^{-1}$ (estiramento assimétrico C-O, deformação O-H e deformação C-O-H dos COOH e estiramento simétrico dos íons COO-); 
$1230 \mathrm{~cm}^{-1}$ (estiramento simétrico C-O e deformação $\mathrm{OH}$ dos $\mathrm{COOH}$ );

$1125 \mathrm{~cm}^{-1}$ (estiramento C-O de álcoois, éteres, ésteres e $\mathrm{COOH}$ );

$1035 \mathrm{~cm}^{-1}$ (estiramento C-O de polissacarídeos).

As impurezas inorgânicas encontradas nesta região são:

$3700 \mathrm{~cm}^{-1}$ estiramento axial de $\mathrm{OH}$ externo da estrutura da caulinita;

$3620 \mathrm{~cm}^{-1}$ estiramento axial de $\mathrm{OH}$ interno da estrutura da caulinita;

$3520,3445,3390 \mathrm{~cm}^{-1}$ estiramento $\mathrm{OH}$ em gibbsita;

1100 - $1090 \mathrm{~cm}^{-1}$ estiramento Si-O-Si; quartzo;

$800-770 \mathrm{~cm}^{-1}$ caulinita, glauconita, montmorilonita, quartzo.

\subsection{RMN}

A ${ }^{13} \mathrm{C}$ RMN é basicamente uma outra forma de espectroscopia de absorção, semelhante à FTIR ou UV-Vis. Sob condições apropriadas em um campo magnético, uma amostra pode absorver radiação eletromagnética na região de radiofrequiência em uma frequiência governada pelas características estruturais da amostra (Carvalho et al., 2004). A absorção é função de determinados núcleos das moléculas. Essencialmente, um experimento de ${ }^{13} \mathrm{C}$ RMN consiste em posicionar uma amostra entre os pólos de um campo eletromagnético e aplicar uma radiofrequiência variável. A excitação do núcleo do estado fundamental para um estado de energia mais alto resulta na absorção de radiação a uma freqüência própria, dando um espectro o qual consiste de uma ou mais linhas de ressonância. Um espectro de ${ }^{13} \mathrm{C} R \mathrm{RN}$ é um registro gráfico das frequiências dos picos de absorção contra suas intensidades. O número e a intensidade dessas linhas estão relacionados com a estrutura da molécula (Carvalho et al., 2004).

Com a técnica de ${ }^{13} \mathrm{C}$ RMN podemos fazer um estudo direcionado para um determinado núcleo, sendo esta uma das grandes vantagens da técnica. 
A ${ }^{13} \mathrm{C}$ RMN é atualmente a técnica instrumental mais usada para caracterização das substâncias húmicas do solo, sendo possível a utilização de amostras sólidas e líquidas (Carvalho et al., 2004).

Uma das observações de grande interesse na avaliação da estrutura de compostos húmicos são as possíveis mudanças estruturais destes, que refletem em alteração de suas propriedades nos solos. Tanto a RMN de ${ }^{13} \mathrm{C}$ quanto a de ${ }^{1} \mathrm{H}$ têm sido aplicadas em estudos relativos a conformações e estruturas moleculares da matéria orgânica com grande sucesso.

A utilização de ${ }^{13} \mathrm{C}$ RMN de estado sólido é cada vez maior, porque possibilita o estudo de substâncias que são pouco solúveis ou mesmo insolúveis. A técnica não é destrutiva, preservando a amostra para outras análises, economizando solventes e permitindo a avaliação in situ da matéria orgânica do solo. Segundo (Preston, 1996), a ênfase inicial em estudos com ${ }^{13} \mathrm{C} \mathrm{RMN}$ em ácidos húmicos e ácidos fúlvicos deve-se à necessidade de isolar a matéria orgânica do solo em frações solúveis e com alta concentração de carbono, a fim de sobrepor algumas limitações das técnicas espectroscópicas disponíveis. Com o desenvolvimento da ${ }^{13} \mathrm{C}$ $\mathrm{RMN}$ e a disponibilidade de equipamentos de maior potência, a técnica de ${ }^{13} \mathrm{C} \mathrm{RMN}$ tem sido aplicada, no estudo da matéria orgânica, em amostras de solo intactos.

No entanto, esta técnica apresenta algumas limitações, tais como, baixa sensibilidade devido a pequena abundância natural da maioria dos núcleos, entre eles o ${ }^{13} \mathrm{C}(\sim 1,1 \%)$, chamado de núcleo raro, e os tempos de relaxação muito longos que exigem experimentos com longa duração.

No caso de medidas de estado sólido, para obter espectros de alta resolução, devem ser resolvidos os três problemas seguintes (Carvalho et al., 2004):

1 - alargamento devido as interações dipolares heteronucleares $\left({ }^{13} \mathrm{C},{ }^{1} \mathrm{H}\right)$;

2 - alargamento devido a anisotropia do desvio químico;

3 - baixa sensibilidade devida aos longos tempos de relaxação spin-rede dos núcleos raros $\left({ }^{13} \mathrm{C}\right)$. 
Estas três interações anisotrópicas estão presentes também nos líquidos, mas felizmente, são eliminadas pelo rápido movimento isotrópico browniano das moléculas.

Estas limitações da ${ }^{13} \mathrm{C}$ RMN de estado sólido têm sido melhoradas recentemente com o desenvolvimento de técnicas novas e sofisticadas, tais como: desacoplamento de alta potência, técnica de rotação segundo o ângulo mágico (MAS) e polarização cruzada (CP) (Stevenson 1994).

A técnica de desacoplamento é utilizada para o estudo de núcleos raros, a eliminação do alargamento de linha dipolar internuclear. O campo local que surge sobre os núcleos raros é devido à presença de núcleos abundantes, como exemplo, prótons em sólidos orgânicos. Desde que exista uma interação dipolar heteronuclear, é possível desacoplar os núcleos raros que estão sendo observados pelos abundantes. O desacoplamento é feito via redução do momento magnético efetivo do núcleo abundante, pela aplicação de um campo de radiofrequiência que mantém o momento de dipolo magnético do mesmo em alta rotação (Carvalho et al., 2004).

A técnica de MAS é usada para eliminar a interação dipolar (homo e heteronuclear), fazendo a amostra rotacionar em torno de um certo ângulo denominado ângulo mágico, que é de $54^{0} 44^{\prime}$. Além de eliminar as interações dipolares esta técnica elimina também anisotropias do deslocamento químico e de interações quadrupolares (Jelinski; Melchior, 2000).

Para superar os problemas relativos à baixa sensibilidade dos núcleos raros e seus longos tempos de relaxação spin-rede foi proposto o método de dupla ressonância denominado CP (Jelinski; Melchior, 2000). A idéia básica deste método é usar a relativamente intensa polarização de spins abundantes para aumentar, por transferência de polarização a pequena polarização dos núcleos raros. Desta técnica resulta um sinal de maior intensidade para núcleos raros e grande redução em seus tempos de relaxação spin-rede (Jelinski; Melchior, 2000). 


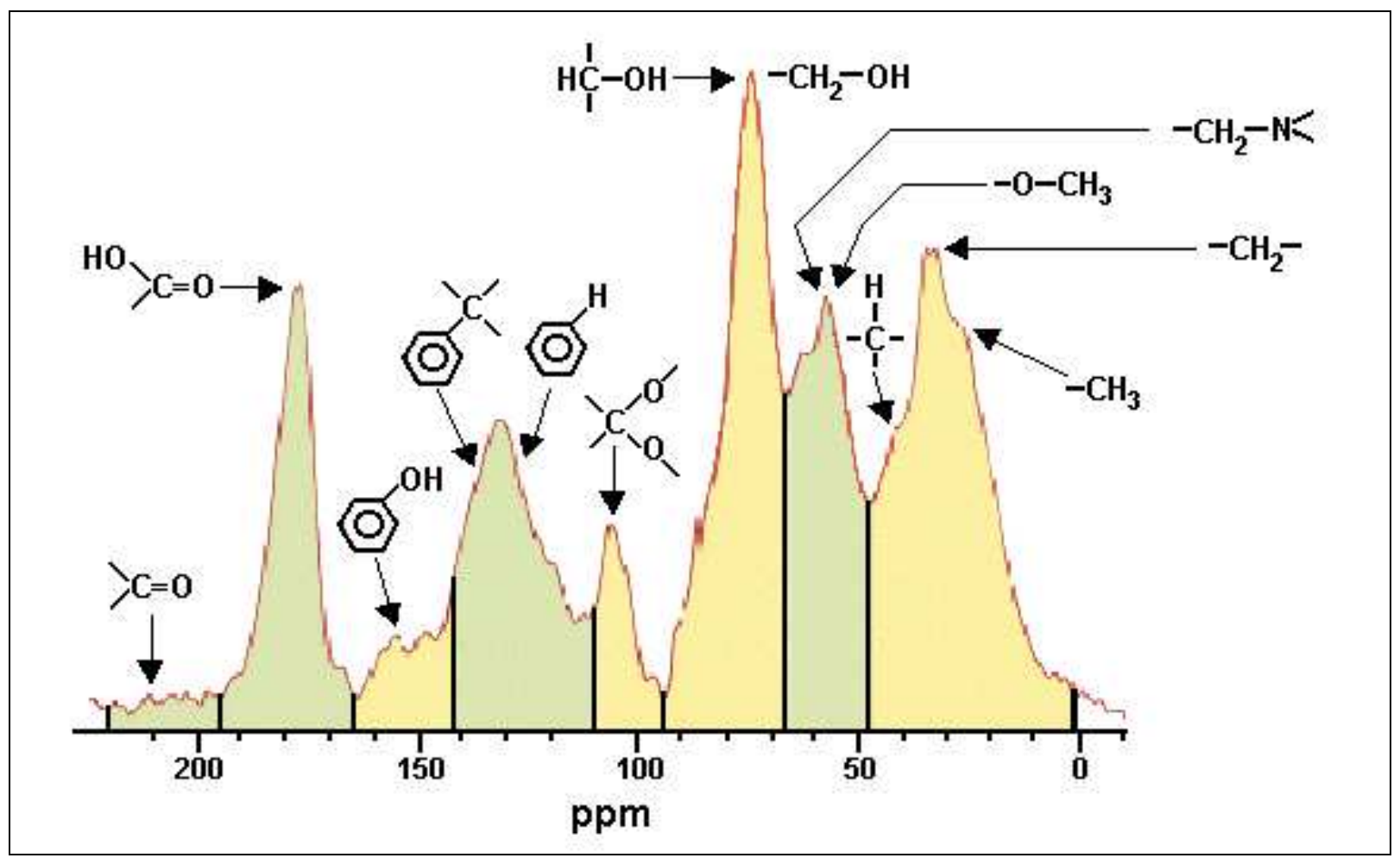

Figura 2.9 - Espectro de ${ }^{13} \mathrm{C}$ RMN típico de ácido húmico mostrando os grupos funcionais associados às bandas correspondentes (Skjemstad; Janik; Taylor, 1998).

Através da RMN podemos identificar grupos funcionais que possibilitam caracterizar a estrutura das substâncias húmicas. $\mathrm{O}$ espectro de ${ }^{13} \mathrm{C} \mathrm{RMN}$ de um ácido húmico ou fúlvico, fornece um inventário de diferentes componentes dos quais o material é composto.

Os principais grupos funcionais detectados por ${ }^{13} \mathrm{C}$ RMN no estado sólido em substâncias húmicas são (Figura 2.7) (Skjemstad; Janik; Taylor, 1998): grupos alifáticos (0-46 ppm), N-alifáticos e metoxílicos (46-67 ppm), o-alifáticos (67-94 ppm), di $o$-alifáticos (94110 ppm), aromáticos (110-144 ppm), o-aromáticos (144-164 ppm), carboxílicos (164-188 ppm) e carbonílicos (188-230 ppm).

Uma das observações de grande interesse na avaliação do efeito dos diferentes manejos do solo sobre os compostos húmicos e frações organominerais são as possíveis mudanças estruturais destes, que refletem em alteração de suas propriedades nos solos. Estas mudanças podem afetar significativamente a dinâmica dos elementos químicos no solo, especialmente os micronutrientes e elementos traços. Certamente a ${ }^{13} \mathrm{C}$ RMN é a principal técnica para 
identificar essas alterações e sua metodologia está bem estabelecida, principalmente a nível internacional.

\subsection{RPE}

Internacionalmente, os primeiros estudos em ciências do solo envolvendo RPE foram desenvolvidos na década de 60 (Rex, 1960; Steelink; Tollin, 1962; Lagercrantz; Yhland, 1963; Steelink, 1964). No Brasil, o uso desta técnica na avaliação qualitativa da matéria orgânica é recente, sendo os primeiros resultados publicados na década de 90 (Martin-Neto et al., 1991, 1994ab, 1998; Bayer et al.,1997).

A RPE ou ressonância de spin eletrônico é o fenômeno de absorção de energia de elétrons desemparelhados de um átomo, molécula ou íon, quando estes se encontram sujeitos a aplicações de um campo magnético e um pulso de radio freqüência, obedecendo ao efeito Zeeman. Ou seja, a transição entre os dois níveis ocorrerá quando uma energia $\Delta \mathrm{E}=g \beta H o$ for fornecida ao sistema. Quando a condição de ressonância é satisfeita, o momento magnético sofre uma transição de uma posição paralela ao campo magnético Ho para uma posição antiparalela a este. A energia $\Delta \mathrm{E}$ normalmente é fornecida ao sistema através da exposição a um campo de microondas de freqüência fixa perpendicular ao campo $H o$, o que é variado até que ocorra a transição. 


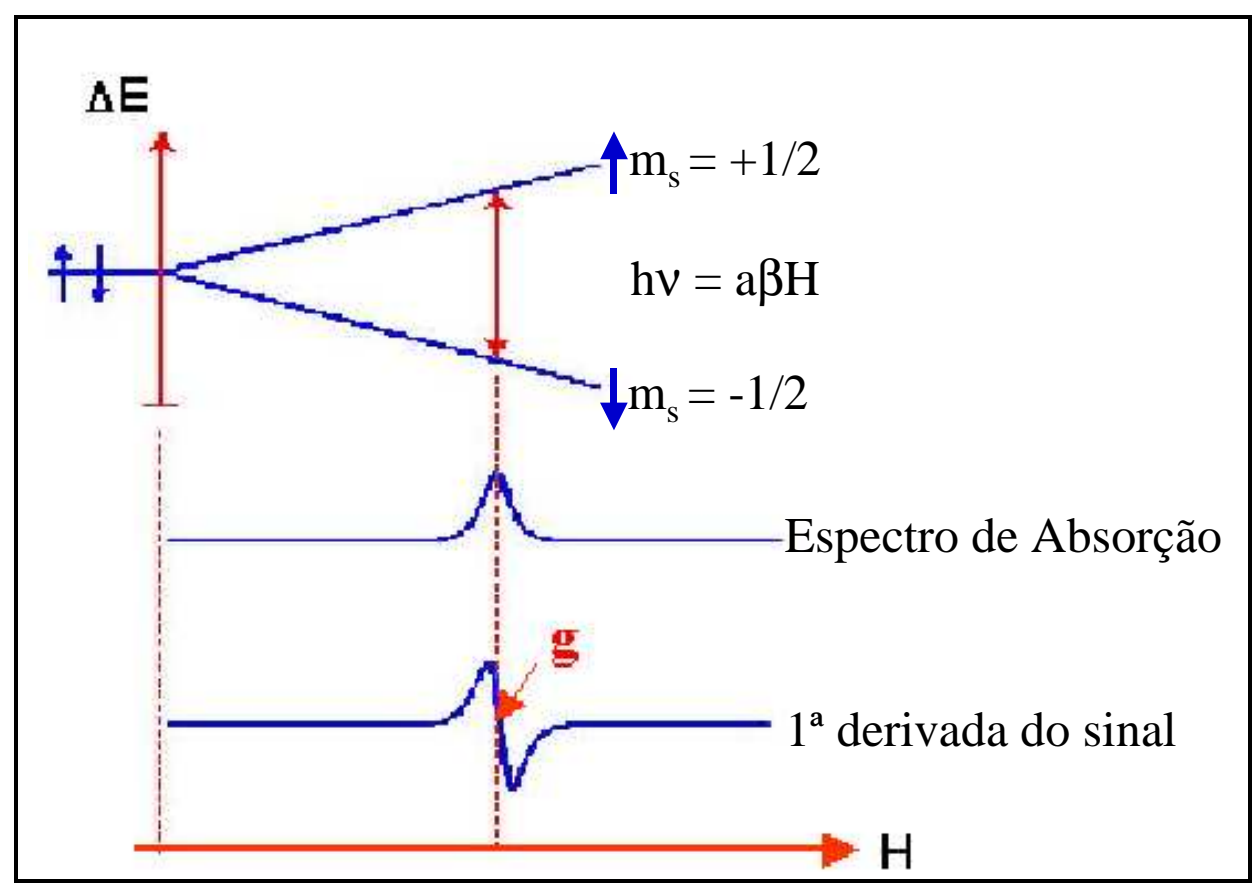

Figura 2.10 - Esquema mostrando: (a) desdobramento dos níveis de energia do spin eletrônico na presença de um campo magnético; (b) forma da linha de absorção de energia do campo de microondas; (c) primeira derivada da linha de absorção.

Com isso, essa técnica é sensível a espécies paramagnéticas, isto é, espécies que possuem átomos ou moléculas com pelo menos um elétron desemparelhado. Incluem-se nessa categoria os elementos de transição, semicondutores e radicais livres.

Os processos de transformação da matéria orgânica no ambiente são conectados com várias reações envolvendo radicais livres. Estes radicais livres podem ser detectados nas substâncias húmicas pela RPE com um sinal estreito e intenso com g entre 2,0030 e 2,0043. Riffaldi e Schnitzer (1972), ressaltam a importância dos radicais livres como catalisadores nas reações de polimerização das substâncias húmicas, e (Steelink; Tollin, 1985), enfatizam a importância dos mesmos na germinação de sementes e no crescimento de raízes. Stevenson (1994) cita as quinonas presentes nos ácidos húmicos como a principal fonte de radicais livres das substâncias húmicas. Riffaldi e Schnitzer (1972), afirmam que os radicais livres do tipo semiquinona são formados a partir da remoção de $\mathrm{H}$ dos grupos $\mathrm{OH}$ dos fenóis (dehidrogenação oxidativa de compostos fenólicos), e que portanto, quanto maior a 
concentração de fenóis no material de origem maior a concentração de spins nos ácidos húmicos formados a partir deles.

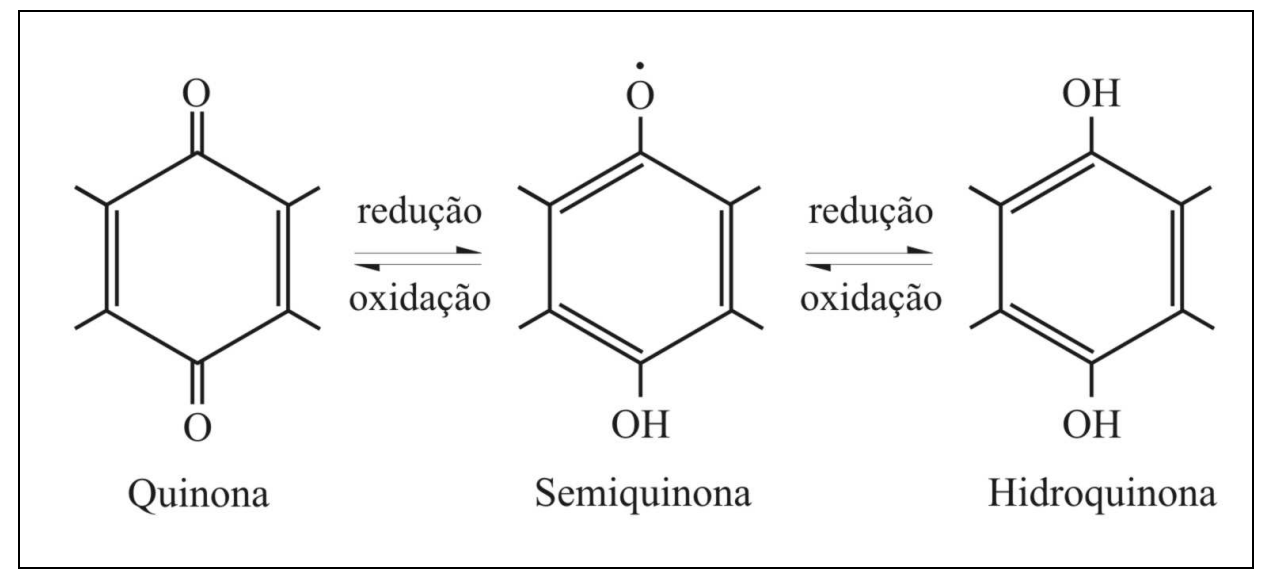

Figura 2.11 - Esquema da estabilização do radical livre do tipo semiquinona (Senesi; Schnitzer, 1977).

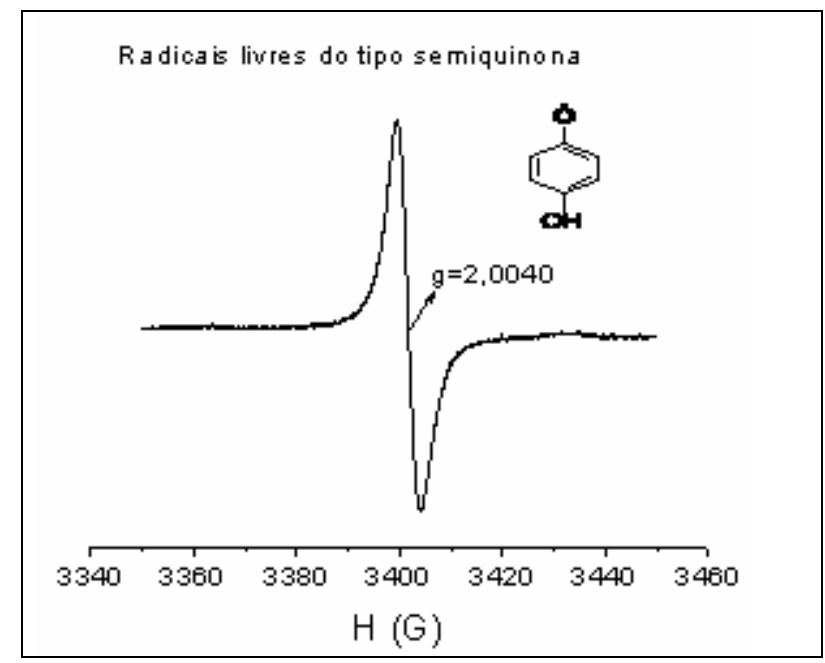

Figura 2.12 - Espectro típico de RPE de ácido húmico mostrando o sinal do radical livre do tipo semiquinona.

A técnica de RPE pode informar sobre a natureza e concentração dos radicais livres orgânicos e inorgânicos, assim como da interação destes com íons metálicos paramagnéticos nas formas livres ou complexadas.

Uma das principais informações a respeito das substâncias húmicas é a medida do grau de humificação (Martin-Neto; Rossel; Sposito, 1998). Um parâmetro que reflete essa propriedade intrínseca das substâncias húmicas é o nível de radicais livres do tipo semiquinona. A técnica de RPE permite detectar e quantificar os radicais livres do tipo semiquinona, e conseqüentemente o grau de humificação das substâncias húmicas. O número 
de spins de radicais livres do tipo semiquinona é proporcional ao grau de humificação da matéria orgânica (Martin-Neto et al., 1994a).

A técnica de RPE é uma das poucas, entre os métodos de laboratório que pode fornecer informações estruturais sem artefatos ou condições experimentais restritivas sobre a complexação dos íons metálicos paramagnéticos, grande parte micronutrientes $(\mathrm{Fe}, \mathrm{Cu}, \mathrm{Cr}$, Mn, Mo) com as substâncias húmicas (Martin-Neto et al., 1991).

\subsection{Fluorescência}

O estado fundamental de uma molécula caracteriza-se pela configuração de menor energia que seus elétrons podem ocupar, ou seja, é o estado mais estável em que a molécula pode permanecer. Com energias acima do estado fundamental existem diversos outros níveis, denominados estados excitados, os quais podem ser acessados quando a molécula recebe um valor de energia equivalente à diferença de energia entre esses estados e o fundamental. Em cada um desses estados existem diversos níveis de energia vibracional.

No estado fundamental os elétrons da molécula ocupam o nível de menor energia vibracional, mas ao serem excitados podem ser promovidos para qualquer nível vibracional de um estado excitado (Figura 2.13). Cerca de $10^{-12} \mathrm{~s}$ depois ocorre a relaxação vibracional, um processo de decaimento não radioativo, que leva o elétron ao nível de menor energia vibracional do estado eletrônico em que ele se encontra.

A molécula pode continuar perdendo energia por processos não radioativos até que o elétron excitado retorne ao estado fundamental ou o elétron pode permitir a diferença de energia na forma de radiação. Essa emissão é chamada de fluorescência e terá sempre uma energia menor que a energia de excitação da molécula devido à relaxação vibracional e a outros processos não radioativos que possam ocorrer (Skoog; Holler; Nieman, 2002).

Transições típicas desse tipo envolvem a promoção de elétrons não-ligantes (n) ou ligantes $(\pi)$ para orbitais antiligantes $\left(\pi^{*}\right)$. O processo de fluorescência envolve a emissão de fótons menos energéticos (maior $\lambda$ ) do que aqueles absorvidos para produzir o estado 
excitado, é um processo rápido, que dura de $10^{-9}$ a $10^{-6} \mathrm{~s}$. Esses processos são altamente prováveis em sistemas moleculares contendo átomos com pares de elétrons não compartilhados, tais como, oxigênio e nitrogênio e em estruturas aromáticas e/ou sistemas alifáticos conjugados de insaturações com alto grau de ressonância, isto é, deslocalização eletrônica de elétrons, como é o caso das substâncias húmicas (Senesi et al., 1991).

Estruturas fluorescentes nativas ou incorporadas às substâncias húmicas, constituem apenas uma pequena porção da macromolécula húmica, entretanto sua variedade e a dependência de suas propriedades, de parâmetros moleculares e ambientais moleculares, permitem a obtenção de informações sobre seu comportamento fluorescente e sobre a natureza química das substâncias húmicas (Senesi; Loffredo, 1999). O comportamento fluorescente médio da molécula é o resultado da soma de todos os espectros individuais dos diferentes fluoróforos da molécula.

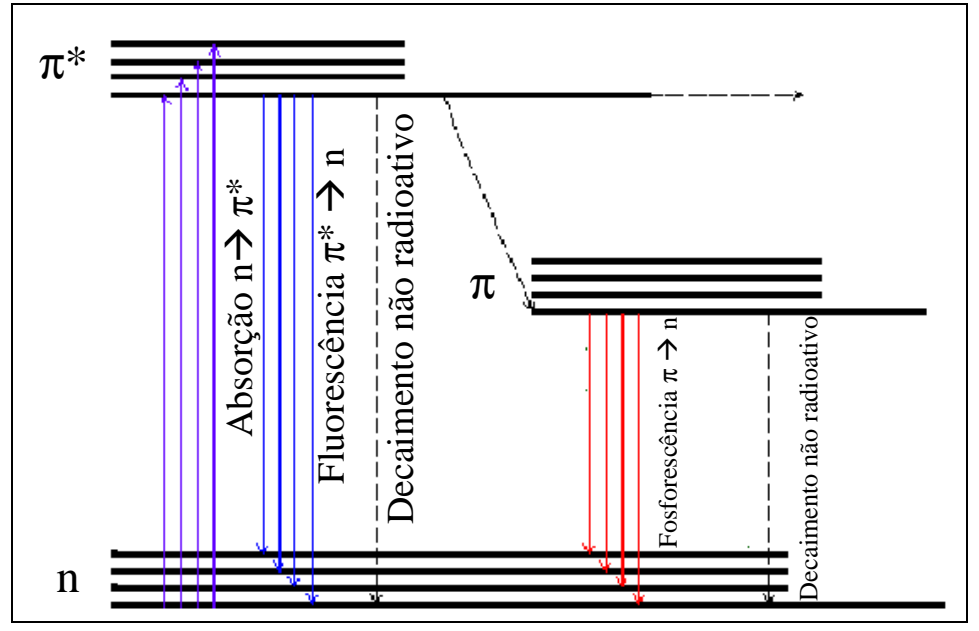

Figura 2.13 - Transição eletrônica fluorescência molecular.

A análise da fluorescência de um composto é uma técnica muito sensível devido à capacidade de se detectar o sinal proveniente de moléculas quando excitadas por um comprimento de onda específico. É também bastante seletiva, uma vez que os comprimentos de onda de excitação e emissão dependem do mesmo composto de interesse, fazendo com que o sinal de fluorescência coletado seja característico de cada molécula em estudo. 
O uso da técnica de fluorescência nos estudos sobre substâncias húmicas está apoiado pela presença estável de várias estruturas fluorescentes intrínsecas a molécula húmica e a seus precursores, particularmente anéis aromáticos, fenóis e grupos quinona (Senesi et al, 1991). Algumas metodologias tem sido sugeridas na literatura (Zsolnay et al., 1999; Kalbitz; Geyer; Geyer, 1999; Milori et al., 2002) no sentido de aplicar esta técnica para avaliação da humificação das substâncias húmicas.

Os espectros de fluorescência podem ser obtidos de três modos: emissão, excitação e excitação com varredura sincronizada. Os espectros de emissão são obtidos medindo a intensidade de radiação emitida como função do comprimento de onda, mantendo fixo o comprimento de onda de excitação, enquanto que os espectros de excitação são obtidos pela medida da intensidade de emissão, fixando o seu comprimento de onda de emissão e variando o comprimento de onda de excitação. Os espectros de excitação com varredura sincronizada são obtidos medindo a intensidade de fluorescência, quando a molécula é varrida por ambos os comprimento de onda, mas mantendo uma diferença de $\Delta \lambda=\lambda_{\text {em }}-\lambda_{\text {exc }}$, entre eles. Quando essa diferença é usada, esta técnica pode aumentar a intensidade de alguns picos, aumentando a sensibilidade do método.

A localização do espectro de emissão pode indicar o grau de humificação das substâncias analisada, como indicavam os primeiros trabalhos com fluorescências em substâncias húmicas.

Zsolnay et al. (1999) desenvolveram um índice de humificação baseado na localização do espectro de fluorescência no modo de emissão. Este índice considera a área de 435-480 nm e a divide pela área de 300-445 nm, quando os espectros forem obtidos através de excitação em $240 \mathrm{~nm}$ e pH da solução igual a 2,0. A partir de resultados obtidos, verificaram que quanto maior a área na região de maiores comprimentos de onda, maior seria o índice de humificação. Os resultados coincidiram com menores valores razões $\mathrm{H} / \mathrm{C}$ e, portanto com maior grau de humificação das substâncias húmicas analisadas. Os autores citam a técnica 
como promissora, visto que é mais rápida e menos custosa que as técnicas de FTIR ou ${ }^{13} \mathrm{C}$ RMN, e dependendo da amostra não são necessárias a concentração e separação dos componentes.

Milori et al. (2002), usaram comprimento de onda azul (465 nm) como fonte de excitação. Observaram que esta absorção é mais ressonante com estruturas cuja concentração aumenta com o grau de humificação de ácidos húmicos. A partir desses estudos definiram que a área total sobre o espectro de fluorescência $\left(\mathrm{A}_{465}\right)$ é proporcional ao grau de humificação. Seus estudos foram realizados com amostras de ácidos húmicos extraídos de diferentes solos brasileiros, sobre condições climáticas distintas e com diferenças texturais e mineralógicas.

Kalbitz, Geyer e Geyer (2000) utilizaram a técnica de fluorescência em modo de excitação com varredura sincronizada, analisaram amostras de águas de lagos sem nenhuma preparação e ácidos fúlvicos. Comparando os resultados verificaram que os resultados foram similares, o que significa que não havia necessidade de extração e fracionamento das substâncias húmicas quando o teor de carbono orgânico dissolvido fosse menor que 3,0 mg de carbono $\mathrm{L}^{-1}$, o que facilitaria na obtenção de resultados como a presença de estruturas aromáticas e o grau de humificação. Também, observaram que como nos espectros de emissão, mudanças para maiores comprimentos de onda nos espectros scans síncronos indicam aumento do número de núcleos aromáticos condensados e maior humificação das substâncias húmicas analisadas.

Portanto, mudanças nos espectros de emissão e scan síncrono de substâncias húmicas, para maiores comprimentos de onda, ao longo do tempo ou após à adição de resíduos orgânicos aos solos, indicam maior humificação das substâncias húmicas nativas ou incorporação de compostos mais aromáticos e condensados à estrutura das substâncias húmicas nativas.

\subsection{FIL}


As metodologias de fluorescência citadas anteriormente exigem a extração e fracionamento químico das substâncias húmicas do solo, resultando na geração de resíduos químicos e tornando a análise de solos um processo lento e trabalhoso. Além disso, os produtos deste tratamento (ácido húmico, ácido fúlvico e humina) podem sofrer modificações em relação a sua forma in situ (Feller; Beare, 1997). Em contrapartida, a FIL aplicada à solos é uma nova metodologia, que tem se mostrado eficiente na análise da matéria orgânica de solos intactos, fornecendo resultados de uma maneira ágil, limpa e em condições próximas das naturais (Milori et al., 2003, 2006).

Baseado neste fato é possível propor a FIL como parâmetro para estudar os processos de humificação em solos submetidos à adição de lodo de esgoto. Sua utilização é de maior relevância para os Latossolos, solos em que os conteúdos de ferro inviabilizam os estudos dos parâmetros de humificação através da ${ }^{13} \mathrm{C}$ RMN e RPE.

A proposta de cálculo deste índice de humificação é a razão entre o valor da área do espectro de emissão de FIL (ACF) e o valor de carbono orgânico total (COT) presente na amostra de solo intacto (Milori et al., 2001), ou seja:

$$
\mathrm{H}_{\mathrm{FIL}}=\frac{\mathrm{ACF}}{\mathrm{COT}}
$$

A FIL baseia-se na análise de pastilhas de solo (Figura 2.14), amostras de solos prensadas em molde de aço ( $1 \mathrm{~cm}$ de diâmetro e $2 \mathrm{~mm}$ de espessura).
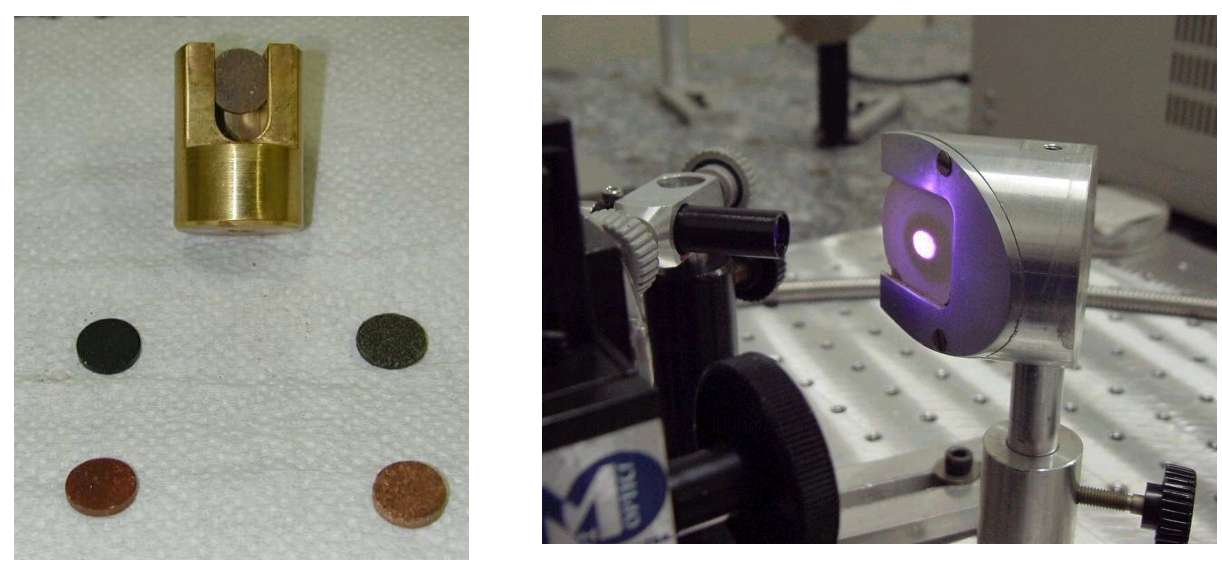

Figura 2.14 - Pastilhas de solo utilizadas para a obtenção do espectro de FIL. 
O princípio da técnica consiste, na excitação da amostra com um laser de argônio sintonizado na linha de $458 \mathrm{~nm}$ com uma potência de $300 \mathrm{~mW}$, onde em seguida a fluorescência emitida é coletada com uma lente convergente com foco sobre um monocromador da marca CVI (1200 $\mathrm{g} \mathrm{mm}^{-1} \mathrm{e}$ "blaze" em $\left.500 \mathrm{~nm}\right)$. A detecção é realizada com uma fotomultiplicadora Hamamatsu com pico de resposta espectral em $530 \mathrm{~nm}$. O sinal da fotomultiplicadora é amplificado e retificado por um amplificador "lock-in" e em seguida enviado para um sistema de aquisição controlada por um computador. A resolução espectral deste sistema para fluorescência de solos é em torno de 4 nm (Figura 2.15).

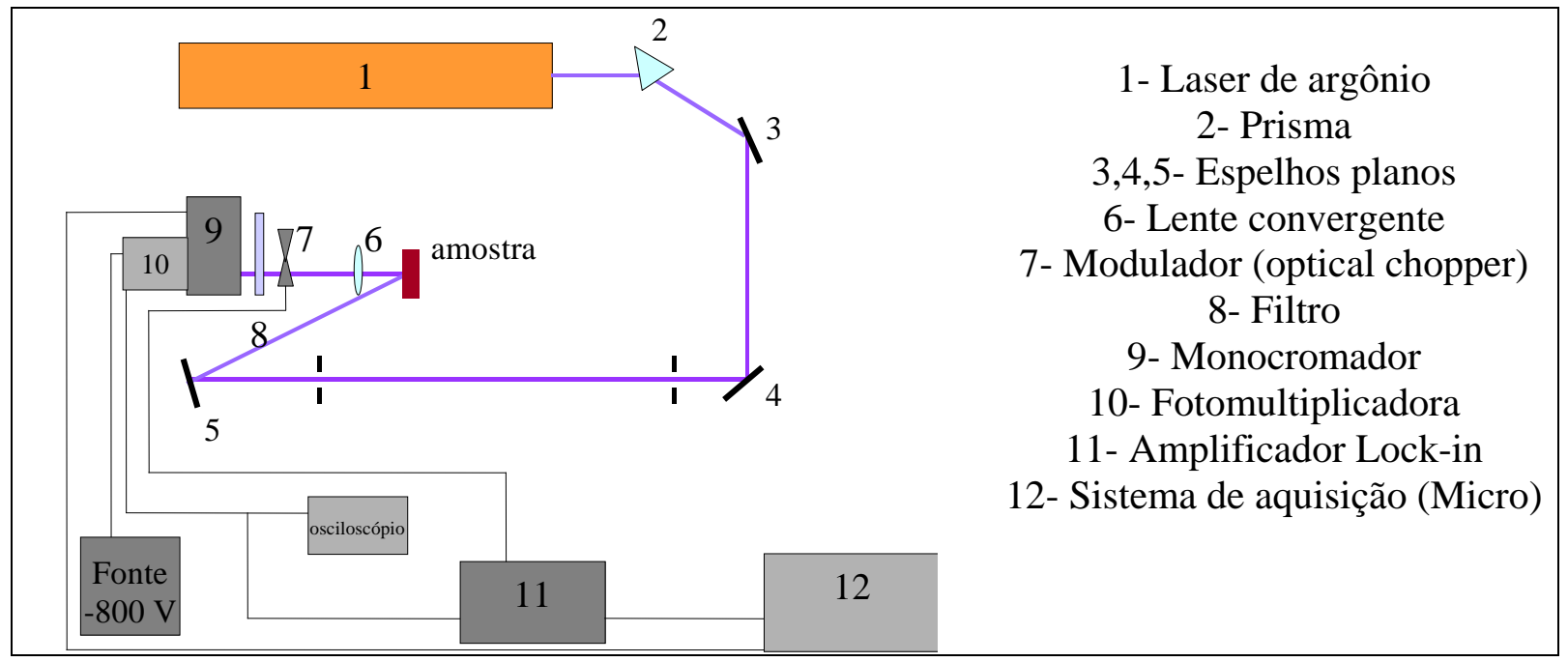

Figura 2.15 - Sistema para medida de FIL.

\subsection{Contaminação do solo por metais pesados}

Como conseqüência do crescimento tecnológico e demográfico mundial, nas últimas décadas, intensificaram-se as atividades industriais e agrícolas, bem como o extrativismo mineral e a urbanização, os quais causaram considerável aumento dos níveis de contaminantes no ambiente, especialmente no solo. A contaminação do solo é crescente no mundo, já existindo grande extensão de áreas contaminadas por agentes diversos, tais como: sais, elementos metálicos, compostos orgânicos, organometálicos e elementos radioativos, que freqüentemente ocorrem em faixas de concentrações que representam perigo ambiental, com 
impactos na vegetação, nos organismos do solo, nas águas superficiais e subterrâneas (Accioly; Siqueira, 2000).

A contaminação do solo pode ser oriunda de contaminantes inorgânicos e orgânicos. Os contaminantes inorgânicos mais freqüentemente encontrados no solo são os metais pesados e os radionuclídeos.

Embora amplamente utilizado, o termo "metal pesado", não possui uma definição única, variando de acordo com o ramo da ciência que o aborda. Nesse, adotamos a definição mais comumente encontrada na literatura, onde metais pesados são elementos químicos com densidade maior que $5 \mathrm{~g} \mathrm{~cm}^{3}$ (Berton, 2000; Marques, 1999; Malavolta, 1994). A expressão engloba metais, semi metais e até não metais como o selênio, portanto, trata-se de um conjunto heterogêneo de elementos. Toda a preocupação que se tem com os metais pesados é devido à sua capacidade de estabelecer ligações com grupos orgânicos em geral, em especial, com o grupo sulfidrila presente em proteínas. Essa característica é que os torna potencialmente tóxicos.

Os metais pesados comumente associados com toxidez ou poluição são: $\mathrm{Ar}, \mathrm{Cd}, \mathrm{Co}, \mathrm{Cr}$, $\mathrm{Cu}, \mathrm{Pb}, \mathrm{Hg}$, Mo, Ni, Se e Zn (Nellessen; Fletcher, 1993). Esses metais atingem o solo por meio de rotas diversas. Rejeitos com altas concentrações de diversos metais são gerados nas indústrias, especialmente na metalúrgica, na indústria coureira, de tintas e pigmentos, e de artefatos galvanizados. Resíduos urbanos, como compostos de lixo, lodo de esgoto e águas residuárias, também são ricos em metais pesados. A maioria desses rejeitos possuem, geralmente, como destino final aterros sanitários ou o solo, onde sofrem transformações químicas que resultam na biodisponibilização de formas anteriormente imobilizadas de metais presentes nos resíduos (Finnecy; Pearce, 1986; Stevenson, 1986; Sheppard et al., 1992). Uma vez liberados para a solução, os metais pesados podem ser lixiviados para o subsolo, atingindo o lençol freático, com sérias consequiências. Podem ainda causar toxidez às plantas e organismos do solo ou ser adsorvidos nas argilas e complexados à matéria orgânica, 
representando uma potencial fonte poluidora (Mattigod; Sposito; Page, 1981). Com isso, torna-se importante avaliar os conteúdos de metais pesados nos solos submetidos à adição de lodo de esgoto.

\subsubsection{Caracterização espectrométrica}

\subsubsection{ICP OES}

A técnica ICP OES é baseada na medida da intensidade da radiação emitida, quando um átomo ou íon excitado pelo plasma retorna ao seu estado fundamental.

A excitação da espécie ocorre quando seus elétrons mais externos têm seu nível de energia aumentado, passando do estado fundamental para o excitado, devido a colisão com elétrons ou íons de argônio existentes no plasma. O elétron não é estável em níveis mais altos de energia, portanto retorna a seu estado fundamental, emitindo a energia que foi absorvida, sob a forma de energia luminosa (Skoog; Holler; Nieman, 2002).

Os elétrons da espécie emitem linhas espectrais, tantas quantas forem suas possíveis transições; as linhas espectrais é que vão determinar o espectro de cada elemento, a intensidade de cada linha vai depender da probabilidade de transição, e do número de átomos que atinge um determinado estado excitado. A luz emitida é focalizada para uma lente que tem a função de ampliar e focalizar a zona de descarga luminosa do plasma quando projetada sobre a fenda de entrada, promovendo melhor iluminação da rede de difração. Uma vez tendo passado pela lente, a luz emitida vai em direção à fenda de entrada do separador de linhas e chega ao monocromador, onde um prisma ou uma rede de difração isola a linha medida. Em amostras com matrizes complexas, a escolha da linha isenta de sobreposições é necessária para funcionamento ideal da técnica. Essa é uma das razões pelas quais a linha de maior intensidade nem sempre seja a escolhida (Skoog, Holler; Nieman, 2002).

A vantagem da ICP OES sobre espectrometria de absorção atômica, é a possibilidade simultânea de medir vários elementos como: P, C, Mg, Ca, Fe, Mn, Al, Si, Cu, Mo, B, Hg, Au 
e outros, ou seja, é uma técnica multielementar, além de poder ser aplicada a diferentes concentrações, devido a possibilidade de escolha de linhas (Montaser; Golightly, 1992). 


\subsection{AMOSTRA DE LODO DE ESGOTO}

O lodo de esgoto é proveniente da ETE da SABESP, em Barueri-SP.

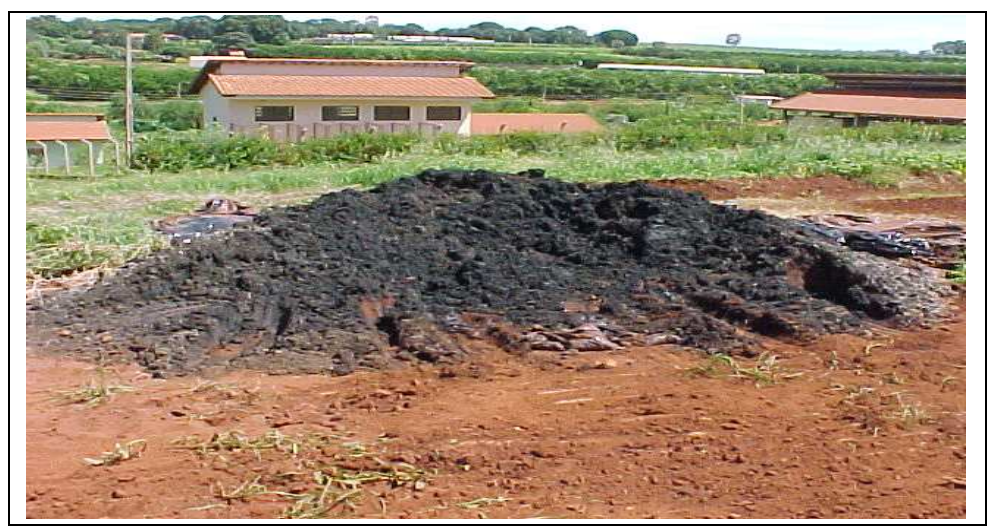

Figura 3.1 - Biossólido originado do lodo de esgoto coletado na ETE da SABESP, Barueri-SP.

\subsection{AMOSTRAS DE SOLO}

\subsection{1 Área experimental}

As amostras de solo foram coletadas em setembro de 2004 , no $7^{\circ}$ ano do experimento em campo, instalado em 1997 em áreas de monocultura de milho sob sistema de cultivo mínimo e adição de lodo de esgoto na área experimental da Faculdade de Ciências Agrárias e Veterinárias da Unesp, Jaboticabal-SP, sob a coordenação do Prof. Dr. Wanderley José de Melo.

O clima da região é do tipo Cwa, segundo a classificação climática de Köeppen, com precipitação média anual de $1360 \mathrm{~mm}$. As temperaturas máximas e mínimas médias anuais são 21 e $15^{\circ} \mathrm{C}$, respectivamente, e a altitude do local é de $575 \mathrm{~m}$.

\subsubsection{Classificação dos solos}

Foram estudados dois tipos de solo, classificados conforme o Sistema Brasileiro de Classificação de Solos (Embrapa, 1999), como LVef (ex Latossolo Roxo) e LVd (ex Latossolo Vermelho escuro), solos de grande ocorrência na região e em todo o estado de São 
Paulo. Os solos analisados foram escolhidos em função de suas diferenças texturais. O LVef e

LVd, apresentam teores de argila de 59 e $36 \%$ e teores de areia de 21 e $59 \%$, respectivamente.

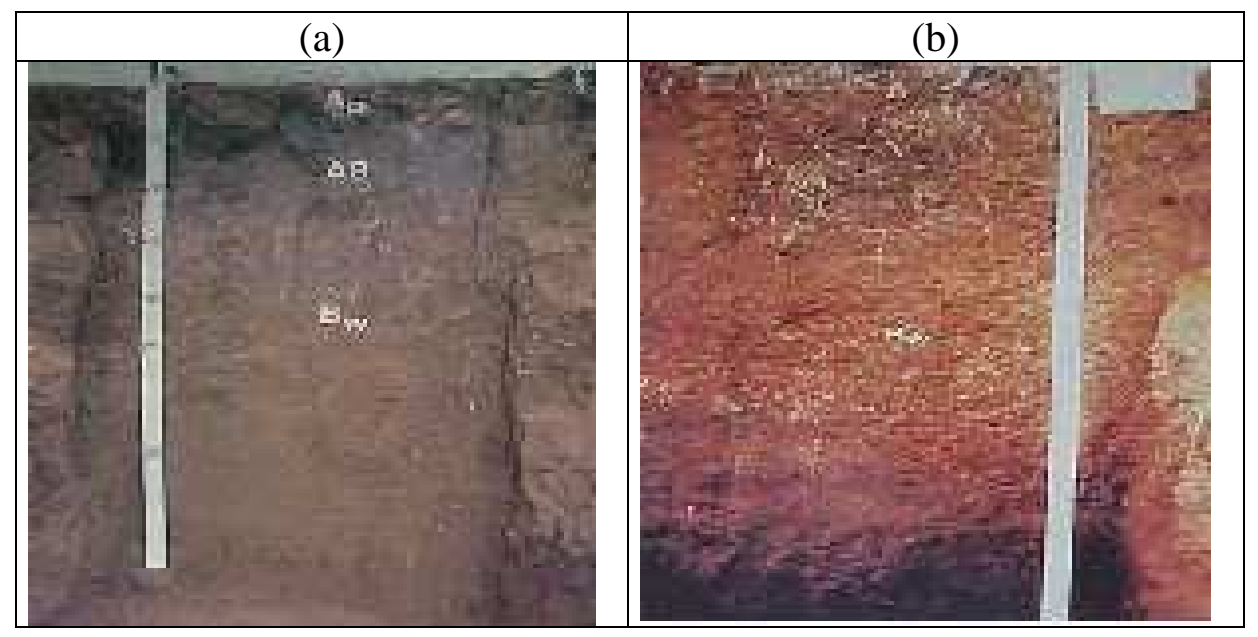

Figura 3.2 - Solos Analisados: Perfil dos solos (a) LVef e (b) LVd.

\subsubsection{Tratamentos}

Estes solos foram submetidos a dois tratamentos distintos, ou seja: Tratamento 1: testemunha, sem adição de lodo de esgoto e sem fertilização mineral no ano agrícola de 1997/98, e submetido à fertilização mineral com base na análise de terra nos anos agrícolas seguintes; Tratamento 2: com adição de lodo de esgoto, provenientes da ETE da SABESP, em Barueri-SP, nas doses 2,5 t ha ${ }^{-1}$ nos anos agrícolas 1997/98 a 1999/00 e 20,0 t ha ${ }^{-1}$ nos demais anos agrícolas, perfazendo uma dose acumulada do resíduo de $87,5 \mathrm{t} \mathrm{ha}^{-1}$, base seca.

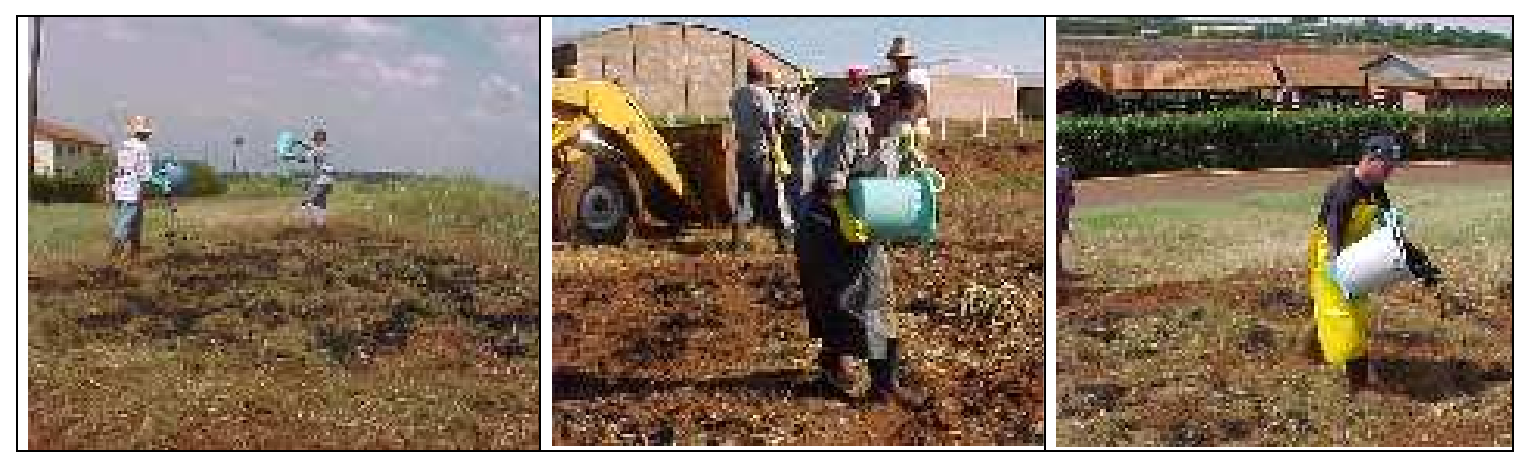

Figura 3.3 - Aplicação do lodo de esgoto ao solo.

\subsubsection{Amostragem}

Os solos foram coletados de parcelas de $6 \mathrm{~m}$ de largura e $10 \mathrm{~m}$ de comprimento $\left(60 \mathrm{~m}^{2}\right)$, nas profundidades de $0-10 ; 10-20 ; 20-40$ e 40-60 cm. 
As amostras foram coletadas conforme o esquema de amostragem ao acaso, cinco pontos, dispostos em zigue-zague na parcela, intercalando-os na linha e entrelinha da cultura. Este procedimento foi adotado visando maior representativa.

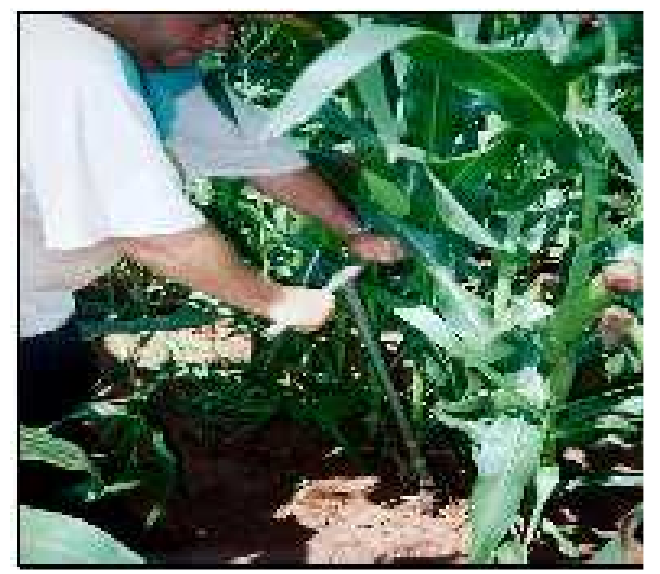

Figura 3.4 - Coleta das amostras de solo.

Tabela 3.1 - Solos estudados e sua classificação conforme o Sistema Brasileiro de Classificação de Solos da Embrapa (1999), as profundidades coletadas e os tratamentos aos quais foram submetidos os solos.

\begin{tabular}{c|c|c}
\hline Solos & $\begin{array}{c}\text { Profundidades } \\
(\mathrm{cm})\end{array}$ & \multicolumn{1}{c}{ Tratamentos } \\
\hline LVef & $0-10$ & Sem adição de lodo de esgoto \\
LVef & $10-20$ & Sem adição de lodo de esgoto \\
LVef & $20-40$ & Sem adição de lodo de esgoto \\
LVef & $40-60$ & Sem adição de lodo de esgoto \\
LVef & $0-10$ & Com adição de lodo de esgoto \\
LVef & $10-20$ & Com adição de lodo de esgoto \\
LVef & $20-40$ & Com adição de lodo de esgoto \\
LVef & $40-60$ & Com adição de lodo de esgoto \\
LVd & $0-10$ & Sem adição de lodo de esgoto \\
LVd & $10-20$ & Sem adição de lodo de esgoto \\
LVd & $20-40$ & Sem adição de lodo de esgoto \\
LVd & $40-60$ & Sem adição de lodo de esgoto \\
LVd & $0-10$ & Com adição de lodo de esgoto \\
LVd & $10-20$ & Com adição de lodo de esgoto \\
LVd & $20-40$ & Com adição de lodo de esgoto \\
LVd & $40-60$ & Com adição de lodo de esgoto \\
\hline
\end{tabular}

\subsection{PREPARO DAS AMOSTRAS DE SOLO E LODO DE ESGOTO}

\section{PARA A EXTRAÇÃO}

Após a coleta as amostras foram levadas ao laboratório e colocadas para secar a temperatura ambiente. Em seguida foi realizada uma limpeza manual para a retirada de raízes 
e restos de plantas, sendo depois passadas em peneira de $0,5 \mathrm{~mm}$ de abertura de malha e homogeneizadas.

\subsection{EXTRAÇÃO E PURIFICAÇÃO DAS SUBSTÂNCIAS HÚMICAS}

A extração de substâncias húmicas foi realizada conforme a metodologia sugerida pela Sociedade Internacional de Substâncias Húmicas (IHSS). Inicialmente foi realizada uma extração com $\mathrm{HCl}$ 0,1 mol L ${ }^{-1}$, em proporção de $1 \mathrm{~g}$ de solo: $10 \mathrm{~mL}$ de solução, foi pesado 100 g de solo e adicionado a este $1000 \mathrm{~mL}$ da solução de $\mathrm{HCl}$ durante uma hora sob agitação. Em seguida foi deixado em repouso por 4 horas, para separar o sobrenadante do resíduo por decantação. O sobrenadante é o extrato 1 de ácido fúlvico. Em seguida foi realizada uma extração com $\mathrm{NaOH}$ 0,1 mol L $\mathrm{L}^{-1}$, em proporção de $1 \mathrm{~g}$ de solo: $10 \mathrm{~mL}$ de solução durante quatro horas sob agitação. Após foi deixado em repouso durante 16 horas, para separar o sobrenadante do resíduo por decantação. O precipitado (humina) foi lavado com água destilada até $\mathrm{pH}$ próximo de 7 e em seguida foi secado a $45^{\circ} \mathrm{C}$. Foi centrifugado o sobrenadante, por 20 minutos a $10000 \mathrm{rpm}$, para a eliminação da argila. Em seguida foi acidificado o sobrenadante com $\mathrm{HCl} 6 \mathrm{~mol} \mathrm{~L}^{-1}$ até $\mathrm{pH}$ 1-2 sob agitação constante e foi deixado em repouso por mais 12 horas, para decantação. A fração do ácido húmico é o precipitado e o sobrenadante é o extrato 2 do ácido fúlvico, que foi separado por sifonação. Foi iniciada a purificação dos ácidos húmicos, redissolveu o precipitado em solução de $\mathrm{KOH}$, $1 \mathrm{~mol} \mathrm{~L}^{-1}$ e foi adicionado $\mathrm{KCl}$ para completar uma concentração de íons $\left[\mathrm{K}^{+}\right]$equivalente a $3 \mathrm{~mol} \mathrm{~L}^{-1}$. A solução foi centrifugada para a eliminação dos sólidos suspensos. Posteriormente o ácido húmico foi reprecipitado, submetido a diálise durante seis dias em membranas Spectra/ Por 6000-8000 D, ativadas segundo a metodologia de (Mc Phie, 1971), limpando-se das substâncias preservadoras, em água destilada, padrão (MiliQ) até eliminação dos íons cloreto, liofilizado e armazenado em dessecador. 


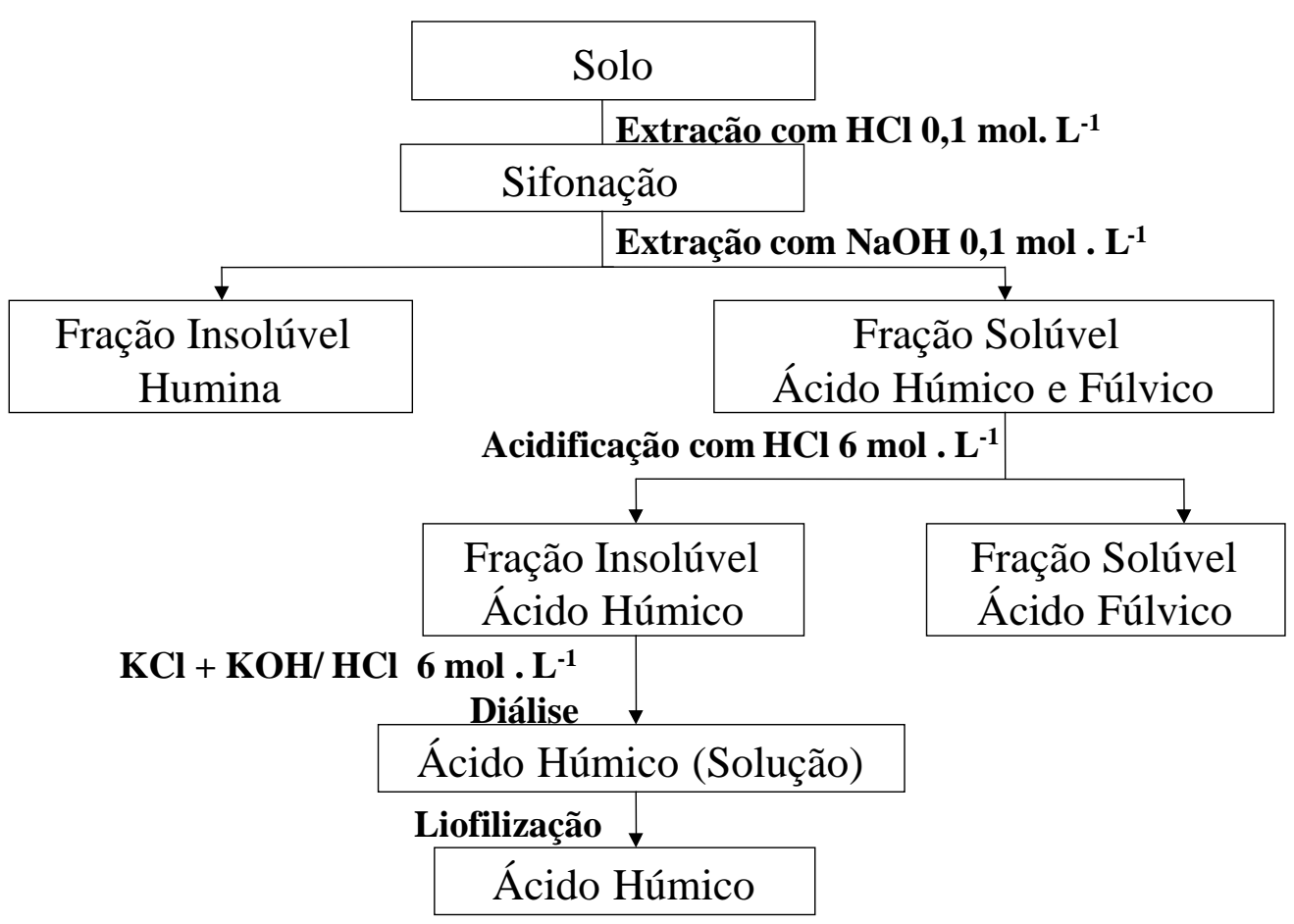

Figura 3.5 - Esquema simplificado de extração e purificação das substâncias húmicas do solo.

A extração de substâncias húmicas para as amostras de lodo de esgoto seguiu a mesma metodologia adotada para as amostras de solo. Observa-se que o material pode ter características distinta das usuais substâncias húmicas extraídas do solo. Contudo, do ponto de vista conceitual esse ácido é chamado na literatura internacional de "humic-like acid", por não existir ainda um termo similar em português, nesse trabalho será chamado de ácido húmico extraído do lodo de esgoto.

\subsection{DETERMINAÇÃO DE METAIS NO PROCESSO DE EXTRAÇÃO DAS SUBSTÂNCIAS HÚMICAS}

A extração de substâncias húmicas foi realizada conforme a metodologia sugerida pela IHSS, porém a esta foram adotadas algumas adaptações como armazenamento de todos os extratos e águas de lavagens, visto que estas amostras seriam destinadas a análise de metais. Inicialmente foi realizada uma extração com $\mathrm{HCl} 0,1 \mathrm{~mol} \mathrm{~L}^{-1}$, em proporção de $1 \mathrm{~g}$ de solo: 10 $\mathrm{mL}$ de solução, foi pesado $100 \mathrm{~g}$ de solo e adicionado a este $1000 \mathrm{~mL}$ da solução de $\mathrm{HCl}$ durante uma hora sob agitação. Em seguida foi deixado em repouso por 4 horas, para separar 
o sobrenadante do resíduo por decantação. O sobrenadante é o extrato 1 de ácido fúlvico. Em seguida foi realizada uma extração com $\mathrm{NaOH} 0,1 \mathrm{~mol} \mathrm{~L}^{-1}$, em proporção de $1 \mathrm{~g}$ de solo: 10 $\mathrm{mL}$ de solução durante quatro horas sob agitação. Após foi deixado em repouso durante 16 horas, para separar o sobrenadante do resíduo por decantação. O precipitado (humina) foi lavado com água destilada até $\mathrm{pH}$ próximo de 7 e em seguida foi secado a $45^{\circ} \mathrm{C}$. Foi centrifugado o sobrenadante, por 20 minutos a 10000 rpm, para a eliminação da argila. Em seguida foi acidificado o sobrenadante com $\mathrm{HCl} 6 \mathrm{~mol} \mathrm{~L}^{-1}$ até $\mathrm{pH}$ 1-2 sob agitação constante e foi deixado em repouso por mais 12 horas, para decantação. A fração do ácido húmico é o precipitado e o sobrenadante é o extrato 2 do ácido fúlvico, que foi separado por sifonação.

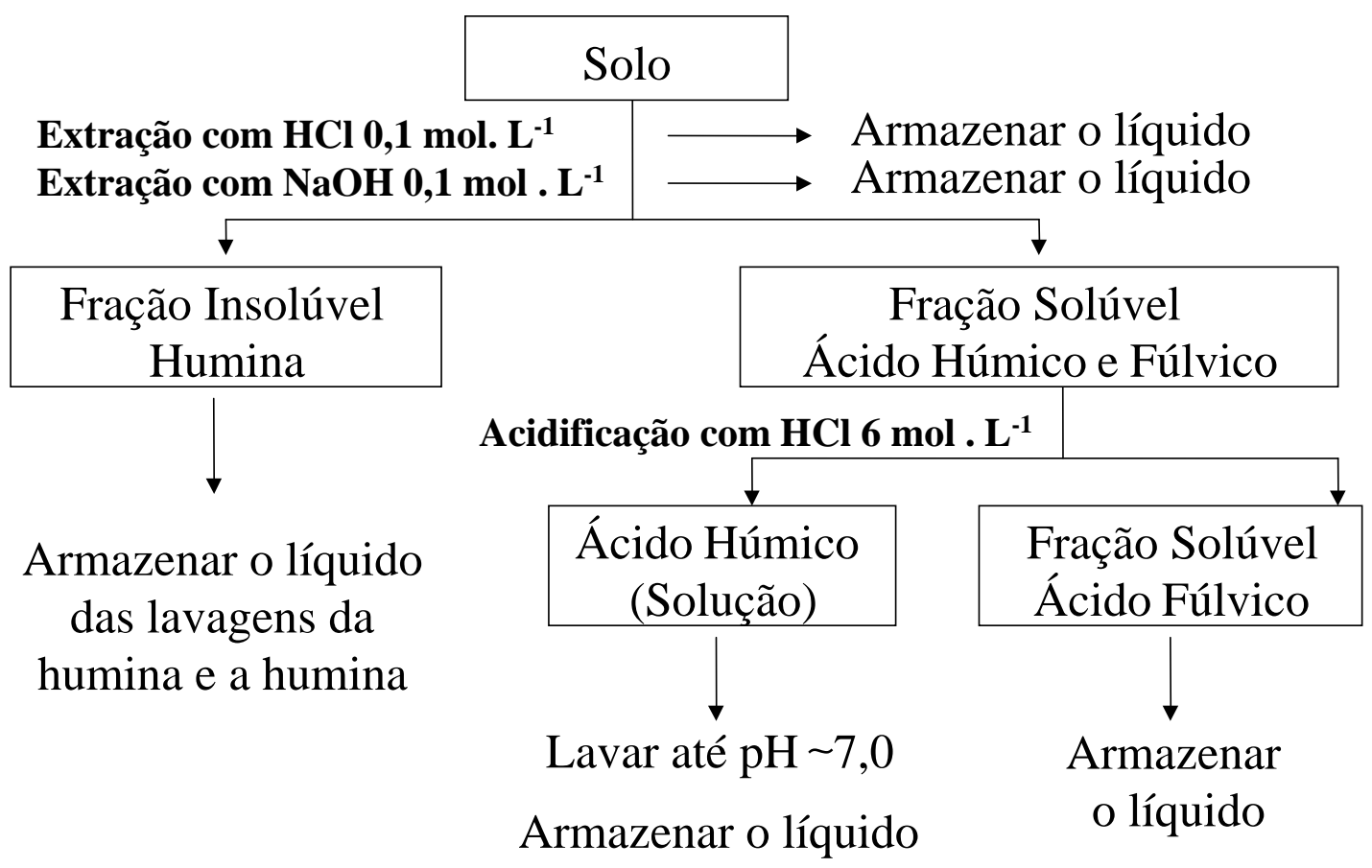

Figura 3.6 - Esquema simplificado de extração e purificação das substâncias húmicas do solo, mostrando as etapas para determinação de metais nas diversas fases do processo.

\subsection{FRACIONAMENTO FÍSICO POR GRANULOMETRIA}

O fracionamento físico dos complexos organominerais foi realizado por peneiramento e sedimentação segundo (Tanner; Jackson, 1947), considerando uma densidade média de 2,65 g $\mathrm{cm}^{-3}$ (González-Pérez, 2003). Os complexos foram separados nas frações > $53 \mu \mathrm{m}, 20-53 \mu \mathrm{m}$, 2-20 $\mu \mathrm{m}$ e $<2 \mu \mathrm{m}$ da forma descrita a seguir. As amostras de solo foram secas a temperatura 
ambiente e submetidas à tratamento com ultra-som, a uma potência de $240 \mathrm{~W}$ durante 8 minutos, para maior dispersão dos agregados. Isso foi realizado em solução de $70 \mathrm{~mL}$ de água destilada para $20 \mathrm{~g}$ de solo. O processo no ultra-som foi usado em banho de gelo para não aquecer o solo. Feito isso, foi peneirado o solo em solução aquosa com peneira de $53 \mu \mathrm{m}$. O peneiramento úmido foi realizado até constatar que não passavam mais partículas de solo, apenas água, com isso a fração areia > $53 \mu \mathrm{m}$ foi obtida. As frações $<53 \mu \mathrm{m}$, constituídas por duas de silte $2-20 \mu \mathrm{m}, 20-53 \mu \mathrm{m}$ e uma de argila $0-2 \mu \mathrm{m}$, foram colocadas nos tubos para sedimentação. Em seguida foram adicionados $10 \mathrm{~mL}$ de $\mathrm{NaOH}$ a $1 \mathrm{~mol} \mathrm{~L}^{-1}$ em cada litro de amostra para separar os agregados. Na separação das frações $<2 \mu \mathrm{m}$ e $2-20 \mu \mathrm{m}$, repetiu-se o procedimento de sedimentação por 20 e 15 vezes, respectivamente, de modo que, ao final do procedimento, a suspensão retirada estivesse transparente, indicando que praticamente todo o solo referente àquela fração havia sido separado (Bayer; Martin-Neto; Saab, 2003). A coleta foi feita em recipientes plásticos de $1 \mathrm{~L}$. Foram adicionados $10 \mathrm{~mL}$ de cloreto de cálcio $(1 \mathrm{~mol}$ $\mathrm{L}^{-1}$ ) para as partículas menores que $2 \mu \mathrm{m}$ após a coleta, para ter rápida sedimentação (Saab, 1999). As frações de areia e silte obtidas foram secas em estufa a $40^{\circ} \mathrm{C}$ e moídas em almofariz de porcelana, a fração de argila foi liofilizada. Na seqüência as frações foram quantificadas e caracterizadas.

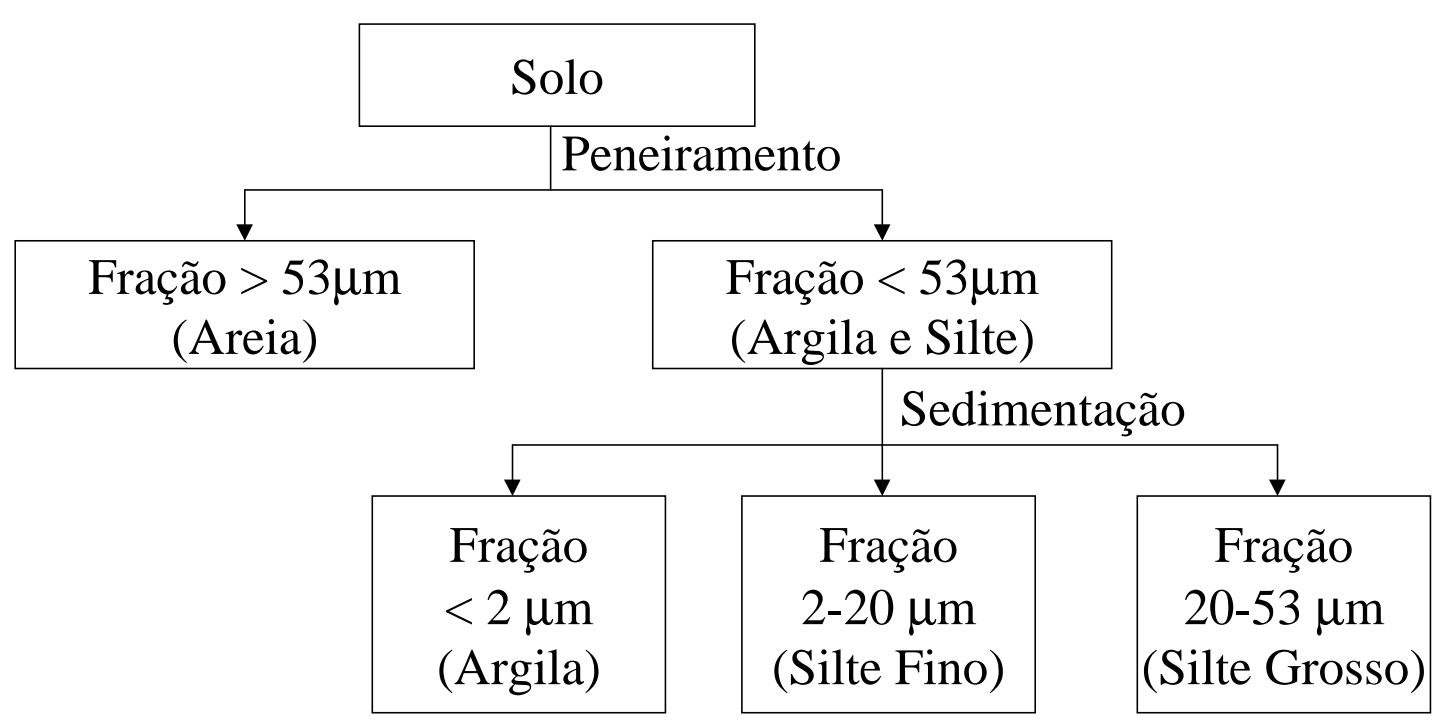

Figura 3.7 - Esquema simplificado do fracionamento físico por granulometria. 


\subsection{CARACTERIZAÇÃO DA MATÉRIA ORGÂNICA}

\subsubsection{MÉTODOS QUÍMICOS}

\subsubsection{Determinação da composição elementar (CHNS)}

A análise química da composição elementar $(\mathrm{C}, \mathrm{N}, \mathrm{H}, \mathrm{S})$ foi realizada para as amostras de ácido húmico, e em duplicata para as amostras de solo intacto.

As medidas foram feitas no equipamento CE - Instruments EA 1110, pertencente ao Instituto de Química de São Carlos-SP.

\subsection{Determinação da razão $\mathrm{C} / \mathrm{N}$}

O cálculo da razão $\mathrm{C} / \mathrm{N}$ foi efetuado a partir dos percentuais de $\mathrm{C}$ e $\mathrm{N}$, e o peso atômico do elemento, aplicando a seguinte razão:

$$
\underline{\mathrm{C}}=\underline{(\mathrm{C} \% / \text { massa molecular } \mathrm{C})}
$$

\subsubsection{Determinação de carbono por via seca (TOC)}

A determinação do teor de carbono foi realizada em duplicata para cada amostra de solo intacto.

As medidas foram realizadas no aparelho TOC Analyser, modelo TOC-V, da marca Shimadzu, acoplado ao Solid Sample Module, modelo SSM-5000 A, da marca Shimadzu, do Laboratório de Química Ambiental, do Instituto de Química de São Carlos-SP

3.7.1.3 Determinação do teor de matéria orgânica por via úmida (Walkley-Black)

A determinação da matéria orgânica do solo foi realizada segundo a reação proposta por (Walkley-Black, 1934), onde ocorre a redução do $\mathrm{Cr}^{6+}$ pela matéria orgânica:

$$
2\left(\mathrm{Cr}_{2} \mathrm{O}_{7}\right)^{2-}+3 \mathrm{C}^{0}+16 \mathrm{H}^{+} \rightarrow 4 \mathrm{Cr}^{3+}+3 \mathrm{CO}_{2}+8 \mathrm{H}_{2} \mathrm{O}
$$


Para essa reação, solução de dicromato de potássio em meio ácido foi empregada em excesso, sendo obtido um volume considerável de sulfocrômica $\mathrm{Cr}^{3+}$ no final da reação (Cantarella; Quaggio, Van Raij, 2001).

A quantificação do teor de matéria orgânica foi realizada a partir da determinação do teor de carbono orgânico do solo e sua posterior conversão através do fator de van Bemmelen $(1,724)$, com base no pressuposto de que a matéria orgânica do solo contém $58 \%$ de carbono orgânico. A fórmula empregada foi:

Carbono Orgânico $\left(\mathrm{g} \mathrm{kg}^{-1}\right) / 1,724$ = Matéria Orgânica

As análises químicas para a determinação do teor de carbono orgânico pelo método de Walkley-Black foram realizadas em triplicata para cada amostras de solo intacto.

Estas análises foram realizadas no Laboratório de Preparo de Amostras da Embrapa Pecuária Sudeste, em São Carlos-SP, onde o resíduo sulfocrômica é tratado segundo o Protocolo de Tratamento de Resíduos do Laboratório de Tratamento de Resíduos Químicos da Embrapa Pecuária Sudeste, e no Laboratório de Solos do Instituto Agronômico do Paraná (IAPAR), em Ponta Grossa-PR.

\subsubsection{Métodos espectroscópicos}

\subsubsection{Absorção de radiação no UV-Vis}

Para a obtenção dos espectros de absorção de radiação no UV-Vis foram utilizadas amostras de ácido húmico, em soluções de $10 \mathrm{mg} \mathrm{kg}^{-1}$ preparadas por diluição a partir de soluções de $2 \mathrm{mg}$ de amostra em $10 \mathrm{~mL}$ de $\mathrm{NaHCO}_{3}$ 0,05 mol L-1 (Stevenson, 1994), ajustadas para $\mathrm{pH}$ 8. As medidas foram realizadas na região de 200 a $800 \mathrm{~nm}$ e as leituras de absorbâncias nos comprimentos de onda de 465 nm ( $\left.E_{4}\right)$ e 665 nm (E).

O espectrômetro utilizado foi o Shimadzu UV-1601 PC pertencente a Embrapa Instrumentação Agropecuária, São Carlos-SP. 


\subsubsection{FTIR}

As medidas por FTIR foram realizadas segundo a metodologia de (Stevenson, 1994), as pastilhas foram preparadas na proporção de 1:100, ou seja, $1 \mathrm{mg}$ de amostra (ácidos húmicos) para cada $100 \mathrm{mg}$ de $\mathrm{KBr}$. Os espectros foram obtidos a partir de 64 varreduras no intervalo de 4000 a $400 \mathrm{~cm}^{-1}$ com resolução espectral de $4 \mathrm{~cm}^{-1}$.

O espectrômetro de FTIR utilizado foi o Perkin-Elmer modelo Spectrum 1000, da Embrapa Instrumentação Agropecuária, São Carlos-SP.

\subsubsection{RMN}

Os espectros de ${ }^{13} \mathrm{C}$ RMN em estado sólido foram obtidos utilizando a seqüência de ${ }^{13} \mathrm{C}$ RMN, CP com amplitude variável (VA) e MAS, empregando uma sonda para amostras sólidas com marca Doty. A freqüência de ressonância foi $100,58 \mathrm{MHz}\left({ }^{13} \mathrm{C}\right)$, a banda espectral utilizada para a CP foi de $50 \mathrm{KHz}$, tempo de contato de $1 \mathrm{~ms}$, tempo de repetição de $500 \mathrm{~ms}$, tempo de aquisição de 0,0128 ms. A varredura foi de 0-230 ppm. As amostras de ácido húmico foram medidas em rotores de zircônia de $5 \mathrm{~mm}$, com MAS de 6,4 KHz. A rampa no canal de $1 \mathrm{H}$ foi de 110-60\% (em kHz) da condição de Hartmann-Hahn (Novotny, 2002). Os deslocamentos químicos foram expressos em ppm em relação ao tetrametilsilano e referenciados em relação ao hexametilbenzeno.

A partir das áreas dos espectros foram calculadas as intensidades relativas dos grupos: alifáticos não substituídos (0-45 ppm), metoxil e N-alifáticos (45-60ppm), O-alifáticos (60110 ppm), aromáticos (110-140 ppm), fenólicos (140-160 ppm), carboxílicos (160-185 ppm) e carbonílicos (185-230 ppm), (Stevenson, 1994; Knicker, 2000).

As porcentagens de alifaticidade e aromaticidade foram calculadas a partir das áreas dos espectros, segundo Stevenson (1994):

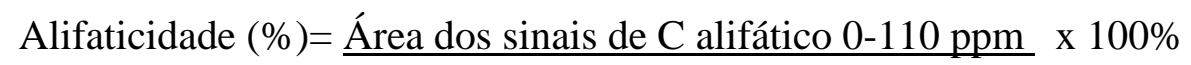




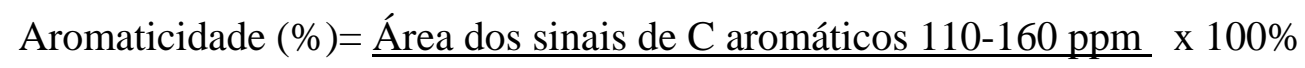

Área dos sinais de C 0-160 ppm

Os espectrômetro de RMN utilizado foi o Varian (Unity 400), que opera em $400 \mathrm{MHz}$ para o ${ }^{1} \mathrm{H}$, pertencente a Embrapa Instrumentação Agropecuária, São Carlos-SP.

\subsubsection{RPE}

As medidas por RPE foram realizadas segundo a metodologia de (Martin-Neto et al., 1991), a potência de microondas utilizada foi de $0,2 \mathrm{~mW}$, amplitude de modulação de $1 \mathrm{G}_{\mathrm{pp}}$ (Gaus pico a pico), freqüência de modulação de $100 \mathrm{KHz}, 16$ varreduras e temperatura ambiente. Foram colocados em torno de $20 \mathrm{mg}$ de amostra em tubos de quartzo de 3,5 $\mathrm{mm}$ de diâmetro interno. As amostras foram medidas em balança eletrônica, com precisão de $\pm 0,05$ mg.

A quantificação do número de radicais livres do tipo semiquinona foi obtida pela área dos sinais do radical livre através da integral dupla do espectro de RPE, usando o rubi como padrão secundário (Singer, 1959; Martin-Neto et al., 1994) e utilizando a aproximação I x $\Delta \mathrm{H}^{2}$ (Poole e Farach, 1972). As quantidades de radicais livres do tipo semiquinona foram determinadas normalizando-as pela massa (ou conteúdo de carbono).

As medidas de radicais livres do tipo semiquinona foram realizadas usando o

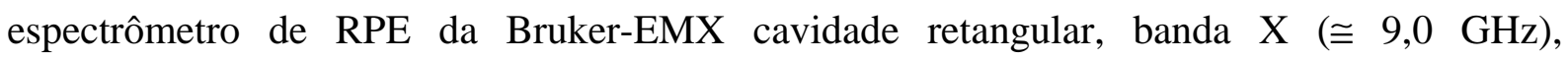
pertencente a Embrapa Instrumentação Agropecuária, São Carlos-SP.

\subsubsection{Fluorescência}

Os espectros de fluorescência foram obtidos utilizando soluções de $10 \mathrm{mg} \mathrm{kg}^{-1}$ preparadas por diluição a partir de soluções de $2 \mathrm{mg}$ de amostra em $10 \mathrm{~mL}$ de $\mathrm{NaHCO}_{3}$ 0,05 mol $\mathrm{L}^{-1}$, ajustadas para $\mathrm{pH}$ 8. Os espectros de fluorescência foram adquiridos nos modos de 
emissão e excitação, segundo as metodologias propostas por (Zsolnay et al., 1999; Milori et al., 2002; Kalbitz; Geyer; Geyer, 1999).

Os espectros de emissão segundo (Znolnay et al.; 1999), foram obtidos com excitação em $240 \mathrm{~nm}$, intervalo de varredura entre 300-700 nm e filtro em $290 \mathrm{~nm}$. A determinação do índice de humificação foi realizada dividindo a área da emissão entre 570-641 nm $\left(\mathrm{A}_{4}\right)$ pela área da emissão entre 356-432 nm ( $\left.\mathrm{A}_{1}\right)$.

Segundo a metodologia proposta por (Milori et al., 2002), foram obtidos os espectros de emissão com excitação em $465 \mathrm{~nm}$, intervalo de varredura entre 480-700 nm e com filtro sempre aberto. A determinação do índice de humificação foi baseada na absorção em 465 nm $\left(\mathrm{A}_{465}\right)$.

A partir da metodologia proposta por (Kalbitz; Geyer; Geyer, 1999), foram obtidos espectros de varredura sincronizada entre $300-520 \mathrm{~nm}$ simultaneamente com excitação e emissão com filtro sempre aberto e diferença de comprimento de onda $\Delta \lambda=55 \mathrm{~nm}$. A determinação do índice de humificação foi realizada a partir da razão entre as intensidades de fluorescência em 400 e 360 nm, ou 470 e 360 nm.

O espectrômetro utilizado para obtenção dos espectros foi o espectrômetro de luminescência Perkin Elmer LS-50B pertencente a Embrapa Instrumentação Agropecuária, São Carlos-SP.

\subsubsection{FIL}

Os espectros de emissão de FIL foram obtidos com uma montagem experimental utilizando amostras de solo (pastilha). Para isto, as amostras de solo foram pastilhadas, com a prensagem em uma forma de aço (8 ton) nas dimensões de $1 \mathrm{~cm}$ de diâmetro, $2 \mathrm{~mm}$ de espessura e aproximadamente $0,5 \mathrm{~g}$ de massa. A utilização de pastilhas de solo é devido à sua fácil manipulação em laboratório e a superfície plana das suas faces, ideal para a análise de FIL. 
A excitação das amostras de solo foi feita com um laser de argônio (Coherent - modelo Innova 90C - $458 \mathrm{~nm}-300 \mathrm{~mW}$ ) sintonizado na linha de $458 \mathrm{~nm}$ com uma potência de 300 mW. A fluorescência emitida foi coletada por uma lente convergente e focalizada sobre a fenda do monocromador da marca CVI (1200 g mm" e "blaze" em $500 \mathrm{~nm})$. A detecção foi feita através de uma fotomultiplicadora Hamamatsu com pico de resposta espectral em 530 nm. O sinal da fotomultiplicadora foi amplificado e retificado por um amplificador "lock-in" e em seguida enviado para um sistema de aquisição controlada por um computador. A resolução espectral deste sistema para fluorescência de solos é em torno de $4 \mathrm{~nm}$.

Como cada pastilha de solo intacto possui duas faces ideais para as medidas de FIL, sendo que, para cada pastilha, foram obtidos dois espectros de FIL. Havendo duas pastilhas por amostra, foi obtido um total de quatro medidas (espectros) de FIL para cada amostra.

Após a obtenção desses dados, foi calculado o grau de humificação das amostras de solo intacto, denominada $\mathrm{H}_{\mathrm{FIL}}$. A proposta de cálculo deste índice de humificação é a razão entre o valor da área (ACF) sobre espectro de emissão de fluorescência (com excitação em 458 nm) e o valor da porcentagem de carbono (COT) presente na amostra de solo intacto (Milori et al., 2001),

$$
\mathrm{H}_{\mathrm{FIL}}=\frac{\mathrm{ACF}}{\mathrm{COT}}
$$

feito para normalizar a relação entre a intensidade de emissão e a concentração de fluoróforos presentes na matéria orgânica da amostra. A adoção da área sobre a curva de fluorescência (ACF) como parâmetro para estimativa da humificação se baseia na metodologia para análise de fluorescência de ácido húmico em solução proposta por (Milori et al., 2002), ou seja, o índice de humificação $\mathrm{A}_{465}$.

As medidas foram realizadas no Instrumento de FIL pertencente à Embrapa Instrumentação Agropecuária, São Carlos-SP. 


\subsection{DETERMINAÇÃO DE METAIS}

\subsubsection{ICP OES}

A digestão foi realizada em banho de areia. Foram adicionados $2,5 \mathrm{~mL}$ de água régia (3 $\mathrm{HCl}: 1 \mathrm{HNO}_{3}$ ) em $250 \mathrm{mg}$ de solo e colocados para digerir a $140^{\circ} \mathrm{C}$ por aproximadamente 2 horas. Após secagem, foram adicionados $2,5 \mathrm{~mL}$ de $\mathrm{HCl} 1,0 \mathrm{~mol} \mathrm{~L}^{-1}$, foi aquecido por mais 30 minutos (até ebulição). Em seguida foi resfriado, filtrado e completado o volume para 12,5 $\mathrm{mL}$.

As condições de operação do equipamento estão descritas na (Tabela 3.2). Os metais analisados e os seus respectivos comprimentos de onda são mostrados na (Tabela 3.3). Os limites de detecção dos metais analisados são mostrados na (Tabela 3.4).

Tabela 3.2 - Descrição e condições operacionais do espectrômetro de ICP OES.

\begin{tabular}{l|c}
\hline Parâmetros & Condições \\
\hline Gerador de freqüência & $40 \mathrm{MHz}$ \\
Modo de observação & Radical \\
Altura de observação & $8 \mathrm{~mm}$ \\
Sistema de difração & Policromador Littrow com grade Echelle \\
Detector & Dispositivo de carga acoplada (CCD) \\
Potência de rádio freqüência & $1,3 \mathrm{~kW}$ \\
Nebulizador & Concêntrico \\
Câmara de nebulização & Ciclônica \\
Vazão do gás de geração do plasma & $15 \mathrm{~L} \mathrm{~min}^{-1}$ \\
Vazão do gás auxiliar & $1,5 \mathrm{~L} \mathrm{~min}^{-1}$ \\
Vazão do gás de nebulização & $0,6 \mathrm{~L} \mathrm{~min}^{-1}$ \\
Replicatas & 3 \\
Tempo de integração & $10 \mathrm{~s}$ \\
\hline
\end{tabular}

Tabela 3.3 - Metais analisados e seus comprimentos de onda.

\begin{tabular}{l|c}
\hline Metais & Comprimentos de onda (nm) \\
\hline Cr(I) & 357,868 \\
Cu(I) & 327,395 \\
Co(I) & 238,892 \\
Fe(II) & 238,204 \\
Mo(I) & 202,032 \\
V(II) & 292,401 \\
Zn(I) & 213,857 \\
\hline
\end{tabular}

(I) e (II) linhas atômicas e iônicas, respectivamente. 
Tabela 3.4 - Limites de detecção dos metais analisados.

\begin{tabular}{l|c}
\hline Metais & Limites de detecção $\left(\mathrm{mg} \mathrm{L}^{-1}\right)$ \\
\hline $\mathrm{Cd}$ & 0,008 \\
$\mathrm{Cr}$ & 0,04 \\
$\mathrm{Co}$ & 0,08 \\
$\mathrm{Cu}$ & 0,03 \\
$\mathrm{Fe}$ & 0,02 \\
$\mathrm{Mn}$ & 0,02 \\
$\mathrm{~V}$ & 0,008 \\
$\mathrm{Zn}$ & 0,03 \\
\hline
\end{tabular}

A determinação de metais nas amostras de solo foi realizada no: espectrômetro ICP OES - visão radial, Vista RL da Varian (Mulgrave, Austrália) equipado com nebulizador VGroove e câmara de nebulização Stuman Master, pertencente a Embrapa Pecuária Sudeste, São Carlos-SP. 


\section{CAPÍTULO 4 RESULTADOS E DISCUSSÕES}

\subsection{CARACTERIZAÇÃO DA MATÉRIA ORGÂNICA}

A matéria orgânica do solo desempenha um papel de suma importância do ponto de vista químico, físico e biológico. A sua origem, as transformações no solo, a composição química e as suas diferentes funções vêm sendo objetivo de muitos estudos. Teores de carbono orgânico total em amostras de solos intactos são as informações mais amplamente disponibilizadas em estudos da matéria orgânica (Shang; Tiessen, 1997). Porém, também é relevante obter informações qualitativas, e as técnicas espectroscópicas para a caracterização da matéria orgânica do solo, especialmente as substâncias húmicas, são as mais indicadas.

As substâncias húmicas representam a parte mais importante da matéria orgânica do solo e, portanto, os efeitos da humificação nas suas estruturas moleculares, e a sua funcionalidade ou reatividade foram caracterizadas por métodos químicos e espectroscópicos. Os ácidos húmicos foram analisados por: análise elementar (CHNS) e por técnicas espectroscópicas: absorção de radiação no UV-Vis, FTIR, RMN, RPE e Fluorescência, e as amostras de solo intacto foram caracterizadas pelos métodos químicos: análise elementar (CHNS), TOC e Walkley-Black; e espectroscópico: FIL.

O uso em conjunto dos métodos químicos e espectroscópicos fornecem grandes avanços na identificação e caracterização dos diferentes compostos húmicos, e na avaliação das alterações estruturais das substâncias húmicas e da matéria orgânica do solo.

\subsubsection{Métodos químicos}

Os valores obtidos para a composição elementar do ácido húmico são mostrados na (Tabela 4.1). 
Tabela 4.1 - Teor de carbono, hidrogênio e nitrogênio em (\%) das amostras de ácido húmico extraídas do LVef e LVd e do lodo de esgoto, determinados pelo método de análise elementar.

\begin{tabular}{c|c|c|c}
\hline Amostras & \multicolumn{3}{|c}{$\%$} \\
\cline { 2 - 4 } & $\mathrm{C}$ & $\mathrm{H}$ & $\mathrm{N}$ \\
\hline LVef/ P1 & 48 & 4 & 4 \\
LVef/ P2 & 49 & 4 & 5 \\
LVef/ P3 & 47 & 5 & 5 \\
LVef/ P4 & 47 & 5 & 5 \\
LVef + B/ P1 & 46 & 5 & 4 \\
LVef + B/ P2 & 44 & 5 & 4 \\
LVef + B/ P3 & 45 & 5 & 4 \\
LVef + B/ P4 & 47 & 5 & 5 \\
LVd/ P1 & 44 & 3 & 4 \\
LVd/ P2 & 45 & 4 & 4 \\
LVd/ P3 & 40 & 4 & 4 \\
LVd/ P4 & 37 & 4 & 3 \\
LVd + B/ P1 & 43 & 4 & 4 \\
LVd + B/ P2 & 43 & 5 & 4 \\
LVd + B/ P3 & 41 & 4 & 4 \\
LVd + B/ P4 & 41 & 4 & 3 \\
Lodo & 51 & 7 & 9 \\
\hline
\end{tabular}

${ }^{(1)}$ LVef $\rightarrow$ (sem adição de lodo de esgoto), LVd $\rightarrow$ (sem adição de lodo de esgoto), + B refere-se aos mesmos solos tratados com lodo de esgoto e Lodo $\rightarrow$ ácido húmico extraído do lodo de esgoto. As profundidades variam de 0-60 cm onde: $\mathrm{P} 1 \rightarrow 0-10 ; \mathrm{P} 2 \rightarrow 10-20 ; \mathrm{P} 3 \rightarrow 20-40$ e $\mathrm{P} 4 \rightarrow 40-60 \mathrm{~cm}$.

Os valores de carbono total e o teor de matéria orgânica dos solos são mostrados na (Tabela 4.2). 
Tabela 4.2 - Teor de carbono em $\left(\mathrm{g} \mathrm{kg}^{-1}\right)$ das amostras de solo intacto, determinados pelos métodos de análise elementar, TOC e Walkley-Black.

\begin{tabular}{c|c|c|c}
\hline Amostras $^{(1)}$ & \multicolumn{3}{|c}{$\mathrm{C}\left(\mathrm{g} \mathrm{kg}^{-1}\right)$} \\
\hline & Análise Elementar & TOC & Walkley-Black \\
\hline LVef/ P1 & $22 \pm 1$ & $18,4 \pm 0,3$ & $13 \pm 2$ \\
LVef/ P2 & $18 \pm 1$ & $18,0 \pm 0,1$ & $12 \pm 2$ \\
LVef/ P3 & $14 \pm 2$ & $13,6 \pm 0,2$ & $9 \pm 1$ \\
LVef/ P4 & $15 \pm 8$ & $10,3 \pm 0,2$ & $6 \pm 1$ \\
LVef + B/ P1 & $18 \pm 2$ & $19,7 \pm 0,2$ & $14 \pm 2$ \\
LVef + B/ P2 & $16 \pm 3$ & $18,2 \pm 0,1$ & $12 \pm 1$ \\
LVef + B/ P3 & $15 \pm 9$ & $15,9 \pm 0,4$ & $11 \pm 2$ \\
LVef + B/ P4 & $10 \pm 1$ & $11,1 \pm 0,2$ & $7 \pm 2$ \\
LVd/ P1 & $9 \pm 4$ & $13,1 \pm 0,3$ & $9 \pm 2$ \\
LVd/ P2 & $11 \pm 2$ & $11,4 \pm 0,3$ & $8 \pm 1$ \\
LVd/ P3 & $7 \pm 2$ & $9,5 \pm 0,4$ & $6 \pm 1$ \\
LVd/ P4 & $7 \pm 2$ & $7,3 \pm 0,1$ & $5 \pm 1$ \\
LVd + B/ P1 & $11 \pm 1$ & $14,8 \pm 0,9$ & $12 \pm 3$ \\
LVd + B/ P2 & $12 \pm 1$ & $13,0 \pm 0,1$ & $9 \pm 2$ \\
LVd + B/ P3 & $10 \pm 3$ & $11,7 \pm 0,4$ & $7 \pm 2$ \\
LVd + B/ P4 & $8 \pm 1$ & $9,0 \pm 0,3$ & $5 \pm 2$ \\
Lodo & - & - & - \\
\hline
\end{tabular}

${ }^{(1)}$ LVef $\rightarrow$ (sem adição de lodo de esgoto), LVd $\rightarrow$ (sem adição de lodo de esgoto), + B refere-se aos mesmos solos tratados com lodo de esgoto e Lodo $\rightarrow$ ácido húmico extraído do lodo de esgoto. As profundidades variam de 0-60 cm onde: $\mathrm{P} 1 \rightarrow 0-10 ; \mathrm{P} 2 \rightarrow 10-20 ; \mathrm{P} 3 \rightarrow 20-40$ e P4 $\rightarrow$ 40-60 cm.

O conhecimento dos teores de carbono é fundamental em diversas áreas da ciência do solo. Diversos métodos têm sido utilizados para a determinação do teor de matéria orgânica do solo. Porém, há uma carência de informações consistentes quanto à definição e recomendação do método mais adequado para a obtenção de resultados confiáveis e satisfatórios (Conceição et al., 1999).

Com isso, neste trabalho três métodos foram utilizados para a determinação de carbono do solo: Análise Elementar CHNS, TOC e Walkley-Black e um método foi utilizado para a determinação de carbono do ácido húmico: Análise Elementar CHNS.

\subsubsection{Determinação da composição elementar (CHNS)}

Valores de carbono determinados pela análise elementar para as amostras de solo, se mostraram insatisfatórios, pois comportamentos como, diminuição linear do teor de carbono das amostras de solo ao longo do perfil e aumento nos teores de carbono nos solos submetidos 
à adição de lodo de esgoto, não foram observados claramente nos resultados adquiridos por esse método (Tabela 4.1). Segundo (Segnini et al., 2005), esses resultados possivelmente devem-se ao fato de se trabalhar com pequenas quantidades de amostra (1 mg), se comparado ao TOC (100 mg) e ao Walkley-Black (1000 mg), influenciando na sua representatividade, face tratar-se de amostras de solo, assim, amostras bastante heterogêneas. Contudo, esse método é de grande relevância e fornece resultados satisfatórios quando as amostras a serem analisadas apresentam maior homogeneidade, como o ácido húmico.

\subsection{Determinação da razão $\mathrm{C} / \mathrm{N}$}

Os valores fornecidos pela análise elementar (Tabela 4.1) para as amostras de ácidos húmicos são próximos dos valores encontrados na literatura (Stevenson, 1994, Simpson; Chefetz; Hatcher, 2003). A partir desses valores foi calculada a razão C/N (Tabela 4.3).

Tabela 4.3 - Valor da razão $\mathrm{C} / \mathrm{N}$ das amostras de ácido húmico obtidos através da determinação da composição elementar (CHNS).

\begin{tabular}{c|c}
\hline Amostras $^{(1)}$ & $\mathrm{C} / \mathrm{N}$ \\
\hline LVef/ P1 & 12 \\
LVef / P2 & 10 \\
LVef / P3 & 9 \\
LVef / P4 & 9 \\
LVef + B/ P1 & 12 \\
LVef + B/ P2 & 11 \\
LVef + B/ P3 & 11 \\
LVef + B/ P4 & 9 \\
LVd/ P1 & 11 \\
LVd/ P2 & 11 \\
LVd/ P3 & 10 \\
LVd/ P4 & 12 \\
LVd + B/ P1 & 11 \\
LVd + B/ P2 & 11 \\
LVd + B/ P3 & 10 \\
LVd + B/ P4 & 14 \\
Lodo & 6 \\
\hline
\end{tabular}

${ }^{(1)}$ LVef $\rightarrow$ (sem adição de lodo de esgoto), LVd $\rightarrow$ (sem adição de lodo de esgoto), + B refere-se aos mesmos solos tratados com lodo de esgoto e Lodo $\rightarrow$ ácido húmico extraído do lodo de esgoto. As profundidades variam de $0-60 \mathrm{~cm}$ onde: $\mathrm{P} 1 \rightarrow 0-10 ; \mathrm{P} 2 \rightarrow 10-20 ; \mathrm{P} 3 \rightarrow 20-40$ e $\mathrm{P} 4 \rightarrow 40-60 \mathrm{~cm}$.

A razão $\mathrm{C} / \mathrm{N}$ fornece informações sobre o processo de humificação das substâncias húmicas. Os resultados obtidos (Tabela 4.3) mostraram menor razão C/N para o ácido húmico 
extraído do lodo de esgoto se comparado aos ácidos húmicos extraídos dos solos. Contudo, esses resultados, mostram-se aparentemente controversos com os dados da literatura visto que, quanto menor a razão $\mathrm{C} / \mathrm{N}$ maior o grau de humificação (Nicolardot; Recous; Mary, 2001). Porém, deve-se ao fato de que o lodo de esgoto apresenta maior concentração de compostos nitrogenados se comparado ao solo (Tabela 4.1).

A partir da razão $\mathrm{C} / \mathrm{N}$ podemos ainda determinar o grau de estabilização da matéria orgânica, do ponto de vista ao ataque microbiano, bem como a estabilidade desse material adicionado ao solo. Apesar da alta concentração de carbono e nitrogênio, 51 e $9 \%$, respectivamente (Tabela 1), o lodo de esgoto apresenta baixa razão $\mathrm{C} / \mathrm{N}$. Esse resultado é devido aos microorganismos presentes em grande quantidade no lodo de esgoto, que necessitam de carbono, como fonte de energia, e de nitrogênio para a síntese de proteínas, consumirem maiores quantidades de carbono do que nitrogênio, durante o processo de decomposição, com isso o ácido húmico extraído do lodo de esgoto apresenta uma baixa razão C/N, consequiência da alta dose de nitrogênio. Segundo Fernandes (2000) o lodo de esgoto apresenta razão $\mathrm{C} / \mathrm{N}$ entre 5 e 11 .

Apesar da baixa razão $\mathrm{C} / \mathrm{N}$ apresentada pelo lodo de esgoto, não foi observada diferença na razão $\mathrm{C} / \mathrm{N}$ dos solos submetidos à adição do resíduo (Figura 4.1). 


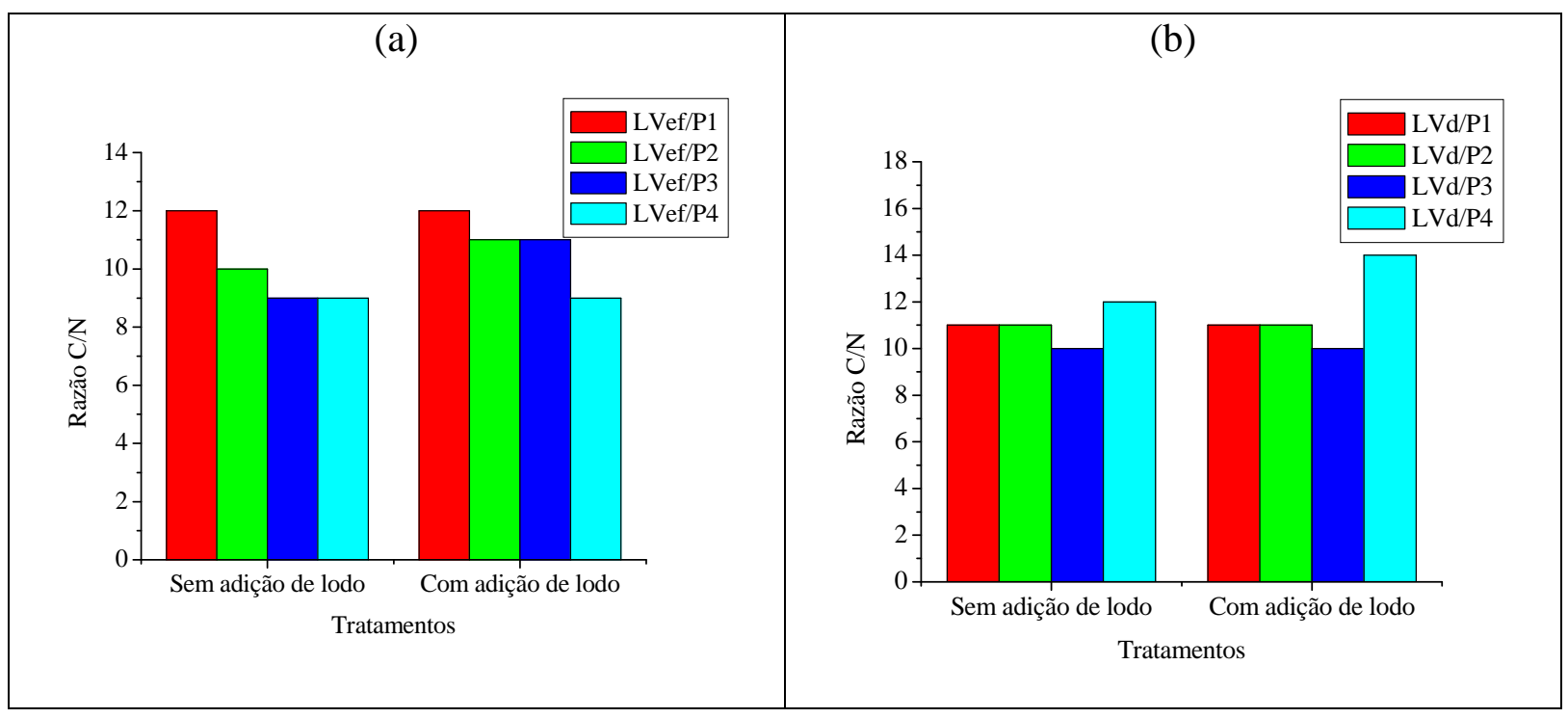

Figura 4.1 - Valores da razão $\mathrm{C} / \mathrm{N}$ obtidos para os ácidos húmicos extraídos do (a) LVef sem e com adição de lodo de esgoto e (b) LVd sem e com adição de lodo de esgoto. As profundidades variam de 0-60 $\mathrm{cm}$ onde: P1 $\rightarrow$ $0-10 ; \mathrm{P} 2 \rightarrow$ 10-20; P3 $\rightarrow$ 20-40 e P4 $\rightarrow$ 40-60 cm.

Os altos teores de nitrogênio incorporados às macromoléculas dos ácidos húmicos, deve-se à decomposição de proteínas e polipeptídios de tecidos de microrganismos, que são incorporados aos ácidos húmicos nativos do solo em formas resistentes à decomposição (Senesi; Miano; Brunetti, 1996).

\subsubsection{Determinação de carbono por via seca (TOC)}

Dentre os métodos utilizados para a determinação de carbono nas amostras de solo, os resultados obtidos por esse método foram os que se mostraram mais coerente. Foi observado uma tendência ao aumento dos teores de carbono nos solos submetidos à adição de lodo de esgoto (Figura 4.2). Esse aporte proporcionado é importante, pois coloca o lodo de esgoto como mais uma alternativa para elevação dos teores de matéria orgânica dos solos (Nascimento et al., 2004). No entanto, a manutenção de altos teores de matéria orgânica pela adição de lodo dependerá de aplicações sucessivas do resíduo (Oliveira et al., 2002), visto que os efeitos sobre os teores de carbono orgânico podem ser temporários (Melo et al., 1994), em decorrência da decomposição da matéria orgânica.

Resultados obtidos por (Marques, 1996), revelaram que somente em taxas elevadas de aplicações seria possível uma ação mais prolongada do lodo de esgoto sobre os teores de 
matéria orgânico dos solos. Porém, o aporte de matéria orgânica proporcionado pela adição de lodo de esgoto observado nos resultados obtidos, deve-se ao longo tempo de duração desse experimento onde, tem-se uma dose acumulada de $87,5 \mathrm{t} \mathrm{ha}^{-1}$.

Contudo, o simples aumento no teor de carbono orgânico pode não significar benefícios ao sistema solo-planta, é preciso conhecer a qualidade do carbono orgânico persistente e principalmente seus efeitos a longo prazo sobre as características químicas e físicas do solo que são de interesse para fins agronômicos e ambientais (Hohla; Jones; Hinesly, 1978; Oliveira et al., 2002).

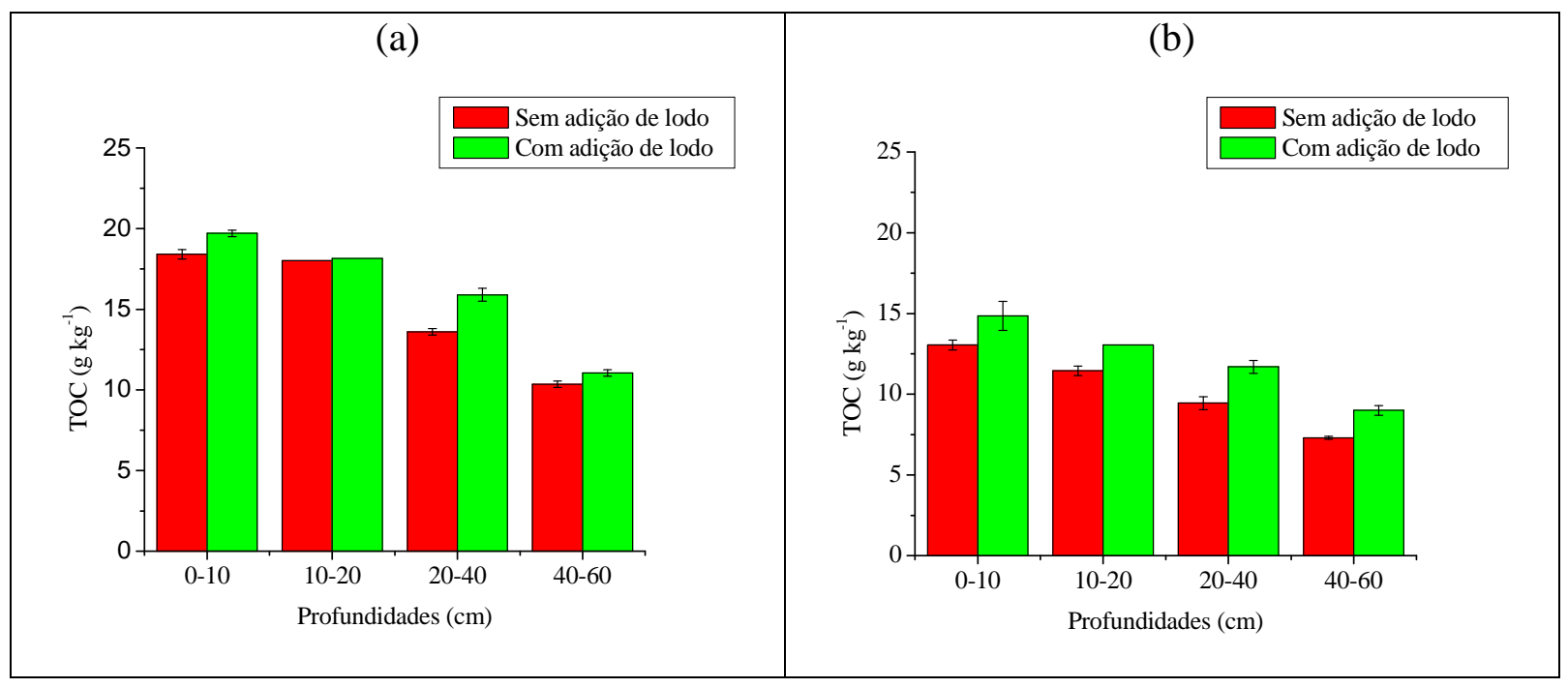

Figura 4.2 - Dados dos teores de carbono para as amostras de solo intacto determinados pelo método de TOC para os solos (a) LVef sem e com adição de lodo de esgoto e (b) LVd sem e com adição de lodo de esgoto em diferentes profundidades.

Corroborando com (Leite; Bernardes; Oliveira, 2004), os resultados obtidos para o teor de carbono apresentam maiores concentrações na camada superficial $(0-10 \mathrm{~cm})$, e diminuem linearmente ao longo do perfil, comportamento também observado nos resultados do teor de carbono pelo método de Walkley-Black (Tabela 4.1). Com isso, o método de determinação do TOC pode ser usado para a determinação de matéria orgânica em análises de rotina do solo com a vantagem de eliminação do $\mathrm{Cr}$ e $\mathrm{H}_{2} \mathrm{SO}_{4}$ concentrado, usados nas determinações por Walkley-Black (Miyazawa et al., 2000). Estes resultados não inviabilizam o uso de outras metodologias, mas evidenciam a necessidade de uma visão mais crítica sobre as limitações de cada método na determinação de carbono em solos (Segnini et al., 2005). 
A partir dos resultados obtidos para os dois solos analisados, LVef e LVd, observamos que, o maior conteúdo de argila no LVef pode favorecer a estabilidade da matéria orgânica humificada por meio da formação de complexos organominerais, tornando a matéria orgânica relativamente mais protegida da degradação microbiana (Canellas et al., 2001), com isso, teores maiores de carbono são observados através dos métodos utilizados para esse solo, se comparado ao LVd que apresenta textura arenosa (Figura 4.2).

\subsubsection{Determinação do teor de matéria orgânica por via úmida}

\section{(Walkley-Black)}

O método de Walkley-BlacK para a determinação do teor de matéria orgânica é o mais utilizado pela maioria dos laboratórios do país, tal fato se deve a facilidade de execução do mesmo e a disponibilidade de instalação em laboratórios desprovidos de equipamentos eletrônicos, tais como, analisador elementar e TOC Analyser.

Este método apresenta algumas desvantagens se comparado aos demais métodos. A determinação da quantidade de matéria orgânica pelo método de Walkley-Black, baseia-se na sua oxidação à $\mathrm{CO}_{2}$ por íons $\left(\mathrm{Cr}_{2} 0_{7}\right)^{2-}$ em meio fortemente ácido, desta forma sem aquecimento externo, contando somente com o calor desprendido pela diluição do $\mathrm{H}_{2} \mathrm{SO}_{4}$ (Cantarella; Guaggio, Van Raij, 2001). Desse modo, a eficiência da oxidação do carbono orgânico do solo com $\mathrm{K}_{2} \mathrm{Cr}_{2} \mathrm{O}_{7}$ em meio $\mathrm{H}_{2} \mathrm{SO}_{4}$ concentrado apresenta uma média de $77 \%$, isto é o $\left(\mathrm{Cr}_{2} \mathrm{O}_{7}\right)^{2-}$ pode oxidar somente $77 \%$ do carbono do solo, ou seja, a oxidação do carbono não é completa; para compensar a oxidação parcial, aplica-se um fator de correção $(1,33)$ (Pavan et al., 1992), o que pode ser considerado como uma desvantagem do método, visto que este fator é igual para todos os solos, embora a porcentagem de carbono oxidável pelo método, possa variar de um solo para outro devido as diferenças entre eles. Além disso, o método de Walkley-Black utiliza na oxidação da matéria orgânica do solo o $\mathrm{Cr}^{6+}$ na presença de $\mathrm{H}_{2} \mathrm{SO}_{4}$ concentrado, com isso, pode vir a contaminar o meio ambiente com metal tóxico $\left(\mathrm{Cr}^{6+}\right)$ além de oferecer riscos ao analista com o uso de $\mathrm{H}_{2} \mathrm{SO}_{4}$ concentrado. Outra 
desvantagem deste método, é o fato de o mesmo apresentar limitações quanto a identificação do carbono mais protegido com isso, observamos valores menores de teores de carbono determinados por esse método se comparados ao analisador elementar e ao TOC.

Foram correlacionados os três métodos utilizados para a determinação do teor de matéria orgânica e carbono (Figura 4.3). Os valores da correlação entre: análise elementar e TOC, análise elementar e Walkley-Black e TOC e Walkley-Black foram respectivamente, $\mathrm{r}=$ $0,96, r=0,83$ e $r=0,99$ e $\mathrm{P}<0,0001$.

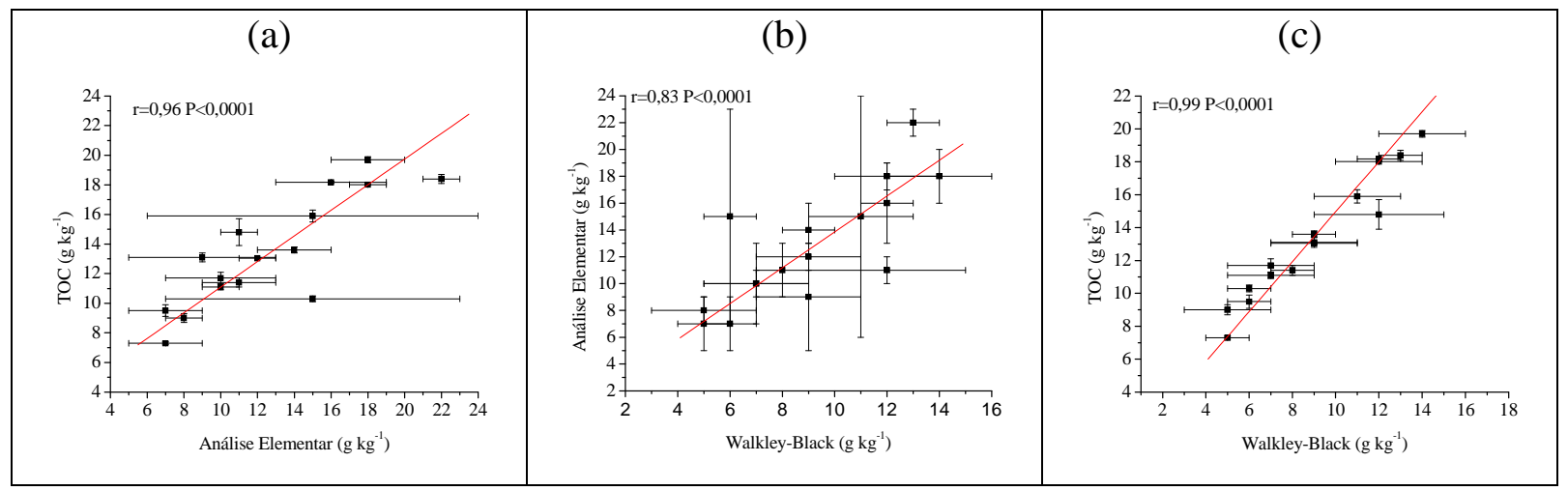

Figura 4.3 - Correlações entre os teores de carbono obtidos pelos métodos: (a) análise elementar e TOC, (b) análise elementar e WalKley-Black e (c) TOC e Walkley-Black.

As técnicas para a determinação de carbono apresentaram boa correlação entre si, contudo observamos menor desvio médio e maior correlação $(r=0,99)$ entre TOC e WalkleyBlack, significativa correlação observada pode estar relacionada a representatividade amostral, visto que utilizaram maiores quantidades de solo para a análise se comparada a análise elementar. Os solos apresentam baixa densidade e constituição orgânica, cujas frações se mostram heterogêneas.

\subsubsection{Métodos espectroscópicos}

\subsubsection{Absorção de radiação no UV-Vis}

Em função da grande quantidade e variabilidade de grupos cromóforos, existentes nas moléculas húmicas, os espectros obtidos por absorção de radiação no UV-Vis são geralmente formados pela sobreposição de várias bandas, sem máximos definidos, apresentando absorção decrescente com o aumento do comprimento de onda, tanto para os ácidos húmicos extraídos 
dos solos (Figura 4.4) como para o ácido húmico extraído do lodo de esgoto (Figura 4.5). Com isso, nos espectros de absorção de radiação no UV-Vis de ácidos húmicos não se distingue nenhuma banda que possa ser atribuída a determinado cromóforo ou grupo principal. Apesar disso, são largamente usados na avaliação do grau de condensação de grupos aromáticos dos ácidos húmicos, baseando-se na razão $\mathrm{E}_{4} / \mathrm{E}_{6}$.

Muitos pesquisadores opinam que a cor escura das substâncias húmicas é devida principalmente aos cromóforos na forma ceto e enol (Stevenson, 1994).

Experimentos de absorção de radiação no UV-Vis foram realizados, a fim de se obter informações sobre o grau de condensação de grupos aromáticos dos ácidos húmicos extraídos dos solos, e do ácidos húmico extraído do lodo de esgoto. Os espectros de absorção de radiação no UV-Vis na região de 400 a 800 nm dos ácidos húmicos extraídos dos solos LVef e LVd, e do ácidos húmicos extraído do lodo de esgoto são mostrados nas (Figuras 4.4 e 4.5), respectivamente. 


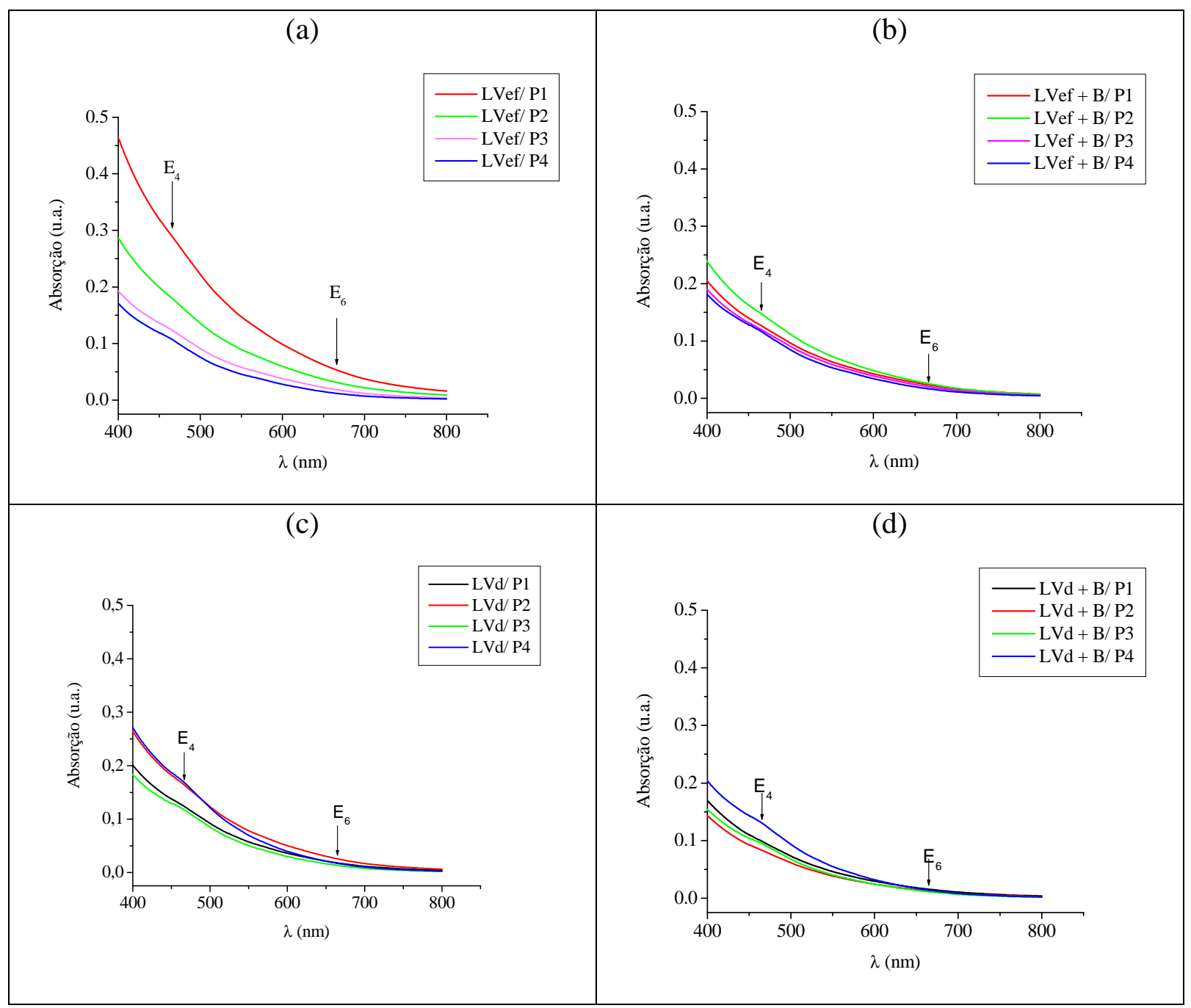

Figura 4.4 - Espectros de absorção de absorção de radiação no UV-Vis de ácido húmico extraídos do (a) LVef $\rightarrow$ sem adição de lodo de esgoto, (b) LVef $+\mathrm{B} \rightarrow$ com adição de lodo de esgoto, (c) LVd $\rightarrow$ sem adição de lodo de esgoto e (d) $\mathrm{LVd}+\mathrm{B} \rightarrow \mathrm{com}$ adição de lodo de esgoto. As profundidades variam de 0-60 cm onde: $\mathrm{P} 1 \rightarrow \mathbf{0}$ $10 ; \mathrm{P} 2 \rightarrow 10-20 ; \mathrm{P} 3 \rightarrow 20-40$ e P4 $\rightarrow$ 40-60 cm.

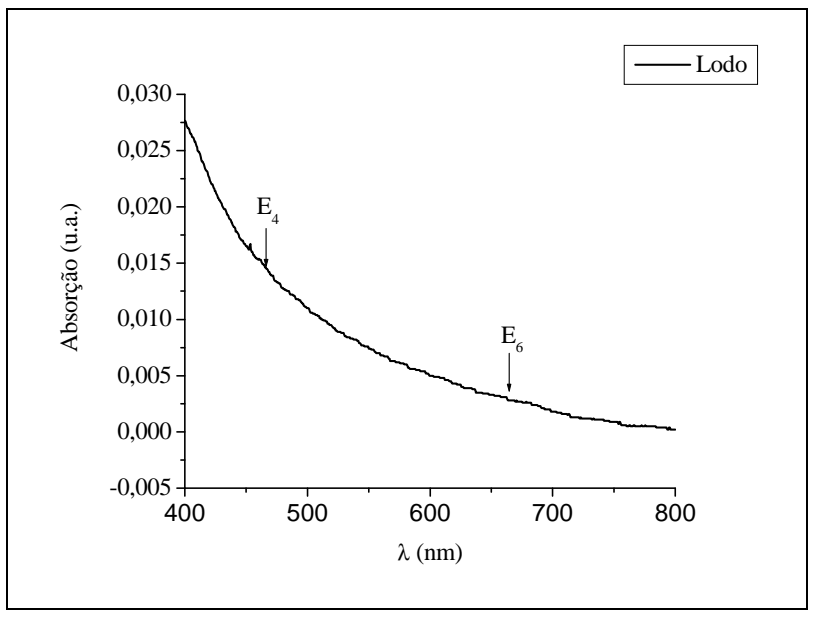

Figura 4.5 - Espectro de absorção de radiação no UV-Vis de ácido húmico extraído do lodo de esgoto. 
Foi obtida a partir de absorção de radiação no UV-Vis a razão entre as absorbâncias em $465 \mathrm{~nm}$ e $665 \mathrm{~nm}$, chamada razão $\mathrm{E}_{4} / \mathrm{E}_{6}$ (Figuras 4.4 e 4.5), a qual tem sido associada ao grau de condensação de grupos aromáticos e por sua vez ao grau de humificação (Schnitzer; Khan, 1978). A razão $E_{4} / E_{6}$ está relacionada ao sistema $\pi$ da molécula húmica e permite, em alguns casos, uma avaliação relativa da massa molecular das amostras. $\mathrm{O}$ decréscimo da razão $\mathrm{E}_{4} / \mathrm{E}_{6}$ está diretamente relacionado com o aumento do peso molecular, condensação de carbonos aromáticos e aromaticidade, e inversamente relacionado à quantidade de grupos alifáticos.

Tabela 4.4 - Dados referentes à absorção de radiação no UV-Vis em $468 \mathrm{~nm}\left(\mathrm{E}_{4}\right)$ e em $665 \mathrm{~nm}\left(\mathrm{E}_{6}\right)$ e a razão entre as mesmas $\left(\mathrm{E}_{4} / \mathrm{E}_{6}\right)$ para os ácidos húmicos extraídos do LVef, $\mathrm{LVd}$ e do lodo de esgoto.

\begin{tabular}{c|c|c|c}
\hline Amostras & $\mathrm{E}_{4}$ & $\mathrm{E}_{6}$ & $\mathrm{E}_{4} / \mathrm{E}_{6}$ \\
\hline LVef/ P1 & 0,2005 & 0,0373 & $5,34 \pm 0,08$ \\
LVef/ P2 & 0,1462 & 0,0255 & $5,74 \pm 0,02$ \\
LVef/ P3 & 0,1648 & 0,0249 & $6,62 \pm 0,20$ \\
LVef/ P4 & 0,1292 & 0,0144 & $8,97 \pm 0,01$ \\
LVef + B/ P1 & 0,1185 & 0,0220 & $5,39 \pm 0,10$ \\
LVef + B/ P2 & 0,1273 & 0,0225 & $5,65 \pm 0,04$ \\
LVef + B/ P3 & 0,1571 & 0,0271 & $5,80 \pm 0,10$ \\
LVef + B/ P4 & 0,1290 & 0,0186 & $6,93 \pm 0,03$ \\
LVd/ P1 & 0,1099 & 0,0155 & $7,09 \pm 0,10$ \\
LVd/ P2 & 0,1404 & 0,0216 & $6,50 \pm 0,10$ \\
LVd/ P3 & 0,1196 & 0,0134 & $8,93 \pm 0,02$ \\
LVd/ P4 & 0,1428 & 0,0142 & $10,06 \pm 0,10$ \\
LVd + B/ P1 & 0,0944 & 0,0148 & $6,38 \pm 0,05$ \\
LVd + B/ P2 & 0,0873 & 0,0132 & $6,61 \pm 0,02$ \\
LVd + B/ P3 & 0,0948 & 0,0111 & $8,54 \pm 0,10$ \\
LVd + B/ P4 & 0,1286 & 0,0136 & $9,46 \pm 0,10$ \\
Lodo & 0,0133 & 0,0024 & $5,54 \pm 0,40$ \\
\hline
\end{tabular}

${ }^{(1)}$ LVef $\rightarrow$ (sem adição de lodo de esgoto), LVd $\rightarrow$ (sem adição de lodo de esgoto), + B refere-se aos mesmos solos tratados com lodo de esgoto e Lodo $\rightarrow$ ácido húmico extraído do lodo de esgoto. As profundidades variam de $0-60 \mathrm{~cm}$ onde: $\mathrm{P} 1 \rightarrow 0-10 ; \mathrm{P} 2 \rightarrow 10-20 ; \mathrm{P} 3 \rightarrow 20-40$ e $\mathrm{P} 4 \rightarrow 40-60 \mathrm{~cm}$.

Os valores determinados pela razão $\mathrm{E}_{4} / \mathrm{E}_{6}$ (Tabela 4.4) variaram de 5,34 a 10,03 para solos sem à adição de lodo de esgoto e de 5,41 a 9,43 para solos com adição de lodo de esgoto (Tabela 4.4). O ácido húmico extraído do lodo de esgoto apresentou razão $\mathrm{E}_{4} / \mathrm{E}_{6}$ igual a 5,54. 


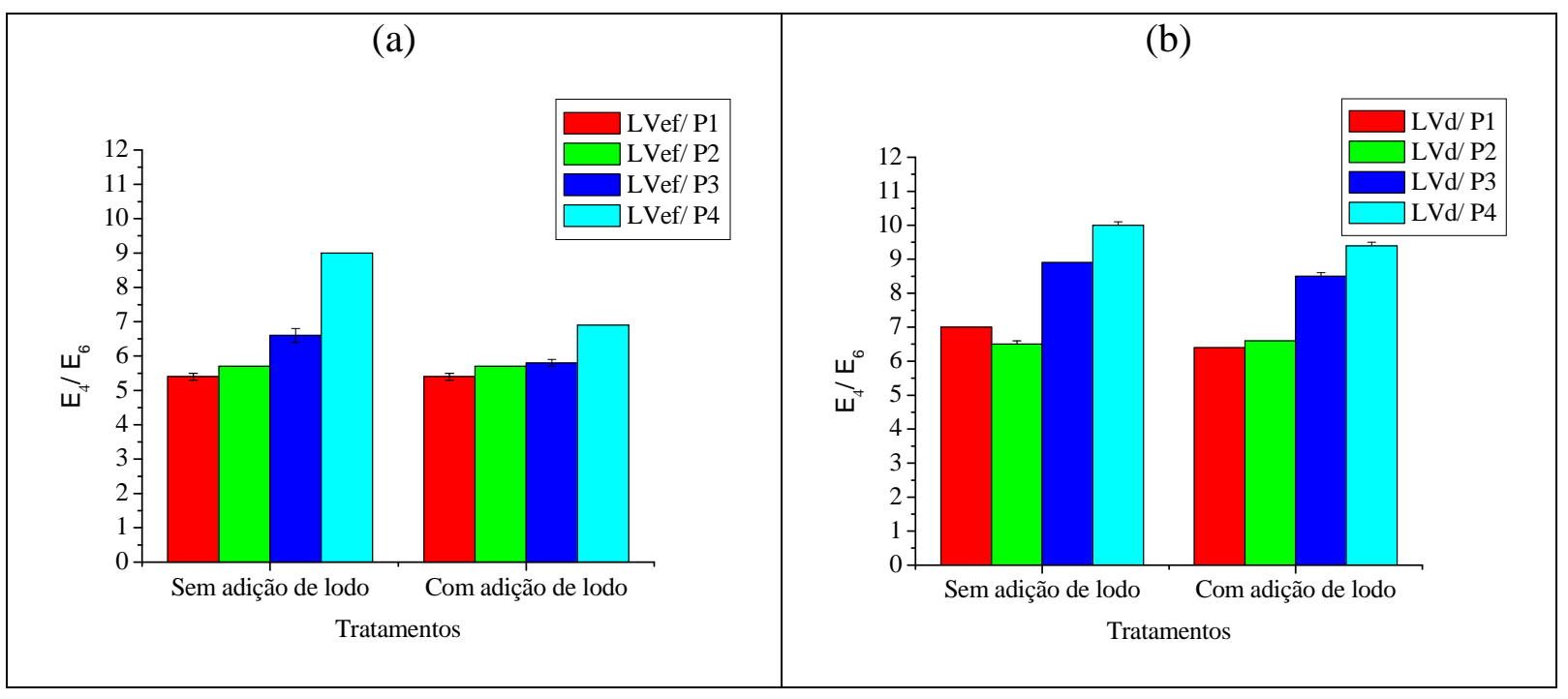

Figura 4.6 - Valores da razão $\mathrm{E}_{4} / \mathrm{E}_{6}$ obtidos para os ácidos húmicos extraídos do (a) LVef sem e com adição de lodo de esgoto e (b) LVd sem e com adição de lodo de esgoto. As profundidades variam de 0-60 cm onde: P1 $\rightarrow$ $0-10 ; \mathrm{P} 2 \rightarrow$ 10-20; P3 $\rightarrow$ 20-40 e P4 $\rightarrow$ 40-60 cm.

Em geral, não foram observados variações significativas para os ácidos húmicos que receberam à adição de lodo de esgoto (Figura 4.6).

Segundo (Stevenson, 1994), a razão $\mathrm{E}_{4} / \mathrm{E}_{6}$ está diretamente relacionada ao aumento da massa e tamanho molecular, condensação dos carbonos aromáticos e a aromaticidade e inversamente relacionada à quantidade de grupos alifáticos. Segundo (Piccolo; Zaccheo; Genevini, 1992; Hevia et al., 2003) a razão $\mathrm{E}_{4} / \mathrm{E}_{6}$ pode ser utilizada como uma forma de estimar a aromaticidade, sendo que quanto menor a razão $\mathrm{E}_{4} / \mathrm{E}_{6}$ maior o grau de aromaticidade das substâncias húmicas.

Contudo, tem sido observado resultados contraditórios e limitações neste procedimento simples, sugerindo o devido cuidado com sua utilização (Colnago et al., 1997). Os valores determinados através da razão $\mathrm{E}_{4} / \mathrm{E}_{6}$ devem ser utilizados e correlacionados com o devido cuidado com outros parâmetros espectroscópicos mais precisos, como nível de radicais livres do tipo semiquinona por RPE e grau de aromaticidade por RMN. 


\subsubsection{FTIR}

Experimentos de FTIR foram realizados, a fim de se obter informações sobre a composição de grupos funcionais, dos ácidos húmicos extraídos dos solos e do lodo de esgoto.

A interpretação dos espectros de FTIR foram realizadas de acordo com (Nakanishi, 1962; Piccolo; Stevenson, 1982; Bloom; Leenheer, 1989; Silverstein; Bassler; Morril, 1994; Canellas et al., 2001; Polak et al., 2005).

Os espectros na região do infravermelho para os ácidos húmicos extraídos dos solos LVef e LVd, submetidos ou não à adição de lodo de esgoto e do ácido húmico extraído do lodo de esgoto estão mostrados nas (Figuras 4.7, 4.8 e 4.9). 


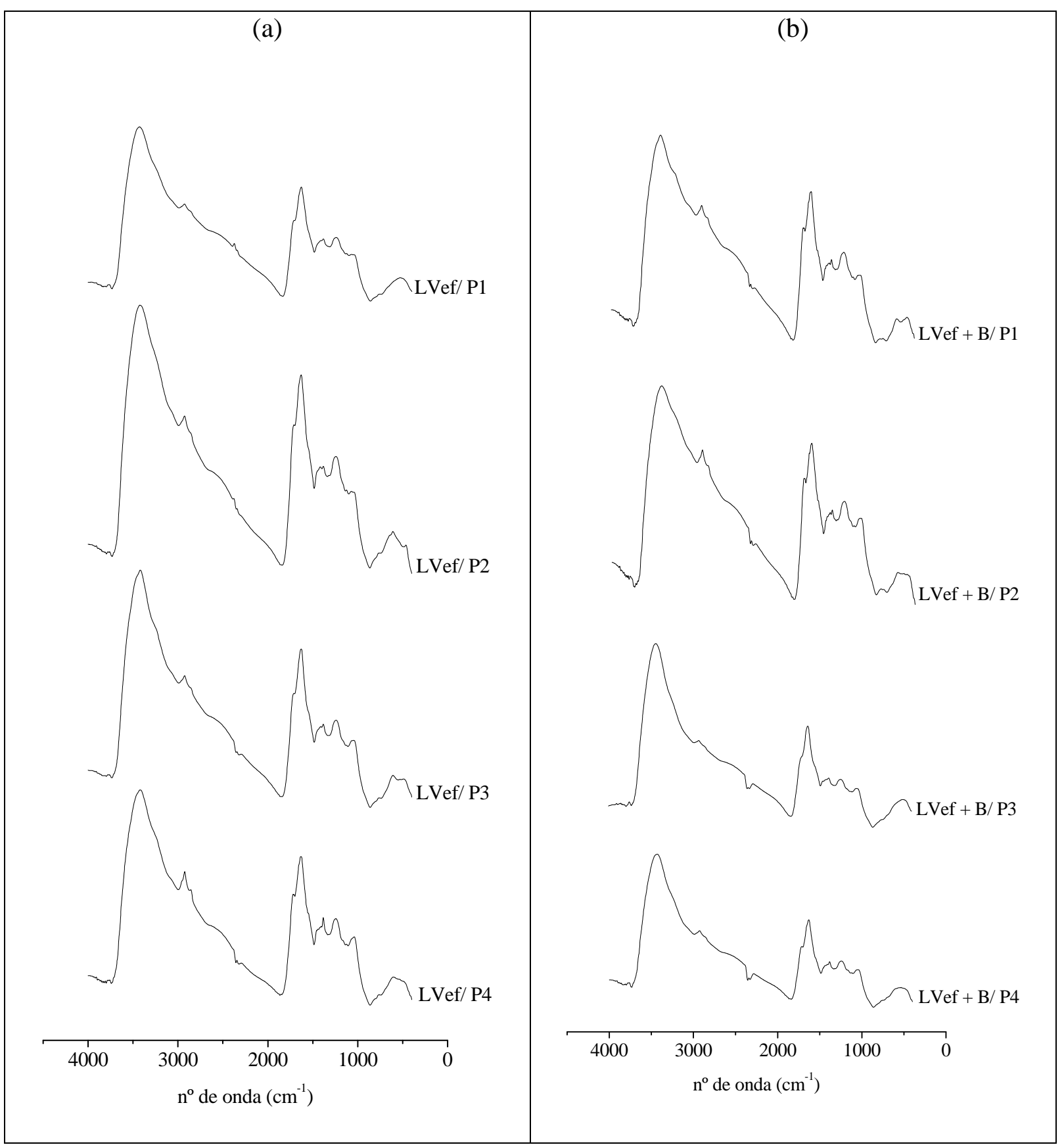

Figura 4.7 - Espectros de FTIR de ácidos húmicos extraídos do (a) LVef $\rightarrow$ sem adição de lodo de esgoto e (b) LVef $+\mathrm{B} \rightarrow$ com adição de lodo de esgoto. As profundidades variam de 0-60 cm onde: P1 $\rightarrow$ 0-10; P2 $\rightarrow 10-20$; $\mathrm{P} 3 \rightarrow 20-40$ e P4 $\rightarrow$ 40-60 cm. 


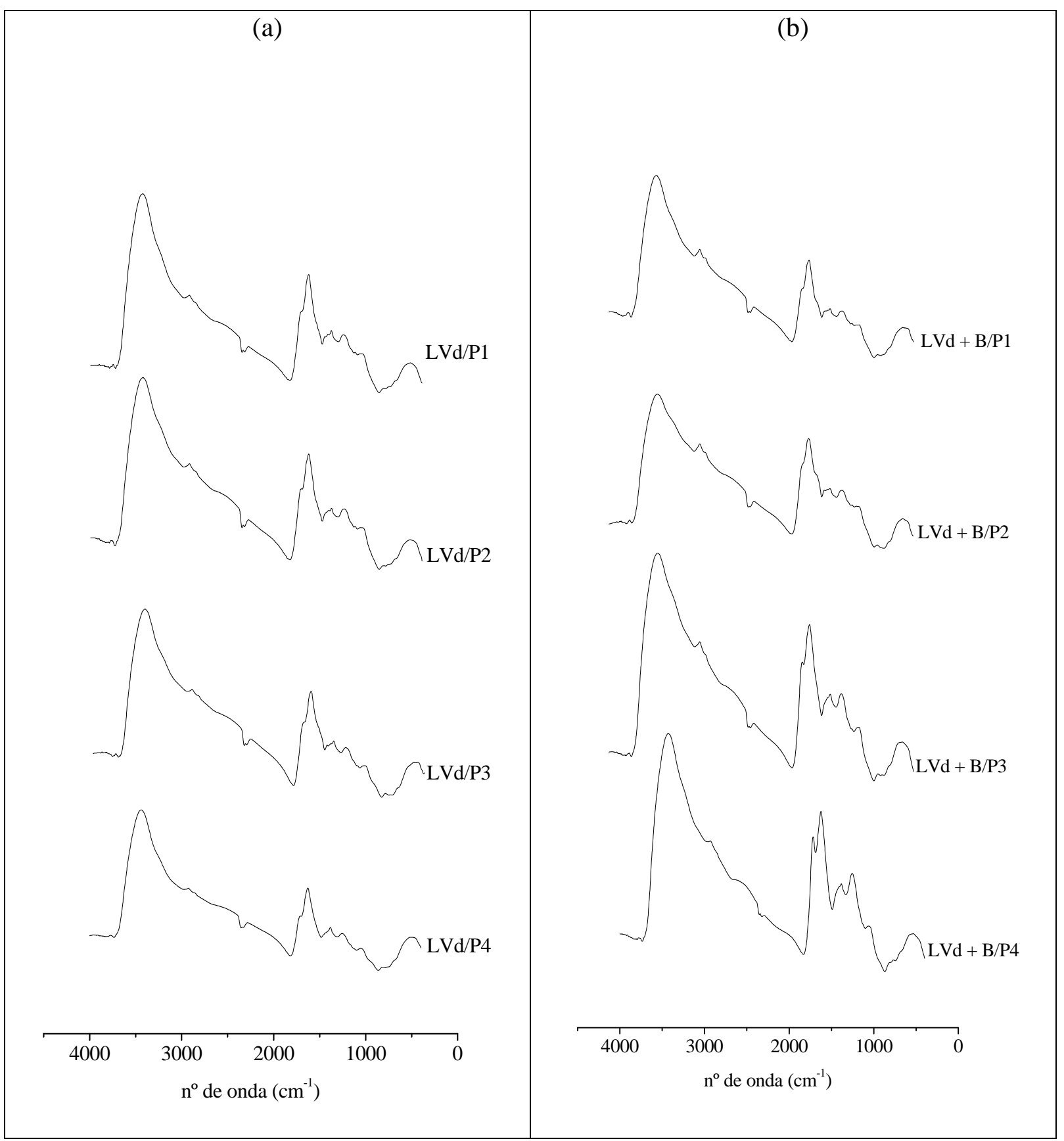

Figura 4.8 - Espectros de FTIR de ácidos húmicos extraídos do (a) LVd $\rightarrow$ sem adição de lodo de esgoto e (b) $\mathrm{LVd}+\mathrm{B} \rightarrow$ com adição de lodo de esgoto. As profundidades variam de 0-60 cm onde: $\mathrm{P} 1 \rightarrow$ 0-10; $\mathrm{P} 2 \rightarrow \mathbf{1 0}-20$; $\mathrm{P} 3 \rightarrow 20-40$ e P4 $\rightarrow$ 40-60 cm. 


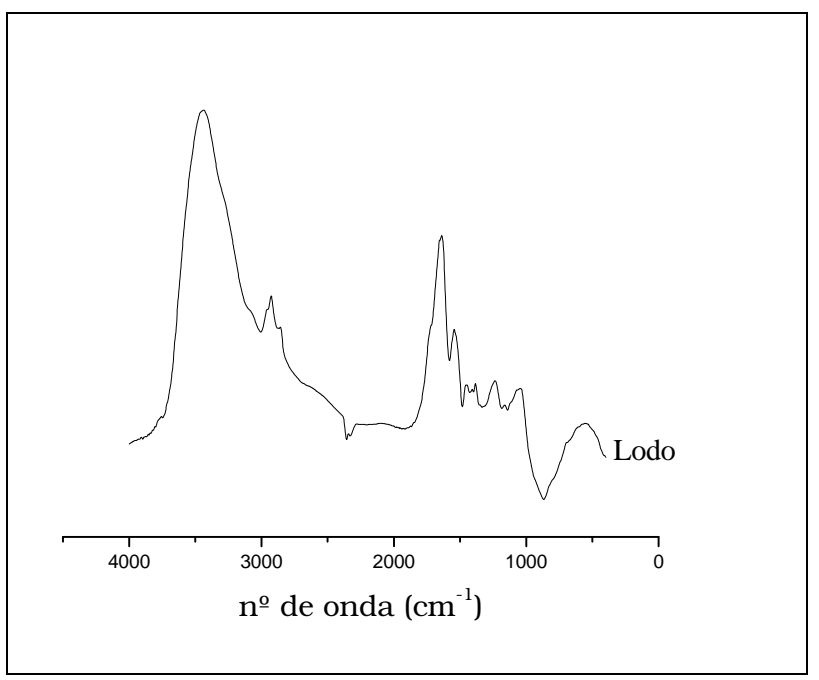

Figura 4.9 - Espectro de FTIR do ácido húmico extraído do lodo.

Foi observado nos espectros de FTIR uma banda intensa e larga na região de alta freqüência, entre 3600 a $3070 \mathrm{~cm}^{-1}$, atribuída a vibrações de estiramento $\mathrm{O}-\mathrm{H}$ de $\mathrm{H}$ ligado a grupos $\mathrm{OH}$ e, possivelmente, estiramento $\mathrm{N}-\mathrm{H}$, comprovando a presença abundante de grupos $\mathrm{OH}$ nos ácidos húmicos, sendo que, no lodo de esgoto, esta se apresentou-se mais pronunciada.

A presença de uma banda de absorção característica de vibrações assimétricas de grupos metileno e metil na região de 2918 a $2925 \mathrm{~cm}^{-1}$, indica a presença de cadeias alifáticas em ácidos húmicos, e comprova o baixo grau de humificação do ácido húmico extraído do lodo de esgoto. Notou-se que esta banda é mais intensa no ácido húmico extraído do lodo de esgoto e dos solos que receberam à adição do resíduo se comparada às bandas dos ácidos húmicos extraídos dos solos sem à adição de lodo de esgoto. Isto indica um alto grau de alifaticidade do ácidos húmicos extraído do lodo de esgoto e dos solos submetidos à adição do resíduo. A presença de grupos $\mathrm{C}-\mathrm{H}\left(\mathrm{CH}_{3}\right)$ pode ainda ser confirmada pela absorção em $1456 \mathrm{~cm}^{-1}$ (deformação $\mathrm{C}-\mathrm{H}$ dos $-\mathrm{CH}_{2} \mathrm{e}-\mathrm{CH}_{3}$ ). $\mathrm{Na}$ amostra do ácido húmico extraído do lodo de esgoto, e para as amostras que receberam à adição de lodo de esgoto foi observada uma absorção adicional em $2850 \mathrm{~cm}^{-1}$. Essa absorção também é atribuída a C-H alifático, só que característico de grupos $\mathrm{CH}_{2}$. 
Também foi observada uma banda de absorção em torno de 1646 a $1635 \mathrm{~cm}^{-1}$, que pode ser atribuída à presença do íon carboxilato (deformação axial assimétrica) (Canellas et al., 2001).

As absorções próximas de $1700 \mathrm{~cm}^{-1}$ correspondem a vibrações de $\mathrm{C}=\mathrm{O}$ de cetonas, quinonas e grupos COOH (Silverstein; Bassler; Morril, 1994). A conversão de COOH para $\mathrm{COO}^{-}$leva à perda de absorção em $1720 \mathrm{~cm}^{-1}\left(\mathrm{C}=\mathrm{O}\right.$ de $\mathrm{COOH}$ ) e $1230 \mathrm{~cm}^{-1}$ (estiramento $\mathrm{C}-\mathrm{O}$ e deformação $\mathrm{OH}$ de $\mathrm{COOH})$. Isso ocorre de duas maneiras: quando se neutraliza o composto e/ou se complexa com metal (Piccolo; Stevenson, 1982). Provavelmente, no ácido húmico a complexação com metal é a mais provável, visto que estes são provenientes de latossolos, solos que apresentam alta concentração de $\mathrm{Fe}^{3+}$, e ainda de solos que receberam à adição de lodo de esgoto. Esta perda da absorção foi evidenciada quando analisou-se o espectro do ácido húmico extraído do lodo de esgoto, que apresenta uma concentração de metais acentuada, se comparada aos demais ácidos húmicos extraídos dos solos que não receberam à adição de lodo de esgoto (Piccolo; Stevenson, 1982).

Também foi observado em todos os espectros um sinal de absorção na região de 1030 a $1035 \mathrm{~cm}^{-1}$, que pode ser atribuído à presença de carboidratos ou Si-O de impurezas silicatadas nos ácidos húmicos, visto que os sinais mais intensos nas amostras de ácido húmico extraídas do LVd se encontram naquelas que receberam à adição de lodo de esgoto. Esse sinal pode também ser referentes a deformação axial de $\mathrm{CO}$ de polissacarídeos.

A absorção compreendida na região de $500 \mathrm{~cm}^{-1}$ geralmente é atribuída à presença de impurezas minerais nas substâncias húmicas (Bloom; Leenheer, 1989).

\subsubsection{RMN}

Experimentos de ${ }^{13} \mathrm{C}$ RMN foram realizados, a fim de se obter informações sobre a composição de grupos funcionais, dos ácidos húmicos extraídos dos solos e do ácido húmico extraído do lodo de esgoto. 
As possíveis atribuições dos sinais foram baseadas no conhecimento acumulado pela ${ }^{13}$ C RMN em solos e ácidos húmicos nos trabalhos de (Wilson, 1984, 1987; Schnitzer; Preston, 1986; Preston et al., 1994a, 1994b, 1996; Kögel-Knaber, 1997; Schulten; Schnitzer, 1997; Veeman, 1997; Zech et al., 1997).

Os espectros na região do infravermelho para os ácidos húmicos extraídos dos solos LVef e LVd, submetidos ou não à adição de lodo de esgoto e do ácido húmico extraído do lodo de esgoto estão mostrados nas (Figuras 4.10, 4.11 e 4.12). 


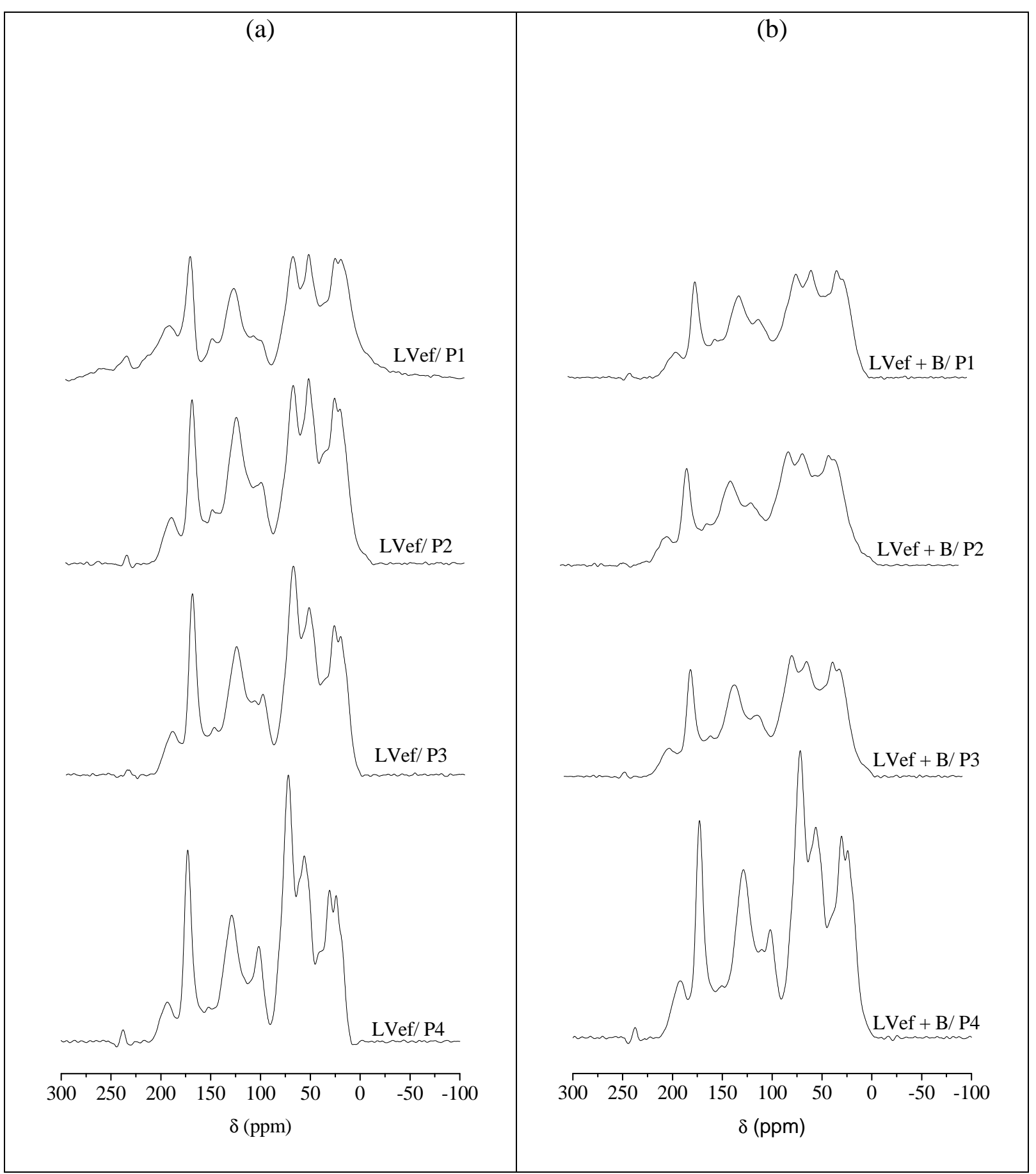

Figura 4.10 - Espectros de ${ }^{13} \mathrm{C}$ RMN de ácidos húmicos extraídos do (a) LVef $\rightarrow$ sem adição de lodo de esgoto e (b) LVef $+\mathrm{B} \rightarrow$ com adição de lodo de esgoto. As profundidades variam de 0-60 cm onde: P1 $\rightarrow$ 0-10; P2 $\rightarrow$ $10-20 ;$ P3 $\rightarrow$ 20-40 e P4 $\rightarrow 40-60 \mathrm{~cm}$. 


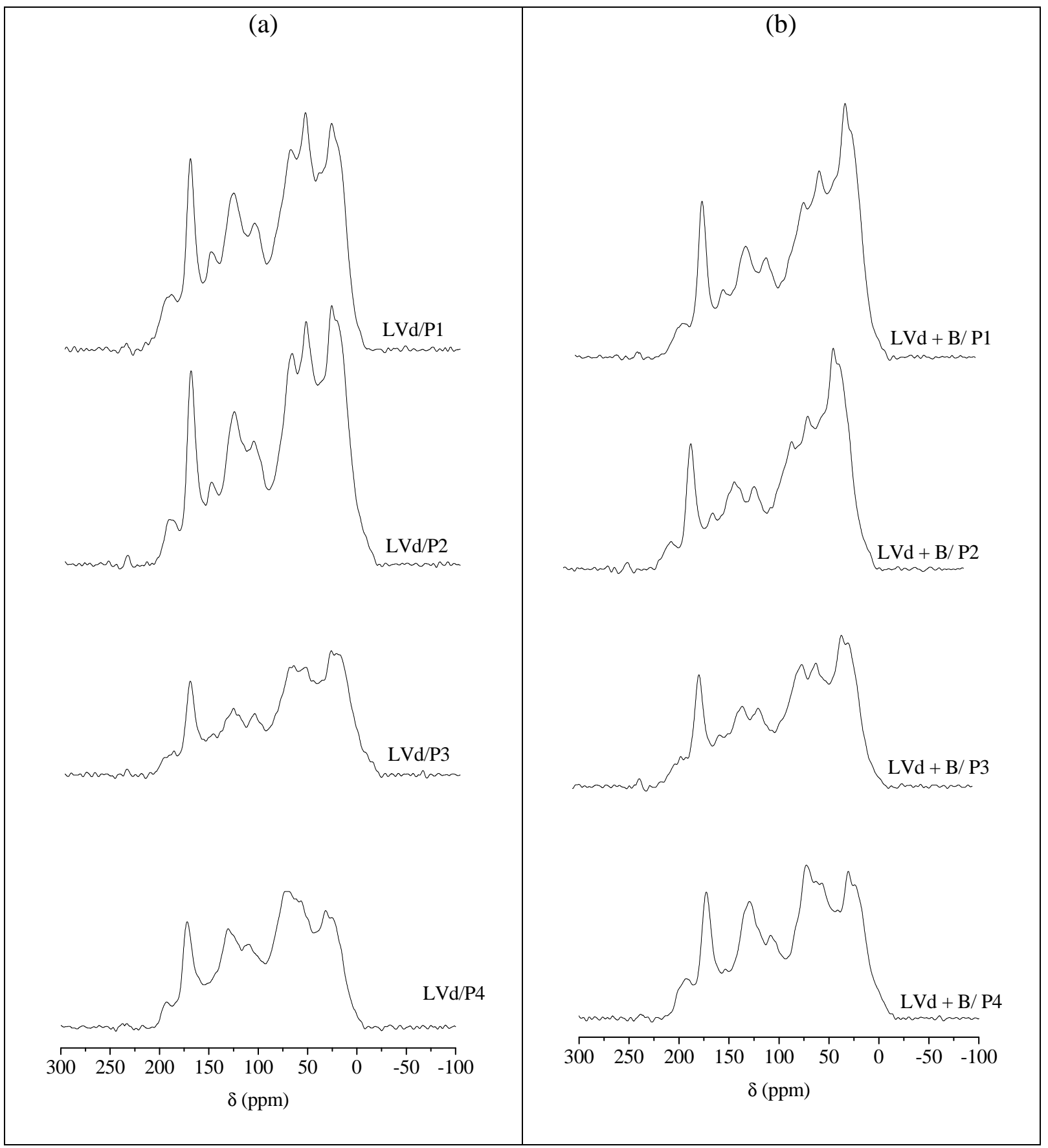

Figura 4.11 - Espectros de ${ }^{13} \mathrm{C}$ RMN de ácidos húmicos extraídos do (a) LVd $\rightarrow$ sem adição de lodo de esgoto e (b) $\mathrm{LVd}+\mathrm{B} \rightarrow$ com adição de lodo de esgoto. As profundidades variam de 0-60 cm onde: $\mathrm{P} 1 \rightarrow 0-10 ; \mathrm{P} 2 \rightarrow 10-$ $20 ; \mathrm{P} 3 \rightarrow 20-40$ e P4 $\rightarrow$ 40-60 cm. 


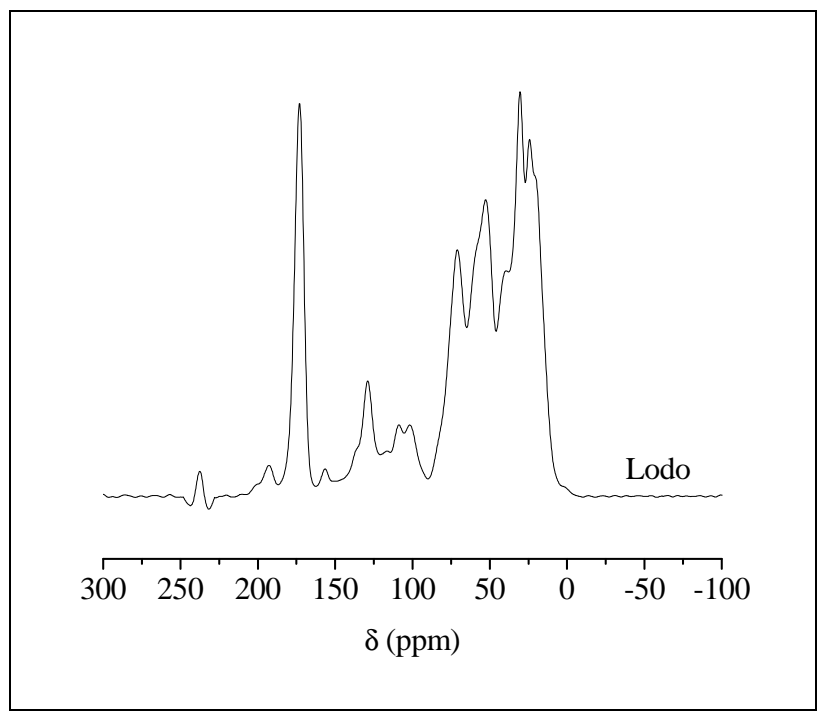

Figura 4.12 - Espectro de ${ }^{13} \mathrm{C}$ RMN do ácido húmico extraído do lodo.

Foram calculados os valores das áreas relativas das bandas nos espectros de ${ }^{13} \mathrm{C} R \mathrm{RN}$ das amostras de ácidos húmicos extraídos dos solos LVef e LVd, submetidos ou não à adição de lodo de esgoto, em diferentes profundidades e do ácido húmico extraído do lodo de esgoto (Tabela 4.5).

Tabela 4.5 - Intensidades relativas (porcentagem da área total) das bandas nos espectros de ${ }^{13} \mathrm{C}$ RMN com VACP-MAS de amostras sólidas de ácidos húmicos.

\begin{tabular}{c|c|c|c|c|c|c|c}
\hline Amostra $^{(1)}$ & $0-45$ & $45-60$ & $60-110$ & $110-140$ & $140-160$ & $160-185$ & $185-230$ \\
\hline LVef/ P1 & 27 & 11 & 21 & 14 & 5 & 11 & 11 \\
LVef/ P2 & 24 & 12 & 26 & 18 & 6 & 11 & 4 \\
LVef/ P3 & 21 & 12 & 29 & 16 & 5 & 12 & 4 \\
LVef/ P4 & 26 & 13 & 32 & 15 & 4 & 12 & 3 \\
LVef + B/ P1 & 25 & 12 & 27 & 16 & 6 & 11 & 3 \\
LVef + B/ P2 & 26 & 11 & 28 & 15 & 6 & 10 & 4 \\
LVef + B/ P3 & 25 & 12 & 27 & 16 & 6 & 11 & 4 \\
LVef + B/ P4 & 22 & 12 & 30 & 16 & 5 & 12 & 4 \\
LVd/ P1 & 25 & 12 & 27 & 15 & 7 & 10 & 4 \\
LVd/ P2 & 30 & 12 & 26 & 14 & 6 & 10 & 3 \\
LVd/ P3 & 31 & 11 & 27 & 13 & 6 & 10 & 3 \\
LVd/ P4 & 23 & 11 & 31 & 16 & 6 & 10 & 2 \\
LVd + B/ P1 & 33 & 12 & 23 & 13 & 6 & 10 & 3 \\
LVd + B/ P2 & 35 & 12 & 24 & 12 & 5 & 9 & 2 \\
LVd + B/ P3 & 29 & 11 & 27 & 14 & 6 & 10 & 3 \\
LVd + B/ P4 & 25 & 10 & 28 & 16 & 6 & 11 & 4 \\
Lodo & 39 & 16 & 22 & 7 & 2 & 13 & 1 \\
\hline
\end{tabular}

${ }^{(1)}$ LVef $\rightarrow$ (sem adição de lodo de esgoto), LVd $\rightarrow$ (sem adição de lodo de esgoto), e + B refere-se aos mesmos solos tratados com lodo de esgoto, Lodo $\rightarrow$ ácido húmico extraído do lodo de esgoto. As profundidades variam de 0-60 cm onde: $\mathrm{P} 1 \rightarrow 0-10 ; \mathrm{P} 2 \rightarrow$ 10-20; P3 $\rightarrow$ 20-40 e P4 $\rightarrow$ 40-60 cm. 
De modo geral, foram observados na região de $\mathrm{C}$ alifáticos $\left(-\mathrm{CH}_{2},-\mathrm{CH}_{3}\right)$, entre $0-45$ ppm, valores mais acentuados para o LVd em comparação com o LVef (Tabela 4.5). Com isso, os maiores valores encontrados correspondem ao LVd $+\mathrm{B} / \mathrm{P} 1(33 \%)$ e $\mathrm{LVd}+\mathrm{B} / \mathrm{P} 2$ (35\%), amostras estas extraídas de solos de superfície $(\mathrm{P} 1 \rightarrow 0-10 \mathrm{~cm}$ e P2 $\rightarrow$ 10-20 cm), submetidas à adição de lodo de esgoto. Este aumento de carbono alifático durante a humificação pode ser explicado pelo enriquecimento de lipídeos extraíveis ou derivados biopoliméricos de plantas e biomacromoléculas alifáticas não saponificáveis da planta e origem microbiana, encontrados em maior concentração na superfície do solo.

Na região dos alifáticos, entre 45-110 ppm, metoxil e N-alifáticos (45-60 ppm) e Oalifáticos (60-110 ppm), não foram observadas diferenças significativas.

Na região de aromáticos, entre 110-160 ppm, foram observados valores mais intensos para os ácidos húmicos extraídos das amostras de solo, se comparados aos extraído do lodo de esgoto, conforme os valores da (Tabela 4.5). Foi observada diferença de até $50 \%$ entre os ácidos húmicos extraídos dos solo com o extraído do lodo de esgoto, o que explica a variação destes grupos aromáticos após à adição de lodo de esgoto.

Observando a região entre 160-185 ppm, região esta que representa basicamente a ressonância do carbono carboxílico, foi detectado um pico bastante evidenciado na estrutura do ácido húmico extraído do lodo de esgoto, porém este se manteve constante, quando foram analisados os ácido húmico extraídos do solo. 
Tabela 4.6 - Grau de Aromaticidade e Alifaticidade de amostras sólidas de ácidos húmicos extraídos dos solos e do lodo de esgoto.

\begin{tabular}{c|c|c}
\hline Amostra $^{(1)}$ & Aromaticidade (\%) & Alifaticidade (\%) \\
\hline LVef/ P1 & 25 & 75 \\
LVef/ P2 & 27 & 73 \\
LVef/ P3 & 26 & 74 \\
LVef/ P4 & 23 & 77 \\
LVef + B/ P1 & 26 & 74 \\
LVef + B/ P2 & 25 & 75 \\
LVef + B/ P3 & 26 & 74 \\
LVef + B/ P4 & 25 & 75 \\
LVd/ P1 & 25 & 76 \\
LVd/ P2 & 23 & 77 \\
LVd/ P3 & 21 & 79 \\
LVd/ P4 & 26 & 74 \\
LVd + B/ P1 & 21 & 79 \\
LVd + B/ P2 & 20 & 80 \\
LVd + B/ P3 & 23 & 77 \\
LVd + B/ P4 & 26 & 74 \\
Lodo & 11 & 89 \\
\hline
\end{tabular}

${ }^{(1)}$ LVef $\rightarrow$ (sem adição de lodo de esgoto), LVd $\rightarrow$ (sem adição de lodo de esgoto), + B refere-se aos mesmos solos tratados com lodo de esgoto e Lodo $\rightarrow$ ácido húmico extraído do lodo de esgoto. As profundidades variam de $0-60 \mathrm{~cm}$ onde: $\mathrm{P} 1 \rightarrow 0-10 ; \mathrm{P} 2 \rightarrow 10-20 ; \mathrm{P} 3 \rightarrow 20-40$ e P4 $\rightarrow$ 40-60 cm.

As medidas de ${ }^{13} \mathrm{C}$ RMN com VACP-MAS mostraram que os ácidos húmicos são bastante alifáticos (alto conteúdo de O-Alquil-C e Alquil C) em comparação ao conteúdo de aromáticos (Tabela 4.6).

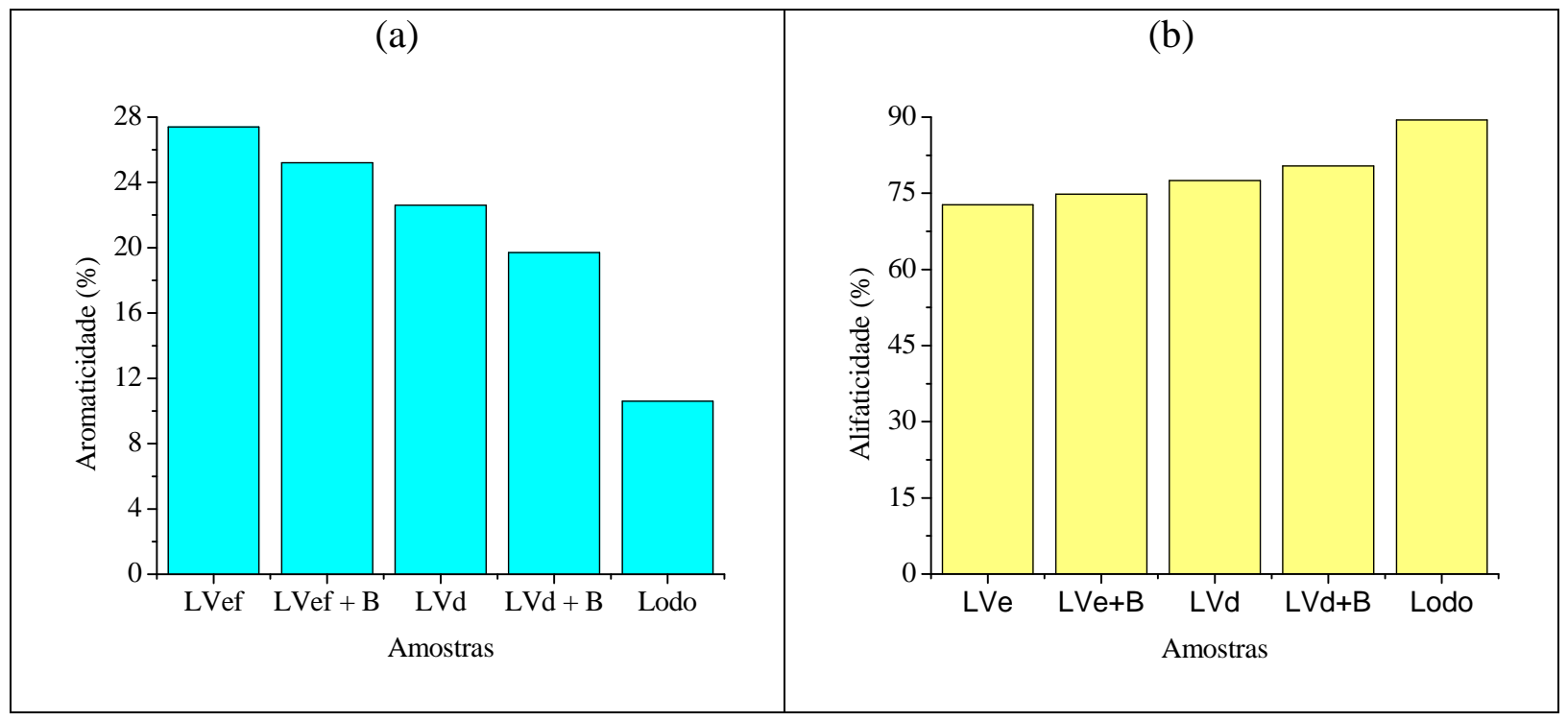

Figura 4.13 - Gráfico da (a) Aromaticidade e (b) Alifaticidade das amostras de ácido húmico extraídas dos solos LVef $\rightarrow$ sem adição de lodo de esgoto, LVd $\rightarrow$ sem adição de lodo de esgoto, + B refere-se aos mesmos solos tratados com lodo de esgoto e Lodo $\rightarrow$ ácido húmico extraído do lodo de esgoto. Na profundidade de 10-20 cm. 
De forma similar aos resultados obtidos por (González-Pérez et al., 2004), foi observado uma variação de 20 a $27 \%$ no grau de aromaticidade para os ácidos húmicos extraídos dos solos (Tabela 4.6). Entretanto, o grau de aromaticidade é menos acentuado (11\%) para o ácido húmico extraído do lodo de esgoto. Isto mostra que o ácido húmico do lodo de esgoto é menos humificado se comparado aos ácidos húmicos dos solos, evidenciando, assim, a alta percentagem de alifáticos, cerca de $89 \%$. Estes resultados estão de acordo com o que foi observado por meio da FTIR, onde o ácido húmico extraído do lodo de esgoto apresentou maior alifaticidade se comparado aos extraídos do solo.

A adição do lodo de esgoto promoveu decréscimo na quantidade de carbonos aromáticos. Contudo, os resultados obtidos mostraram que essa diminuição do grau de aromaticidade após a adição de lodo de esgoto foi verificada em superfície $(0-10 \mathrm{~cm})$ apenas para o LVd e em profundidade de $(10-20 \mathrm{~cm})$ para o LVef e LVd (Figura 4.13).

\subsubsection{RPE}

O sinal do radical livre orgânico das substâncias húmicas, detectável por RPE, é atribuído a radicais livres do tipo semiquinona. Quanto maior a concentração de radicais livres do tipo semiquinona, maior a humificação da matéria orgânica (Senesi, 1990; MartinNeto et al., 1991, 1998). Normalmente a maior humificação está relacionada à formação de compostos mais aromáticos (Kögel-Knaber; Zech; Hatcher, 1991). 
Tabela 4.7 - Concentração de radicais livres do tipo semiquinona e largura de linha das amostras de ácidos húmicos extraídos dos solos, LVef e LVd e do lodo de esgoto, fornecida por RPE.

\begin{tabular}{c|c|c}
\hline Amostra $^{(1)}$ & $\begin{array}{c}\text { Radicais livres do tipo semiquinona } \\
\text { spins } \mathrm{g}^{-1} \text { de C }\left(10^{17}\right)\end{array}$ & $\begin{array}{c}\text { Largura de linha } \\
\text { Gauss }\end{array}$ \\
\hline LVef/ P1 & $4,39 \pm 0,25$ & $4,74 \pm 0,07$ \\
LVef/ P2 & $7,84 \pm 0,04$ & $4,23 \pm 0,04$ \\
LVef/ P3 & $6,29 \pm 0,03$ & $4,55 \pm 0,10$ \\
LVef/ P4 & $8,21 \pm 0,12$ & $4,55 \pm 0,06$ \\
LVef + B/ P1 & $3,26 \pm 0,09$ & $5,11 \pm 0,17$ \\
LVef + B/ P2 & $3,56 \pm 0,06$ & $5,21 \pm 0,04$ \\
LVef + B/ P3 & $4,24 \pm 0,10$ & $4,96 \pm 0,10$ \\
LVef + B/ P4 & $6,95 \pm 0,14$ & $4,69 \pm 0,07$ \\
LVd/ P1 & $2,33 \pm 0,20$ & $4,94 \pm 0,28$ \\
LVd/ P2 & $2,44 \pm 0,11$ & $4,79 \pm 0,07$ \\
LVd/ P3 & $1,05 \pm 0,08$ & $5,09 \pm 0,13$ \\
LVd/ P4 & $1,63 \pm 0,03$ & $5,08 \pm 0,10$ \\
LVd + B/ P1 & $1,40 \pm 0,01$ & $5,01 \pm 0,03$ \\
LVd + B/ P2 & $0,98 \pm 0,07$ & $4,90 \pm 0,29$ \\
LVd + B/ P3 & $1,23 \pm 0,03$ & $5,13 \pm 0,10$ \\
LVd + B/ P4 & $1,58 \pm 0,14$ & $3,67 \pm 0,74$ \\
Lodo & $1,32 \pm 0,01$ & $5,87 \pm 0,06$ \\
\hline
\end{tabular}

${ }^{(1)}$ LVef $\rightarrow$ (sem adição de lodo de esgoto), LVd $\rightarrow$ (sem adição de lodo de esgoto), + B refere-se aos mesmos solos tratados com lodo de esgoto e Lodo $\rightarrow$ ácido húmico extraído do lodo de esgoto. As profundidades variam de $0-60 \mathrm{~cm}$ onde: $\mathrm{P} 1 \rightarrow 0-10 ; \mathrm{P} 2 \rightarrow 10-20 ; \mathrm{P} 3 \rightarrow 20-40$ e P4 $\rightarrow 40-60 \mathrm{~cm}$.

Foi observado a partir dos resultados obtidos que a incorporação de lodo de esgoto alterou significativamente a concentração de radicais livres do tipo semiquinona nos dois solos tratados, LVef e LVd (Figura 4.14). Foi observada uma redução de mais de $50 \%$ na concentração de radicais livres do tipo semiquinona para os solos submetidos à adição de lodo de esgoto, quando comparada aos solos sem à adição, essa diminuição contudo, é mais acentuada nas primeiras camadas do solo e menos acentuada em profundidade, visto que o resíduo foi aplicado e incorporado na camada de 0-10 cm (Tabela 4.7). Apesar dessa técnica não demonstrar o comportamento linear ao longo do perfil do solo observado pela demais técnicas espectroscópicas, vemos a partir dos resultados obtidos por RPE uma maior sensibilidade com isso, uma variação mais significativa devido a adição do lodo de esgoto ao solo. 


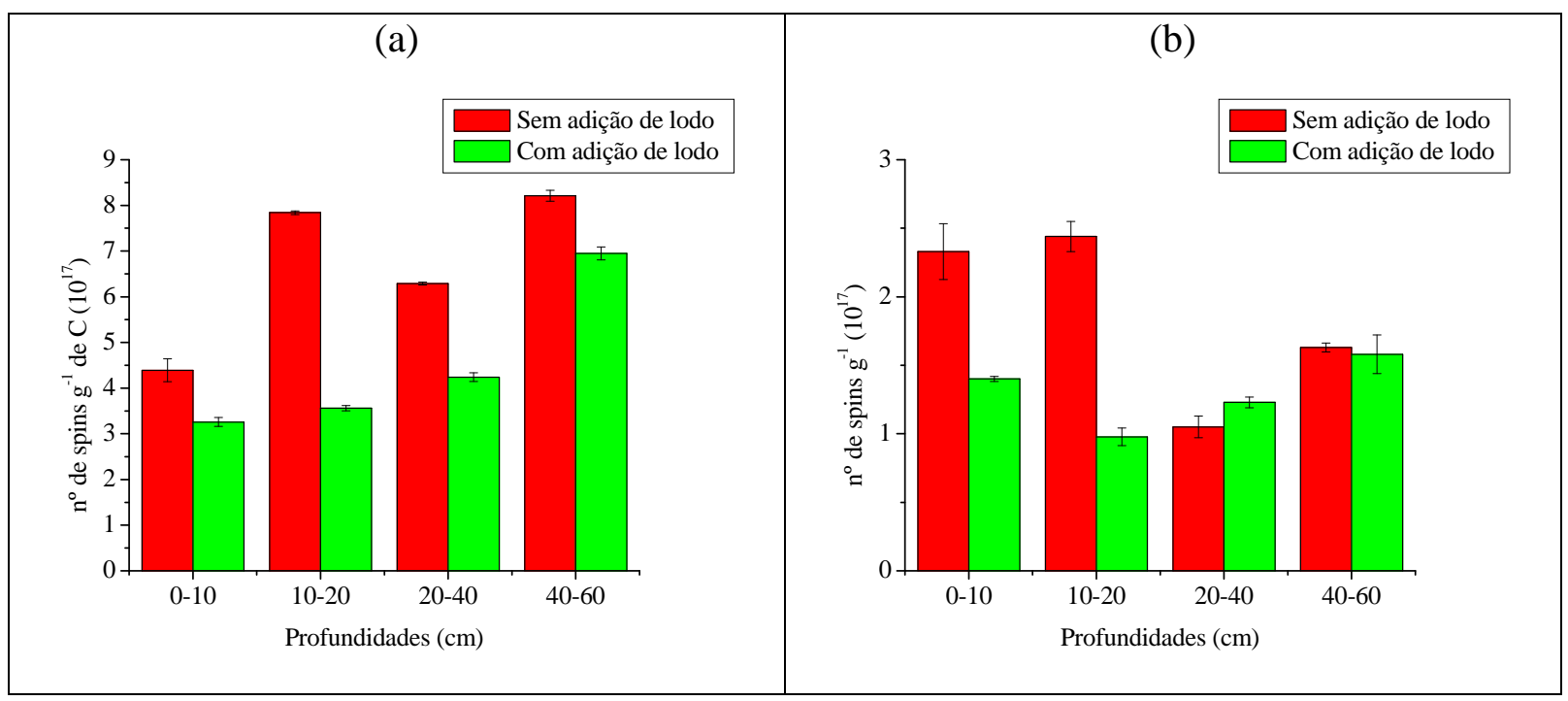

Figura 4.14 - Nível de radical livre do tipo semiquinona em spins $\mathrm{g}^{-1}$ de carbono obtidos para os ácidos húmicos extraídos do (a) LVef sem e com adição de lodo de esgoto e (b) LVd sem e com adição de lodo de esgoto, em diferentes profundidades.

A partir dos resultados obtidos para a concentração de radicais livres do tipo semiquinona (Tabela 4.7), foi observado em média, uma concentração maior desses no LVef se comparado ao LVd, indicando que o LVef apresenta-se como mais humificado se comparado ao LVd. Parte desse comportamento pode ser atribuído a diferença textural significativa apresentada pelos solos, sendo o LVef um solo argiloso, com teores maiores de carbono observados através da determinação de TOC, se comparado ao LVd que apresenta uma textura arenosa (Figura 4.2).

Características adicionais dos radicais livres do tipo semiquinona podem ser obtidas usando a largura de linha do sinal de RPE (Poole; Farach, 1972; Martin-Neto et al., 2001). Segundo Martin-Neto et al. (2001), mostraram que a largura de linha dos radicais livres do tipo semiquinona diminuiu com a diminuição do pH para os Latossolos e ácidos húmicos de turfa, fornecendo evidências de que o tempo de relaxação do estado excitado do sinal semiquinona dessas substâncias húmicas é maior em $\mathrm{pH}$ ácido. Esses resultados, em termos, significam que para pH ácido, há ambiente molecular (sítios hidrofóbicos), os quais tem sua formação desfavorecida com pH básico devido as mudanças conformacionais (induzida pela desprotonação de grupos funcionais ácidos). Nesse ambiente, em pH ácido a interação com o 
meio externo é menos efetiva, resultando no aumento do tempo de relaxação do radical livre do tipo semiquinona.

Os dados de Martin-Neto et al. (2001) e Sposito, Martin-Neto e Yang (1996) também evidenciam que, geralmente amostras de ácido húmico com maior concentração de radicais livres do tipo semiquinona são associadas a sinais com menor largura de linha, devido ao maior grau de humificação e radicais mais protegidos com relação ao meio externo.

Corroborando com Martin-Neto et al. (2001) e Sposito, Martin-Neto e Yang (1996), a partir dos resultados foi verificado que o ácido húmico com maior grau de humificação, e com maior concentração de radicais livres do tipo semiquinona, apresenta menor largura de linha (Tabela 4.7). Se comparado os valores obtidos para a largura de linha dos ácidos húmicos analisados (ácido húmico extraído do lodo de esgoto e ácidos húmicos extraídos dos solos, LVef e LVd) o maior valor encontrado da largura de linha $(5,9 \pm 0,1)$ foi para o ácido húmico extraído do lodo de esgoto (Tabela 4.7), comprovando assim, o seu baixo grau de humificação, visto que este apresenta um dos menores níveis de radicais livres do tipo semiquinona $1,32 \times 10^{17}$ spins $^{-1}$ de carbono.

Podemos observar a partir dos resultados obtidos, um aumento do valor da largura de linha com à adição do lodo de esgoto para o LVef, essa diminuição do grau de humificação dos ácidos húmicos pode ser atribuída à incorporação de compostos menos humificados procedentes do lodo de esgoto, com maiores conteúdos de hidrogênio como mostra a análise elementar (Tabela 4.1).

\subsubsection{Fluorescência}

A fluorescência tem sido amplamente reconhecida como uma técnica relativamente simples, sensível e útil para o estudo estrutural e funcional relativo as amostras tal como o ácido húmico. 
As principais vantagens desta técnica são, a alta sensibilidade e seletividade, pois somente aqueles grupos funcionais que fluorescem podem ser observados. Com isso, o uso da técnica de fluorescência nos estudos sobre substâncias húmicas está apoiado pela presença estável de várias estruturas fluorescentes intrínsecas a molécula húmica e a seus precursores, particularmente anéis aromáticos, fenóis e grupos quinona (Senesi et al., 1991).

Os espectros de fluorescência das substâncias húmicas são constituídos pela soma dos espectros dos diferentes tipos de fluoróforos presentes nelas, consequiência da complexidade molecular e heterogeneidade das mesmas.

Experimentos de fluorescência foram realizados, baseados nas metodologias sugeridas na literatura (Zsolnay et al., 1999; Milori et al., 2002; Kalbitz, Geyer, Geyer, 1999), a fim de se obter informações sobre a humificação das substâncias húmicas.

\subsection{Espectros de emissão}

Os espectros de emissão foram medidos com excitação em $240 \mathrm{~nm}$ e $465 \mathrm{~nm}$. Através desses espectros, foi calculado o grau de humificação das amostras usando as metodologias propostas por (Zsolnay et al., 1999; Milori et al., 2002), respectivamente. 


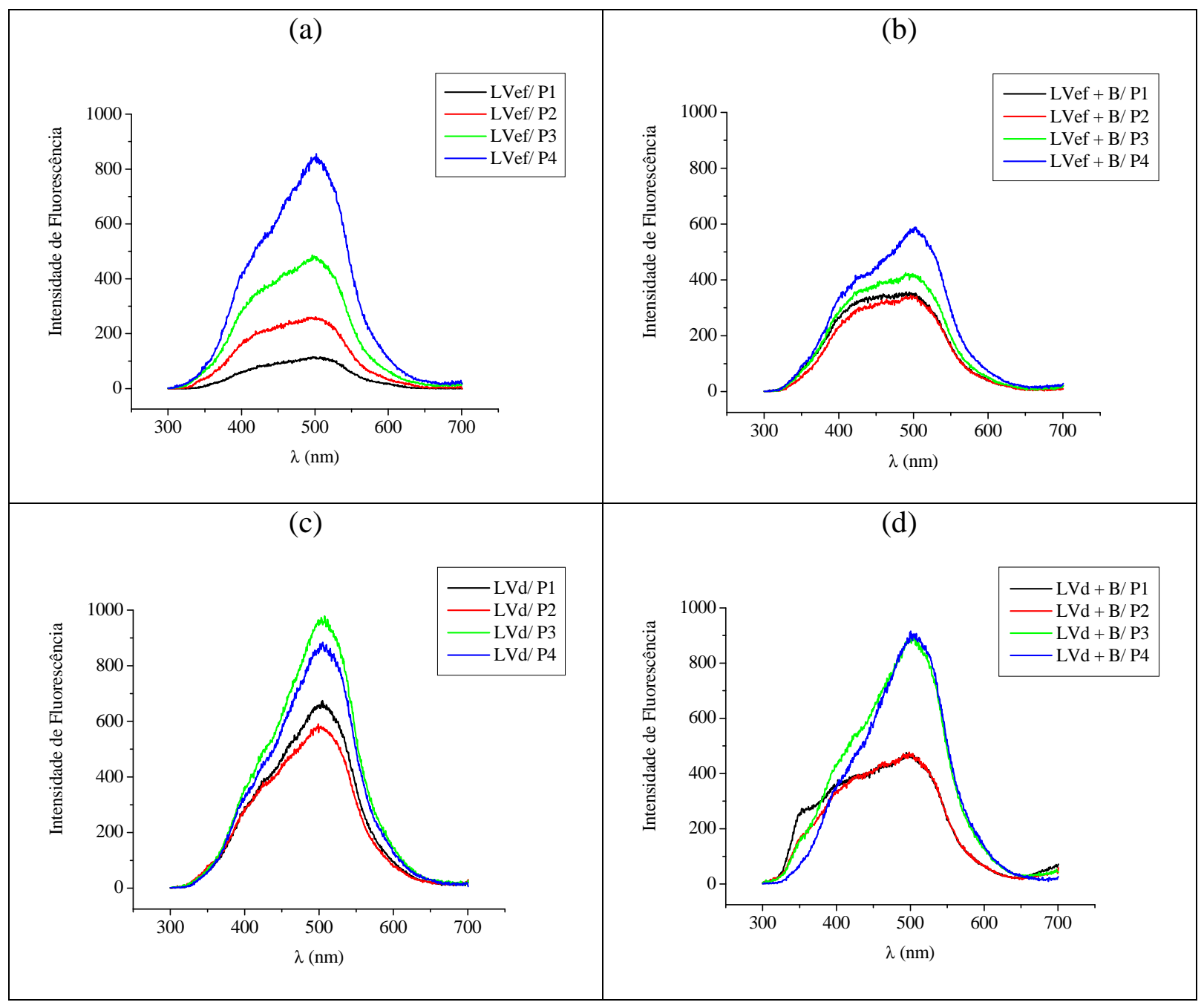

Figura 4.15 - Espectros de emissão de fluorescência $(\lambda \operatorname{exc}=240 \mathrm{~nm}$ ) de ácidos húmicos extraídos do (a) LVef $\rightarrow$ sem adição de lodo de esgoto, (b) LVef $+\mathrm{B} \rightarrow$ com adição de lodo de esgoto, (c) LVd $\rightarrow$ sem adição de lodo de esgoto e $(\mathrm{d}) \mathrm{LVd}+\mathrm{B} \rightarrow$ com adição de lodo de esgoto. As profundidades variam de 0-60 cm onde: $\mathrm{P} 1 \rightarrow \mathbf{0 -}$ $10 ; \mathrm{P} 2 \rightarrow 10-20 ; \mathrm{P} 3 \rightarrow 20-40$ e P4 $\rightarrow$ 40-60 cm.

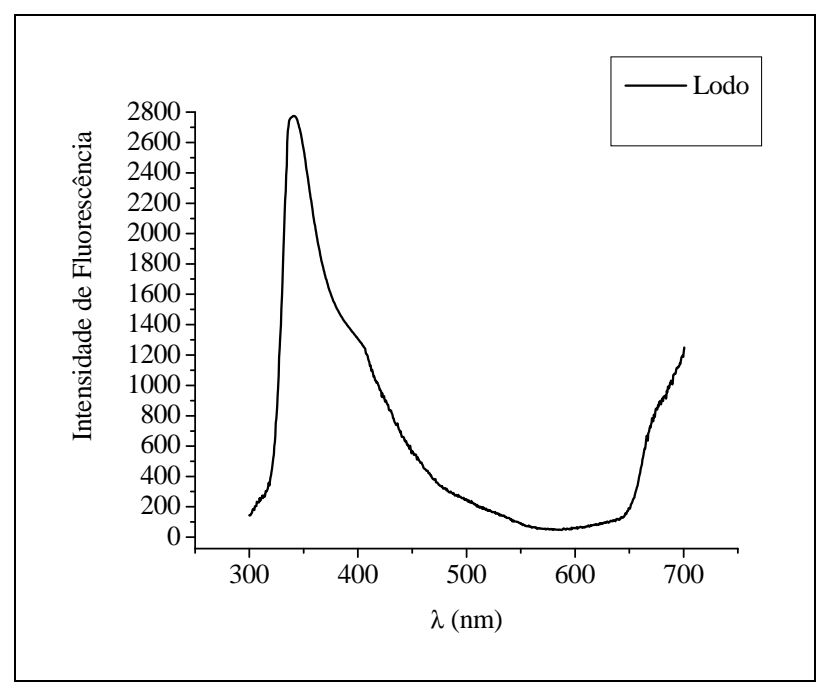

Figura 4.16 - Espectro de emissão de fluorescência $(\lambda \operatorname{exc}=240 \mathrm{~nm})$ do ácido húmico extraído do lodo de esgoto. 
Foi observado que o máximo de emissão para os ácidos húmicos extraídos dos solos está em torno de $500 \mathrm{~nm}$ porém, o ácido húmico extraído do lodo de esgoto apresentou esse em $341 \mathrm{~nm}$ (Figuras 4.15 e 4.16).

A partir dos espectros de emissão (Figuras 4.15 e 4.16), foi observado para as os ácidos húmicos extraídos dos solos submetidos à adição de lodo de esgoto, o aparecimento de uma banda próxima a $341 \mathrm{~nm}$, semelhante a banda apresentada pelo ácido húmico extraído do lodo de esgoto, essa pode ser decorrente da presença de estruturas aromáticas simples, como quinonas e estruturas não condensadas, prováveis no resíduo pouco humificado.

Foi observada uma intensidade de fluorescência maior para os ácidos húmicos extraídos do LVd se comparadas ao LVef (Figura 4.15), esse pode estar relacionado as diferenças texturais apresentadas por estes solos, visto que o maior conteúdo de argila no LVef pode favorecer a estabilidade da matéria orgânica humificada por meio da formação de complexos organominerais, tornando a matéria orgânica relativamente mais protegida da degradação microbiana (Canellas et al., 2001), com isso, teores maiores de carbono e menor grau de humificação são observados através da fluorescência para este solo, se comparado ao LVd que apresenta uma textura arenosa.

A fluorescência de ácidos húmicos em comprimentos de onda longos, como neste caso, é associada a sistemas insaturados conjugados (hidrocarbonetos aromáticos condensados tipo tetraceno de estrutura linear ou pirileno de estrutura cíclica), e/ou a núcleos aromáticos altamente substituídos por C=O e COOH (Lumb, 1978; Senesi, 1992; Rivero et al., 1998; Olk, Brunetti, Senesi, 1999).

A proposta de (Zsolnay et al., 1999) é que, se as moléculas fluorescentes tornam-se mais condensadas, seus espectros de emissão, com excitação em $240 \mathrm{~nm}$ e com intervalo de varredura entre 300 e $700 \mathrm{~nm}$, tenderão a exibir um deslocamento sobre comprimentos de onda maiores. Zsolnay et al. (1999), obteve essas conclusões excitando diferentes amostras com radiação ultravioleta em $240 \mathrm{~nm}$. A partir desses, observou no espectro de emissão da 
matéria orgânica dissolvida, um deslocamento para comprimentos de ondas maiores, demonstrando progresso no processo de humificação. Deste modo, segundo (Zsolnay et al., 1999) a área sobre o maior quarto da emissão $(570-641 \mathrm{~nm})$ dividido pela área do menor quarto (356-432 nm), denominado $\mathrm{A}_{4} / \mathrm{A}_{1}$, pode ser usada como índice de humificação.

Tabela 4.8 - Dados referentes ao índice de humificação proposto por Zsolnay.

\begin{tabular}{c|c|c|c}
\hline Amostra $^{(1)}$ & $\mathrm{A}_{4}$ & $\mathrm{~A}_{1}$ & $\mathrm{~A}_{4} / \mathrm{A}_{1}\left(10^{-2}\right)$ \\
\hline LVef/ P1 & 1947 & 9768 & $20 \pm 6$ \\
LVef/ P2 & 2756 & 13370 & $21 \pm 2$ \\
LVef/ P3 & 3605 & 14187 & $25 \pm 3$ \\
LVef/ P4 & 7073 & 23145 & $31 \pm 2$ \\
LVef + B/ P1 & 2888 & 18239 & $16 \pm 1$ \\
LVef + B/ P2 & 2974 & 17081 & $17 \pm 1$ \\
LVef + B/ P3 & 2952 & 14818 & $20 \pm 3$ \\
LVef + B/ P4 & 5386 & 23044 & $23 \pm 1$ \\
LVd/ P1 & 6955 & 20546 & $34 \pm 2$ \\
LVd/ P2 & 5091 & 15438 & $33 \pm 4$ \\
LVd/ P3 & 9958 & 23281 & $43 \pm 1$ \\
LVd/ P4 & 8697 & 20501 & $42 \pm 1$ \\
LVd + B/ P1 & 4421 & 26065 & $17 \pm 1$ \\
LVd + B/ P2 & 4462 & 23259 & $19 \pm 1$ \\
LVd + B/ P3 & 8871 & 28800 & $31 \pm 1$ \\
LVd + B/ P4 & 8984 & 21478 & $42 \pm 1$ \\
Lodo & 5327 & 105547 & $5 \pm 1$ \\
\hline
\end{tabular}

${ }^{(1)}$ LVef $\rightarrow$ (sem adição de lodo de esgoto), LVd $\rightarrow$ (sem adição de lodo de esgoto), + B refere-se aos mesmos solos tratados com lodo de esgoto e Lodo $\rightarrow$ ácido húmico extraído do lodo de esgoto. As profundidades variam de 0-60 cm onde: $\mathrm{P} 1 \rightarrow 0-10 ; \mathrm{P} 2 \rightarrow$ 10-20; P3 $\rightarrow$ 20-40 e P4 $\rightarrow$ 40-60 cm.

A partir dos resultados obtidos para o índice de humificação proposto por (Zsolnay et al., 1999) (Tabela 4.8), foi observado uma diminuição gradual com à adição de lodo de esgoto ao solo (Figura 4.17), tanto para o LVef como para o LVd, sendo o menor valor encontrado do índice de humificação para o ácido húmico extraído do lodo de esgoto, comprovando assim, o baixo grau de humificação do resíduo. 


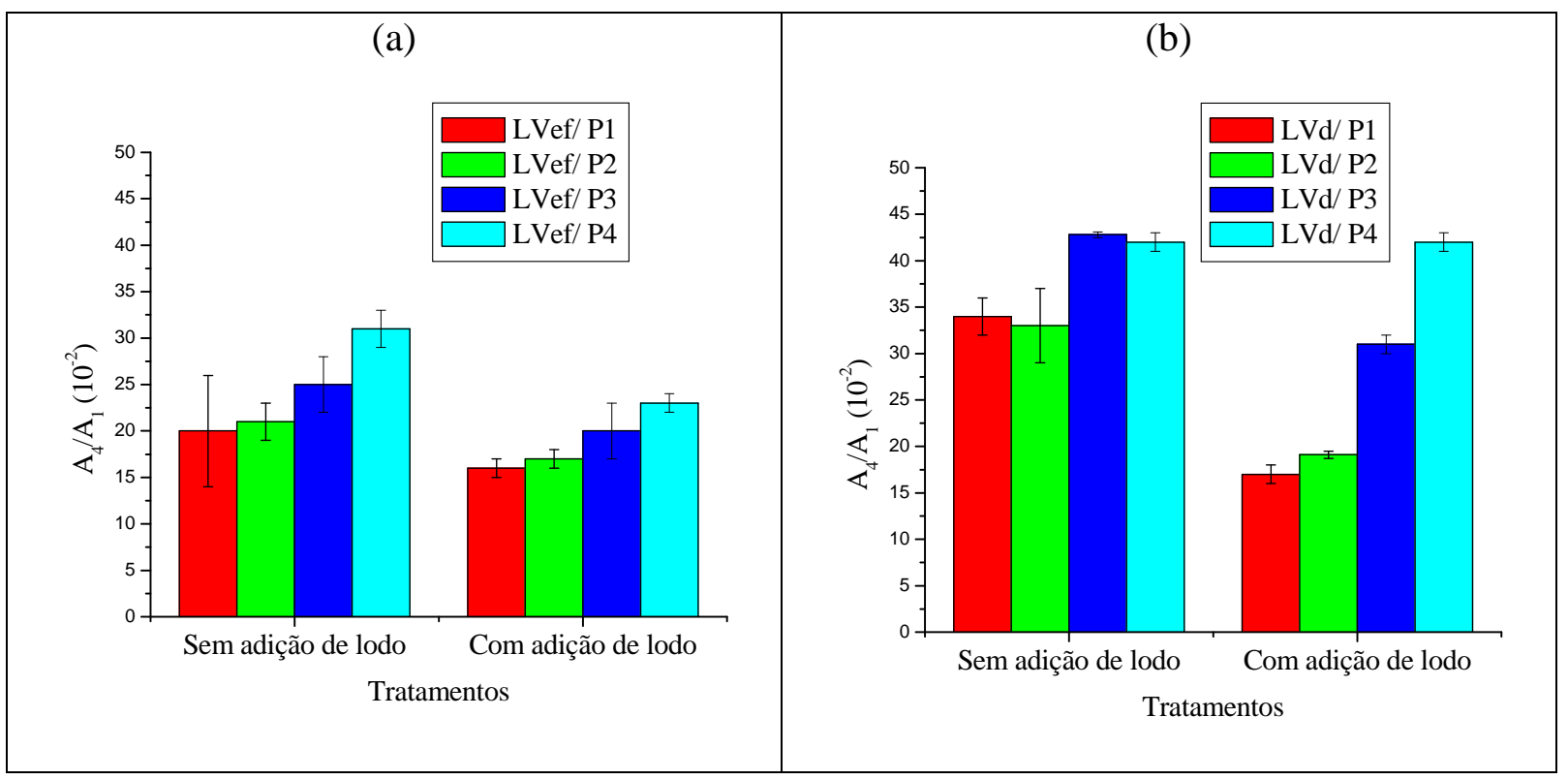

Figura 4.17 - Valores do índice de humificação obtidos para os ácidos húmicos extraídos dos solos, (a) LVef sem e com adição de lodo de esgoto e (b) LVd sem e com adição de lodo de esgoto. As profundidades variam de 0-60 cm onde: $\mathrm{P} 1 \rightarrow 0-10 ; \mathrm{P} 2 \rightarrow 10-20 ; \mathrm{P} 3 \rightarrow 20-40$ e P4 $\rightarrow$ 40-60 cm.

A metodologia proposta por (Milori et al., 2002), mede o espectro de emissão com excitação em 465 nm e intervalo de varredura entre 480 e $700 \mathrm{~nm}$. Essa absorção é mais ressonante com estruturas cuja concentração aumenta com o grau de humificação de amostras em ácidos húmicos. Segundo (Milori et al., 2002), a área total sobre o espectro de fluorescência resultante da luz de excitação azul, feita nas mesmas condições experimentais (concentração de 20 ppm, $\mathrm{pH}=8,0$ ) é proporcional ao grau de humificação e será denominada de índice de humificação $\mathrm{A}_{465}$. 


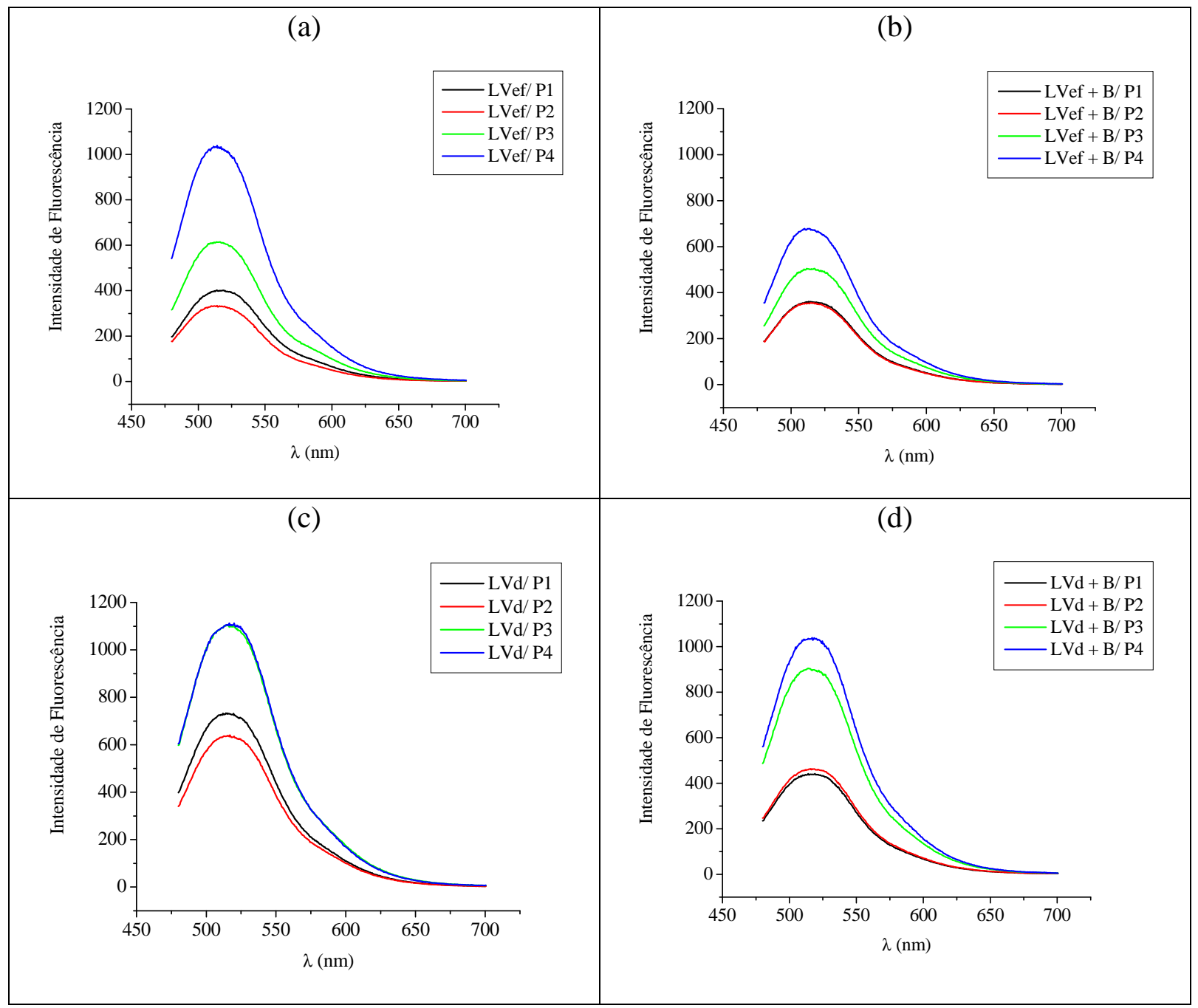

Figura 4.18 - Espectros de emissão de fluorescência $(\lambda$ exc $=465 \mathrm{~nm})$ de ácidos húmicos extraídos do (a) LVef $\rightarrow$ sem adição de lodo de esgoto, (b) LVef $+\mathrm{B} \rightarrow$ com adição de lodo de esgoto, (c) LVd $\rightarrow$ sem adição de lodo de esgoto e (d) $\mathrm{LVd}+\mathrm{B} \rightarrow$ com adição de lodo de esgoto. As profundidades variam de $0-60 \mathrm{~cm}$ onde: $\mathrm{P} 1 \rightarrow 0$ $10 ; \mathrm{P} 2 \rightarrow 10-20 ; \mathrm{P} 3 \rightarrow 20-40$ e $\mathrm{P} 4 \rightarrow 40-60 \mathrm{~cm}$.

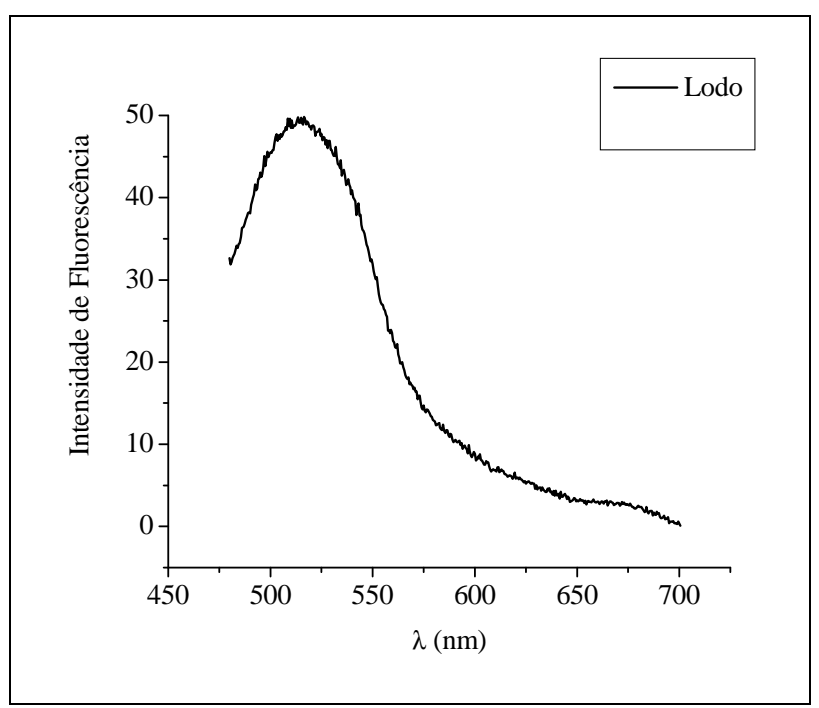

Figura 4.19 - Espectro de emissão de fluorescência $(\lambda$ exc $=465 \mathrm{~nm})$ do ácido húmico extraído do lodo. 
A partir dos espectros (Figuras 4.18 e 4.19) foi observada, uma única banda larga centrada em $510 \mathrm{~nm}$.

A intensidade de fluorescência diminui significativamente $(\approx 95 \%)$ para o ácido húmico extraído do lodo de esgoto se comparado aos ácidos húmicos extraídos dos solos, LVef e LVd.

Observando os resultados obtidos para o LVd sem e com adição do lodo de esgoto, é nítida a diminuição da intensidade de fluorescência para o ácido húmico extraído da P1 (0-10 $\mathrm{cm}$ ), o que é explicado pelo fato do lodo de esgoto acumular preferencialmente na superfície do solo. Essa diminuição também foi observada nos espectros (Figura 4.15) obtidos para o ácidos húmicos extraídos do LVd pela metodologia de Zsolnay.

Tabela 4.9 - Dados referentes ao índice de humificação proposto por Milori.

\begin{tabular}{c|c|c|c}
\hline Amostra & $\mathrm{A}_{465}$ & $\mathrm{~A}_{465}$ & $\mathrm{~A}_{465}\left(10^{3}\right)$ \\
\hline LVef/ P1 & 23890 & 31965 & $28 \pm 6$ \\
LVef/ P2 & 26163 & 31628 & $29 \pm 4$ \\
LVef/ P3 & 48541 & 39781 & $44 \pm 6$ \\
LVef/ P4 & 80792 & 65675 & $73 \pm 11$ \\
LVef + B/ P1 & 26200 & 28308 & $27 \pm 2$ \\
LVef + B/ P2 & 27724 & 32814 & $30 \pm 4$ \\
LVef + B/ P3 & 39652 & 32389 & $36 \pm 5$ \\
LVef + B/ P4 & 52495 & 56368 & $54 \pm 3$ \\
LVd/ P1 & 58332 & 66347 & $62 \pm 6$ \\
LVd/ P2 & 51141 & 60198 & $56 \pm 6$ \\
LVd/ P3 & 89184 & 88536 & $89 \pm 1$ \\
LVd/ P4 & 88513 & 88921 & $89 \pm 1$ \\
LVd + B/ P1 & 38767 & 35380 & $37 \pm 2$ \\
LVd + B/ P2 & 37230 & 34844 & $36 \pm 2$ \\
LVd + B/ P3 & 71940 & 73854 & $73 \pm 1$ \\
LVd + B/ P4 & 82966 & 89365 & $86 \pm 5$ \\
Lodo & 4225 & 6862 & $6 \pm 2$ \\
\hline
\end{tabular}

${ }^{(1)}$ LVef $\rightarrow$ (sem adição de lodo de esgoto), LVd $\rightarrow$ (sem adição de lodo de esgoto), + B refere-se aos mesmos solos tratados com lodo de esgoto e Lodo $\rightarrow$ ácido húmico extraído do lodo de esgoto. As profundidades variam de 0-60 cm onde: $\mathrm{P} 1 \rightarrow$ 0-10; P2 $\rightarrow$ 10-20; P3 $\rightarrow$ 20-40 e P4 $\rightarrow$ 40-60 cm.

A partir dos resultados obtidos para o índice de humificação $\left(\mathrm{A}_{465}\right)$ proposto por (Milori et al., 2002) (Tabela 4.9), foi observado que todos os valores obtidos para os ácidos húmicos extraídos dos solos, tanto para o LVef como para o LVd, apresentaram valores 
significativamente maiores que o obtido para o ácido húmico extraído do lodo de esgoto, indicando menor humificação desse resíduo se comparado ao solo.

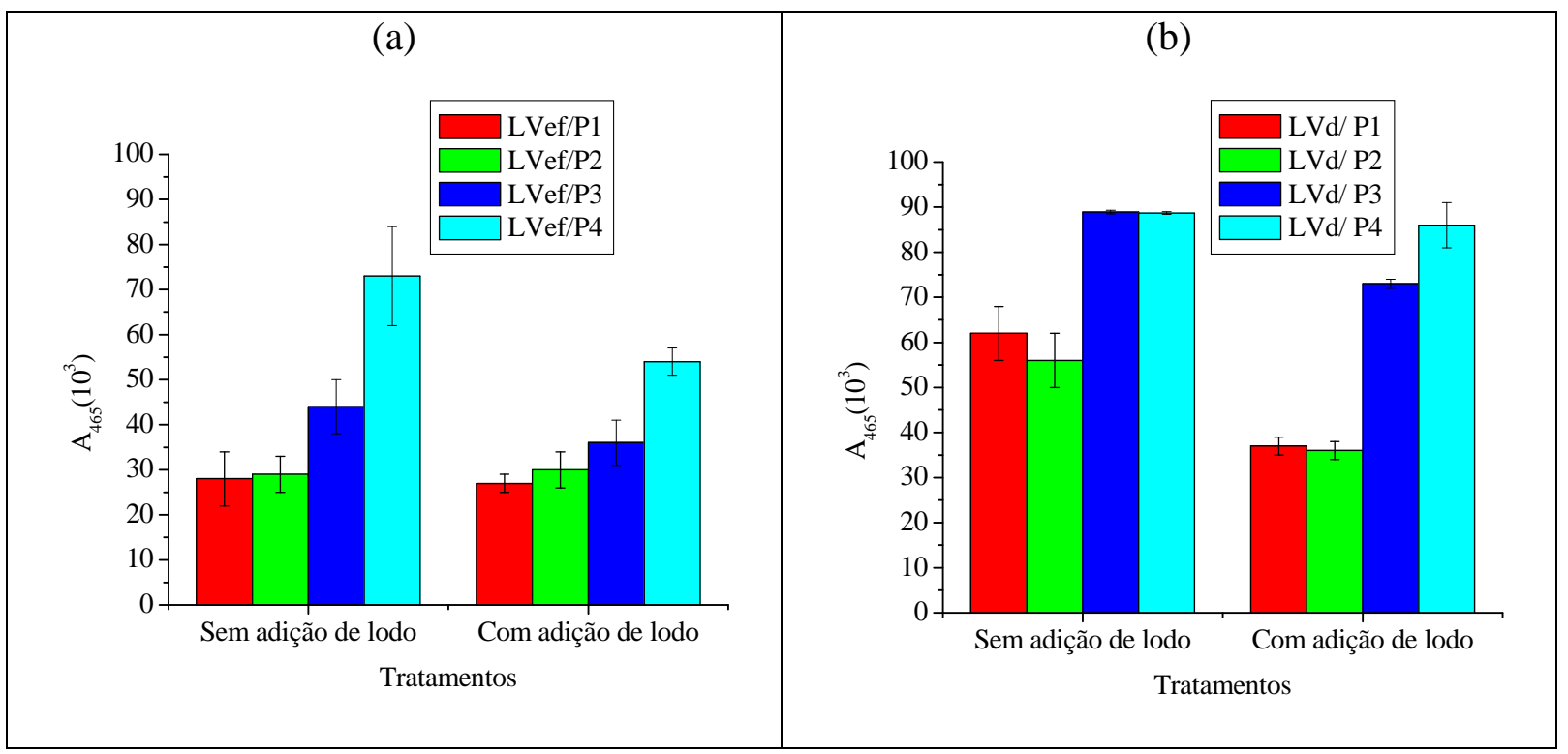

Figura 4.20 - Valores de $\mathrm{A}_{465}$ obtidos para os ácidos húmicos extraídos dos solos, (a) LVef sem e com adição de lodo de esgoto e (b) LVd sem e com adição de lodo de esgoto. As profundidades variam de 0-60 cm onde: $\mathrm{P} 1 \rightarrow$ $0-10 ; \mathrm{P} 2 \rightarrow$ 10-20; P3 $\rightarrow$ 20-40 e P4 $\rightarrow$ 40-60 cm.

\subsection{Espectros de varredura sincronizada}

O espectro de varredura sincronizada, medida com diferença constante entre excitação e emissão $(\Delta \lambda=55 \mathrm{~nm})$, permitiu avaliar o grau de humificação através da metodologia proposta por (Kalbitz, Geyer, Geyer, 1999). De acordo com essa proposta, os espectros de fluorescência sincronizados das substâncias húmicas apresentam dois picos, um em torno de 360 e outro em $465 \mathrm{~nm}$, e um ombro em torno de $470 \mathrm{~nm}$. Esses perfis mudam dependendo do grau de humificação, e isto pode ser medido pela razão dos picos de fluorescência. O deslocamento no máximo de intensidade de fluorescência de menores para maiores comprimentos de onda está associado com um aumento no número de núcleos aromáticos altamente substituídos e/ou com um sistema conjugado insaturado capaz de exibir alto grau de ressonância. Então, a razão da intensidade de fluorescência em 400 e 360 nm, ou 470 e 360 nm pode ser usada para medir o grau de policondensação ou humificação das substâncias húmicas. No presente estudo foi possível identificar claramente dois picos médios, um em 460 e outro em 399 nm, e com isso usar como índice de humificação a razão $\mathrm{I}_{460} / \mathrm{I}_{399}$. 


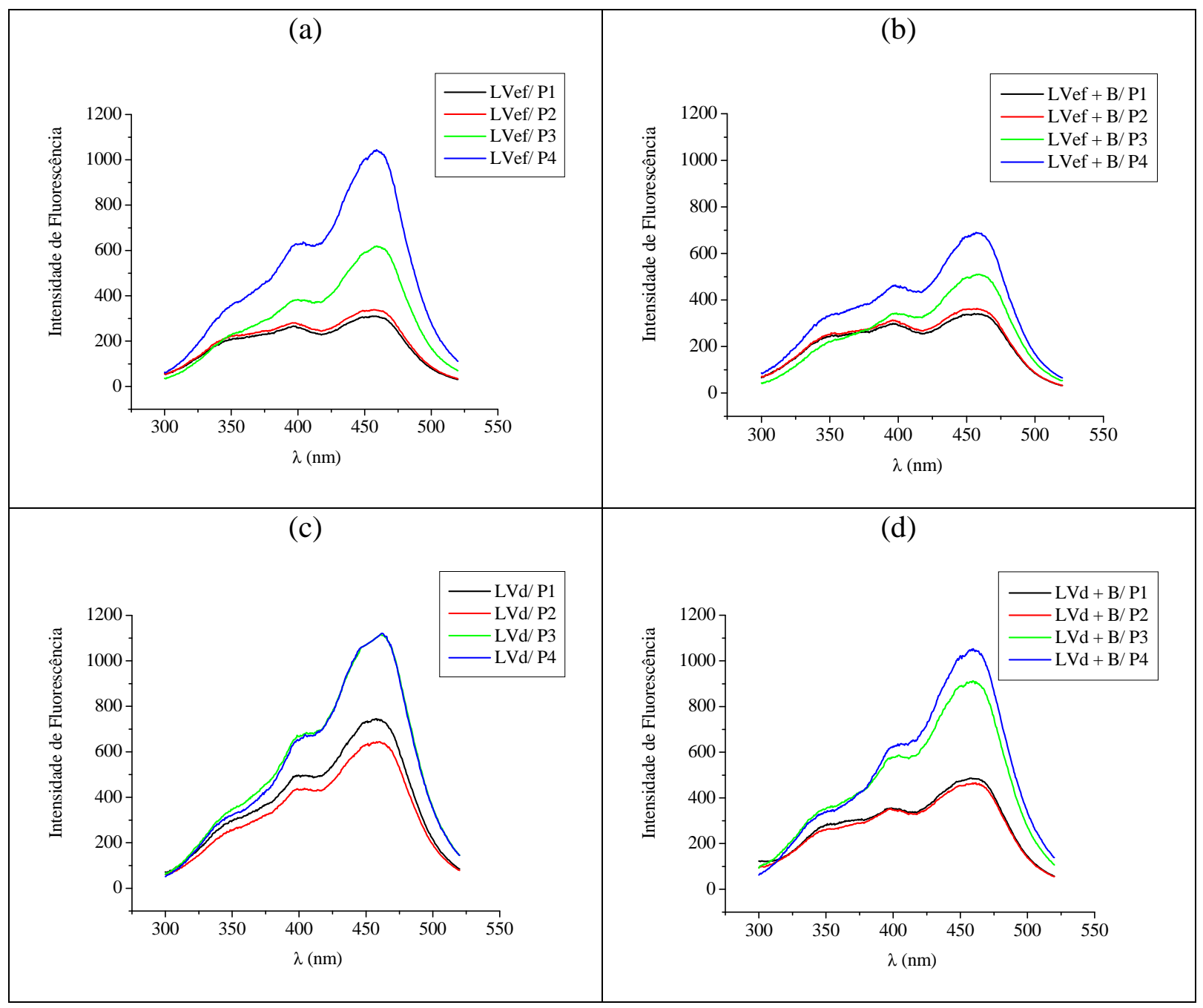

Figura 4.21 - Espectros sincronizado de fluorescência de ácidos húmicos extraídos do (a) LVef $\rightarrow$ sem adição de lodo de esgoto, (b) LVef $+\mathrm{B} \rightarrow$ com adição de lodo de esgoto, (c) LVd $\rightarrow$ sem adição de lodo de esgoto e (d) $\mathrm{LVd}+\mathrm{B} \rightarrow$ com adição de lodo de esgoto. As profundidades variam de 0-60 cm onde: $\mathrm{P} 1 \rightarrow \mathbf{0 - 1 0}$; $\mathrm{P} 2 \rightarrow$ 10-20; $\mathrm{P} 3 \rightarrow 20-40$ e $\mathrm{P} 4 \rightarrow 40-60 \mathrm{~cm}$.

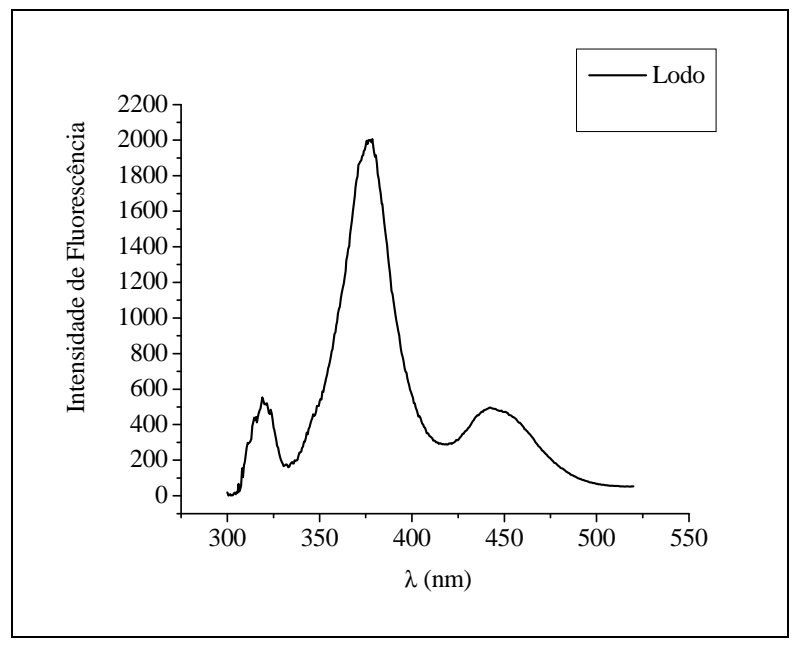

Figura 4.22 - Espectro sincronizado de fluorescência do ácido húmico extraído do lodo. 
Tabela 4.10 - Dados referentes ao índice de humificação proposto por Kalbitz.

\begin{tabular}{c|c|c|c}
\hline Amostra $^{(1)}$ & $\mathrm{I}_{460}$ & $\mathrm{I}_{399}$ & $\mathrm{I}_{460} / \mathrm{I}_{399}$ \\
\hline LVef/ P1 & 355,00 & 248,07 & $1,44 \pm 0,39$ \\
LVef/ P2 & 370,04 & 284,32 & $1,30 \pm 0,14$ \\
LVef/ P3 & 562,85 & 378,51 & $1,49 \pm 0,18$ \\
LVef/ P4 & 944,26 & 599,99 & $1,57 \pm 0,12$ \\
LVef + B/ P1 & 352,98 & 301,61 & $1,17 \pm 0,02$ \\
LVef + B/ P2 & 391,03 & 320,25 & $1,22 \pm 0,07$ \\
LVef + B/ P3 & 462,54 & 337,46 & $1,37 \pm 0,17$ \\
LVef + B/ P4 & 707,66 & 461,79 & $1,53 \pm 0,06$ \\
LVd/ P1 & 788,50 & 507,47 & $1,55 \pm 0,07$ \\
LVd/ P2 & 694,36 & 443,71 & $1,56 \pm 0,13$ \\
LVd/ P3 & 1108,01 & 667,15 & $1,66 \pm 0,01$ \\
LVd/ P4 & 1111,26 & 657,39 & $1,69 \pm 0,02$ \\
LVd + B/ P1 & 463,85 & 344,20 & $1,34 \pm 0,02$ \\
LVd + B/ P2 & 450,58 & 342,50 & $1,32 \pm 0,01$ \\
LVd + B/ P3 & 923,95 & 578,48 & $1,59 \pm 0,02$ \\
LVd + B/ P4 & 1080,11 & 633,14 & $1,71 \pm 0,04$ \\
Lodo & 67,29 & 103,78 & $0,64 \pm 0,03$ \\
\hline
\end{tabular}

${ }^{(1)}$ LVef $\rightarrow$ (sem adição de lodo de esgoto), LVd $\rightarrow$ (sem adição de lodo de esgoto), + B refere-se aos mesmos solos tratados com lodo de esgoto e Lodo $\rightarrow$ ácido húmico extraído do lodo de esgoto. As profundidades variam de $0-60 \mathrm{~cm}$ onde: $\mathrm{P} 1 \rightarrow 0-10 ; \mathrm{P} 2 \rightarrow 10-20 ; \mathrm{P} 3 \rightarrow 20-40$ e $\mathrm{P} 4 \rightarrow 40-60 \mathrm{~cm}$.

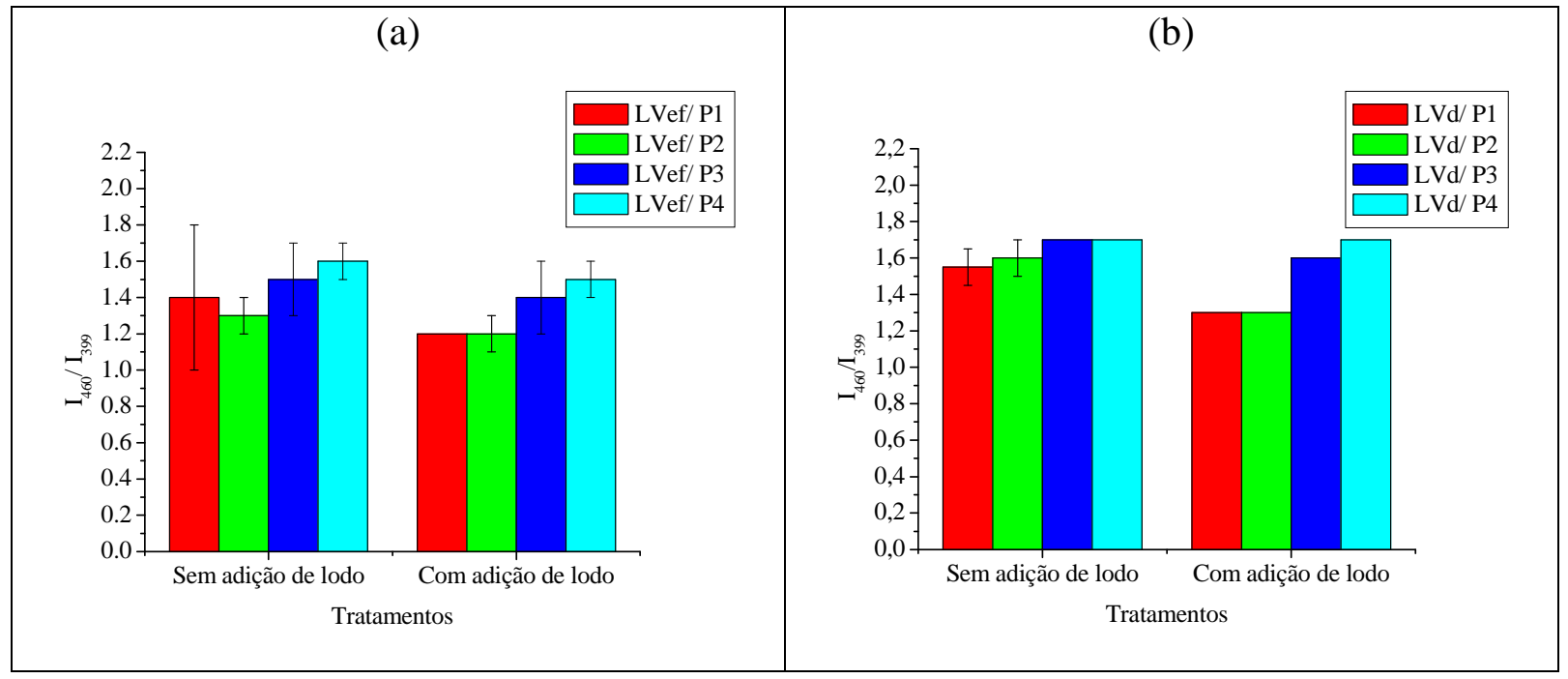

Figura 4.23 - Valores de $\mathrm{I}_{460} / \mathrm{I}_{399}$ obtidos para os ácidos húmicos extraídos do (a) LVef sem e com adição de lodo de esgoto e (b) LVd sem e com adição de lodo de esgoto. As profundidades variam de 0-60 cm onde: P1 $\rightarrow$ $0-10 ; \mathrm{P} 2 \rightarrow$ 10-20; P3 $\rightarrow$ 20-40 e P4 $\rightarrow$ 40-60 cm.

Os índices de humificação para os ácidos húmicos apresentaram boa correlações entre as metodologias utilizadas para fluorescência (Figura 4.24). 


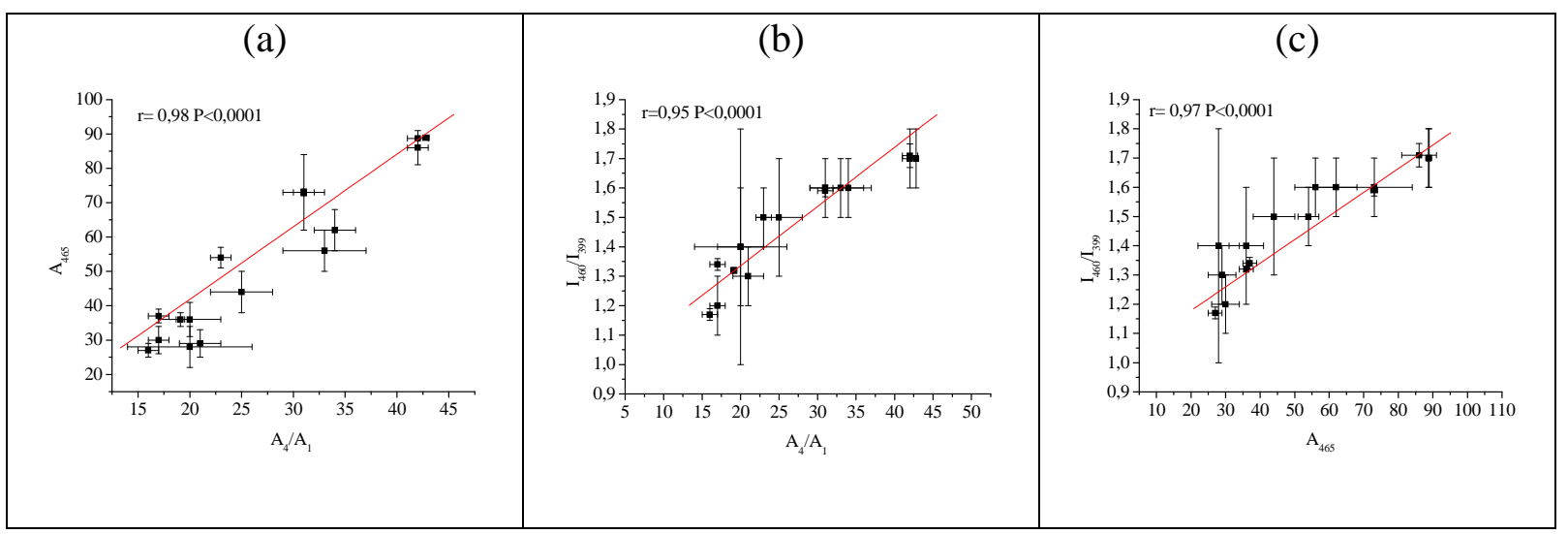

Figura 4.24 - Correlação entre as metodologias utilizadas: (a) Zsolnay e Milori; (b) Zsolnay e Kalbitz e (c) Milori e Kalbitz.

\subsubsection{FIL}

Experimentos de FIL foram realizados, a fim de se obter informações sobre o grau de humificação ( $\left.\mathrm{H}_{\mathrm{FIL}}\right)$ das amostras de solo intacto (Equação 4.1). A proposta de cálculo deste índice de humificação é a razão entre o valor da ACF e o valor de COT presente na amostra de solo intacto (Milori et al., 2001), ou seja:

$$
\mathrm{H}_{\mathrm{FIL}}=\frac{\mathrm{ACF}}{\mathrm{COT}}
$$

$\mathrm{Na}$ (Tabela 4.11), estão apresentados os resultados provenientes da análise de carbono das amostras de solo intacto, obtidos pela técnica de TOC e as médias das áreas determinadas pela FIL. 
Tabela 4.11 - Dados referentes à análise elementar de carbono pela técnica de TOC e área dos espectros de FIL de amostras de solo intacto.

\begin{tabular}{c|c|c|c}
\hline \multirow{2}{*}{ Amostra } & \multicolumn{3}{|c}{ Solo Intacto } \\
\cline { 2 - 4 } & $\mathrm{C}(\%)$ & Área (u.a.) & $\mathrm{H}_{\mathrm{FIL}}$ \\
\hline LVef/ P1 & $1,84 \pm 0,03$ & $130 \pm 7$ & $71 \pm 4$ \\
LVef/ P2 & $1,80 \pm 0,01$ & $146 \pm 8$ & $81 \pm 5$ \\
LVef/ P3 & $1,36 \pm 0,02$ & $146 \pm 1$ & $107 \pm 1$ \\
LVef/ P4 & $1,03 \pm 0,02$ & $135 \pm 4$ & $131 \pm 4$ \\
LVef + B/ P1 & $1,97 \pm 0,02$ & $130 \pm 6$ & $66 \pm 3$ \\
LVef + B/ P2 & $1,82 \pm 0,01$ & $123 \pm 5$ & $68 \pm 3$ \\
LVef + B/ P3 & $1,59 \pm 0,04$ & $124 \pm 21$ & $78 \pm 13$ \\
LVef + B/ P4 & $1,11 \pm 0,02$ & $137 \pm 5$ & $124 \pm 5$ \\
LVd/ P1 & $1,31 \pm 0,03$ & $299 \pm 11$ & $150 \pm 6$ \\
LVd/ P2 & $1,15 \pm 0,03$ & $333 \pm 6$ & $174 \pm 6$ \\
LVd/ P3 & $0,95 \pm 0,04$ & $312 \pm 45$ & $245 \pm 16$ \\
LVd/ P4 & $0,73 \pm 0,01$ & $379 \pm 39$ & $330 \pm 27$ \\
LVd + B/ P1 & $1,49 \pm 0,09$ & $277 \pm 12$ & $105 \pm 5$ \\
LVd + B/ P2 & $1,30 \pm 0,01$ & $272 \pm 12$ & $119 \pm 5$ \\
LVd + B/ P3 & $1,17 \pm 0,04$ & $303 \pm 7$ & $147 \pm 42$ \\
LVd + B/ P4 & $0,90 \pm 0,03$ & $329 \pm 7$ & $252 \pm 3$ \\
\hline
\end{tabular}

${ }^{(1)}$ Solo Intacto: $\mathrm{LVef} \rightarrow$ (sem adição de lodo de esgoto), LVd $\rightarrow$ (sem adição de lodo de esgoto), + B refere-se aos mesmos solos tratados com lodo de esgoto. As profundidades variam de 0-60 cm onde: $\mathrm{P} 1 \rightarrow 0-10 ; \mathrm{P} 2 \rightarrow$ $10-20 ; \mathrm{P} 3 \rightarrow$ 20-40 e P4 $\rightarrow$ 40-60 cm.

$\mathrm{Na}$ (Figura 4.25), temos o comportamento do grau de humificação em função da profundidade para os solos analisados, LVef e LVd, submetidos ou não à adição de lodo de esgoto.

De maneira geral, foi observado um incremento no grau de humificação em profundidade para todos os tratamentos. Contudo, nos solos que receberam lodo de esgoto foi observado que, em todas as profundidades, o grau de humificação foi menor que o dos solos que não receberam o lodo de esgoto, além do que o gradiente é menos acentuado, com isso, constatamos uma diminuição gradualmente no grau de humificação em função da adição de lodo de esgoto (Santos et al., 2005). Esta diminuição do grau de humificação pode ser atribuída à incorporação de compostos menos humificados procedentes do lodo de esgoto (González-Pérez et al., 2004). 


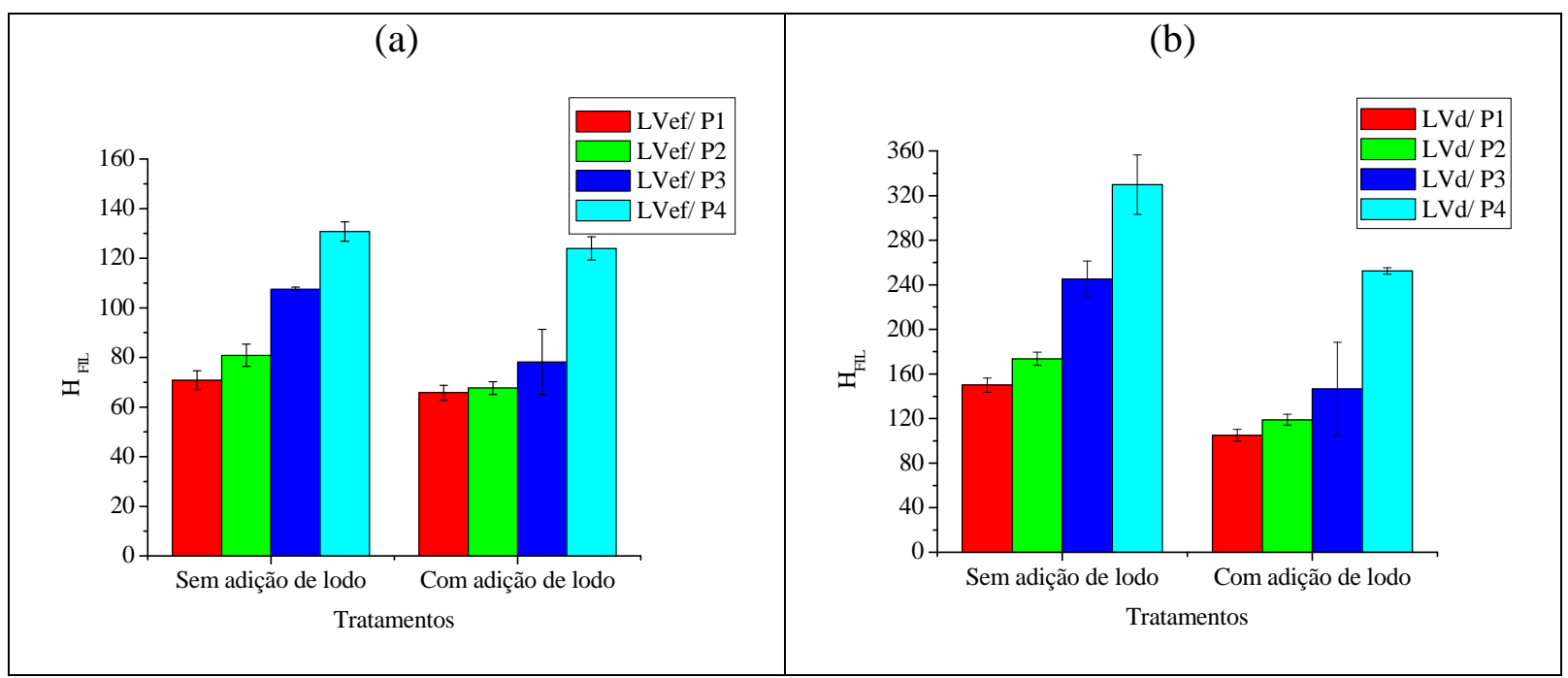

Figura 4.25 - Valores de $\mathrm{H}_{\mathrm{FIL}}$ obtidos para as amostras de solo intacto do (a) LVef sem e com adição de lodo de esgoto e (b) LVd sem e com adição de lodo de esgoto. As profundidades variam de 0-60 cm onde: P1 $\rightarrow$ 0-10 $\mathrm{cm} ; \mathrm{P} 2 \rightarrow 10-20 ; \mathrm{P} 3 \rightarrow 20-40$ e P4 $\rightarrow$ 40-60 cm.

Corroborando com (Narimoto et al., 2005), foi observado que na superfície, a matéria orgânica do solo se encontra menos humificada, isto se deve ao fato do resíduo vegetal ou do lodo de esgoto acumular preferencialmente na superfície do solo.

Os solos submetidos à adição de lodo apresentaram uma humificação mais uniforme nas profundidades P1 e P2 (0-10 e 10-20 cm), devido à incorporação do resíduo realizada pela aragem do solo nesse tratamento.

Variações no grau de humificação podem ser observadas também através da RPE, (Senesi et al., 1989), encontraram menor teor de radicais livres do tipo semiquinona para ácidos húmicos de solos da Califórnia tratados com lodo de esgoto. Resultados semelhantes foram encontrados por (González-Pérez, 2003) para latossolos brasileiros submetidos à adição de lodo de esgoto. Os resultados obtidos no trabalho ora apresentado foram similares aos obtidos por (Senesi et al., 1989) e (González-Pérez, 2003).

Nas correlações entre fluorescência em solução e na FIL, os índices de humificação refletem de maneira satisfatória as características da matéria orgânica, já que as medidas foram realizadas com solo intacto. Os valores obtidos para as correlações entre a FIL e as metodologias de fluorescência em solução utilizadas: $\mathrm{A}_{4} / \mathrm{A}_{1} ; \mathrm{A}_{465}$ e $\mathrm{I}_{460} / \mathrm{I}_{399}$, foram respectivamente, $\mathrm{r}=0,95$ e $\mathrm{P}<0,0001 ; \mathrm{r}=0,77$ e $\mathrm{P}<0,0001$ e $\mathrm{r}=0,86$ e $\mathrm{P}<0,0001$. 


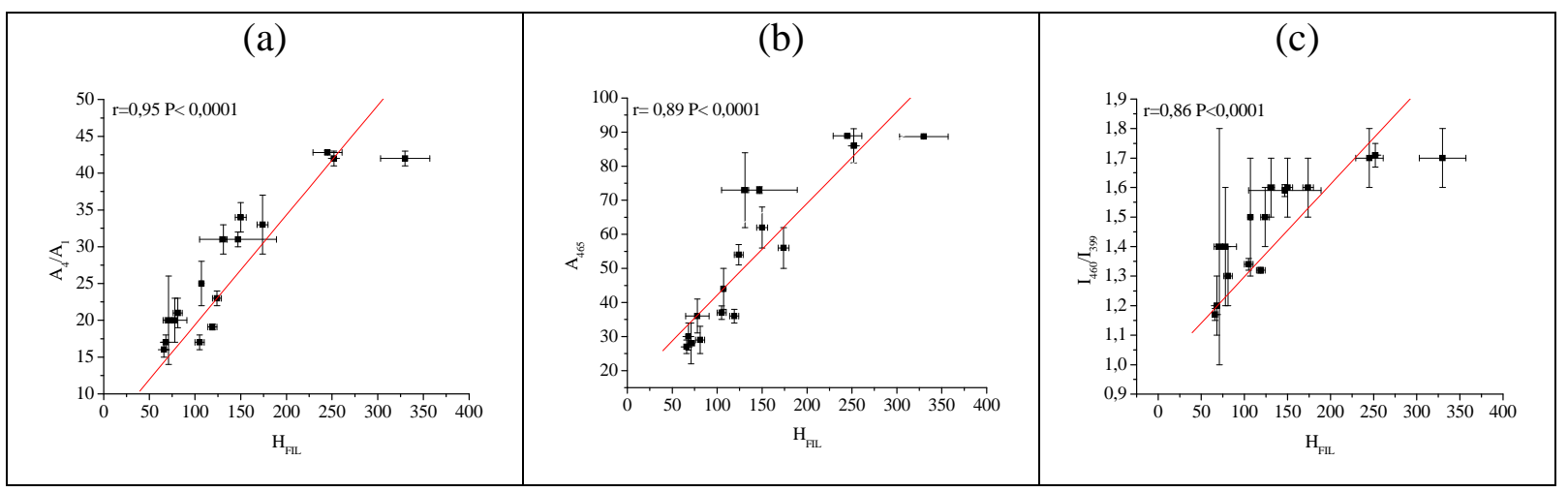

Figura 4.26 - Correlação entre o grau de humificação determinado pela FIL e as metodologias de fluorescência em solução utilizadas: (a) $\mathrm{H}_{\mathrm{FIL}}$ e $\mathrm{A}_{4} / \mathrm{A}_{1}$; (b) $\mathrm{H}_{\mathrm{FIL}}$ e $\mathrm{A}_{465}$ e (c) $\mathrm{H}_{\mathrm{FIL}}$ e $\mathrm{I}_{460} / \mathrm{I}_{399}$.

\subsection{DETERMINAÇÃO DE METAIS}

A presença de metais pesados, definidos como os elementos químicos com densidade maior que $5 \mathrm{~g} \mathrm{~cm}^{-3}$ no lodo de esgoto tem sido objetivo de muitos estudos devido ao fato destes elementos permanecerem no solo por um tempo indefinido, e dessa forma, causar perigo à saúde humana e animal ao entrarem na cadeia alimentar (Berton, 2000).

A determinação de elementos tóxicos em solo é uma importante ferramenta para monitorar a poluição ambiental. A análise total destes elementos nos solos intactos, nas suas frações químicas e físicas pode fornecer evidências de possíveis contaminações e contribuir para estimar a mobilidade no ambiente (Camargo, Alleoni, Casagrande, 2001).

Com isso, nesse trabalho foi determinada a concentração dos metais pesados $(\mathrm{Cd}, \mathrm{Cr}$, $\mathrm{Cu}, \mathrm{Fe}, \mathrm{Co}, \mathrm{Mn}, \mathrm{Mo}, \mathrm{V}$ e Zn) por ICP OES no lodo de esgoto e nas amostras de solos, LVef e LVd, nas suas frações físicas (areia, argila e silte) e químicas (ácido húmico, ácido fúlvico e humina).

\subsubsection{Lodo de esgoto}

A presença de metais potencialmente tóxicos presentes no lodo de esgoto preocupa pesquisadores quanto à utilização deste resíduo. Em geral, os metais pesados encontrados no lodo de esgoto são: $\mathrm{Cd}, \mathrm{Cr}, \mathrm{Cu}, \mathrm{Ni}, \mathrm{Pb}, \mathrm{Fe}, \mathrm{Co}, \mathrm{Mn}, \mathrm{Mo}, \mathrm{Hg}, \mathrm{Sn}$ e $\mathrm{Zn}$. Entre esses, deve-se ressaltar que alguns são essenciais às plantas $(\mathrm{Cu}, \mathrm{Co}, \mathrm{Cr}, \mathrm{Fe}, \mathrm{Mn}, \mathrm{Mo}, \mathrm{Ni}$ e $\mathrm{Zn})$. Nesse trabalho, foram abordados os metais pesados: $\mathrm{Cd}, \mathrm{Cr}, \mathrm{Cu}, \mathrm{Fe}, \mathrm{Co}, \mathrm{Mn}, \mathrm{V}$ e $\mathrm{Zn}$. 
Como pode-se observar (Tabela 4.12), um dos metais pesados que aparecem em maior concentração é o Zn, $2158 \mathrm{mg} \mathrm{kg}^{-1}$. É bom lembrar, contudo, que o Zn é um micronutriente essencial às plantas e que muitos solos brasileiros apresentem deficiência relacionada à esse elemento. Resultados obtidos em anos anteriores por (Melo, Melo, Melo, 2001) para os mesmos solos, mostraram aumento nos teores de Zn após à adição de lodo de esgoto.

Tabela 4.12 - Concentração em $\mathrm{mg} \mathrm{kg}^{-1}$ de metais pesados permitida e determinada para o lodo de esgoto.

\begin{tabular}{c|cc}
\hline Metal $^{(1)}$ & $\begin{array}{c}\text { Concentração Máxima } \\
\text { Permitida no Lodo }\end{array}$ & $\begin{array}{c}\text { Concentração para o Lodo } \\
\text { ETE Barueri }\end{array}$ \\
\hline $\mathrm{Cd}$ & $----------------------------\mathrm{mg} \mathrm{kg}^{-1}$------------------------ \\
$\mathrm{Cr}$ & 85 & 10 \\
$\mathrm{Cu}$ & - & 611 \\
$\mathrm{Fe}$ & 4300 & 765 \\
$\mathrm{Co}$ & - & 16958 \\
$\mathrm{Mn}$ & - & $\mathrm{n} . \mathrm{d}$ \\
$\mathrm{Mo}$ & - & 44165 \\
$\mathrm{~V}$ & 75 & 3 \\
$\mathrm{Zn}$ & - & 28 \\
$\mathrm{C}$ & 7500 & 2158 \\
\hline
\end{tabular}

${ }^{(1)}$ Metais pesados determinados no lodo de esgoto; ${ }^{(2)}$ Concentração máxima permitida no lodo de esgoto pela norma P 4230 (CETESB, 1999).

Apesar do resíduo ser proveniente do tratamento de esgoto urbano e industrial de região muito industrializada, verificou-se que os teores dos metais pesados $\mathrm{Cd}, \mathrm{Cr}, \mathrm{Cu}, \mathrm{Fe}, \mathrm{Co}, \mathrm{Mn}$, $\mathrm{V}$ e Zn, encontrados no lodo de esgoto (Tabela 4.12), estão abaixo dos limites estabelecidos pela norma P 4.230 da CETESB-1999, que determina os critérios para o uso agrícola do lodo de esgoto no Estado de São Paulo.

\subsubsection{Solo intacto}

O acúmulo de metais pesados no solo, em função de aplicações sucessivas de lodo de esgoto, é um dos aspectos que causa preocupação com relação à segurança ambiental necessária para a viabilização do uso desse resíduo na agricultura. Contudo, a partir dos resultados obtidos para as amostras de solo intacto, não foi possível visualizar alterações nos teores de $\mathrm{Cd}, \mathrm{Cr}, \mathrm{Cu}, \mathrm{Co}, \mathrm{Mo}$ e $\mathrm{Zn}$ dos solos submetidos à adição de lodo de esgoto. Os teores totais desses metais no solo intacto se mostraram abaixo do limite de detecção do método 
analítico utilizado. Contudo, é impróprio afirmar que esses metais não estão presentes nas amostras de solo analisadas, visto que foram detectados no lodo de esgoto (Tabela 4.13) adicionado ao solo.

Tabela 4.13 - Concentração em mg kg ${ }^{-1}$ de metais pesados determinados para o solo por ICP OES.

\begin{tabular}{|c|c|c|c|c|c|c|c|c|c|}
\hline Amostra $^{(1)}$ & $\mathrm{Cd}$ & $\mathrm{Cr}$ & $\mathrm{Cu}$ & $\mathrm{Fe}$ & Co & Mn & Mo & $\mathrm{V}$ & $\mathrm{Zn}$ \\
\hline LVef/ P1 & $<\mathrm{LD}$ & $<\mathrm{LD}$ & 2 & 13766 & $<\mathrm{LD}$ & 40327 & 5 & 11 & $<\mathrm{LD}$ \\
\hline LVef/ P2 & $<\mathrm{LD}$ & $<\mathrm{LD}$ & $<\mathrm{LD}$ & 1991 & $<\mathrm{LD}$ & 6442 & $<\mathrm{LD}$ & 1 & $<\mathrm{LD}$ \\
\hline LVef/ P3 & $<\mathrm{LD}$ & $<\mathrm{LD}$ & $<\mathrm{LD}$ & 6589 & $<\mathrm{LD}$ & 19328 & $<\mathrm{LD}$ & 5 & $<\mathrm{LD}$ \\
\hline LVef/ P4 & $<\mathrm{LD}$ & $<\mathrm{LD}$ & $<\mathrm{LD}$ & 1167 & $<\mathrm{LD}$ & 4134 & $<\mathrm{LD}$ & 1 & $<\mathrm{LD}$ \\
\hline LVef + B/ P1 & $<\mathrm{LD}$ & $<\mathrm{LD}$ & $<\mathrm{LD}$ & 955 & $<\mathrm{LD}$ & 3744 & $<\mathrm{LD}$ & $<\mathrm{LD}$ & $<\mathrm{LD}$ \\
\hline LVef + B/ P2 & $<\mathrm{LD}$ & $<\mathrm{LD}$ & $<\mathrm{LD}$ & 239 & $<\mathrm{LD}$ & 1336 & $<\mathrm{LD}$ & $<\mathrm{LD}$ & $<\mathrm{LD}$ \\
\hline LVef + B/ P3 & $<\mathrm{LD}$ & 59 & $<\mathrm{LD}$ & 3040 & $<\mathrm{LD}$ & 7302 & $<\mathrm{LD}$ & 3 & $<\mathrm{LD}$ \\
\hline $\mathrm{LVef}+\mathrm{B} / \mathrm{P} 4$ & $<\mathrm{LD}$ & $<\mathrm{LD}$ & $<\mathrm{LD}$ & 2668 & $<\mathrm{LD}$ & 6579 & $<\mathrm{LD}$ & 2 & $<\mathrm{LD}$ \\
\hline LVd/ P1 & $<\mathrm{LD}$ & $<\mathrm{LD}$ & $<\mathrm{LD}$ & 7487 & $<\mathrm{LD}$ & 23770 & $<\mathrm{LD}$ & 6 & 1 \\
\hline $\mathrm{LVd} / \mathrm{P} 2$ & $<\mathrm{LD}$ & 48 & 138 & 147530 & $<\mathrm{LD}$ & $<\mathrm{LD}$ & $<\mathrm{LD}$ & 41 & 37 \\
\hline $\mathrm{LVd} / \mathrm{P} 3$ & $<\mathrm{LD}$ & $<\mathrm{LD}$ & $<\mathrm{LD}$ & 2804 & $<\mathrm{LD}$ & 8560 & $<\mathrm{LD}$ & 2 & $<\mathrm{LD}$ \\
\hline $\mathrm{LVd} / \mathrm{P} 4$ & $<\mathrm{LD}$ & $<\mathrm{LD}$ & $<\mathrm{LD}$ & 3224 & $<\mathrm{LD}$ & 11203 & $<\mathrm{LD}$ & 2 & $<\mathrm{LD}$ \\
\hline $\mathrm{LVd}+\mathrm{B} / \mathrm{P} 1$ & $<\mathrm{LD}$ & $<\mathrm{LD}$ & $<\mathrm{LD}$ & 164 & $<\mathrm{LD}$ & 1071 & $<\mathrm{LD}$ & $<\mathrm{LD}$ & $<\mathrm{LD}$ \\
\hline $\mathrm{LVd}+\mathrm{B} / \mathrm{P} 2$ & $<\mathrm{LD}$ & $<\mathrm{LD}$ & $<\mathrm{LD}$ & $<\mathrm{LD}$ & $<\mathrm{LD}$ & 226 & $<\mathrm{LD}$ & $<\mathrm{LD}$ & $<\mathrm{LD}$ \\
\hline $\mathrm{LVd}+\mathrm{B} / \mathrm{P} 3$ & $<\mathrm{LD}$ & $<\mathrm{LD}$ & $<\mathrm{LD}$ & 5025 & $<\mathrm{LD}$ & 15553 & $<\mathrm{LD}$ & 4 & $<\mathrm{LD}$ \\
\hline $\mathrm{LVd}+\mathrm{B} / \mathrm{P} 4$ & 1 & 94 & 39048 & 24504 & $<\mathrm{LD}$ & $<\mathrm{LD}$ & $<\mathrm{LD}$ & 20 & $<\mathrm{LD}$ \\
\hline
\end{tabular}

Utilizando diferentes métodos de extração, Pigozzo et al. (2004) observaram que os metais pesados: $\mathrm{Cd}, \mathrm{Cr}$, $\mathrm{Ni}, \mathrm{Co}$ e $\mathrm{Pb}$, foram encontrados no lodo de esgoto ao se fazer a decomposição total da amostra com a mistura nítrico-perclórica, porém ao se fazer a extração do solo contendo o lodo de esgoto, com o extrator DTPA-TEA (mistura extratora formada com ácido dietilenotriaminopentaacético $0,005 \mathrm{~mol} \mathrm{~L} \mathrm{~L}^{-1}+$ trietanolamina $0,1 \mathrm{~mol} \mathrm{~L}^{-1}+\mathrm{CaCl}_{2}$ 0,01 mol L ${ }^{-1}$ corrigida à $\left.\mathrm{pH} 7,3\right)$, os mesmos não foram detectados, isto é, suas concentrações estavam abaixo do limite de detecção do método usado.

Para todos os metais analisados, não foi observada relação entre a aplicação do lodo e os teores disponíveis avaliados (Tabela 4.13). O fato de não conseguirmos observar a presença destes metais no solo, possivelmente é devido à sua complexidade e diversidade estrutural 
(Saiz-Jimenes, 1996; Clapp; Hayes, 1999). Os diversos tipos de fracionamento do solo tentam reduzir essa heterogeneidade, procurando separar frações semelhantes quanto à natureza, dinâmica e função, mas ao mesmo tempo suficientemente diferente uma das outras Com isso, os fracionamentos físico e químico dos solos foram realizados, a fim de se obter resultados mais próximos dos reais a respeito dos teores de metais pesados decorrentes da adição do lodo de esgoto ao solo, conseqüentemente da afinidade química destes metais às frações do solo.

\subsubsection{Frações físicas}

Esta etapa consistiu em verificar a qual fração física do solo encontram-se, preferencialmente os metais pesados adicionados via lodo de esgoto, de modo a fornecer subsídios às discussões sobre o uso deste resíduo na agricultura.

\subsubsection{Fração areia (> 53 $\mu \mathrm{m})$}

Os resultados (Tabela 4.14) mostraram que as aplicações de lodo de esgoto aos solos não proporcionaram aumentos significativos dos metais, $\mathrm{Cd}, \mathrm{Cr}, \mathrm{Cu}, \mathrm{Co}, \mathrm{Mo}, \mathrm{V}$ e $\mathrm{Zn}$ na fração granulométrica $>53 \mu \mathrm{m}$, areia. 
Tabela 4.14 - Concentração em $\mathrm{mg} \mathrm{kg}^{-1}$ de metais de pesados determinados para a fração areia por ICP OES.

\begin{tabular}{|c|c|c|c|c|c|c|c|c|c|}
\hline Amostra $^{(1)}$ & $\mathrm{Cd}$ & $\mathrm{Cr}$ & $\mathrm{Cu}$ & $\mathrm{Fe}$ & Co & $\mathrm{Mn}$ & Mo & V & $\mathrm{Zn}$ \\
\hline & & & & & & & & & \\
\hline LVef/ P1 & $<\mathrm{LD}$ & $<\mathrm{LD}$ & $<\mathrm{LD}$ & 526 & $<\mathrm{LD}$ & 1353 & $<\mathrm{LD}$ & 1 & $<\mathrm{LD}$ \\
\hline LVef/ P2 & LD & $<\mathrm{LD}$ & 7 & 285 & $<\mathrm{LD}$ & 608 & $<\mathrm{LD}$ & $<\mathrm{LD}$ & $<\mathrm{LD}$ \\
\hline LVef/ P3 & LD & $<\mathrm{LD}$ & $<\mathrm{LD}$ & 869 & $<\mathrm{LD}$ & 2592 & $<\mathrm{LD}$ & 1 & $<\mathrm{LD}$ \\
\hline LVef/ P4 & $<\mathrm{LD}$ & $<\mathrm{LD}$ & $<\mathrm{LD}$ & 1981 & $<\mathrm{LD}$ & 6210 & $<\mathrm{LD}$ & 2 & $<\mathrm{LD}$ \\
\hline LVef + B/ P1 & $<\mathrm{LD}$ & $<\mathrm{LD}$ & 17 & 25 & $<\mathrm{LD}$ & $<\mathrm{LD}$ & $<\mathrm{LD}$ & $<\mathrm{LD}$ & $<\mathrm{LD}$ \\
\hline LVef + B/ P2 & $<\mathrm{LD}$ & $<\mathrm{LD}$ & $<\mathrm{LD}$ & 4133 & $<\mathrm{LD}$ & 12771 & $<\mathrm{LD}$ & 4 & $<\mathrm{LD}$ \\
\hline LVef + B/ P3 & $<\mathrm{LD}$ & $<\mathrm{LD}$ & $<\mathrm{LD}$ & 5817 & $<\mathrm{LD}$ & 18043 & $<\mathrm{LD}$ & 4 & 1 \\
\hline $\mathrm{LVef}+\mathrm{B} / \mathrm{P} 4$ & $<\mathrm{LD}$ & $<\mathrm{LD}$ & $<\mathrm{LD}$ & 3092 & $<\mathrm{LD}$ & 9540 & $<\mathrm{LD}$ & 3 & $<\mathrm{LD}$ \\
\hline LVd/ P1 & $<\mathrm{LD}$ & $<\mathrm{LD}$ & 2 & 4338 & $<\mathrm{LD}$ & 13957 & $<\mathrm{LD}$ & 4 & $<\mathrm{LD}$ \\
\hline $\mathrm{LVd} / \mathrm{P} 2$ & $<\mathrm{LD}$ & $<\mathrm{LD}$ & $<\mathrm{LD}$ & 3610 & $<\mathrm{LD}$ & 11925 & $<\mathrm{LD}$ & 3 & $<\mathrm{LD}$ \\
\hline $\mathrm{LVd} / \mathrm{P} 3$ & $<\mathrm{LD}$ & $<\mathrm{LD}$ & $<\mathrm{LD}$ & 3052 & $<\mathrm{LD}$ & 9611 & $<\mathrm{LD}$ & 3 & $<\mathrm{LD}$ \\
\hline $\mathrm{LVd} / \mathrm{P} 4$ & $<\mathrm{LD}$ & $<\mathrm{LD}$ & 20 & 287 & $<\mathrm{LD}$ & 197 & 6 & $<\mathrm{LD}$ & $<\mathrm{LD}$ \\
\hline $\mathrm{LVd}+\mathrm{B} / \mathrm{P} 1$ & $<\mathrm{LD}$ & $<\mathrm{LD}$ & $<\mathrm{LD}$ & 9335 & $<\mathrm{LD}$ & 28409 & $<\mathrm{LD}$ & 9 & $<\mathrm{LD}$ \\
\hline $\mathrm{LVd}+\mathrm{B} / \mathrm{P} 2$ & $<\mathrm{LD}$ & $<\mathrm{LD}$ & $<\mathrm{LD}$ & 8675 & $<\mathrm{LD}$ & 26206 & $<\mathrm{LD}$ & 8 & $<\mathrm{LD}$ \\
\hline $\mathrm{LVd}+\mathrm{B} / \mathrm{P} 3$ & $<\mathrm{LD}$ & $<\mathrm{LD}$ & $<\mathrm{LD}$ & 3476 & $<\mathrm{LD}$ & 10937 & $<\mathrm{LD}$ & 3 & $<\mathrm{LD}$ \\
\hline $\mathrm{LVd}+\mathrm{B} / \mathrm{P} 4$ & $<\mathrm{LD}$ & 33 & $<\mathrm{LD}$ & 2596 & $<\mathrm{LD}$ & 5959 & $<\mathrm{LD}$ & 3 & $<\mathrm{LD}$ \\
\hline
\end{tabular}

$<\mathrm{LD}=$ abaixo do limite de detecção

${ }^{(1)}$ Fração areia extraída dos solos: LVef $\rightarrow$ (sem adição de lodo de esgoto), LVd $\rightarrow$ (sem adição de lodo de esgoto) e + B refere-se aos mesmos solos tratados com lodo de esgoto. As profundidades variam de 0-60 cm onde: $\mathrm{P} 1 \rightarrow 0-10 ; \mathrm{P} 2 \rightarrow 10-20 ; \mathrm{P} 3 \rightarrow 20-40$ e $\mathrm{P} 4 \rightarrow 40-60 \mathrm{~cm}$.

Contudo, foi observado um aumento dos teores de Fe e Mn decorrentes da adição de lodo de esgoto (Figura 4.27).

Os resultados indicam que a fração areia possui uma baixa capacidade de fixação de metais, visto que quase não mostra os efeitos da adição do lodo de esgoto. Esses resultados são semelhantes aos resultados obtidos por (Gonzáles-Pérez, 2003).

Como exemplos, na (Figura 4.27) são apresentadas as variações dos teores de Fe e Mn para o LVd, devida à adição de lodo de esgoto. 


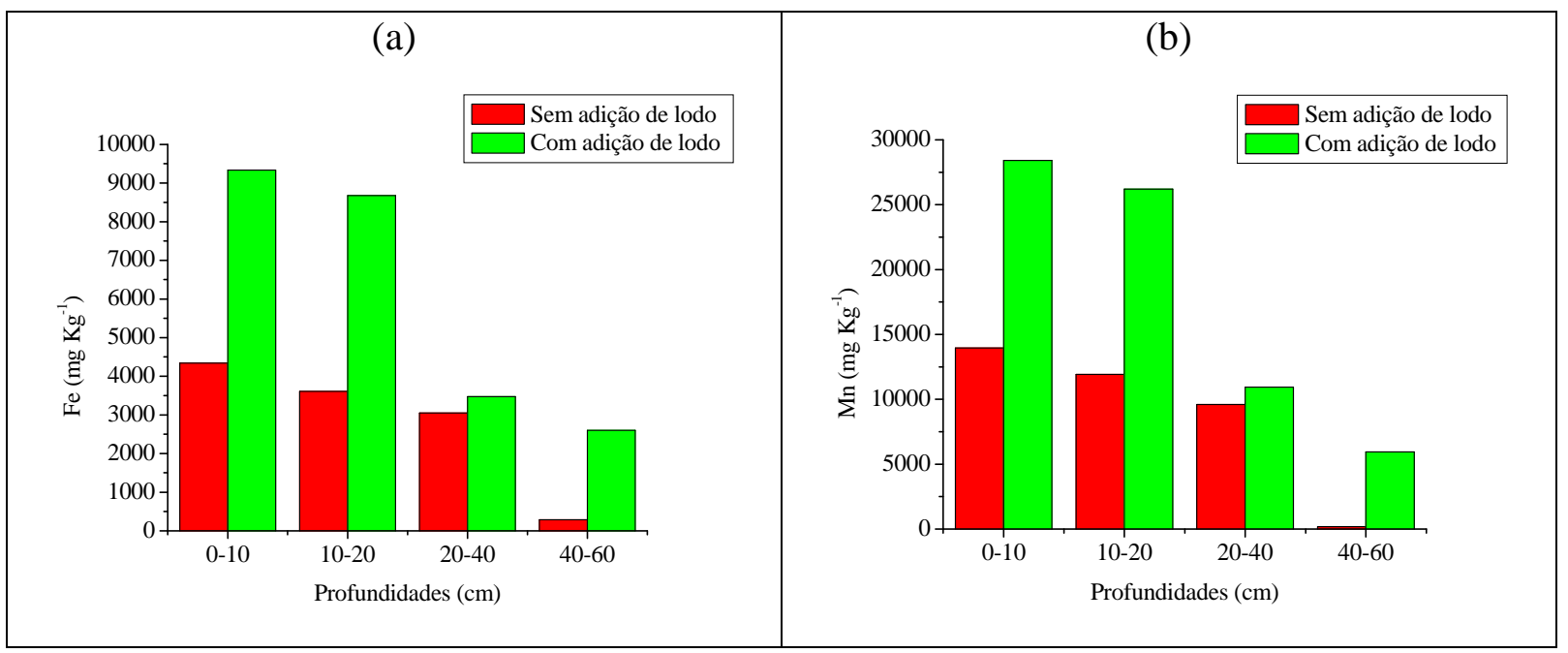

Figura 4.27 - Efeitos dos teores totais de (a) Fe e (b) Mn para as amostras da fração areia (> 53 m) extraídas do LVd submetidos à adição de lodo de esgoto.

\subsubsection{Fração silte grosso $(20-53 \mu \mathrm{m})$}

Os resultados (Tabela 4.15) mostraram que as aplicações de lodo de esgoto aos solos proporcionaram variações significativas para alguns metais na fração granulométrica de 20$53 \mu \mathrm{m}$, silte grosso.

Para a fração silte grosso extraída do $\mathrm{LVd}$, não foram observadas variações nos teores de Cd, Co e Mo, após à adição de lodo de esgoto ao solo. Contudo, foram observados aumentos nos teores de Cr, Co, Mo e Zn para o LVef, decorrente da adição do resíduo. 
Tabela 4.15 - Concentração em $\mathrm{mg} \mathrm{kg}^{-1}$ de metais de pesados determinados para a fração silte grosso por ICP OES.

\begin{tabular}{|c|c|c|c|c|c|c|c|c|}
\hline Amostra $^{(1)}$ & $\mathrm{Cd}$ & $\mathrm{Cr}$ & $\mathrm{Cu}$ & $\mathrm{Fe}$ & $\mathrm{Co}$ & Mn & Mo & $\mathrm{Zn}$ \\
\hline LVef/ P1 & 10 & 124 & 156 & 88445 & 58 & 1330 & 17 & 192 \\
\hline LVef/ P2 & 9 & 104 & 150 & 67885 & 52 & 1278 & 15 & 194 \\
\hline LVef/ P3 & 9 & 117 & 154 & 75870 & 54 & 1231 & 15 & 193 \\
\hline LVef/ P4 & 7 & 47 & 56 & 28091 & 24 & 375 & 13 & 63 \\
\hline LVef $+B / P 1$ & 11 & 180 & 214 & 121125 & 75 & 1725 & 18 & 257 \\
\hline LVef $+B / P 2$ & 9 & 114 & 146 & 77250 & 56 & 1169 & 16 & 171 \\
\hline LVef + B/ P3 & 10 & 129 & 154 & 90485 & 64 & 1242 & 17 & 180 \\
\hline LVef + B/ P4 & 7 & 79 & 116 & 44572 & 41 & 868 & 13 & 146 \\
\hline $\mathrm{LVd} / \mathrm{P} 1$ & 3 & 25 & 9 & 5025 & 8 & 137 & 6 & 24 \\
\hline $\mathrm{LVd} / \mathrm{P} 2$ & 3 & 39 & 9 & 8371 & 9 & 146 & 6 & 17 \\
\hline $\mathrm{LVd} / \mathrm{P} 3$ & 3 & 34 & 7 & 6657 & 8 & 106 & 6 & 12 \\
\hline $\mathrm{LVd} / \mathrm{P} 4$ & 3 & 41 & 8 & 7450 & 8 & 108 & 6 & 14 \\
\hline $\mathrm{LVd}+\mathrm{B} / \mathrm{P} 1$ & 3 & 30 & 12 & 6357 & 8 & 121 & 6 & 28 \\
\hline $\mathrm{LVd}+\mathrm{B} / \mathrm{P} 2$ & 3 & 19 & 8 & 2590 & 7 & 112 & 6 & 17 \\
\hline $\mathrm{LVd}+\mathrm{B} / \mathrm{P} 3$ & 3 & 16 & 7 & 1456 & 7 & 95 & 5 & 15 \\
\hline $\mathrm{LVd}+\mathrm{B} / \mathrm{P} 4$ & 3 & 40 & 8 & 8238 & 10 & 135 & 6 & 18 \\
\hline
\end{tabular}

${ }^{(1)}$ Fração silte fino extraída dos solos: LVef $\rightarrow$ (sem adição de lodo de esgoto), LVd $\rightarrow$ (sem adição de lodo de esgoto) e + B refere-se aos mesmos solos tratados com lodo de esgoto. As profundidades variam de 0-60 cm onde: $\mathrm{P} 1 \rightarrow 0-10 ; \mathrm{P} 2 \rightarrow$ 10-20; $\mathrm{P} 3 \rightarrow 20-40$ e $\mathrm{P} 4 \rightarrow$ 40-60 cm.

Como exemplos, na (Figura 4.28) são apresentadas as variações dos teores de $\mathrm{Cr}, \mathrm{Cu}$ e Co para o LVef e Zn para o LVd, devida à adição de lodo de esgoto. 


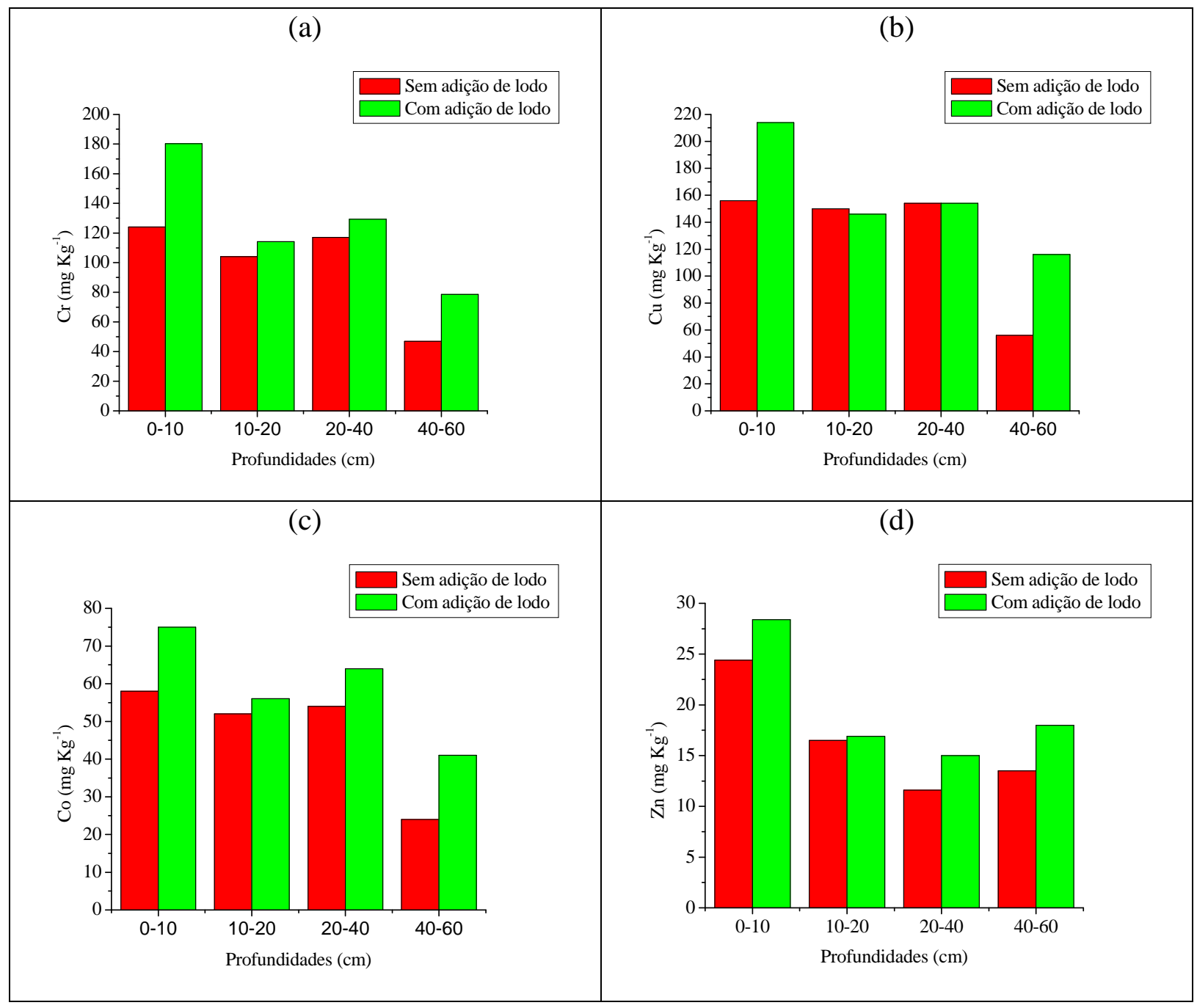

Figura 4.28 - Efeitos dos teores totais de (a) Cr, (b) $\mathrm{Cu}$ e (c) Co para a fração silte grosso (20-53 $\mu$ m) extraídas do LVef submetido à adição de lodo de esgoto e efeitos dos teores totais de (d) Zn para a fração silte grosso (20$53 \mu \mathrm{m})$ extraídas do LVd submetido à adição de lodo de esgoto.

Os teores de metais pesados encontrados na fração silte grosso podem ser um indicativo de que os metais possuem maior afinidade por essa fração se comparada à fração areia.

\subsubsection{Fração silte fino $(2-20 \mu \mathrm{m})$}

A fixação de metais é dependente de vários fatores físicos, químicos e biológicos, incluindo o tamanho das partículas e o conteúdo de matéria orgânica.

Os resultados obtidos mostraram uma maior afinidade dos metais pela fração silte fino se comparada às frações anteriormente estudadas. Esse comportamento é devido aos metais se complexarem preferencialmente nas frações granulométricas de menor tamanho devido à maior área superficial dos minerais presentes nas mesmas e de óxidos de ferro (Quian et al., 
1996). O aumento dos teores totais de metais pesados com o decréscimo do tamanho das partículas indica que o seu comportamento está governado por processos de sorção.

Outra explicação para esse resultado pode ser decorrente da fração silte fino apresentar maior conteúdo de carbono e matéria orgânica (González-Pérez, 2003) se comparada às demais frações físicas do solo. A matéria orgânica é o principal gerador de cargas negativas dos solos, devido a grande quantidade de grupos funcionais, tais como carboxílicos e fenólicos, conseqüentemente importantes sítios de adsorção de metais. Martin-Neto et al. (1994a) e Bayer et al. (2002) mostraram que a fração silte fino é a fração que apresenta matéria orgânica com maior grau de humificação, o que significa que essa fração possui maior capacidade de complexação de metais, tanto pelos minerais como pelo alto grau de humificação da matéria orgânica associada a eles.

Tabela 4.16 - Concentração em $\mathrm{mg} \mathrm{kg}^{-1}$ de metais de pesados determinados para a fração silte fino por ICP OES.

\begin{tabular}{|c|c|c|c|c|c|c|c|c|}
\hline Amostra $^{(1)}$ & $\mathrm{Cd}$ & $\mathrm{Cr}$ & $\mathrm{Cu}$ & $\mathrm{Fe}$ & $\mathrm{Co}$ & Mn & Mo & $\mathrm{Zn}$ \\
\hline & & & & & & & & \\
\hline LVef/ P1 & 14 & 73 & 103 & 80389 & 53 & 853 & 24 & 95 \\
\hline LVef/ P2 & 18 & 174 & 267 & 186359 & 116 & 2302 & 31 & 264 \\
\hline LVef/ P3 & 14 & 111 & 154 & 124944 & 77 & 1319 & 23 & 153 \\
\hline LVef/ P4 & 10 & 69 & 100 & 79879 & 50 & 718 & 19 & 93 \\
\hline LVef + B/ P1 & 14 & 121 & 155 & 129019 & 81 & 1465 & 24 & 169 \\
\hline $\mathrm{LVef}+\mathrm{B} / \mathrm{P} 2$ & 13 & 110 & 146 & 123554 & 80 & 1538 & 23 & 150 \\
\hline $\mathrm{LVef}+\mathrm{B} / \mathrm{P} 3$ & 13 & 121 & 171 & 129429 & 86 & 1622 & 24 & 167 \\
\hline LVef + B/ P4 & 10 & 83 & 125 & 88884 & 58 & 989 & 19 & 126 \\
\hline LVd/ P1 & 3 & 30 & 18 & 12524 & 11 & 403 & 7 & 44 \\
\hline $\mathrm{LVd} / \mathrm{P} 2$ & 4 & 49 & 18 & 20942 & 14 & 516 & 7 & 48 \\
\hline $\mathrm{LVd} / \mathrm{P} 3$ & 3 & 36 & 13 & 16608 & 12 & 399 & 7 & 39 \\
\hline LVd/ P4 & 3 & 45 & 14 & 21165 & 14 & 384 & 7 & 36 \\
\hline $\mathrm{LVd}+\mathrm{B} / \mathrm{P} 1$ & 7 & 77 & 75 & 16051 & 18 & 624 & 13 & 188 \\
\hline $\mathrm{LVd}+\mathrm{B} / \mathrm{P} 2$ & 4 & 42 & 26 & 15000 & 11 & 395 & 7 & 62 \\
\hline $\mathrm{LVd}+\mathrm{B} / \mathrm{P} 3$ & 3 & 33 & 16 & 14343 & 11 & 391 & 6 & 44 \\
\hline $\mathrm{LVd}+\mathrm{B} / \mathrm{P} 4$ & 3 & 20 & 10 & 5014 & 8 & 317 & 6 & 33 \\
\hline
\end{tabular}

${ }^{(1)}$ Fração silte fino extraída dos solos: LVef $\rightarrow$ (sem adição de lodo de esgoto), LVd $\rightarrow$ (sem adição de lodo de esgoto) e + B refere-se aos mesmos solos tratados com lodo de esgoto. As profundidades variam de 0-60 cm onde: $\mathrm{P} 1 \rightarrow 0-10 ; \mathrm{P} 2 \rightarrow 10-20 ; \mathrm{P} 3 \rightarrow 20-40$ e $\mathrm{P} 4 \rightarrow 40-60 \mathrm{~cm}$.

Foram observados a partir dos resultados (Tabela 4.16) um aumento nos teores de metais pesados com à adição de lodo de esgoto ao solo. Contudo, os maiores incrementos foram observados para os metais Cu e Zn na fração silte fino, extraída do LVd (Figura 4.26). 
Os resultados mostraram que esse aumento no teor de metais pesados incorporados ao solo via lodo de esgoto é maior na superfície do solo $(0-10 \mathrm{~cm})$, coerente com à adição de lodo de esgoto, que foi incorporado com grade nesta camada.

Como exemplos, na (Figura 4.29) são apresentadas as variações dos teores $\mathrm{Cu}$ e $\mathrm{Zn}$ para o LVd, devido à adição de lodo de esgoto.

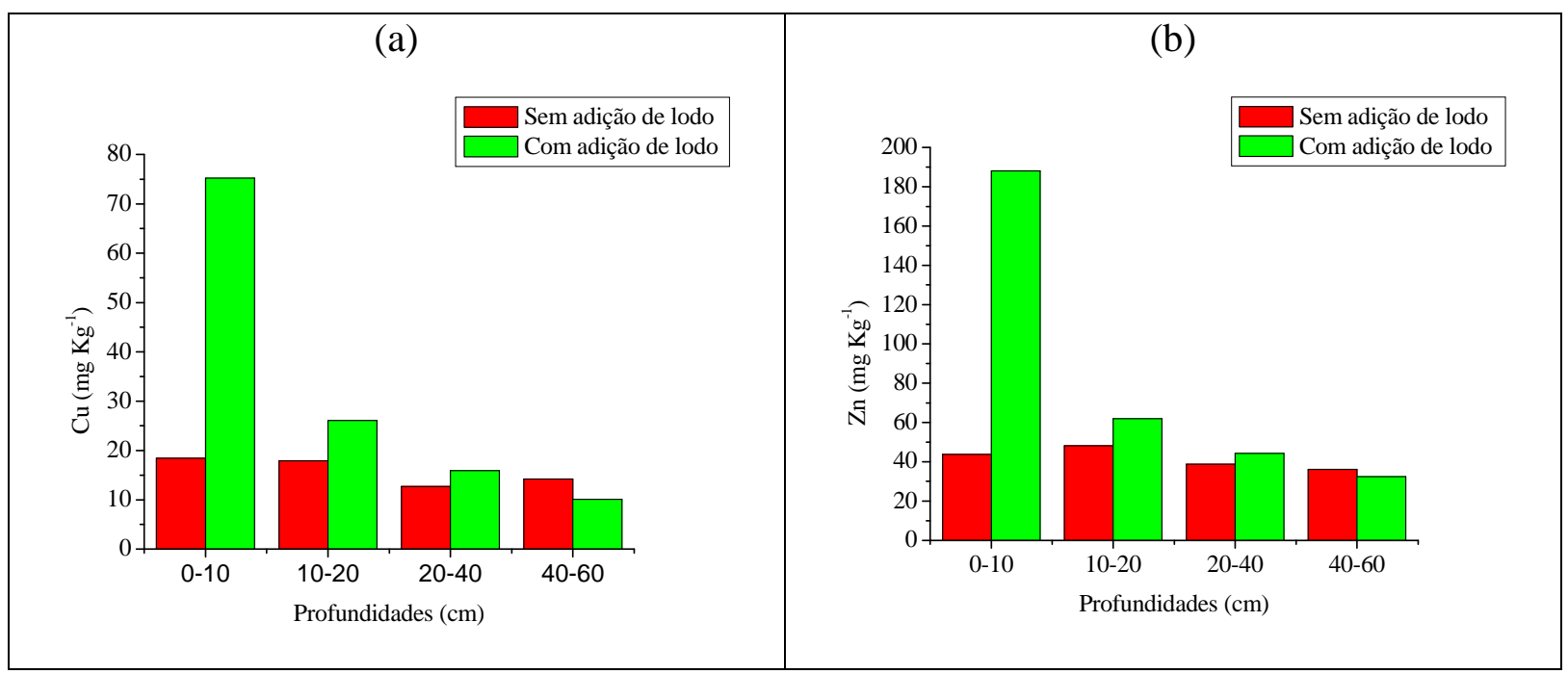

Figura 4.29 - Efeitos dos teores totais de (a) $\mathrm{Cu}$ e (b) Zn para a fração silte fino (2-20 $\mu \mathrm{m}$ ) extraídas do $\mathrm{LVd}$ submetido à adição de lodo de esgoto.

\subsubsection{Fração argila $(<2 \mu \mathrm{m})$}

Os resultados (Tabela 4.17) mostraram que as aplicações de lodo de esgoto aos solos proporcionaram variações para alguns metais na fração granulométrica de $<2 \mu \mathrm{m}$, argila. 
Tabela 4.17 - Concentração em $\mathrm{mg} \mathrm{kg}^{-1}$ de metais de pesados determinados para a fração argila por ICP OES.

Amostra $^{(1)}$

Quanto aos teores de metais pesados nas frações granulométricas dos solos, as frações silte apresentaram concentrações de metais superiores às encontradas nas demais frações, com exceção do Mn, visto que aparece em maior concentração nas fração argila. Contudo, o maior conteúdo de cargas negativas, decorrentes da presença de matéria orgânica e argilominerais na fração argila deveria exercer uma poder complexante superior, o que não foi observado se comparado os resultados obtidos entre as frações argila e silte.

Comparando esses resultados com os obtidos para as amostras de solo intacto foi observado que essa se mostrou mais eficiente na detecção de metais pesados oriundo do lodo de esgoto. Contudo, visando complementar os resultados obtidos, foram observados os teores de metais pesados nas frações químicas do solo.

\subsubsection{Frações químicas}

Esta etapa consistiu em verificar a qual fração química do solo encontram-se preferencialmente os metais pesados adicionados via lodo de esgoto, de modo a fornecer subsídios às discussões sobre o uso deste resíduo na agricultura. 
O fracionamento químico foi elaborado com base na metodologia sugerida pela IHSS, onde o objetivo era armazenar e estudar todas as frações químicas, águas de lavagem e resíduos gerados durante esse processo. O estudo foi realizado com o LVd submetido à adição de lodo de esgoto, visto que suas frações físicas apresentaram as alterações mais significativas decorrentes da adição de lodo de esgoto.

\subsubsection{Fração humina}

A partir dos resultados obtidos na (Tabela 4.18), podemos observar a presença dos metais $\mathrm{Cd}, \mathrm{Cr}, \mathrm{Cu}, \mathrm{Fe}, \mathrm{V}$ e $\mathrm{Zn}$. Os altos teores de $\mathrm{Cu}$ encontrados na fração humina possivelmente são decorrentes da adição do lodo de esgoto.

Tabela 4.18 - Concentração em $\mathrm{mg} \mathrm{kg}^{-1}$ de metais de pesados determinados para a fração humina por ICP OES.

\begin{tabular}{l|ccccccccc}
\hline Amostra $^{(1)}$ & $\mathrm{Cd}$ & $\mathrm{Cr}$ & $\mathrm{Cu}$ & $\mathrm{Fe}$ & $\mathrm{Co}$ & $\mathrm{Mn}$ & $\mathrm{Mo}$ & $\mathrm{V}$ & $\mathrm{Zn}$ \\
& $---------------------------------\mathrm{mg} \mathrm{kg}^{-1}---------------------------$ \\
\hline $\mathrm{LVd}+\mathrm{B} / \mathrm{P} 1$ & 2 & 37 & 4 & 8713 & $<\mathrm{LD}$ & $<\mathrm{LD}$ & $<\mathrm{LD}$ & 14 & 17 \\
$\mathrm{LVd}+\mathrm{B} / \mathrm{P} 2$ & 1 & 30 & 2 & 7274 & $<\mathrm{LD}$ & $<\mathrm{LD}$ & $<\mathrm{LD}$ & 18 & 10 \\
$\mathrm{LVd}+\mathrm{B} / \mathrm{P} 3$ & 3 & 31 & 3 & 7982 & $<\mathrm{LD}$ & $<\mathrm{LD}$ & $<\mathrm{LD}$ & 19 & 7 \\
$\mathrm{LVd}+\mathrm{B} / \mathrm{P} 4$ & $<\mathrm{LD}$ & 9 & $<\mathrm{LD}$ & 1815 & $<\mathrm{LD}$ & $<\mathrm{LD}$ & $<\mathrm{LD}$ & 3 & 4 \\
\hline
\end{tabular}

$<\mathrm{LD}=$ abaixo do limite de detecção

${ }^{(1)}$ Fração humina extraída do solo: $\mathrm{LVd}+\mathrm{B} \rightarrow$ (submetido à adição de lodo de esgoto). As profundidades variam de 0-60 cm onde: $\mathrm{P} 1 \rightarrow$ 0-10; P2 $\rightarrow$ 10-20; P3 $\rightarrow$ 20-40 e P4 $\rightarrow$ 40-60 cm.

Comparando-se a fração humina ao solo total, pode-se observar uma maior quantidade de metais pesados incorporados à primeira, tal comportamento pode ser atribuído à maior homogeneidade da fração se comparado ao solo.

\subsubsection{2 Água de lavagem da humina}

O armazenamento e a análise da água de lavagem da humina faz parte da metodologia desenvolvida neste trabalho.

Os resultados obtidos mostraram que quantidades significativas de metais são perdidas durante o processo de extração, decorrentes do descarte da água de lavagem da humina. Esses metais presentes na água de lavagem da humina podem estar complexados com a matéria orgânica dissolvida. Com isso, os resultados mostraram a importância de se analisar todos os 
resíduos da extração de substâncias húmicas para se avaliar o comportamento dos metais nas frações químicas do solo.

Tabela 4.19 - Concentração em $\mathrm{mg} \mathrm{L}^{-1}$ de metais de pesados determinados para a água de lavagem da humina por ICP OES.

\begin{tabular}{|c|c|c|c|c|c|c|c|c|c|}
\hline Amostra $^{(1)}$ & $\mathrm{Cd}$ & $\mathrm{Cr}$ & $\mathrm{Cu}$ & $\mathrm{Fe}$ & $\mathrm{Co}$ & $\mathrm{Mn}$ & Mo & $\mathrm{V}$ & $\mathrm{Zn}$ \\
\hline & & & & & & & & & \\
\hline $\mathrm{LVd}+\mathrm{B} / \mathrm{P} 1$ & $<\mathrm{LD}$ & 5 & 4 & 260 & 3 & 17 & 1 & $<\mathrm{LD}$ & 761 \\
\hline $\mathrm{LVd}+\mathrm{B} / \mathrm{P} 2$ & 2 & 3 & 1 & 116 & $<\mathrm{LD}$ & 5 & $<\mathrm{LD}$ & 1 & 241 \\
\hline $\mathrm{LVd}+\mathrm{B} / \mathrm{P} 3$ & $<\mathrm{LD}$ & 2 & 2 & 357 & 1 & 12 & $<\mathrm{LD}$ & 1 & 308 \\
\hline $\mathrm{LVd}+\mathrm{B} / \mathrm{P} 4$ & $<\mathrm{LD}$ & 2 & 1 & 379 & 1 & 14 & 3 & $<\mathrm{LD}$ & 133 \\
\hline
\end{tabular}

$<\mathrm{LD}=$ abaixo do limite de detecção

${ }^{(1)}$ Fração ácido fúlvico 1 extraída do solo: $\mathrm{LVd}+\mathrm{B} \rightarrow$ (submetido à adição de lodo de esgoto). As profundidades

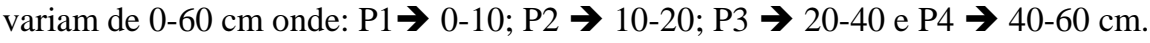

Quanto aos teores de metais na fração humina e na água de lavagem, a fração humina apresentou concentrações de metais superiores, com exceção do $\mathrm{Zn}$, visto que aparece em maior concentração na água de lavagem da humina. A alta concentração de Zn na água de lavagem pode ser atribuída à elevada quantidade do metal no resíduo (Tabela 4.12).

\subsubsection{Fração ácido fúlvico 1}

A partir dos resultados obtidos para a fração ácido fúlvico 1 observou-se a presença de Cd, Cr, Cu, Fe, Co, Mn, Mo, V e Zn (Tabela 4.20) na fração ácido fúlvico 1.

Tabela 4.20 - Concentração em $\mathrm{mg} \mathrm{L}^{-1}$ de metais de pesados determinados para a fração ácido fúlvico 1 por ICP OES.

\begin{tabular}{|c|c|c|c|c|c|c|c|c|c|}
\hline Amostra $^{(1)}$ & $\mathrm{Cd}$ & $\mathrm{Cr}$ & $\mathrm{Cu}$ & $\mathrm{Fe}$ & $\mathrm{Co}$ & $\mathrm{Mn}$ & Mo & $\mathrm{V}$ & $\mathrm{Zn}$ \\
\hline $\mathrm{LVd}+\mathrm{B} / \mathrm{P} 1$ & 3 & 9 & 44 & 763 & 2 & 130 & 3 & 3 & 19122 \\
\hline $\mathrm{LVd}+\mathrm{B} / \mathrm{P} 2$ & 2 & 5 & 30 & 584 & 3 & 104 & 1 & 2 & 12939 \\
\hline $\mathrm{LVd}+\mathrm{B} / \mathrm{P} 3$ & 1 & 2 & 16 & 264 & 3 & 53 & 2 & 2 & 5915 \\
\hline $\mathrm{LVd}+\mathrm{B} / \mathrm{P} 4$ & 1 & $<\mathrm{LD}$ & 6 & 81 & 1 & 34 & 1 & 1 & 1236 \\
\hline
\end{tabular}

$<\mathrm{LD}=$ abaixo do limite de detecção

${ }^{(1)}$ Fração ácido fúlvico 1 extraída do solo: $\mathrm{LVd}+\mathrm{B} \rightarrow$ (submetido à adição de lodo de esgoto). As profundidades variam de 0-60 cm onde: $\mathrm{P} 1 \rightarrow 0-10 ; \mathrm{P} 2 \rightarrow 10-20 ; \mathrm{P} 3 \rightarrow 20-40$ e P4 $\rightarrow$ 40-60 cm.

O ácido fúlvico como, fração orgânica do solo apresenta uma quantidade maior de grupos funcionais se comparada a humina, por isso o seu poder de complexação de metais pesados é maior que o apresentado pela humina. 


\subsubsection{Fração ácido fúlvico 2}

Os teores de metais observados na fração de ácido fúlvico 2, são menores que os obtidos para a fração de ácido fúlvico 1 (Tabela 4.21).

Tabela 4.21 - Concentração em mg L ${ }^{-1}$ de metais de pesados determinados para a fração ácido fúlvico 2 por ICP OES.

\begin{tabular}{|c|c|c|c|c|c|c|c|c|c|}
\hline $\operatorname{Amostra}^{(1)}$ & $\mathrm{Cd}$ & $\mathrm{Cr}$ & $\mathrm{Cu}$ & $\mathrm{Fe}$ & Co & $\mathrm{Mn}$ & Mo & V & $\mathrm{Zn}$ \\
\hline $\mathrm{LVd}+\mathrm{B} / \mathrm{P} 1$ & 1 & 4 & 10 & 78 & 1 & 10 & $<\mathrm{LD}$ & 7 & 919 \\
\hline $\mathrm{LVd}+\mathrm{B} / \mathrm{P} 2$ & $<\mathrm{LD}$ & 4 & 12 & 86 & 3 & 11 & $<\mathrm{LD}$ & 10 & 886 \\
\hline $\mathrm{LVd}+\mathrm{B} / \mathrm{P} 3$ & 1 & 2 & 7 & 40 & 1 & 9 & 3 & 12 & 526 \\
\hline $\mathrm{LVd}+\mathrm{B} / \mathrm{P} 4$ & 3 & 1 & 3 & 20 & 1 & 5 & 2 & 12 & 271 \\
\hline
\end{tabular}

$<\mathrm{LD}=$ abaixo do limite de deteç̧ão

${ }^{(1)}$ Fração ácido fúlvico 2 extraída do solo: $\mathrm{LVd}+\mathrm{B} \rightarrow$ (submetido à adição de lodo de esgoto). As profundidades variam de 0-60 cm onde: $\mathrm{P} 1 \rightarrow 0-10 ; \mathrm{P} 2 \rightarrow 10-20 ; \mathrm{P} 3 \rightarrow 20-40$ e $\mathrm{P} 4 \rightarrow 40-60 \mathrm{~cm}$.

\subsubsection{Fração ácido húmico}

A partir dos resultados obtidos na (Tabela 4.22) pode-se observar a capacidade de complexação de metais pesados apresentada pela fração ácido húmico. Esse se deve ao seu alto conteúdo de grupos carboxílicos e fenólicos, que possuem um alto poder de complexar metais, segundo Zech et al. (1997).

Tabela 4.22 - Concentração em $\mathrm{mg} \mathrm{kg}^{-1}$ de metais de pesados determinados para a fração ácido húmico por ICP OES.

\begin{tabular}{|c|c|c|c|c|c|c|c|c|c|}
\hline $\operatorname{Amostra}^{(1)}$ & $\mathrm{Cd}$ & $\mathrm{Cr}$ & $\mathrm{Cu}$ & $\mathrm{Fe}$ & $\begin{array}{r}\mathrm{Co} \\
\mathrm{g} \mathrm{k}\end{array}$ & $\mathrm{Mn}$ & Mo & V & $\mathrm{Zn}$ \\
\hline $\mathrm{LVd}+\mathrm{B} / \mathrm{P} 1$ & $<\mathrm{LD}$ & 29 & 91 & 8820 & 2 & 45 & 1 & 19 & 1709 \\
\hline $\mathrm{LVd}+\mathrm{B} / \mathrm{P} 2$ & 1 & 70 & 73 & 33018 & 2 & 73 & 2 & 75 & 1739 \\
\hline $\mathrm{LVd}+\mathrm{B} / \mathrm{P} 3$ & 1 & 40 & 23 & 23979 & 1 & 54 & 1 & 43 & 1157 \\
\hline $\mathrm{LVd}+\mathrm{B} / \mathrm{P} 4$ & $<\mathrm{LD}$ & 6 & 20 & 989 & 2 & 26 & 1 & 3 & 702 \\
\hline
\end{tabular}

$<\mathrm{LD}=$ abaixo do limite de detecção

${ }^{(1)}$ Fração ácido húmico extraída do solo: $\mathrm{LVd}+\mathrm{B} \rightarrow$ (submetido à adição de lodo de esgoto). As profundidades variam de 0-60 cm onde: $\mathrm{P} 1 \rightarrow 0-10 ; \mathrm{P} 2 \rightarrow 10-20 ; \mathrm{P} 3 \rightarrow 20-40$ e $\mathrm{P} 4 \rightarrow 40-60 \mathrm{~cm}$.

Segundo os resultados obtidos observou-se uma maior concentração dos metais pesados adicionados ao solo por adição de lodo de esgoto na superfície. Com isso observa-se um pequeno movimento de metais pesados abaixo da zona de incorporação do lodo de esgoto. A 
relativa falta de movimento dos metais pesados nos solos tratados com lodo de esgoto, é devida principalmente sua forte complexação à matéria orgânica do solo.

Foram observados a partir dos resultados (Tabela 4.22) a alta capacidade dos ácidos húmicos se comparados às demais frações do solo em seqüestrar e complexar os metais pesados provenientes do lodo de esgoto. Esse resultado é de grande relevância, uma vez que demonstra a chance de retenção desses metais no solo, sem risco imediato de contaminação de plantas e águas de lençol freático.

A metodologia de digestão adotada visou a extração dos teores totais de metais do solo, de suas frações físicas e químicas. Na literatura (Vieira et al., 2005) encontramos trabalhos sobre a decomposição assistida por radiação de micoondas com HF. Talvez essa possa proporcionar resultados satisfátorios para amostras de solo total. 


\section{CAPÍTULO 5 CONCLUSÕES}

A utilização de três métodos para a determinação do teor de carbono e matéria orgânica dos solos analisados permitiu a obtenção de resultados com maior confiabilidade, já que a literatura apresenta dúvidas quanto à recomendação do método mais adequado para a obtenção de resultados precisos.

Resultados mais consistentes foram obtidos pelo método do TOC, possivelmente devido a representatividade amostral e ao menor intervalo de precisão da medida, comprovando uma maior sensibilidade e confiabilidade do método. A confiabilidade nos resultados obtidos é imprescindível, principalmente quando se quer avaliar as alterações da matéria orgânica de solos submetidos à adição de lodo de esgoto.

Os resultados espectroscópicos para os solos, LVef e LVd, mostram que a utilização de diferentes técnicas espectroscópicas como, absorção de radiação no UV-Vis, FTIR, RMN, RPE, fluorescência e FIL, fornecem resultados significativos à respeito das variações na matéria orgânica dos solos, após à adição de lodo de esgoto.

Através de FTIR e RMN foram observados no ácido húmico extraído do lodo de esgoto, banda intensiva na região de grupos metileno e metil, indicando o alto grau de alifaticidade do resíduo. Conseqüentemente, diminuição do grau de aromaticidade e aumento do grau de alifaticidade, promovido pela adição de lodo de esgoto aos solos analisados. Esta diminuição do grau de aromaticidade pode ser atribuída à incorporação de compostos menos humificados procedentes do resíduo incorporado. Contudo, as diferenças são mais acentuadas nas amostras de 0-10 e 10-20 cm, visto que a aplicação e a incorporação do resíduo ocorreu na superfície do solo.

A quantificação do número de radicais livres do tipo semiquinona pela técnica de RPE nos forneceu resultados significativos e claros a cerca da diminuição do grau de humificação promovido pela incorporação do lodo de esgoto ao solo. Essa diminuição observada é mais 
significativa na superfície do solo, corroborando com os resultados obtidos FTIR e RMN. A correlação positiva entre o número de radicais livres do tipo semiquinona e a largura de linha, nos evidenciam mais uma alternativa para se estudar as alterações ocorridas na matéria orgânica de solos submetidos à adição de lodo de esgoto.

A fluorescência forneceu resultados coerentes acerca do grau de humificação das amostras de ácidos húmicos extraídos de solos com características texturais bastante divergentes. As três metodologias de fluorescência empregadas, Zsolnay, Milori e Kalbitz, apresentaram boas correlações entre si e com as demais técnicas espectroscópicas empregadas.

A técnica de FIL se mostrou eficiente na determinação do grau de humificação da matéria orgânica de solos submetidos ou não à adição de lodo de esgoto, fornecendo resultados significativos acerca da importância da adição deste resíduo ao solo. Com isso, foi observado uma diminuição no grau de humificação devido à adição do resíduo ao solo, devido à incorporação de compostos menos humificados procedentes do lodo de esgoto. Destacamos ainda, a importância da técnica de FIL a este trabalho, devido à vantagem de ser uma alternativa para se analisar solos com alto teor de óxidos de ferro.

Os resultados obtidos a partir das técnicas químicas e espectroscópicas nos mostraram que os benefícios proporcionados pela adição de lodo de esgoto ao solo num experimento de campo de longa duração podem ser significativos não apenas para solos com alto teor de argila (LVef), onde a capacidade de complexação da matéria orgânica é maior se comparada aos solos arenosos mas também, para solos onde o teor de areia (LVd) é elevado, visto que esses solos são mais pobres e à adição de um resíduo com um alto teor de matéria orgânica, apresenta-se como uma fonte importante de nutrientes e matéria orgânica, melhorando as suas propriedades químicas e físicas. Com isso, podemos confirmar que a importância da adição do lodo de esgoto ao solo, não é apenas de caráter ambiental. 
A dinâmica da matéria orgânica dos solos analisados pode ser eficientemente avaliada por técnicas químicas e espectroscópicas utilizadas, visto que essas permitiram a observação de variações significativas na decomposição e humificação, decorrentes da adição do resíduo ao solo. Bem como, permitiram determinar a natureza química e as variações de grupamentos funcionais da matéria orgânica devido à adição de lodo de esgoto aos solos analisados.

Constatamos que à adição de doses, durante 7 anos consecutivos, de lodo de esgoto de origem urbana e industrial, nos solos LVef e LVd, não alcançou os limites estabelecidos pela norma P 4.230 da CETESB-1999, que determina os critérios para o uso agrícola do lodo de esgoto no Estado de São Paulo.

A análise dos metais $\mathrm{Cd}, \mathrm{Cr}, \mathrm{Cu}, \mathrm{Fe}, \mathrm{Co}, \mathrm{Mn}, \mathrm{Mo}, \mathrm{V}$ e $\mathrm{Zn}$ nos solos tratados com lodo de esgoto não evidenciou o aumento destes elementos, mesmo quando o lodo apresenta níveis superiores aos encontrados no solo.

A ampliação da avaliação dos teores de metais pesados além dos procedimentos convencionais do solo total, forneceu resultados significativos a cerca do destino dos metais oriundos do lodo de esgoto.

Os resultados obtidos em relação aos teores de metais nas frações físicas do solo, mostraram que a composição granulométrica e a porcentagem de carbono, são dois fatores que interferem na fixação dos metais, com isso maiores teores de metais foram encontradas para as frações silte fino e argila.

A metodologia desenvolvida para avaliar os teores de metais nas frações químicas do solo se mostrou satisfatória, visto que teores de metais pesados mais próximos dos teores adicionados foram observados por essa. A água de lavagem da humina, descartada durante o processo de extração química das substâncias húmicas apresentou concentrações significativas de metais, em destaque Zn. O ácido húmico, devido a grande quantidade de grupos reativos (carboxílicos e fenólicos), mostrou ser um forte agente complexante de metais. 


\section{CAPITULO 6 REFERÊNCIAS BIBLIOGRÁFICAS}

ACCIOLY, A. M. A.; SIQUEIRA, J. O. Contaminação química e biorremediação do solo In: NOVAIS, R. F.; ALVAREZ V, V. H.; SCHAEFER, C. E. G. R. Tópicos em ciência do solo. Viçosa: UFV, 2000. p. 299-352.

BAES, A. V.; BLOOM, P. R. Fulvic acid ultraviolet-visible spectra: influence of solvent and pH. Soil Science Society of American Journal, v. 54, p. 1248, 1990.

BAYER, C. Dinâmica da matéria orgânica em sistemas de manejo de solos. 1996. 241 f. Tese (Doutorado em Ciência do Solo ) - Faculdade de Agronomia, Universidade Federal do Rio Grande do Sul, Porto Alegre, 1996.

BAYER, C.; MARTIN-NETO, L.; MIELNICZUK, J.; CERETTA, C. A. Fracionamento da matéria orgânica e sua avaliação qualitativa por EPR num solo submetido dez anos a diferentes sistemas de cultura em plantio direto. In: SIMPÓSIO NACIONAL DE INSTRUMENTAÇÃO AGROPECUÁRIA, 1., 1996, São Carlos. Anais... São Carlos: Embrapa Instrumentação Agropecuária, 1997. p. 115-121.

BAYER, C.; MIELNICZUK, J.; AMADO, T. J. C.; MARTIN-NETO, L.; FERNANDES, S. V. Organic matter storage in a sandy clay loam acrisol affected by tillage and cropping systems in southern Brazil. Soil and Tillage Research, v. 54, p. 101-109, 2000.

BAYER, C.; MIELNICZUK, J.; MARTIN-NETO, L.; ERNANI, P. R. Stocks and humification degree of organic matter fractions as affected by no-tillage on a subtropical soil. Plant and Soil, v. 238, p. 133-140, 2002.

BAYER, C.; MARTIN-NETO, L.; SAAB, S. C. Diminuição da humificação da matéria orgânica de um cambissolo húmico em plantio direto. Revista Brasileira de Ciência do Solo, v. 27, p. 537-544, 2003.

BERTON, R. S.; CAMARGO, O. A.; VALADARES, J. M. A. S. Absorção de nutrientes pelo milho em resposta a adição de lodo de esgoto a 5 solos paulistas. Revista Brasileira de Ciência do Solo, v. 13, p. 187-190, 1989.

BERTON, R. S. Ricos de contaminação do agroecossistema com metais pesados. In: BETTIOL, W.; CAMARGO, O. A. Impacto ambiental do uso agrícola do lodo de esgoto. Jaguariúna: EMBRAPA, 2000. cap. 16, p. 259-268.

BERTONCINI, E. I. Comportamento de Cd, Cr, Cu, Ni e Zn em latossolos sucessivamente tratados com biossólido: extração seqüencial, fitodisponibilidade e caracterização de substâncias húmicas. 2002. 210 f. Tese (Doutorado em Solos e Nutrição de Plantas) - Escola Superior de Agricultura "Luiz de Queiroz", Universidade de São Paulo, Piracicaba, 2002.

BETTIOL, W.; CAMARGO, O. A. Reciclagem de lodo de esgoto na agricultura. In: MELO, I. S.; SILVA, C. M. M. S.; SCRAMIN, S.; SPESSOTO, A. (Ed.). Biodegradação. Jaguariúna: Embrapa Meio Ambiente, 2001. p. 93-106. 
BLOOM, P. R.; LEENHEER, J. A. Vibrational, eletronic, and high-energy spectroscopic methods for characterizing humic substances. In: HAYES, M. H. B.; MacCARTHY, P.; MALCOLM, R. L.; SWIFT, R. S. (Ed.) Humic substances II: In search of structure. New York: John Wiley, 1989. p. 410-446.

BRAVARD, S.; RIGHI, D. Characterization of fulvic and humic acids from an oxisol spodosol toposequence of Amazonia, Brazil. Geoderma, v. 48, n. 1-2, p. 151-162, 1991.

BURDON, J. Are the traditional concepts of structures of humic substances realistic? Soil Science, v. 166, n. 11, p. 752-769, 2001.

CAMARGO, O. A.; ALLEONI, L. R. F.; CASAGRANDE, J. C. Reações dos micronutrientes e elementos tóxicos no solo. In: FERREIRA, M. E.; CRUZ, M. C. P.; RAIJ, B.; ABREU, C. A. (Eds). Micronutrientes e elementos tóxicos na agricultura. Jaboticabal: $\mathrm{CNPq} /$ FAPESP/ POTAFOS, 2001. p. 89-124.

CANELLAS, L. P.; SANTOS, G. A.; MORAES, A. A.; RUMJANEK, V. M.; OLIVARES, F. L. Avaliação de características de ácidos húmicos de resíduos de origem urbana: I. Métodos espectroscópicos (UV-Vis, IV, RMN ${ }^{13} \mathrm{C}-\mathrm{CP} / \mathrm{MAS}$ ) e Microscopia eletrônica de varredura. Revista Brasileira de Ciência do Solo, v. 24, p. 741-750, 2000.

CANELLAS, L. P.; SANTOS, G. A.; RUMJANEK, V. M.; MORAES, A. A.; GURIDI, F. Distribuição da matéria orgânica e características de ácidos húmicos em solos com adição de resíduos de origem urbana. Pesquisa Agropecuária Brasileira, v. 36, n. 12, p. 1529-1538, 2001.

CANTARELLA, H.; QUAGGIO, J. A.; VAN RAIJ, B. Determinação da matéria orgânica. In: VAN RAIJ, B.; ANDRADE, J. C.; CANTARELLA, H.; QUAGGIO, J.A. (Eds). Análise química para avaliação da fertilidade de solos tropicais. Campinas: UNICAMP, 2001. cap. 9, p. 173-180.

CARVALHO, E. R.; MARTIN-NETO, L.; MILORI, D. M. B. P.; ROCHA, J. C. ROSA, A. $\mathrm{H}$. Interactions of chlorine with tropical aquatic fulvic acids and formation of intermediates observed by fluorescence spectroscopy. Journal of the Brazilian Chemical Society, v. 15, n. 53, p. 421, 2004.

CERRI, C. C.; MORAES, J. F. L. Conseqüências do uso e manejo do solo no teor de matéria orgânica. In: GUERRINI, I. A.; BÜLL, L. T. (Eds.). Matéria orgânica do solo: problemas e soluções. Botucatu: Faculdade de Ciências Agronômicas, 1992. p. 25-62.

CHEN, Y.; SCHNITZER, M. Scanning electron-microscopy of a humic-acid and of a fulvicacid and its metal and clay complexes. Soil Science Society of American Journal, v. 40, p. 682-686, 1976.

CHEN, Y.; SENESI, N.; SCHNITZER, M. Information provide on humic substances by $\mathrm{E}_{4} / \mathrm{E}_{6}$ ratios. Soil Science Society of American Journal, v. 41, p. 352, 1977.

CLAPP, C. E.; HAYES, M. H. B. Sizes and shapes of humic substances. Soil Science, v. 164, n. 12, p. 777-789, 1999. 
COLNAGO, L. A.; MARTIN-NETO, L.; MIYAZAWA, E. M. V.; BONAGAMBA, T. J.; PANEPUCCI, H. Estudo da razão E4/E6 e aromaticidade por RMN de $\mathrm{C}^{13}$ em estado sólido de AH de um Latossolo Roxo. In: ENCONTRO BRASILEIRO SOBRE SUBSTÂNCIAS HÚMICAS, 2., 1997, São Carlos. Anais... São Carlos: Sociedade Brasileira de Substâncias húmicas/ Embrapa Instrumentação Agropecuária, 1997. p. 167.

COMPANHIA DE TECNOLOGIA DE SANEAMENTO AMBIENTAL. Aplicação de lodos de sistemas de tratamento biológico em áreas agrícolas: critérios para projeto e operação. São Paulo: CETESB, 1999. 32p. (Manual Técnico, Norma P.4.230).

CONCEIÇÃO, M.; MANZATTO, C. V.; ARAÚJO, W. S.; MARTIN-NETO, L.; SAAB, S. C.; CUNHA, T. J. F.; FREIXO, A. A. Estudo comparativo de métodos de determinação do teor de matéria orgânica em organossolos. Rio de Janeiro: EMBRAPA, 1999. 4 p. (Comunicado Técnico).

CONSELHO NACIONAL DO MEIO AMBIENTE. Regulamentação do uso agrícola de lodo de esgoto. Disponível em:

<http://www.mma.gov.br/port/conama/processos/cb5f6214/propreslodolimpa21ctaj1.pdf>. Acesso em: 2 nov. 2005.

CONTE, P.; PICCOLO, A. Conformation arrangement of dissolved humic substances: influence of solution composition on association of humic molecules. Environmental Science \& Technology, v. 33, p. 1682-1690, 1999.

COSTA, A. C. S.; ALMEIDA, V.C.; LENZI, E.; NOZAKI, J. Determinação de cobre, alumínio e ferro em solos derivados do basalto através de extrações seqüenciais. Química Nova, v. 25, n. 4, p. 548-552, 2002

DIAS, B. O. Caracterização da matéria orgânica de latossolo sob aplicação continuada de lodo de esgoto. 2005. 68 f. Dissertação (Mestrado em Solos e Nutrição de Plantas), Universidade Federal de Lavras, Lavras, 2005.

DIALLO, M. S.; SIMPSON, A.; GASSMAN, P.; FAULON, J. L.; JOHNSON, J. H.; GODDARD, W. A.; HATCHER, P. G. 3-D Structural modeling of humic acids through experimental characterization, computer assisted structure elucidation and atomistic simulations. Environmental Science \& Technology, v. 37, p. 1783-1793, 2003.

DIEKOW, J.; BAYER, C.; MIELNICZUK, J. Dinâmica da matéria orgânica do solo e sua importância. In: SEMANA DE ESTUDOS AGRONÔMICOS DA UNICENTRO, 1., 2004, Guarapuava. Anais... Guarapuava: Universidade Estadual do Centro-Oeste, 2004. p. 143-153.

EMPRESA BRASILEIRA DE PESQUISA AGROPECUÁRIA. Centro Nacional de Pesquisa de Solos. Sistema Brasileiro de Classificação de Solos. Rio de Janeiro, 1999. 412 p.

FELLER, C.; BEARE, M. H. Physical control of soil organic matter dynamics in the tropics. Geoderma, v. 79, p. 69-116, 1997.

FERNANDES, F.; ANDRAUS, S.; ANDREOLI, C. V. Eficiência dos processos de desinfecção do lodo da ETE-Belém com vista a seu uso agrícola. Sanare, v. 5, n. 5, p. 46-58, jan./abr. 1996. 
FERNANDES, F. Estabilização e Higienização de Biossólidos. In: BETTIOL, W.; CAMARGO, O. A. Impacto ambiental do uso agrícola do lodo de esgoto. Jaguariúna: EMBRAPA, 2000. cap. 3, p. 45-67.

FINNECY, E. E.; PEARCE, K. W. Land contamination and reclamation. In: HESTER, R. E. (Ed.). Understanding our environment. London: The Royal Society of Chemistry, 1986. p. 172-225.

FUNGARO, D. A.; FLUES, M. S. M; CELEBRONI, A. P. Estabilização de solos com zinco usando zeólitas sintetizadas a partir de cinzas de carvão. Química Nova, v. 27, n. 4, p. 582$585,2004$.

GHOSH, K.; SCHNITZER, M. Macromolecular structures of humic substances. Soil Science, v. 129 , p. $266-276,1980$.

GONZÁLEZ-PÉREZ, M. Estudos Espectroscópicos da dinâmica da matéria orgânica e complexação com íons metálicos em solos submetidos à adição de lodo de esgoto. 2003. 128 f. Tese (Doutorado em Química Analítica) - Instituto de Química de São Carlos, Universidade de São Paulo, São Carlos, 2003.

GONZÁLEZ-PÉREZ, M.; MARTIN-NETO, L.; SAAB, S. C.; NOVOTNY, E. H.; MILORI, D. M. B. P.; BAGNATO, V. S.; COLNAGO, L. A.; MELO, W. J.; KNICKER, H. Characterization of humic acids from a Brazilian Oxisol under different tillage systems by EPR, ${ }^{13}$ C NMR, FTIR and fluorescence spectroscopy. Geoderma, v. 118, p. 181-190, 2004.

HAYES, M. H. B.; CLAPP, C. E. Humic substances: considerations of compositions, aspects of structures, and environmental influences. Soil Science, v. 166, p. 723-737, 2001.

HERNANDEZ, T.; MORENO, J. I.; COSTA, F. Infrared spectroscopic characterization of sewage sludge humic acids. Evidence of sludge organic matter-metal interactions.

Agrochimica, v. 37, n. 1, p. 12-17, 1993.

HEVIA, G. G.; BUSCHIAZZO, D. E.; HEPPER, E. N.; URIOSTE, A. M.; ANTÓN, E. L. Organic matter in size fractions of soils of the semiarid Argentina. Effects of climate, soil texture and management. Geoderma, v. 116, n. 3-4, p. 265-277, 2003.

HOHLA, G. N.; JONES, R. L.; HINESLY, T. D. The effect of anaerobically disgested sewage sludge on fractions of blount silt loam. Journal of Environmental Quality, v. 7, p. 559-563, 1978.

INSTITUTO AMBIENTAL DO PARANÁ. Utilização agrícola do lodo de esgoto. Disponível em: <http://www.mma.gov.br/conama/>. Acesso em: 2 nov. 2005.

INSTITUTO BRASILEIRO DE GEOGRAFIA E ESTATÍSTICA. Dimensão Ambiental Saneamento. Tratamento de Esgoto. Rio de Janeiro: IBGE, 2002. Página Indicadores de Desenvolvimento Sustentável - Brasil 2002. Disponível em: 〈http://www.ibge.gov.br〉. Acesso em: 10 maio 2005.

JELINSKI, L. W.; MELCHIOR, M. T. High-Resolution NMR of solids. Applied Spectroscopy Reviews, v. 35, n. 1 e 2, p. 25-93, 2000. 
KABATA-PENDIAS, A.; PENDIAS, H. Trace Elements in Soils and Plants. 3. ed. Boca Raton: CRC, 1985. 315 p.

KALBITZ, K.; GEYER, W.; GEYER, S. Spectroscopic properties of dissolved humic substances - a reflection of land use history in a fen area. Biogeochemistry, v. 47, p. 219-238, 1999.

KALBITZ, K.; GEYER, W.; GEYER, S. A comparative characterization of dissolved organic matter by means of original aqueous samples and isolated humic substances. Chemosphere, v. 40, p. 1305-1312, 2000.

KIRKHAM, B. B. Agricultural use phosphosrus in sewage sludge. Advances in Agronomy, v. 35, p. 129-163, 1982.

KNICKER, H. Biogenic nitrogen in soils as revealed by solid-state carbon-13 and nitrogen-15 nuclear magnetic resonance spectroscopy. Journal of Environmental Quality, v. 29, n. 3, p. 715-723, 2000.

KÖGEL-KNABER, I.; ZECH, W.; HATCHER, P.G. Chemical structural studies of florest soil humic acids: aromatic carbon fraction. Soil Science Society of America, v. 55, p. 241247, 1991.

KÖGEL-KNABER, I. ${ }^{13} \mathrm{C}$ and ${ }^{15} \mathrm{~N}$ NMR spectroscopy as a tool in soil organic matter studies. Geoderma, v. 80, p. 243-270, 1997.

LAGERCRANTZ, C.; YHLAND, M. Photo-induced free radical reactions in the solutions of some tars and humic acids. Acta Chemica Scandinavica, v. 17, p. 1299-1306, 1963.

LEITE, C. M. B.; BERNARDES, R. S.; OLIVEIRA, S. A. Método de Walkley-Black na determinação da matéria orgânica em solos contaminados por chorume. Revista Brasileira de Engenharia Agrícola e Ambiental, v. 8, n. 1, p. 111-115, 2004.

LUCHESE, E. B.; FAVERO, L. O. B.; LENZI, E. Fundamentos da química do solo: teoria e prática. Rio de Janeiro: Freitas Bastos Editora, 2002. 159 p.

LUMB, M. D. Lumescence Spectroscopy. New York: Academic Press, 1978. 375 p.

MACCARTHY, P.; MALCOLM, R. L.; CLAPP, C. E.; BLOOM, P. R. An introduction to soil humic substances. In: MACCARTHY, P.; CLAPP, C. E.; MALCOLM, R. L.; BLOOM, P. R. (Ed.). Humic substances in soil and crop sciences: selected readings. Madison: American Society of Agronomy, Madison, 1990. cap. 1, p. 1-12.

MACCARTHY, P. The principles of humic substances. Soil Science, v. 166, n. 11, p. 738$751,2001$.

MALAVOLTA, E. Fertilizantes e seu impacto ambiental: micronutrientes e metais pesados, mitos, mistificação e fatos. São Paulo: ProduQuímica, 1994. 153 p.

MANGRICH, A. S. Estruturas químicas de substâncias húmicas: estratégias de pesquisa. In: ENCONTRO BRASILEIRO DE SUBSTÂNCIAS HÚMICAS, 4., 2001, Viçosa. Anais... Viçosa: Sociedade Brasileira de Substâncias húmicas/ Universidade Federal de Viçosa, 2001. p. 15-17. 
MARQUES, J. C. Caracterização química e espectroscópica de substâncias húmicas de solos submetidos à adição de lodo de esgoto. 1998. 93 f. Dissertação (Mestrado em Química Analítica) - Instituto de Química de São Carlos, Universidade de São Paulo, São Carlos, 1998.

MARQUES, M. O. Incorporação de lodo de esgoto em solo cultivado com cana de açúcar. 1999. 111 f. Tese (Livre Docência) - Faculdade de Ciências Agrárias e Veterinárias, Universidade Estadual Paulista Júlio de Mesquita Filho, Jaboticabal, 1999.

MARTIN-NETO, L.; NASCIMENTO, O. R.; TALAMONI, J.; POPPI, N. R. EPR of micronutrients-humic substances complexes extracted from brazilian soil. Soil Science, v. 151, p. 369-376, 1991.

MARTIN-NETO, L.; ANDRIULO, A, E.; TRAGUETTA, D. Effects of cultivation on ESR spectra of organic matter from soil size fractions of a mollisol. Soil Science, v. 157, p. 365372, 1994a.

MARTIN-NETO, L; VIEIRA, E.; SPOSITO, G. Mechanism of atrazine sorption by humic acid: a spectroscopic study. Environmental Science and Technology, v. 28, p. 1867-1873, 1994b.

MARTIN-NETO, L; ROSSEL, R.; SPOSITO, G. Correlation of spectroscopic indicators of humification with mean annual rainfull along a temperature grassland climosequence.

Geoderma, v. 81, p. 305-311, 1998.

MARTIN-NETO, L; TRAGHETTA, D. G.; VAZ, C. M. P.; CRESTANA, S.; SPOSITO, G. On the interaction mechanisms of atrazine and hydroxyatrazine with humic substances.

Journal of Environmental Quality, v. 30, p. 520-525, 2001.

MATTIGOD, S. V.; SPOSITO, G.; PAGE, A. L. Factors affecting the solubilities of trace metals in soils. In: BAKER, D. E. (Ed.). Chemistry in the soil environment. Madison: American Society of Agronomy, 1981. 259 p.

MC PHIE, P. Enzyme Purification and Related Techniques: dialysis. In: JACOBY, W. B. (Ed.). Methods in Enzymology. New York: Academic Press, 1971. v. 22, p. 25-175

MELO, W. J.; MARQUES, M. O.; SANTIAGO, G.; CHELLI, R. A.; LEITE, S. A. S. Efeito de doses crescentes de lodo de esgoto sobre frações da matéria orgânica e CTC de um latossolo cultivado com cana de açúcar. Revista Brasileira de Ciência do Solo, v. 18, p. 449455, 1994.

MELO, W. J.; MARQUES, M. O. Potencial do lodo de esgoto como fonte de nutrientes para as plantas. In: BETTIOL, W.; CAMARGO, O. A. Impacto ambiental do uso agrícola do lodo de esgoto. Jaguariúna: EMBRAPA, 2000. cap. 5, p. 109-141.

MELO, W. J.; MELO, V. P.; MELO, G. M. P. Grain production and lead content in sorghum plants cropped in a soil contaminated with lead. In: INTERNATIONAL CONFERENCE ON THE BIOGEOCHEMISTRY OF TRACE ELEMENTS, 6., 2001, Ontário: Proceedings... 2001, p. 424. 1 CD-ROM. 
MIELNICZUK, J. Matéria orgânica e a sustentabilidade de sistemas agrícolas. In: SANTOS, G. A.; CAMARGO, F. A. O. (Eds). Fundamentos da matéria orgânica do solo: ecossistemas tropicais e subtropicais. Porto Alegre: Gênesis, 1999. p. 1-8. MILORI, D. M. B. P.; MARTIN-NETO, L.; VAZ, C. M. P.; BAGNATO, V. S. Sensor de Teor e qualidade de matéria orgânica de solo. BR n. PI 0106477-0, 18 de dez. 2001.

MILORI, D. M. B. P; MARTIN-NETO, L.; BAYER, C.; MIELNICZUK, J.; BAGNATO, V. S. Humification degree of soil humic acids determined by fluorescence spectroscopy. Soil Science, v. 167, n. 11, p. 739-749, 2002.

MILORI, D. M. B. P; MARTIN-NETO, L.; BAYER, C. Nova metodologia utilizando fluorescência induzida por laser para análise de solos inteiros. In: CONGRESSO BRASILEIRO DE CIÊNCIA DO SOLO, 29., 2003, Ribeirão Preto. Anais... Ribeirão Preto: Sociedade Brasileira de Ciência do Solo, 2003.

MILORI, D. M. B. P.; GALETI, H. V. A.; MARTIN-NETO, L.; DIEKOW, J.; GONZÁLEZPÉREZ, M.; BAYER, C.; SALTON, J. Organic matter study of whole soil sample using laserinduced fluorescence spectroscopy. Soil Science Society American Journal, v. 70, p. 57-63, 2006.

MIYAZAWA, M.; PAVAN, M. A.; OLIVEIRA, E. L.; IONASHIRO, M.; SILVA, A. K. Gravimetric determination of soil organic matter. Brazilian Archives of Biology and Technology, v. 43, n. 5, p. 475-478, 2000.

MONTASER, A.; GOLIGHTLY, D. W. Inductively Coupled Plasmas in Analytical Atomic Spectrometry. New York: VCH, 1992. 1017 p.

NAKANISHI, K. Infrared absorption spectroscopy. Tokyo: Nankondo, 1962. 233 p.

NARIMOTO, K. M.; SANTOS, L. M.; MILORI, D. M. B. P.; MELO, W. J.; DIECKOW, J.; MARTIN-NETO, L. Caracterização da matéria orgânica de um argissolo tratado com biossólido por fluorescência induzida por laser. In: CONGRESSO BRASILEIRO DE CIÊNCIA DO SOLO, 30., 2005, Recife. Anais... Sociedade Brasileira de Ciência do Solo, 2005. 1 CD-ROM.

NASCIMENTO, C. W. A.; BARROS, D. A. S.; MELO, E. E. C.; OLIVEIRA, A. B. Alterações químicas em solos e crescimento de milho e feijoeiro após aplicação de lodo de esgoto. Revista Brasileira de Ciência do Solo, v. 28, p. 385-392, 2004.

NELLESSEN, J. E.; FLETCHER, J. S. Assesment of published literature on the uptake, accumulation, and translocation of heavy metals by vascular plants. Chemosphere, v. 27, p. 1669-1680, 1993.

NELSON, D. W.; SOMMERS, L. E. Total carbon, organic carbon, and organic matter. In: BIGHAM, J. M. (Ed.). Methods of Soil analysis. Madson: Soil Science Society of America and American Society of America and American Society of Agronomy, 1996. p.961-1010. (Soil Science Society of American Book Series, 5).

NICOLARDOT, B.; RECOUS, S.; MARY, B. Simulation of C and N mineralisation during crop residue decomposition: a simple dynamic model based on the $\mathrm{C}: \mathrm{N}$ ratio of the residues. Plant Soil, v. 228, p. 83-103, 2001. 
NOVOTNY, E. H. Estudos espectroscópicos e cromatográficos de substâncias húmicas de solos sob diferentes sistemas de preparo. 2002. $231 \mathrm{f}$. Tese (Doutorado em Físico Química) - Instituto de Química de São Carlos, Universidade de São Paulo, São Carlos, 2002. OLIVEIRA, F. C.; MATTIAZO, M, E.; MARCIANO, C. R.; ROSSETTO, R. Efeitos de aplicações sucessivas de lodo de esgoto em um latossolo amarelo distrófico cultivado com cana de açúcar: carbono orgânico, condutividade elétrica, pH e CTC. Revista Brasileira de Ciência do Solo, v. 26, p. 505-519, 2002.

OLIVEIRA, F. C. Disposição de lodo de esgoto e composto de lixo urbano num latossolo vermelho amarelo cultivado com cana-de-açúcar. 2000. $247 \mathrm{f}$. Tese (Doutorado em Solos e Nutrição de Plantas) - Escola Superior de Agricultura "Luiz de Queiroz", Universidade de São Paulo, Piracicaba, 2000.

OLK, D. C.; BRUNETTI, G.; SENESI, N. Organic matter in double - cropped lowland rice soils: chemical and spectroscopical properties. Soil Science, v. 164, n. 19, p. 633-649, 1999.

PAVAN, M. A.; BOCH, M. F.; ZEMPULSKI, H. C.; MIYAZAWA, M.; ZOCOLER, D. C. Manual de análise química de solo e controle de qualidade. Londrina: IAPAR, 1992. 40 p.

PEDROZA, J. P.; VAN HAANDEL, A. C.; BELTRÃO, N. E. M.; DIONÍSIO, J. A. Produção e componentes do algodoeiro herbáceo em função da aplicação de biossólidos. Revista Brasileira de Engenharia Agrícola e Ambiental, v. 7, n. 3, p. 483-488, 2003.

PICCOLO, A.; STEVENSON, F. J. Infrared spectra of $\mathrm{Cu}^{+2}, \mathrm{~Pb}^{+2}$ and $\mathrm{Ca}^{+2}$ complexes of soil humic substances. Geoderma, v. 27, p. 195-208, 1982.

PICCOLO, A.; ZACCHEO, P.; GENEVINI, P. G. Chemical characterization of humic substances extracted from organic-waste-amended soils. Bioresource Technology, v. 40, p. 272-282, 1992.

PICCOLO, A.; NARDI, S.; CONCHERI, G. Micelle-Like conformation of humic substances as revealed by size exclusion chromatography. Chemosphere, v. 33, p. 595, 1996.

PICCOLO, A. The supramolecular structure of humic substances. Soil Science, v. 166, p. 810-832, 2001.

PICCOLO, A. The supramolecular structure of humic substances: A novel understanding of humus chemistry and implications in soil science. Advances in Agronomy, v.75, p.57-134, 2002 .

PIGOZZO, A. T. J.; GOBBIL, M. A.; SCAPIM, C. A.; LENZI, E.; JUNIOR, J. L.; BREDA, C. C. Disponibilidade de metais de transição no solo tratado com lodo de esgoto. Acta Scientiarum Agronomy, v. 26, n. 4, p. 443-451, 2004.

POLAK, J.; SULKOWSKI, W. W.; BARTOSZEK, M.; PAPIEZ, W. Spectroscopic studies of the progress of humification processes in humic acid extracted from sewage sludge. Journal of Molecular Structure, v. 744-747, p. 983-989, 2005.

POOLE, C. P.; FARACH, H. A. The theory of magnetic resonance. New York: John Wiley, 1972. $452 \mathrm{p}$. 
PRESTON, C. M.; HEMPLING, R.; SCHULTEN, H. R.; SCHNITZER, M.; TROFYMOV, J. A.; AXELSON, D. E. Characterization of organic matter in a forest soil of coastal British Columbia by NMR and pyrolisis-field ionozation mass spectrometry. Plant and Soil, v. 158, p. 69-82, 1994a.

PRESTON, C. M.; NEWMAN, R. H.; ROTHER, P. Using ${ }^{13}$ C CPMAS NMR to assess effects of cultivation on the organic matter of particle size fractions in a grassland soil. Soil Science, v. 157, p. 26-35, 1994b.

PRESTON, C. M. Applications of NMR to soil organic matter analysis: history and prospects. Soil Science, v. 161, n. 3, p. 144-166, 1996.

PROGRAMA DE PESQUISAS EM SANEAMENTO BÁSICO. Lodo e Esgoto. Curitiba: PROSAB. Página Lodo e Esgoto. Disponível em:

<http://www.finep.gov.br/prosab/index.html>. Acesso em: 2 nov. 2005.

QUIAN, J.; SHAN, X.; WANG, Z.; TU, Q. Distribution and plant availability of heavy metals in different particle-size fractions of soil. Science of the Total Environment, v. 187, p.131$141,1996$.

REEVES, D.W. The role of soil organic matter in maintaining soil quality in continuous cropping systems. Soil and Tillage Research, v. 43, p. 131-167, 1997.

REX, R. W. Electron paramagnetic resonance studies of stable free radicals in lignins and humic acids. Nature, v. 188, p. 1185-1186, 1960.

RIFFALDI, R.; SCHNITZER, M. Electron spin resonance spectrometry of humic substances. Soil Science Society of America Journal, v. 36, p. 301-305, 1972.

RIVERO, C.; SENESI, N.; PAOLINI, J.; D'ORAZIO, V. Characteristics of humic acids of some Venezuelan soils. Geoderma, v. 81, p. 227-239, 1998.

ROCHA, G. N; GONÇALVES, J. L. M.; MOURA, I. M. Mudanças da fertilidade do solo e crescimento de um povoamento de Eucalyptus grandis fertilizado com biossólido. Revista Brasileira de Ciência do Solo, v. 28, p. 623-639, 2004.

SAAB, S. C. Caracterização da matéria orgânica em gleissolos por espectroscopias de EPR, RMN, IV e UV-Visível. 1999. 111 f. Tese (Doutorado em Química Analítica) Instituto de Química de São Carlos, Universidade de São Paulo, São Carlos, 1999.

SAIZ-JIMENEZ, C. The chemical structure of humic substances: recent advances. In: PICCOLO, A. (Ed.). Humic substances in terrestrial ecosystems. Amsterdam: Elsevier, 1996. p. 1-44.

SANTOS, H. F.; TSUTIYA, M. T. Aproveitamento e disposição final do lodo de esgoto de estações de tratamento do Estado de São Paulo. Engenharia Sanitária e Ambiental, v. 2, n. 2, p. 70-81, 1997.

SANTOS, L. M.; NARIMOTO, K. M.; GALETI, H. V. A.; PARABOCZ, V.; SILVA, W. T. L.; MILORI, D. M. B. P.; MELO, W. J.; MARTIN-NETO, L. Caracterização de amostras de solos submetidos à adição de lodo de esgoto utilizando fluorescência induzida por laser (FIL). In: CONGRESSO BRASILEIRO DE CIÊNCIA DO SOLO, 30., 2005, Recife. Anais... Sociedade Brasileira de Ciência do Solo, 2005. 1 CD-ROM. 
SCHNITZER, M.; KHAN. S. U. Humic substances in the environment. New York: Marcel Dekker, 1972. p. 192-197

SCHNITZER, M.; KHAN, S. U. Humic substances chemistry and reactions: soil organic matter. New York: Elsevier, 1978. p. 319.

SCHNITZER, M.; PRESTON, C. M. Analysis of humic acids by solution and solid-state carbon-13 nuclear magnetic resonance. Soil Science Society of America Journal, v. 50, p. 326-331, 1986.

SCHNITZER, M.; KODAMA, H.; RIPMEESTER, J. A. Determination of the aromaticity of humic substances by X-ray diffraction analysis. Soil Science Society American Journal, v. 55, p. 745-750, 1991.

SCHULTEN, H. R., SCHNITZER, M. A state of the art structural concept for humic substances. Naturwissenschaften, v. 80, p. 29-30, 1993.

SCHULTEN, H. R.; SCHNITZER, M. Chemical model structures for soil organic matter and soils. Soil Science, v. 162, p. 115-130, 1997.

SEGNINI, A.; SILVA, W. T. L.; SANTOS, L. M.;MILORI, D. M. B. P.; MARTIN-NETO, L. Determinação de carbono e matéria orgânica em Latossolos por diferentes métodos. In: ENCONTRO BRASILEIRO DE SUBSTÂNCIAS HÚMICAS, 6., 2005, Rio de Janeiro. Anais... Rio de Janeiro: Sociedade Brasileira de Substâncias húmicas/ Embrapa Solos, 2005. p. $168-170$.

SENESI, N.; SCHNITZER, M. Effects of $\mathrm{pH}$, reaction time, chemical reduction and irradiation on ESR spectra of fulvic acid. Soil Science, v. 123, p. 224-234, 1977.

SENESI, N.; SPOSITO, G.; MARTIN, J. P. Copper(II) and Iron(III) complexation by soil humic acids: an IR and ESR study. The Science Total Environmental, v. 55, p. 351, 1986.

SENESI, N.; SPOSITO, G.; HOLTZCLAW, K. M.; BRADFORD, G. R. Chemical properties of metal-humic acid fractions of a sewage sludge amended aridisol. Journal of Environmental Quality, v. 18, n. 2, p.186-194, 1989.

SENESI, N. Molecular and quantitative aspects of the chemistry of fulvic acid and its interactions with metal ions and organic chemicals. Part I. The electron spin resonance approach. Analytic Chimica Acta, v. 232, p. 51-75, 1990.

SENESI, N.; MIANO, T. M.; PROVENZANO, M. R.; BRUNETTI, G. Characterization, differentiation, and classification of humic substances by spectroscopy. Soil Science, v. 152, n. 4, p. 259-271, 1991.

SENESI, N. Application of Electron Spin Resonance and Fluorescence Spectroscopies to the Study of Humic Substances In: KUBAT, J. (Ed.). Humus, its structure and role in agriculture and environment. Amsterdam: Elsevier, 1992. p. 11-26.

SENESI, N.; MIANO, T. M.; BRUNETTI, G. Humic like substances amendments and effects on native soil humic substances. In: PICCOLO, A. (Ed.) Humic substances in terrestrial ecosystems. Amsterdan: Elsevier, 1996. cap. 14, p. 531-593. 
SENESI, N.; LOFFREDO, E. The Chemistry of Soil Organic Matter. In: SPARKS, D. L. (Ed.) Soil physical chemistry. Boca Raton: CRC, 1999. cap. 6, p. 242-370.

SHANG, C. E.; TIESSEN, H. Organic matter lability in a tropical oxisol: evidence from shifting cultivation, chemical oxidation, particle size, density and magnetic fractionations. Soil Science, v. 162, p. 795-807, 1997.

SHEPPARD, S. C.; GAUDET, C.; SHEPPARD, M. I.; CURETON, P. M.; WONG, M. P. The development of assessment and remediation guidelines for contaminated soils, a review of a science. Canadian Journal of Soil Science, v. 72, p. 359-394, 1992.

SILVA, L. M. V.; PASQUAL, A. Dinâmica e modelagem da matéria orgânica do solo com ênfase ao ecossistema tropical. Energia na Agricultura, v. 14, n. 13-24, 1999.

SILVA, C. M. M. S.; FAY, E. F. Agrotóxicos e Ambiente. Brasília: Embrapa Informação Tecnológica, 2004. 400 p.

SILVERSTEIN, R. M.; BASSLER, G.; MORRIL, T. C. Identificação Espectroscópica de Compostos Orgânicos. Rio de Janeiro: Guanabara-Koogan, 1994. 387 p.

SIMÕES, M. L. Estudos de interações hidrofóbicas em substâncias húmicas e componentes do solo utilizando análises espectroscópicas. 2005. 147 f. Tese (Doutorado em Ciências e Engenharia de Materiais) - Escola de Engenharia de São Carlos, Universidade de São Paulo, São Carlos, 2005.

SIMONETE, M. A. Alterações nas propriedades químicas de um Argissolo adubado com lodo de esgoto e desenvolvimento e acúmulo de nutrientes em plantas de milho. 2001. 89 f. Tese (Doutorado em Solos e Nutrição de Plantas) - Escola Superior de Agricultura "Luiz de Queiroz", Universidade de São Paulo, Piracicaba, 2001.

SIMPSON, A. J. Determining the molecular weight, aggregation, structures and interactions of natural organic matter using diffusion ordered spectroscopy. Magnetic Resonance in Chemistry, v. 40,p. S72-S80, 2002a.

SIMPSON, A. J.; KINGERY, W. L.; SWAW, D. R.; SPRAUL, M.; HUMPFER, E.; DVORTSAK, P. Molecular structures and associations of humic substances in the terrestrial environment. Naturwissenschaften, v. 89, p. 84-88, 2002 b.

SIMPSON, M. J.; CHEFETZ, B.; HATCHER, P. G. Phenanthere sorption to structurally modified humic acids. Journal of Environmental Quality, v. 32, n. 5, p. 1750-1758, 2003.

SINGER, L. S. Synthetic ruby as a secondary standard for the measurement of intensities in electron paramagnetic resonance. Journal Applied Physiology, v. 30, p. 1463-1464, 1959.

SKJEMSTAD, J. O.; JANIK, L. J.; TAYLOR, J. A. Non-Living soil organic matter: what do we know about it?. Australian Journal of Experimental Agriculture, v. 38, p. 667-680, 1998.

SKOOG, D. A.; HOLLER, F. J.; NIEMAN, T. A. Análise Instrumental. 5. ed. Porto Alegre: Bookman, 2002. 836 p.

SPARKS, D. L. Environmental Soil Chemistry. Newark: Academic Press, 1999. 267 p. 
SPOSITO, G. The Chemistry of Soils. New York: Oxford University, 1989. 277 p.

SPOSITO, G.; MARTIN-NETO, L.; YANG, A. Atrazine complexation by soil humic acids. Journal of Environmental Quality, v. 25, p. 1203-1209, 1996.

STEELINK, C.; TOLLIN, G. Stable free radicals in soil humic acid. Biochimica et Biophysica Acta, v. 59, p. 25-34, 1962.

STEELINK, C. Free radical studies of lignin degradation products and soil humic acids.

Geochimica et Cosmochimica Acta, v. 28, p. 1615-1622, 1964.

STEELINK, C.; TOLLIN, G. Free radicals in soil. In: McLAREN, A. D.; PETERSON, G. M. (Eds.). Soil biochemistry. New York: Marcel Dekker, 1985. v. 5, p. 147-169.

STEVENSON, F. J. Humus Chemistry: genesis, composition, reactions. 1. New York: John Wiley, 1982. $443 \mathrm{p}$.

STEVENSON, F. J. Cycles of soil: carbon, nitrogen, phosphorus, sulfur, micronutrients. New York: John Wiley, 1986. 380 p.

STEVENSON, F. J. Humus Chemistry: genesis, composition, reactions. 2. ed. New York: John Wiley, 1994. 496 p.

STUART, B. Modern Infrared Spectroscopy: Analytical Chemistry by Open Learning. New York: John Willey, 1996. 179 p.

SUTTON, R.; SPOSITO, G. Molecular Structure in Soil Humic Substances: The New View. Environmental Science and Technology, v. 39, n. 23, p. 9009-9015, 2005.

SWIFT, R. S. Molecular weight, size, shape, and charge characteristics of humic substances: Some basic considerations. In: HAYES, M. H. B.; MacCARTHY, P.; MALCOLM, R. L.; SWIFT, R. S. (Eds.) Humic substances II: In search of structure. New York: John Wiley, 1989. p. 449-466.

SWIFT, R. S. Macromolecular properties of soil humic substances: Fact, fiction, and opinion. Soil Science, v. 164, n. 11, p. 790-802, 1999.

TANNER, C. B.; JACKSON, M. L. Nomographs of sedimentation times for soil particles under gravity or centrifugal acceleration. Soil Science Society Proceedings, p. 60-65, 1947.

TSUTYA, M. T. Alternativas de disposição final de biossólidos gerados em estações de tratamento de esgoto. In: BETTIOL, W.; CAMARGO, O. A. Impacto ambiental do uso agrícola do lodo de esgoto. Jaguariúna: EMBRAPA, 2000. cap.4, p. 69-106.

VEEMAN, W. S. Nuclear magnetic resonance: a simple introduction to the principles and applications. Geoderma, v. 80, p. 225-242, 1997.

VIEIRA, E. C.; KAMOGAWA, M. Y.; LEMOS, S. L.; NÓBREGA, J. A. NOGUEIRA, A. R. Decomposição de amostras de solos assistida por radiação microondas: estratégia para evitar a formação de fluoretos insolúveis. Revista Brasileira de Ciência do Solo, v. 29, p. 547-553, 2005. 
VINKLER, P.; LAKATOS, B.; MEISEL, J. Infrared spectroscopic investigations of humic substances and their metal complexes. Geoderma, v. 15, p. 231-242, 1976.

WALKLEY, A.; BLACK, I. A. An examination of the Degtjareff method for determining soil organic matter and a proposed modification of the chromic acid titration method. Soil Science, v. 37, p. 29-38, 1934.

WALKLEY, A. A critical examination of a rapid method for determining organic carbon in soils: Effect of variation in digestion condition and of inorganic constituents. Soil Science, v. 63, p. 251-264, 1947.

WANDRUSZKA, von R. The micellar model of humic acid: evidence from pyrene fluorescence measurements. Soil Science, v. 163, p. 921-930, 1998.

WERSHAW, R. L. A new model for humic materials and their interactions with hydrophobic organic chemical in soil-water or sediment-water systems. Journal of Contaminant Hydrology, v. 1, p. 29-45, 1986.

WERSHAW, R. L. Model for humus in soils and sediments. Environmental Science \& Technology, v. 27, p. 814-816, 1993.

WILSON, M. A. Soil organic matter maps by nuclear magnetic resonance. Journal of Soil Science, v. 35, p. 209-215, 1984.

WILSON, M. A. NMR techniques and applications in geochemistry and soil chemistry. Oxford: Pergamon, 1987. 353 p.

ZECH, W.; SENESI, N.; GUGGENBERGER, G.; KAISER, K.; LEHMANN, J.; MIANO, T. M.; MILTNER, A.; SCHROTH, G. Factors controlling humification and mineralization of soil organic matter in the tropics. Geoderma, v. 79, p. 117-161, 1997.

ZSOLNAY, A.; BAIGAR, E.; JIMENEZ, M.; STEINWEG, B.; SACCOMANDI, F.

Differentiating with fluorescence spectroscopy the sources of dissolved organic matter in soils subjected to drying. Chemosphere, v. 38, n. 1, p. 45-50, 1999. 